\title{
Two oyster species that show differential susceptibility to virus infection also show differential proteomic responses to generic dsRNA.
}

Muhammad Masood, David A. Raftos and Sham V. Nair

Department of Biological Sciences

Macquarie University

NSW 2109

Australia.

Table of contents

\begin{tabular}{|l|l|}
\hline Title & Page number \\
\hline Supplementry Table S1 & S2-S16 \\
\hline Supplementry Table S2 & S17-S22 \\
\hline Supplementry Table S3 & S23-S61 \\
\hline Supplementry Table S4 & S62-S91 \\
\hline Supplementry Table S5 & S92-S96 \\
\hline Supplementary methods & S97-S101 \\
\hline
\end{tabular}


Supplementary Table S1: All Sydney rock oyster proteins.

\begin{tabular}{|c|c|}
\hline Accession & Name \\
\hline gi|405974790 & ATP synthase subunit beta, mitochondrial [Crassostrea gigas] \\
\hline gi|405974703 & ATP synthase subunit alpha, mitochondrial [Crassostrea gigas] \\
\hline gi|405978716 & Alpha-actinin, sarcomeric [Crassostrea gigas] \\
\hline gi|405977961 & T-complex protein 1 subunit delta, partial [Crassostrea gigas] \\
\hline gi|405964948 & Fructose-bisphosphate aldolase [Crassostrea gigas] \\
\hline gi|405978809 & $\begin{array}{l}\text { Serine/threonine-protein phosphatase } 2 \mathrm{~A} 65 \mathrm{kDa} \text { regulatory subunit } \mathrm{A} \text { alpha isoform } \\
\text { [Crassostrea gigas] }\end{array}$ \\
\hline gi|405959695 & Clathrin heavy chain 1 [Crassostrea gigas] \\
\hline gi|405957058 & Glyceraldehyde-3-phosphate dehydrogenase [Crassostrea gigas] \\
\hline gi|405950190 & Vinculin [Crassostrea gigas] \\
\hline gi|405972882 & T-complex protein 1 subunit beta [Crassostrea gigas] \\
\hline gi|405974681 & Major vault protein [Crassostrea gigas] \\
\hline gi|405974443 & Adenosylhomocysteinase A [Crassostrea gigas] \\
\hline gi|405963584 & 14-3-3 protein epsilon [Crassostrea gigas] \\
\hline gi|405978369 & T-complex protein 1 subunit alpha [Crassostrea gigas] \\
\hline gi|405957859 & $26 \mathrm{~S}$ protease regulatory subunit $6 \mathrm{~A}$ [Crassostrea gigas] \\
\hline gi|405959600 & T-complex protein 1 subunit eta [Crassostrea gigas] \\
\hline gi|405963058 & T-complex protein 1 subunit gamma [Crassostrea gigas] \\
\hline gi|405973892 & Guanine nucleotide-binding protein subunit beta-2-like 1 [Crassostrea gigas] \\
\hline gi|405970867 & Enolase [Crassostrea gigas] \\
\hline gi|405961849 & Ras-related protein Rab-7a [Crassostrea gigas] \\
\hline gi|405957582 & Serine/threonine-protein phosphatase PP1-alpha catalytic subunit [Crassostrea gigas] \\
\hline gi|405965075 & Aldehyde dehydrogenase, mitochondrial [Crassostrea gigas] \\
\hline gi|405970598 & Citrate synthase, mitochondrial [Crassostrea gigas] \\
\hline gi|405959090 & Malate dehydrogenase, cytoplasmic, partial [Crassostrea gigas] \\
\hline gi|405950834 & Sperm-associated antigen 6 [Crassostrea gigas] \\
\hline gi|405959540 & Transaldolase [Crassostrea gigas] \\
\hline gi|405950430 & 14-3-3 protein gamma [Crassostrea gigas] \\
\hline gi|405965040 & Glycogen phosphorylase, muscle form [Crassostrea gigas] \\
\hline gi|405973142 & Actin-related protein 3 [Crassostrea gigas] \\
\hline gi|405961646 & ADP,ATP carrier protein [Crassostrea gigas] \\
\hline gi|405963233 & Phosphoglycerate kinase 1 [Crassostrea gigas] \\
\hline gi|405960081 & $60 S$ acidic ribosomal protein P0 [Crassostrea gigas] \\
\hline gi|405976088 & $40 S$ ribosomal protein SA [Crassostrea gigas] \\
\hline gi|405971611 & V-type proton ATPase subunit B [Crassostrea gigas] \\
\hline gi|405957821 & Mechanosensory protein 2 [Crassostrea gigas] \\
\hline gi|405972837 & Retinal dehydrogenase 1 [Crassostrea gigas] \\
\hline gi|405963427 & Malate dehydrogenase, mitochondrial [Crassostrea gigas] \\
\hline gi|405976915 & Proteasome subunit alpha type-7-like protein [Crassostrea gigas] \\
\hline gi|405957820 & Mechanosensory protein 2, partial [Crassostrea gigas] \\
\hline gi|405974897 & Peroxiredoxin-5, mitochondrial [Crassostrea gigas] \\
\hline gi|405973893 & Serine/threonine-protein phosphatase $2 \mathrm{~A}$ catalytic subunit beta isoform [Crassostrea gigas] \\
\hline gi|405977322 & Polyadenylate-binding protein 4 [Crassostrea gigas] \\
\hline gi|405970566 & Guanine nucleotide-binding protein $\mathrm{G}(\mathrm{o})$ subunit alpha [Crassostrea gigas] \\
\hline gi|405961263 & Phosphoenolpyruvate carboxykinase [GTP] [Crassostrea gigas] \\
\hline
\end{tabular}




\begin{tabular}{|c|c|}
\hline Accession & Name \\
\hline gi|405965244 & Dolichyl-diphosphooligosaccharide--protein glycosyltransferase subunit 2 [Crassostrea gigas] \\
\hline gi|405971056 & Flotillin-2 [Crassostrea gigas] \\
\hline gi|405962453 & Cdc42-like protein [Crassostrea gigas] \\
\hline gi|405957088 & $33 \mathrm{kDa}$ inner dynein arm light chain, axonemal [Crassostrea gigas] \\
\hline gi|405976231 & Protein FAM49B [Crassostrea gigas] \\
\hline gi|405969917 & Ras-related protein Rab-1A [Crassostrea gigas] \\
\hline gi|405961968 & Actin-related protein 2 [Crassostrea gigas] \\
\hline gi|405964525 & Proteasome subunit alpha type-2 [Crassostrea gigas] \\
\hline gi|405950795 & Non-neuronal cytoplasmic intermediate filament protein [Crassostrea gigas] \\
\hline gi|405975835 & $\mathrm{NAD}(\mathrm{P})$ transhydrogenase, mitochondrial [Crassostrea gigas] \\
\hline gi|405977168 & Signal recognition particle 54 kDa protein [Crassostrea gigas] \\
\hline gi|405964445 & Cystathionine gamma-lyase [Crassostrea gigas] \\
\hline gi|405967540 & $60 S$ ribosomal protein L23 [Crassostrea gigas] \\
\hline gi|405973252 & Fructose-bisphosphate aldolase [Crassostrea gigas] \\
\hline gi|405971602 & hypothetical protein CGI_10010586 [Crassostrea gigas] \\
\hline gi|405969654 & Sodium/potassium-transporting ATPase subunit alpha [Crassostrea gigas] \\
\hline gi|405966599 & $60 \mathrm{kDa}$ heat shock protein, mitochondrial [Crassostrea gigas] \\
\hline gi|405959640 & Transitional endoplasmic reticulum ATPase [Crassostrea gigas] \\
\hline gi|405964519 & Glycerol-3-phosphate dehydrogenase [NAD+], cytoplasmic [Crassostrea gigas] \\
\hline gi|405953549 & T-complex protein 1 subunit zeta [Crassostrea gigas] \\
\hline gi|405973024 & Glutaredoxin-3 [Crassostrea gigas] \\
\hline gi|405954435 & Proteasome subunit beta type-2 [Crassostrea gigas] \\
\hline gi|405950385 & Programmed cell death 6-interacting protein [Crassostrea gigas] \\
\hline gi|405950098 & 14-3-3 protein zeta [Crassostrea gigas] \\
\hline gi|405959157 & Ornithine aminotransferase, mitochondrial [Crassostrea gigas] \\
\hline gi|405965429 & RNA-binding motif, single-stranded-interacting protein 3 [Crassostrea gigas] \\
\hline gi|405961548 & T-complex protein 1 subunit theta [Crassostrea gigas] \\
\hline gi|405965726 & NADP-dependent malic enzyme [Crassostrea gigas] \\
\hline gi|405952673 & Myophilin [Crassostrea gigas] \\
\hline gi|405972993 & Ras-like GTP-binding protein Rho1 [Crassostrea gigas] \\
\hline gi|405959086 & UTP--glucose-1-phosphate uridylyltransferase [Crassostrea gigas] \\
\hline gi|405961802 & ADP-ribosylation factor [Crassostrea gigas] \\
\hline gi|405969358 & ATPase family AAA domain-containing protein $2 \mathrm{~B}$ [Crassostrea gigas] \\
\hline gi|405962772 & Ras suppressor protein 1 [Crassostrea gigas] \\
\hline gi|405971077 & AP-2 complex subunit beta [Crassostrea gigas] \\
\hline gi|405968861 & UDP-glucose 4-epimerase [Crassostrea gigas] \\
\hline gi|405972952 & Plastin-3 [Crassostrea gigas] \\
\hline gi|405951837 & Hydroxyacyl-coenzyme A dehydrogenase, mitochondrial [Crassostrea gigas] \\
\hline gi|405966326 & $40 S$ ribosomal protein S13 [Crassostrea gigas] \\
\hline gi|405971745 & GTP-binding nuclear protein Ran [Crassostrea gigas] \\
\hline gi|405965548 & Adenylyl cyclase-associated protein 1 [Crassostrea gigas] \\
\hline gi|405960861 & Protein quaking-B [Crassostrea gigas] \\
\hline gi|405978782 & Nucleoside diphosphate kinase B [Crassostrea gigas] \\
\hline gi|405952674 & Myophilin [Crassostrea gigas] \\
\hline gi|405954743 & C-Myc-binding protein [Crassostrea gigas] \\
\hline gi|405977299 & Putative sodium/potassium-transporting ATPase subunit beta-2 [Crassostrea gigas] \\
\hline
\end{tabular}




\begin{tabular}{|c|c|}
\hline Accession & Name \\
\hline gi|405950079 & Tektin-2 [Crassostrea gigas] \\
\hline gi|405952464 & Spliceosome RNA helicase BAT1 [Crassostrea gigas] \\
\hline gi|405968311 & Isocitrate dehydrogenase [NAD] subunit alpha, mitochondrial [Crassostrea gigas] \\
\hline gi|405961297 & Coatomer subunit gamma-2 [Crassostrea gigas] \\
\hline gi|405958345 & $26 \mathrm{~S}$ protease regulatory subunit $6 \mathrm{~B}$ [Crassostrea gigas] \\
\hline gi|405972312 & Myosin-2 essential light chain [Crassostrea gigas] \\
\hline gi|405958969 & $40 S$ ribosomal protein S16 [Crassostrea gigas] \\
\hline gi|405973339 & Actin-2 [Crassostrea gigas] \\
\hline gi|405961918 & Ras-related protein Rab-5C [Crassostrea gigas] \\
\hline gi|405954717 & Tryptophanyl-tRNA synthetase, cytoplasmic [Crassostrea gigas] \\
\hline gi|405966318 & Ropporin-1-like protein [Crassostrea gigas] \\
\hline gi|405969074 & Spermatogenesis-associated protein 18-like protein [Crassostrea gigas] \\
\hline gi|405962126 & rRNA 2'-O-methyltransferase fibrillarin [Crassostrea gigas] \\
\hline gi|46359620 & elongation factor 1 alpha [Crassostrea gigas] \\
\hline gi|405971643 & Proteasome subunit beta type-3 [Crassostrea gigas] \\
\hline gi|405970995 & Transcription factor BTF3-like protein 4 [Crassostrea gigas] \\
\hline gi|405952733 & Glycerol-3-phosphate dehydrogenase, mitochondrial [Crassostrea gigas] \\
\hline gi|405960271 & Putative phosphoglycerate mutase [Crassostrea gigas] \\
\hline gi|405972127 & Eukaryotic translation initiation factor 3 subunit $\mathrm{M}$, partial [Crassostrea gigas] \\
\hline gi|405970124 & Dynein light chain 1, axonemal, partial [Crassostrea gigas] \\
\hline gi|405967947 & Transgelin-2 [Crassostrea gigas] \\
\hline gi|405968450 & Calcium-transporting ATPase sarcoplasmic/endoplasmic reticulum type [Crassostrea gigas] \\
\hline gi|40643036 & ribosomal protein S5 [Crassostrea gigas] \\
\hline gi|405976932 & Synaptobrevin, partial [Crassostrea gigas] \\
\hline gi|405950221 & V-type proton ATPase catalytic subunit A [Crassostrea gigas] \\
\hline gi|405972954 & $40 S$ ribosomal protein $S 7$ [Crassostrea gigas] \\
\hline gi|405964515 & Proteasome subunit alpha type-4 [Crassostrea gigas] \\
\hline gi|405965232 & $60 S$ ribosomal protein L12 [Crassostrea gigas] \\
\hline gi|405978739 & Putative small nuclear ribonucleoprotein Sm D2 [Crassostrea gigas] \\
\hline gi|405977575 & $40 \mathrm{~S}$ ribosomal protein S12 [Crassostrea gigas] \\
\hline gi|405966541 & Fructose-1,6-bisphosphatase 1 [Crassostrea gigas] \\
\hline gi|405951393 & Cullin-associated NEDD8-dissociated protein 1 [Crassostrea gigas] \\
\hline gi|405976470 & Rab GDP dissociation inhibitor beta [Crassostrea gigas] \\
\hline gi|405946008 & Actin-related protein $2 / 3$ complex subunit 5 [Crassostrea gigas] \\
\hline gi|405967516 & Ubiquitin-conjugating enzyme E2 N [Crassostrea gigas] \\
\hline gi|56603670 & beta-tubulin [Crassostrea gigas] \\
\hline gi|405954742 & $26 \mathrm{~S}$ proteasome non-ATPase regulatory subunit 13 [Crassostrea gigas] \\
\hline gi|405962672 & Pyruvate dehydrogenase E1 component subunit beta, mitochondrial [Crassostrea gigas] \\
\hline gi|405968084 & Alanine aminotransferase 2 [Crassostrea gigas] \\
\hline gi|405956161 & Annexin A7 [Crassostrea gigas] \\
\hline gi|405959655 & $26 \mathrm{~S}$ proteasome non-ATPase regulatory subunit 11 [Crassostrea gigas] \\
\hline gi|405976181 & Transcription elongation factor B polypeptide 2 [Crassostrea gigas] \\
\hline gi|405960811 & Phosphate carrier protein, mitochondrial [Crassostrea gigas] \\
\hline gi|405964308 & Carbonyl reductase [NADPH] 1 [Crassostrea gigas] \\
\hline gi|405962500 & V-type proton ATPase subunit $\mathrm{H}$ [Crassostrea gigas] \\
\hline gi|405973023 & Glycogenin-1 [Crassostrea gigas] \\
\hline
\end{tabular}




\begin{tabular}{|c|c|}
\hline Accession & Name \\
\hline gi|405975453 & $N(G), N(G)$-dimethylarginine dimethylaminohydrolase 1 [Crassostrea gigas] \\
\hline gi|405964154 & $40 S$ ribosomal protein S9 [Crassostrea gigas] \\
\hline gi|405969330 & Cytosolic non-specific dipeptidase [Crassostrea gigas] \\
\hline gi|405978353 & Ubiquitin-conjugating enzyme E2-17 kDa [Crassostrea gigas] \\
\hline gi|405973036 & Ribose-5-phosphate isomerase [Crassostrea gigas] \\
\hline gi|405964798 & Coatomer subunit beta [Crassostrea gigas] \\
\hline gi|405964569 & Alpha-centractin [Crassostrea gigas] \\
\hline gi|405958175 & Calcium-binding protein 39 [Crassostrea gigas] \\
\hline gi|405970587 & Universal stress protein A-like protein [Crassostrea gigas] \\
\hline gi|405961963 & Spectrin beta chain [Crassostrea gigas] \\
\hline gi|405970367 & Piwi-like protein 1 [Crassostrea gigas] \\
\hline gi|405974492 & $40 \mathrm{~S}$ ribosomal protein S14 [Crassostrea gigas] \\
\hline gi|405965163 & Beta-hexosaminidase subunit beta [Crassostrea gigas] \\
\hline gi|405962319 & Histone H3 [Crassostrea gigas] \\
\hline gi|405952804 & 40 S ribosomal protein S17 [Crassostrea gigas] \\
\hline gi|405973257 & ATP-citrate synthase [Crassostrea gigas] \\
\hline gi|405976315 & Small nuclear ribonucleoprotein Sm D3 [Crassostrea gigas] \\
\hline gi|405972488 & Protein DJ-1 [Crassostrea gigas] \\
\hline gi|405960103 & Guanine nucleotide-binding protein G(i) subunit alpha [Crassostrea gigas] \\
\hline gi|405971692 & Tumor protein D54 [Crassostrea gigas] \\
\hline gi|405949998 & Fatty acid-binding protein, adipocyte [Crassostrea gigas] \\
\hline gi|405967288 & $40 \mathrm{~S}$ ribosomal protein $\mathrm{S} 4, \mathrm{X}$ isoform [Crassostrea gigas] \\
\hline gi|405957468 & Dynein light chain roadblock-type 2 [Crassostrea gigas] \\
\hline gi|405955110 & Programmed cell death protein 10 [Crassostrea gigas] \\
\hline gi|405960115 & Actin-related protein $2 / 3$ complex subunit 4 [Crassostrea gigas] \\
\hline gi|405968525 & Calcium-binding mitochondrial carrier protein SCaMC-2 [Crassostrea gigas] \\
\hline gi|405964683 & Ras-related protein Rab-3 [Crassostrea gigas] \\
\hline gi|405952808 & EH domain-containing protein 1 [Crassostrea gigas] \\
\hline gi|84619356 & soma ferritin [Crassostrea gigas] \\
\hline gi|405954100 & Triosephosphate isomerase [Crassostrea gigas] \\
\hline gi|405968443 & 4-hydroxyphenylpyruvate dioxygenase [Crassostrea gigas] \\
\hline gi|405976318 & 6-phosphogluconate dehydrogenase, decarboxylating [Crassostrea gigas] \\
\hline gi|405963183 & hypothetical protein CGI_10018075 [Crassostrea gigas] \\
\hline gi|405953650 & Cleavage stimulation factor $64 \mathrm{kDa}$ subunit [Crassostrea gigas] \\
\hline gi|405970739 & Dynein light chain 2, cytoplasmic [Crassostrea gigas] \\
\hline gi|405968618 & Integrin-linked protein kinase [Crassostrea gigas] \\
\hline gi|405966986 & Paramyosin [Crassostrea gigas] \\
\hline gi|405954084 & Pyrroline-5-carboxylate reductase 2 [Crassostrea gigas] \\
\hline gi|405967058 & Glutathione S-transferase P 1 [Crassostrea gigas] \\
\hline gi|405957470 & Small nuclear ribonucleoprotein-associated protein B' [Crassostrea gigas] \\
\hline gi|405978471 & F-box only protein 36 [Crassostrea gigas] \\
\hline gi|405951090 & CAP-Gly domain-containing linker protein 3 [Crassostrea gigas] \\
\hline gi|405963114 & Hydroxysteroid dehydrogenase-like protein 2 [Crassostrea gigas] \\
\hline gi|405966026 & Alanine--glyoxylate aminotransferase 2, mitochondrial [Crassostrea gigas] \\
\hline gi|405958990 & Lin-7-like protein B [Crassostrea gigas] \\
\hline gi|405975810 & ALK tyrosine kinase receptor [Crassostrea gigas] \\
\hline
\end{tabular}




\begin{tabular}{|c|c|}
\hline Accession & Name \\
\hline gi|405962570 & AP-2 complex subunit alpha-2 [Crassostrea gigas] \\
\hline gi|405967909 & $26 \mathrm{~S}$ proteasome non-ATPase regulatory subunit 8 [Crassostrea gigas] \\
\hline gi|405958300 & GDP-L-fucose synthetase [Crassostrea gigas] \\
\hline gi|405967652 & hypothetical protein CGI_10017178 [Crassostrea gigas] \\
\hline gi|405968843 & Peptidyl-prolyl cis-trans isomerase E [Crassostrea gigas] \\
\hline gi|405978785 & Nucleoside diphosphate kinase-like protein 5 [Crassostrea gigas] \\
\hline gi|405978693 & Uncharacterized protein yfeX [Crassostrea gigas] \\
\hline gi|405975002 & Eukaryotic translation initiation factor 6 [Crassostrea gigas] \\
\hline gi|40642988 & ribosomal protein S3a [Crassostrea gigas] \\
\hline gi|405959764 & Phospholipid scramblase 2 [Crassostrea gigas] \\
\hline gi|405959092 & Radial spoke head protein 9-like protein [Crassostrea gigas] \\
\hline gi|405965704 & Muscle-specific protein 20 [Crassostrea gigas] \\
\hline gi|405957970 & Sjoegren syndrome nuclear autoantigen 1 [Crassostrea gigas] \\
\hline gi|405961702 & Myosin regulatory light chain A, smooth adductor muscle [Crassostrea gigas] \\
\hline gi|405966837 & dpy-30-like protein [Crassostrea gigas] \\
\hline gi|405971996 & Glutathione S-transferase A [Crassostrea gigas] \\
\hline gi|405964668 & Ras-related protein Rab-8A [Crassostrea gigas] \\
\hline gi|405953653 & Sorting nexin-12 [Crassostrea gigas] \\
\hline gi|405954434 & Microtubule-associated protein RP/EB family member 3 [Crassostrea gigas] \\
\hline gi|405970591 & Universal stress protein A-like protein [Crassostrea gigas] \\
\hline gi|405972489 & Isocitrate dehydrogenase [NADP] cytoplasmic [Crassostrea gigas] \\
\hline gi|405975469 & Tektin-3 [Crassostrea gigas] \\
\hline gi|405968528 & hypothetical protein CGI_10017744 [Crassostrea gigas] \\
\hline gi|405960099 & Dolichyl-diphosphooligosaccharide--protein glycosyltransferase subunit 1 [Crassostrea gigas] \\
\hline gi|405962950 & Mitogen-activated protein kinase 1 [Crassostrea gigas] \\
\hline gi|405962264 & Peroxisomal NADH pyrophosphatase NUDT12 [Crassostrea gigas] \\
\hline gi|405947958 & Succinate dehydrogenase [ubiquinone] iron-sulfur subunit, mitochondrial [Crassostrea gigas] \\
\hline gi|405960192 & EF-hand calcium-binding domain-containing protein 1 [Crassostrea gigas] \\
\hline gi|405950642 & Guanine nucleotide-binding protein $\mathrm{G}(\mathrm{q})$ subunit alpha [Crassostrea gigas] \\
\hline gi|405950538 & Talin-1 [Crassostrea gigas] \\
\hline gi|405975242 & Calponin-2 [Crassostrea gigas] \\
\hline gi|405959519 & Succinate-semialdehyde dehydrogenase, mitochondrial [Crassostrea gigas] \\
\hline gi|405975056 & Myosin heavy chain, striated muscle [Crassostrea gigas] \\
\hline gi|405963909 & Lactoylglutathione lyase [Crassostrea gigas] \\
\hline gi|405971552 & Vesicle-associated membrane protein/synaptobrevin-binding protein [Crassostrea gigas] \\
\hline gi|405972843 & Obg-like ATPase 1 [Crassostrea gigas] \\
\hline gi|405960672 & $40 S$ ribosomal protein S28 [Crassostrea gigas] \\
\hline gi|405967409 & Vacuolar protein sorting-associated protein 35 , partial [Crassostrea gigas] \\
\hline gi|405963565 & Septin-2 [Crassostrea gigas] \\
\hline gi|405969967 & Thymidine phosphorylase [Crassostrea gigas] \\
\hline gi|405958510 & hypothetical protein CGI_10014543 [Crassostrea gigas] \\
\hline gi|405970772 & Growth factor receptor-bound protein 2 [Crassostrea gigas] \\
\hline gi|405961149 & Phospholipid scramblase 2 [Crassostrea gigas] \\
\hline gi|405965140 & Alpha-endosulfine [Crassostrea gigas] \\
\hline gi|405971658 & Cathepsin B [Crassostrea gigas] \\
\hline gi|405969953 & Allograft inflammatory factor 1 [Crassostrea gigas] \\
\hline
\end{tabular}




\begin{tabular}{|c|c|}
\hline Accession & Name \\
\hline gi|405962800 & Inorganic pyrophosphatase [Crassostrea gigas] \\
\hline gi|350663 & calmodulin \\
\hline gi|405945238 & Eukaryotic initiation factor 4A-II, partial [Crassostrea gigas] \\
\hline gi|405963212 & 1,2-dihydroxy-3-keto-5-methylthiopentene dioxygenase [Crassostrea gigas] \\
\hline gi|405963786 & Annexin A7 [Crassostrea gigas] \\
\hline gi|405964873 & DNA-directed RNA polymerase II subunit RPB4 [Crassostrea gigas] \\
\hline gi|405968787 & Dynamin-1-like protein [Crassostrea gigas] \\
\hline gi|40642982 & putative ribosomal protein S25 [Crassostrea gigas] \\
\hline gi|405957124 & hypothetical protein CGI_10008733 [Crassostrea gigas] \\
\hline gi|405957021 & Splicing factor 3 subunit 1 [Crassostrea gigas] \\
\hline gi|405966810 & Peroxiredoxin-1 [Crassostrea gigas] \\
\hline gi|156915032 & calmodulin [Crassostrea gigas] \\
\hline gi|405970999 & Acyl-protein thioesterase 2 [Crassostrea gigas] \\
\hline gi|405958519 & hypothetical protein CGI_10014553, partial [Crassostrea gigas] \\
\hline gi|405967706 & Alpha-parvin [Crassostrea gigas] \\
\hline gi|405974926 & Ras-related protein Rap-1b [Crassostrea gigas] \\
\hline gi|405951162 & Surfeit locus protein 4 [Crassostrea gigas] \\
\hline gi|405965410 & $40 S$ ribosomal protein S15 [Crassostrea gigas] \\
\hline gi|405952104 & Ubiquitin-conjugating enzyme E2-17 kDa, partial [Crassostrea gigas] \\
\hline gi|405962441 & UPF0468 protein C16orf80-like protein [Crassostrea gigas] \\
\hline gi|405972166 & $60 S$ ribosomal protein L30 [Crassostrea gigas] \\
\hline gi|46909259 & ATP synthase beta subunit [Modiolus americanus] \\
\hline gi|405977845 & hypothetical protein CGI_10017842 [Crassostrea gigas] \\
\hline gi|405960426 & 4-aminobutyrate aminotransferase, mitochondrial [Crassostrea gigas] \\
\hline gi|405969211 & Calcium-binding mitochondrial carrier protein Aralar1 [Crassostrea gigas] \\
\hline gi|405957003 & Core histone macro-H2A.1 [Crassostrea gigas] \\
\hline gi|405960404 & Transmembrane protein Tmp21 [Crassostrea gigas] \\
\hline gi|405973201 & hypothetical protein CGI_10009700 [Crassostrea gigas] \\
\hline gi|405959361 & Tubulin beta chain [Crassostrea gigas] \\
\hline gi|405964694 & Myosin regulatory light chain sqh [Crassostrea gigas] \\
\hline gi|405962936 & Ubiquitin-conjugating enzyme E2 G2 [Crassostrea gigas] \\
\hline gi|405957219 & CutA-like protein [Crassostrea gigas] \\
\hline gi|405968728 & hypothetical protein CGI_10023309 [Crassostrea gigas] \\
\hline gi|405972698 & Inosine-5'-monophosphate dehydrogenase 2 [Crassostrea gigas] \\
\hline gi|405962104 & Pancreatic triacylglycerol lipase [Crassostrea gigas] \\
\hline gi|405951454 & Outer dense fiber protein 3 [Crassostrea gigas] \\
\hline gi|405968170 & Endophilin-B1 [Crassostrea gigas] \\
\hline gi|71040621 & ribosomal protein S18 [Crassostrea gigas] \\
\hline gi|405952901 & Myosin catalytic light chain LC-1, mantle muscle [Crassostrea gigas] \\
\hline gi|405950779 & Stress-induced-phosphoprotein 1 [Crassostrea gigas] \\
\hline gi|405951840 & 40 S ribosomal protein S19 [Crassostrea gigas] \\
\hline gi|40642980 & ribosomal protein S10 [Crassostrea gigas] \\
\hline gi|405974984 & Glutamate dehydrogenase 1, mitochondrial [Crassostrea gigas] \\
\hline gi|40643004 & ribosomal protein S20 [Crassostrea gigas] \\
\hline gi|405972362 & Heterogeneous nuclear ribonucleoprotein Q [Crassostrea gigas] \\
\hline gi|405953394 & Dynein heavy chain, cytoplasmic [Crassostrea gigas] \\
\hline
\end{tabular}




\begin{tabular}{|c|c|}
\hline Accession & Name \\
\hline gi|405970294 & $\begin{array}{l}\text { Putative methylmalonate-semialdehyde dehydrogenase [acylating], mitochondrial [Crassostrea } \\
\text { gigas] }\end{array}$ \\
\hline gi|405977799 & S-phase kinase-associated protein 1 [Crassostrea gigas] \\
\hline gi|405965094 & Chloride intracellular channel exc-4 [Crassostrea gigas] \\
\hline gi|405950284 & Peptidyl-prolyl cis-trans isomerase B [Crassostrea gigas] \\
\hline gi|405964938 & Coactosin-like protein [Crassostrea gigas] \\
\hline gi|405947472 & hypothetical protein CGI_10000124, partial [Crassostrea gigas] \\
\hline gi|405962281 & Sacsin [Crassostrea gigas] \\
\hline gi|163637081 & $\mathrm{H} 2 \mathrm{~A}$ histone family member $\mathrm{V}$ [Crassostrea gigas] \\
\hline gi|405951735 & Multidrug resistance-associated protein 1 [Crassostrea gigas] \\
\hline gi|260424007 & Rieske-like apoprotein [Crassostrea gigas] \\
\hline gi|405974628 & Calcium-dependent protein kinase isoform 2 [Crassostrea gigas] \\
\hline gi|405973144 & Importin subunit beta-1 [Crassostrea gigas] \\
\hline gi|405976712 & hypothetical protein CGI_10006577 [Crassostrea gigas] \\
\hline gi|405974805 & Muscle LIM protein Mlp84B [Crassostrea gigas] \\
\hline gi|405977525 & Puromycin-sensitive aminopeptidase [Crassostrea gigas] \\
\hline gi|405975462 & Adenylate kinase 2, mitochondrial [Crassostrea gigas] \\
\hline gi|405962873 & Filamin-C [Crassostrea gigas] \\
\hline gi|405971206 & Small nuclear ribonucleoprotein E [Crassostrea gigas] \\
\hline gi|405952287 & Glycerol-3-phosphate dehydrogenase [NAD+], cytoplasmic [Crassostrea gigas] \\
\hline gi|405950753 & StAR-related lipid transfer protein 5 [Crassostrea gigas] \\
\hline gi|405972836 & Retinal dehydrogenase 1 [Crassostrea gigas] \\
\hline gi|405967101 & $60 S$ ribosomal protein L13 [Crassostrea gigas] \\
\hline gi|32169292 & ribosomal protein L7 [Crassostrea gigas] \\
\hline gi|405959617 & hypothetical protein CGI_10004941 [Crassostrea gigas] \\
\hline gi|405965653 & Adenosine kinase 1 [Crassostrea gigas] \\
\hline gi|405967050 & Tektin-4 [Crassostrea gigas] \\
\hline gi|405977927 & $60 S$ ribosomal protein L9 [Crassostrea gigas] \\
\hline gi|405975708 & Succinyl-CoA:3-ketoacid-coenzyme A transferase 1, mitochondrial [Crassostrea gigas] \\
\hline gi|405964146 & Protein disulfide-isomerase [Crassostrea gigas] \\
\hline gi|405950429 & 14-3-3 protein zeta [Crassostrea gigas] \\
\hline gi|405976085 & CDGSH iron sulfur domain-containing protein 2 [Crassostrea gigas] \\
\hline gi|405959643 & Thimet oligopeptidase [Crassostrea gigas] \\
\hline gi|405954888 & Ganglioside-induced differentiation-associated protein 1 [Crassostrea gigas] \\
\hline gi|405971092 & Rootletin [Crassostrea gigas] \\
\hline gi|405963773 & ATP synthase subunit gamma, mitochondrial [Crassostrea gigas] \\
\hline gi|405953044 & Dynein beta chain, ciliary [Crassostrea gigas] \\
\hline gi|405963279 & Leukocyte elastase inhibitor [Crassostrea gigas] \\
\hline gi|405962295 & Radixin [Crassostrea gigas] \\
\hline gi|405953320 & hypothetical protein CGI_10004855 [Crassostrea gigas] \\
\hline gi|405961366 & Dynactin subunit 2 [Crassostrea gigas] \\
\hline gi|405975080 & hypothetical protein CGI_10025135 [Crassostrea gigas] \\
\hline gi|405952544 & Leucine-rich repeat-containing protein 48 [Crassostrea gigas] \\
\hline gi|405961865 & Ubiquitin-like modifier-activating enzyme 1 [Crassostrea gigas] \\
\hline gi|405956988 & Uncharacterized protein C11D3.13 [Crassostrea gigas] \\
\hline gi|405977689 & Pre-mRNA-splicing factor SPF27 [Crassostrea gigas] \\
\hline gi|405973723 & Peptidyl-prolyl cis-trans isomerase FKBP1A [Crassostrea gigas] \\
\hline
\end{tabular}




\begin{tabular}{|c|c|}
\hline Accession & Name \\
\hline gi|405955347 & 3-ketoacyl-CoA thiolase, mitochondrial [Crassostrea gigas] \\
\hline gi|405973481 & Catenin beta [Crassostrea gigas] \\
\hline gi|405971478 & S-formylglutathione hydrolase [Crassostrea gigas] \\
\hline gi|405977878 & Phosphatidylinositol-binding clathrin assembly protein [Crassostrea gigas] \\
\hline gi|405953092 & Asparaginyl-tRNA synthetase, cytoplasmic [Crassostrea gigas] \\
\hline gi|405958080 & Calmodulin [Crassostrea gigas] \\
\hline gi|405953134 & hypothetical protein CGI_10005248 [Crassostrea gigas] \\
\hline gi|405962156 & Alpha-aminoadipic semialdehyde synthase, mitochondrial [Crassostrea gigas] \\
\hline gi|405970434 & $60 \mathrm{~S}$ acidic ribosomal protein $\mathrm{P} 1$ [Crassostrea gigas] \\
\hline gi|405963559 & Sarcoplasmic calcium-binding protein [Crassostrea gigas] \\
\hline gi|405973830 & Enkurin [Crassostrea gigas] \\
\hline gi|405969027 & Glycolipid transfer protein [Crassostrea gigas] \\
\hline gi|405966068 & Dipeptidyl-peptidase 3 [Crassostrea gigas] \\
\hline gi|405953142 & Dihydropyrimidinase [Crassostrea gigas] \\
\hline gi|405955335 & hypothetical protein CGI_10002180 [Crassostrea gigas] \\
\hline gi|405973087 & SH3 domain-binding glutamic acid-rich protein [Crassostrea gigas] \\
\hline gi|405975424 & Calcium-dependent protein kinase 31 [Crassostrea gigas] \\
\hline gi|405962967 & Ribosomal protein S6 kinase 2 alpha [Crassostrea gigas] \\
\hline gi|405976037 & Charged multivesicular body protein 5 [Crassostrea gigas] \\
\hline gi|405973234 & $40 S$ ribosomal protein S3 [Crassostrea gigas] \\
\hline gi|405950169 & Vacuolar protein sorting-associated protein 28-like protein [Crassostrea gigas] \\
\hline gi|405963288 & Membrane-associated progesterone receptor component 2 [Crassostrea gigas] \\
\hline gi|405959669 & Synaptojanin-2-binding protein [Crassostrea gigas] \\
\hline gi|405966380 & Tropomodulin [Crassostrea gigas] \\
\hline gi|405978438 & $\mathrm{N}$-terminal EF-hand calcium-binding protein 1 [Crassostrea gigas] \\
\hline gi|29119645 & paramyosin protein [Crassostrea gigas] \\
\hline gi|405952417 & Calmodulin [Crassostrea gigas] \\
\hline gi|405955698 & hypothetical protein CGI_10001640 [Crassostrea gigas] \\
\hline gi|405970121 & Transcription initiation factor IIA subunit 1 [Crassostrea gigas] \\
\hline gi|405970507 & hypothetical protein CGI_10021010 [Crassostrea gigas] \\
\hline gi|405977412 & Protein-L-isoaspartate(D-aspartate) O-methyltransferase [Crassostrea gigas] \\
\hline gi|405967713 & 4-coumarate--CoA ligase [Crassostrea gigas] \\
\hline gi|405971207 & Histone deacetylase complex subunit SAP18 [Crassostrea gigas] \\
\hline gi|405951773 & Reticulocyte-binding protein 2-like protein a [Crassostrea gigas] \\
\hline gi|405968526 & Coactosin [Crassostrea gigas] \\
\hline gi|405954309 & Constitutive coactivator of PPAR-gamma-like protein 1-like protein [Crassostrea gigas] \\
\hline gi|405961591 & Cell differentiation protein RCD1-like protein [Crassostrea gigas] \\
\hline gi|405966073 & Glia maturation factor beta [Crassostrea gigas] \\
\hline gi|405972793 & Uncharacterized protein y4mH [Crassostrea gigas] \\
\hline gi|405955817 & 40 S ribosomal protein S24 [Crassostrea gigas] \\
\hline gi|405968514 & Mannose-6-phosphate isomerase [Crassostrea gigas] \\
\hline gi|405976150 & Purine nucleoside phosphorylase [Crassostrea gigas] \\
\hline gi|405947752 & $60 S$ ribosomal protein L17 [Crassostrea gigas] \\
\hline gi|405960908 & hypothetical protein CGI_10000618 [Crassostrea gigas] \\
\hline gi|405971282 & Histone H1.2 [Crassostrea gigas] \\
\hline gi|405958681 & Programmed cell death protein 6 [Crassostrea gigas] \\
\hline
\end{tabular}




\begin{tabular}{|c|c|}
\hline Accession & Name \\
\hline gi|405950001 & Transmembrane emp24 domain-containing protein 2 [Crassostrea gigas] \\
\hline gi|405975439 & Golgi SNAP receptor complex member 1 [Crassostrea gigas] \\
\hline gi|405951631 & Ras-related protein Rab-21 [Crassostrea gigas] \\
\hline gi|405952677 & Enhancer of yellow 2 transcription factor-like protein [Crassostrea gigas] \\
\hline gi|405957535 & Putative ATP-dependent RNA helicase DDX6 [Crassostrea gigas] \\
\hline gi|405958773 & HBXIP-like protein [Crassostrea gigas] \\
\hline gi|405959601 & T-complex protein 1 subunit eta [Crassostrea gigas] \\
\hline gi|405962679 & Allene oxide synthase-lipoxygenase protein [Crassostrea gigas] \\
\hline gi|405963508 & GMP reductase 2 [Crassostrea gigas] \\
\hline gi|405965375 & WD repeat-containing protein 82 [Crassostrea gigas] \\
\hline gi|405965856 & mago nashi-like protein 2 [Crassostrea gigas] \\
\hline gi|405972780 & Putative D-tyrosyl-tRNA(Tyr) deacylase 2 [Crassostrea gigas] \\
\hline gi|405972966 & Mps one binder kinase activator-like 2B [Crassostrea gigas] \\
\hline gi|405974200 & COP9 signalosome complex subunit 7a [Crassostrea gigas] \\
\hline gi|405974406 & NipSnap-like protein 2 [Crassostrea gigas] \\
\hline gi|405976506 & Counting factor associated protein D [Crassostrea gigas] \\
\hline gi|405974087 & hypothetical protein CGI_10020432 [Crassostrea gigas] \\
\hline gi|405978156 & Plasma membrane calcium-transporting ATPase 3 [Crassostrea gigas] \\
\hline gi|405966464 & Guanine nucleotide-binding protein subunit gamma- 1 [Crassostrea gigas] \\
\hline gi|405957004 & Heterogeneous nuclear ribonucleoprotein A/B [Crassostrea gigas] \\
\hline gi|405977625 & Glutathione S-transferase omega-1 [Crassostrea gigas] \\
\hline gi|405964579 & Actin [Crassostrea gigas] \\
\hline gi|405965637 & Tubulin alpha-1C chain [Crassostrea gigas] \\
\hline gi|51701468 & RecName: Full=Histone $\mathrm{H} 2 \mathrm{~A}$ \\
\hline gi|229485193 & peroxiredoxin 6 [Saccostrea glomerata] \\
\hline gi|405965590 & Tubulin beta chain [Crassostrea gigas] \\
\hline gi|40643020 & ribosomal protein S3 [Crassostrea gigas] \\
\hline gi|405971150 & Voltage-dependent anion-selective channel protein 2 [Crassostrea gigas] \\
\hline gi|42494887 & heat shock protein 70 [Argopecten irradians] \\
\hline gi|33114086 & histone H2B [Mytilus edulis] \\
\hline gi|405966634 & Actin, adductor muscle [Crassostrea gigas] \\
\hline gi|51315709 & RecName: Full=Histone $\mathrm{H} 4$ \\
\hline gi|405970171 & T-complex protein 1 subunit epsilon [Crassostrea gigas] \\
\hline gi|405977015 & Ras-related protein Rab-11B [Crassostrea gigas] \\
\hline gi|405958790 & Arginine kinase [Crassostrea gigas] \\
\hline gi|405962568 & RuvB-like 2 [Crassostrea gigas] \\
\hline gi|206814475 & calmodulin [Hyriopsis schlegelii] \\
\hline gi|405950969 & Ras-related protein Rab-2 [Crassostrea gigas] \\
\hline gi|405970768 & $26 \mathrm{~S}$ proteasome non-ATPase regulatory subunit 14 [Crassostrea gigas] \\
\hline gi|405956929 & Putative deoxyribose-phosphate aldolase [Crassostrea gigas] \\
\hline gi|405973432 & COP9 signalosome complex subunit 4 [Crassostrea gigas] \\
\hline gi|194068377 & tektin [Saccostrea kegaki] \\
\hline gi|405964869 & hypothetical protein CGI_10024545 [Crassostrea gigas] \\
\hline gi|405969319 & hypothetical protein CGI_10023395, partial [Crassostrea gigas] \\
\hline gi|405963182 & Ras-related protein Rab-14 [Crassostrea gigas] \\
\hline gi|405966123 & 4-hydroxybutyrate coenzyme A transferase [Crassostrea gigas] \\
\hline
\end{tabular}




\begin{tabular}{|c|c|}
\hline Accession & Name \\
\hline gi|405949952 & GDP-mannose 4,6 dehydratase [Crassostrea gigas] \\
\hline gi|443787 & actin [Crassostrea virginica] \\
\hline gi|405954457 & Isochorismatase domain-containing protein 2, mitochondrial [Crassostrea gigas] \\
\hline gi|405975730 & Cleavage and polyadenylation specificity factor subunit 5 [Crassostrea gigas] \\
\hline gi|405946263 & Dihydropteridine reductase [Crassostrea gigas] \\
\hline gi|405965384 & Cytosolic Fe-S cluster assembly factor nubp2 [Crassostrea gigas] \\
\hline gi|405952237 & Sorting nexin-6 [Crassostrea gigas] \\
\hline gi|405970601 & Ras-related protein Rab-18-B [Crassostrea gigas] \\
\hline gi|405964143 & GTP-binding protein SAR1b [Crassostrea gigas] \\
\hline gi|405957660 & Proteasome subunit beta type-1 [Crassostrea gigas] \\
\hline gi|405959509 & AP-1 complex subunit mu-1 [Crassostrea gigas] \\
\hline gi|405970027 & Actin-related protein $2 / 3$ complex subunit 2 [Crassostrea gigas] \\
\hline gi|405969599 & Exportin-1 [Crassostrea gigas] \\
\hline gi|405963071 & ADP-ribosylation factor-like protein 3 [Crassostrea gigas] \\
\hline gi|22203717 & ribosomal protein S2 [Chlamys farreri] \\
\hline gi|405960626 & Interleukin enhancer-binding factor 2-like protein [Crassostrea gigas] \\
\hline gi|51989573 & cytoplasmic aspartate aminotransferase [Crassostrea gigas] \\
\hline gi|405976266 & Eukaryotic translation initiation factor 3 subunit $\mathrm{E}$ [Crassostrea gigas] \\
\hline gi|405959423 & Putative D-lactate dehydrogenase, mitochondrial [Crassostrea gigas] \\
\hline gi|405976041 & Ras-related C3 botulinum toxin substrate 1 [Crassostrea gigas] \\
\hline gi|46359622 & polyubiquitin [Crassostrea gigas] \\
\hline gi|405971901 & Protein I(2)37Cc [Crassostrea gigas] \\
\hline gi|405968786 & Succinyl-CoA ligase [GDP-forming] subunit beta, mitochondrial [Crassostrea gigas] \\
\hline gi|405975643 & Solute carrier family 2 , facilitated glucose transporter member 1 [Crassostrea gigas] \\
\hline gi|405953685 & Regulator of differentiation 1 [Crassostrea gigas] \\
\hline gi|405959608 & Importin subunit alpha-7 [Crassostrea gigas] \\
\hline gi|405950612 & DDI1-like protein 2 [Crassostrea gigas] \\
\hline gi|405962822 & Vesicle-trafficking protein SEC22b [Crassostrea gigas] \\
\hline gi|405973112 & Aspartate aminotransferase, mitochondrial [Crassostrea gigas] \\
\hline gi|405973770 & 3-oxoacyl-[acyl-carrier-protein] reductase [Crassostrea gigas] \\
\hline gi|405975869 & Proteasome subunit alpha type-6 [Crassostrea gigas] \\
\hline gi|405950783 & Alpha-soluble NSF attachment protein [Crassostrea gigas] \\
\hline gi|405953900 & 60S ribosomal protein L38, partial [Crassostrea gigas] \\
\hline gi|405978445 & Epidermal retinal dehydrogenase 2 [Crassostrea gigas] \\
\hline gi|405962827 & Ribose-phosphate pyrophosphokinase 1 [Crassostrea gigas] \\
\hline gi|405958267 & Zinc finger MYND domain-containing protein 12 [Crassostrea gigas] \\
\hline gi|405954301 & MAP kinase-activated protein kinase 2 [Crassostrea gigas] \\
\hline gi|405959422 & $60 S$ ribosomal protein L14 [Crassostrea gigas] \\
\hline gi|46909219 & fructose-bisphosphate aldolase [Modiolus americanus] \\
\hline gi|405976110 & $60 S$ ribosomal protein L13a [Crassostrea gigas] \\
\hline gi|405968616 & hypothetical protein CGI_10015501 [Crassostrea gigas] \\
\hline gi|405958450 & $\begin{array}{l}\text { Serine/threonine-protein phosphatase } 2 \mathrm{~A} 56 \mathrm{kDa} \text { regulatory subunit alpha isoform [Crassostrea } \\
\text { gigas] }\end{array}$ \\
\hline gi|405963331 & Succinyl-CoA ligase [ADP-forming] subunit beta, mitochondrial [Crassostrea gigas] \\
\hline gi|405965667 & Aldehyde dehydrogenase family 8 member A1 [Crassostrea gigas] \\
\hline gi|40642998 & actin related protein $2 / 3$ complex, $21 \mathrm{kDa}$ subunit [Crassostrea gigas] \\
\hline gi|405970761 & Phosphotriesterase-related protein [Crassostrea gigas] \\
\hline
\end{tabular}




\begin{tabular}{|c|c|}
\hline Accession & Name \\
\hline gi|405959701 & Aldo-keto reductase family 1 member B10 [Crassostrea gigas] \\
\hline gi|405962781 & $26 \mathrm{~S}$ proteasome non-ATPase regulatory subunit 3 [Crassostrea gigas] \\
\hline gi|405975470 & Sec1 family domain-containing protein 1 [Crassostrea gigas] \\
\hline gi|405963980 & Mitogen-activated protein kinase 14 [Crassostrea gigas] \\
\hline gi|197690574 & alanopine dehydrogenase 2 [Crassostrea gigas] \\
\hline gi|405972861 & Isocitrate dehydrogenase [NAD] subunit beta, mitochondrial [Crassostrea gigas] \\
\hline gi|405965302 & Acyl-CoA dehydrogenase family member 9 , mitochondrial [Crassostrea gigas] \\
\hline gi|405961648 & Developmentally-regulated GTP-binding protein 2 [Crassostrea gigas] \\
\hline gi|405950725 & Electron transfer flavoprotein subunit beta [Crassostrea gigas] \\
\hline gi|405958893 & Betaine--homocysteine S-methyltransferase 2 [Crassostrea gigas] \\
\hline gi|405965397 & Rap1 GTPase-GDP dissociation stimulator 1-A [Crassostrea gigas] \\
\hline gi|405950187 & Protein arginine N-methyltransferase 1 [Crassostrea gigas] \\
\hline gi|405954518 & COP9 signalosome complex subunit 5 [Crassostrea gigas] \\
\hline gi|405971091 & Serine--pyruvate aminotransferase, mitochondrial [Crassostrea gigas] \\
\hline gi|405975744 & Eukaryotic translation initiation factor 3 subunit $F$ [Crassostrea gigas] \\
\hline gi|405959136 & Coiled-coil domain-containing protein C6orf97 [Crassostrea gigas] \\
\hline gi|405970698 & Multidrug resistance protein 1 [Crassostrea gigas] \\
\hline gi|405971276 & Syntenin-1 [Crassostrea gigas] \\
\hline gi|405955604 & $26 \mathrm{~S}$ protease regulatory subunit 7 [Crassostrea gigas] \\
\hline gi|405951430 & Protein muscleblind [Crassostrea gigas] \\
\hline gi|405974534 & Actin [Crassostrea gigas] \\
\hline gi|405976235 & Uroporphyrinogen decarboxylase [Crassostrea gigas] \\
\hline gi|116282657 & heat shock protein 70 [Pinctada fucata] \\
\hline gi|405976952 & Nck-associated protein 1 [Crassostrea gigas] \\
\hline gi|209921945 & calcineurin A subunit [Pinctada fucata] \\
\hline gi|405951746 & Transmembrane 9 superfamily member 2 [Crassostrea gigas] \\
\hline gi|405963530 & Transmembrane protein 49 [Crassostrea gigas] \\
\hline gi|405968988 & Fatty acid-binding protein, heart [Crassostrea gigas] \\
\hline gi|405951580 & Vesicle transport protein SEC20 [Crassostrea gigas] \\
\hline gi|405952265 & Omega-amidase NIT2-B [Crassostrea gigas] \\
\hline gi|405954501 & ADP-ribosylation factor-like protein 1 [Crassostrea gigas] \\
\hline gi|405960602 & N-terminal acetyltransferase B complex catalytic subunit NAT5 [Crassostrea gigas] \\
\hline gi|405962622 & Protein henna [Crassostrea gigas] \\
\hline gi|405963253 & Fumarate hydratase class I, aerobic [Crassostrea gigas] \\
\hline gi|405964636 & Estradiol 17-beta-dehydrogenase 11 [Crassostrea gigas] \\
\hline gi|405965226 & DNA-directed RNA polymerases I, II, and III subunit RPABC1 [Crassostrea gigas] \\
\hline gi|405967886 & Ras-related protein Rab-32 [Crassostrea gigas] \\
\hline gi|405967896 & Developmentally-regulated GTP-binding protein 1 [Crassostrea gigas] \\
\hline gi|405968356 & NADH dehydrogenase [ubiquinone] iron-sulfur protein 8, mitochondrial [Crassostrea gigas] \\
\hline gi|405969415 & Small nuclear ribonucleoprotein F [Crassostrea gigas] \\
\hline gi|405971690 & Pre-mRNA branch site p14-like protein [Crassostrea gigas] \\
\hline gi|405977265 & Long-chain specific acyl-CoA dehydrogenase, mitochondrial [Crassostrea gigas] \\
\hline gi|405977571 & UPF0632 protein A [Crassostrea gigas] \\
\hline gi|405977621 & Dehydrogenase/reductase SDR family member 1 [Crassostrea gigas] \\
\hline gi|405978304 & Carbohydrate kinase domain-containing protein [Crassostrea gigas] \\
\hline gi|48476117 & isocitrate dehydrogenase [Crassostrea gigas] \\
\hline
\end{tabular}




\begin{tabular}{|c|c|}
\hline Accession & Name \\
\hline gi|22758854 & ribosomal protein L11 [Argopecten irradians] \\
\hline gi|405969077 & Proteasome subunit beta type-4 [Crassostrea gigas] \\
\hline gi|405971281 & Leucine-rich repeat-containing protein 40 [Crassostrea gigas] \\
\hline gi|405971443 & UDP-N-acetylhexosamine pyrophosphorylase [Crassostrea gigas] \\
\hline gi|405974697 & C-terminal-binding protein [Crassostrea gigas] \\
\hline gi|405958322 & Exportin-7 [Crassostrea gigas] \\
\hline gi|405977672 & 2-amino-3-ketobutyrate coenzyme A ligase, mitochondrial, partial [Crassostrea gigas] \\
\hline gi|405964296 & Casein kinase I isoform alpha [Crassostrea gigas] \\
\hline gi|405972655 & Calcineurin subunit B type 1 [Crassostrea gigas] \\
\hline gi|405975219 & Ras-related protein Rab-4B [Crassostrea gigas] \\
\hline gi|40642992 & ribosomal protein L18 [Crassostrea gigas] \\
\hline gi|405953427 & Putative saccharopine dehydrogenase [Crassostrea gigas] \\
\hline gi|405978441 & Peroxisomal acyl-coenzyme A oxidase 1 [Crassostrea gigas] \\
\hline gi|405966181 & Aquaporin-4 [Crassostrea gigas] \\
\hline gi|405967675 & Stomatin-like protein 2, partial [Crassostrea gigas] \\
\hline gi|405973652 & hypothetical protein CGI_10021791 [Crassostrea gigas] \\
\hline gi|405972959 & Choline transporter-like protein 1 [Crassostrea gigas] \\
\hline gi|405963796 & hypothetical protein CGI_10010422 [Crassostrea gigas] \\
\hline gi|405960347 & Eukaryotic peptide chain release factor subunit 1 [Crassostrea gigas] \\
\hline gi|405977338 & Copine-8 [Crassostrea gigas] \\
\hline gi|405971018 & hypothetical protein CGI_10016017 [Crassostrea gigas] \\
\hline gi|405965053 & Succinate dehydrogenase cytochrome b560 subunit, mitochondrial [Crassostrea gigas] \\
\hline gi|405977162 & hypothetical protein CGI_10022027, partial [Crassostrea gigas] \\
\hline gi|405976874 & Peroxisomal 3,2-trans-enoyl-CoA isomerase [Crassostrea gigas] \\
\hline gi|405973846 & ADP-ribosylation factor-like protein 2 [Crassostrea gigas] \\
\hline gi|405959057 & Glutaryl-CoA dehydrogenase, mitochondrial [Crassostrea gigas] \\
\hline gi|405963876 & Ribose-phosphate pyrophosphokinase 3, mitochondrial [Crassostrea gigas] \\
\hline gi|405973157 & Prohibitin [Crassostrea gigas] \\
\hline gi|405961934 & Ectoine hydroxylase, partial [Crassostrea gigas] \\
\hline gi|405965788 & 3,2-trans-enoyl-CoA isomerase, mitochondrial [Crassostrea gigas] \\
\hline gi|405967210 & Signal peptidase complex catalytic subunit SEC11A [Crassostrea gigas] \\
\hline gi|405961041 & Ras-related protein Ral-A [Crassostrea gigas] \\
\hline gi|405967201 & Guanine nucleotide-binding protein G(s) subunit alpha [Crassostrea gigas] \\
\hline gi|405968330 & Tetratricopeptide repeat protein 26 [Crassostrea gigas] \\
\hline gi|405951729 & Vesicle-fusing ATPase 1 [Crassostrea gigas] \\
\hline gi|223364534 & ferritin [Mytilus galloprovincialis] \\
\hline gi|405951856 & Glucose-6-phosphate isomerase [Crassostrea gigas] \\
\hline gi|405959789 & $60 S$ ribosomal protein L6 [Crassostrea gigas] \\
\hline gi|405955497 & L-threonine 3-dehydrogenase, mitochondrial [Crassostrea gigas] \\
\hline gi|405957422 & Phosphatidylinositol 4-kinase type 2-beta [Crassostrea gigas] \\
\hline gi|405959700 & Aldo-keto reductase family 1 member B10 [Crassostrea gigas] \\
\hline gi|405973300 & Small nuclear ribonucleoprotein Sm D1 [Crassostrea gigas] \\
\hline gi|405974400 & Carbonyl reductase [NADPH] 1 [Crassostrea gigas] \\
\hline gi|405978187 & Glycerol kinase [Crassostrea gigas] \\
\hline gi|405975587 & D-beta-hydroxybutyrate dehydrogenase [Crassostrea gigas] \\
\hline gi|405952182 & 40 S ribosomal protein S8 [Crassostrea gigas] \\
\hline
\end{tabular}




\begin{tabular}{|c|c|}
\hline Accession & Name \\
\hline gi|405965399 & Glutaredoxin-1 [Crassostrea gigas] \\
\hline gi|405953048 & hypothetical protein CGI_10005386 [Crassostrea gigas] \\
\hline gi|15419048 & tropomyosin [Crassostrea gigas] \\
\hline gi|405959825 & hypothetical protein CGI_10007518 [Crassostrea gigas] \\
\hline gi|405963194 & Ras-related protein Rab-6B [Crassostrea gigas] \\
\hline gi|405950901 & Cysteine synthase [Crassostrea gigas] \\
\hline gi|405961757 & Citrate lyase subunit beta-like protein, mitochondrial [Crassostrea gigas] \\
\hline gi|405966177 & Cytochrome b5 [Crassostrea gigas] \\
\hline gi|405972644 & Neuron navigator 2 [Crassostrea gigas] \\
\hline gi|116008297 & mitochondrial H+ ATPase a subunit [Pinctada fucata] \\
\hline gi|405974676 & Replication factor $\mathrm{C}$ subunit 5 [Crassostrea gigas] \\
\hline gi|40643018 & ribosomal protein S27-1 [Crassostrea gigas] \\
\hline gi|405952874 & Vacuolar protein sorting-associated protein 45 [Crassostrea gigas] \\
\hline gi|405954068 & Pyruvate kinase isozymes M1/M2 [Crassostrea gigas] \\
\hline gi|405954837 & Tryptophanyl-tRNA synthetase, cytoplasmic [Crassostrea gigas] \\
\hline gi|405955167 & Microsomal glutathione S-transferase 1 [Crassostrea gigas] \\
\hline gi|405957653 & Dynein alpha chain, flagellar outer arm [Crassostrea gigas] \\
\hline gi|405963209 & D-3-phosphoglycerate dehydrogenase, partial [Crassostrea gigas] \\
\hline gi|405963789 & Cysteine desulfurase, mitochondrial [Crassostrea gigas] \\
\hline gi|405964718 & Transmembrane and coiled-coil domains protein 1 [Crassostrea gigas] \\
\hline gi|405970811 & Sushi repeat-containing protein SRPX2 [Crassostrea gigas] \\
\hline gi|405973910 & Lamin-B receptor [Crassostrea gigas] \\
\hline gi|7212448 & cytochrome c oxidase subunit II [Crassostrea gigas] \\
\hline gi|34484249 & sodium/potassium ATPase alpha subunit [Macoma nasuta] \\
\hline gi|405950746 & ATP-binding cassette sub-family E member 1 [Crassostrea gigas] \\
\hline gi|405950913 & $\begin{array}{l}\text { Bifunctional ATP-dependent dihydroxyacetone kinase/FAD-AMP lyase (cyclizing) [Crassostrea } \\
\text { gigas] }\end{array}$ \\
\hline gi|405953454 & Mitochondrial glutamate carrier 2 [Crassostrea gigas] \\
\hline gi|405957104 & U1 small nuclear ribonucleoprotein C [Crassostrea gigas] \\
\hline gi|405968465 & Cytochrome P450 20A1 [Crassostrea gigas] \\
\hline gi|405971269 & Intraflagellar transport protein 52-like protein [Crassostrea gigas] \\
\hline gi|405972789 & $60 S$ ribosomal protein L7a [Crassostrea gigas] \\
\hline gi|44885727 & arginine kinase [Scapharca broughtonii] \\
\hline gi|197690576 & putative strombine dehydrogenase [Crassostrea gigas] \\
\hline gi|22758864 & ribosomal protein L7 [Argopecten irradians] \\
\hline gi|22758902 & ribosomal protein L12 [Argopecten irradians] \\
\hline gi|27363131 & ribosomal protein S19 [Chlamys farreri] \\
\hline gi|405945303 & Rhomboid-related protein 2 [Crassostrea gigas] \\
\hline gi|405950619 & RNA-binding protein Raly [Crassostrea gigas] \\
\hline gi|405950848 & Inositol monophosphatase [Crassostrea gigas] \\
\hline gi|405951280 & Glyoxylate reductase/hydroxypyruvate reductase [Crassostrea gigas] \\
\hline gi|405952130 & Mitochondrial 2-oxoglutarate/malate carrier protein [Crassostrea gigas] \\
\hline gi|405952227 & Pre-mRNA-processing factor 39 [Crassostrea gigas] \\
\hline gi|405953377 & hypothetical protein CGI_10004678 [Crassostrea gigas] \\
\hline gi|405953774 & Tyrosyl-tRNA synthetase, cytoplasmic [Crassostrea gigas] \\
\hline gi|405953925 & hypothetical protein CGI_10003843 [Crassostrea gigas] \\
\hline gi|405954117 & Alpha-1,3-mannosyltransferase ALG2 [Crassostrea gigas] \\
\hline
\end{tabular}




\begin{tabular}{|c|c|}
\hline Accession & Name \\
\hline gi|405954119 & hypothetical protein CGI_10003535 [Crassostrea gigas] \\
\hline gi|405954839 & hypothetical protein CGI_10002700 [Crassostrea gigas] \\
\hline gi|405956182 & $40 \mathrm{~S}$ ribosomal protein S29 [Crassostrea gigas] \\
\hline gi|405957022 & hypothetical protein CGI_10020943 [Crassostrea gigas] \\
\hline gi|405957442 & 40 S ribosomal protein S26 [Crassostrea gigas] \\
\hline gi|405958861 & Carnitinyl-CoA dehydratase [Crassostrea gigas] \\
\hline gi|405959766 & DNA polymerase epsilon catalytic subunit A [Crassostrea gigas] \\
\hline gi|405960244 & Cytosolic purine 5'-nucleotidase [Crassostrea gigas] \\
\hline gi|405960530 & Putative serine protease F56F10.1 [Crassostrea gigas] \\
\hline gi|405960556 & Acyl-CoA dehydrogenase family member 10 [Crassostrea gigas] \\
\hline gi|405961146 & Solute carrier family 2 , facilitated glucose transporter member 8 [Crassostrea gigas] \\
\hline gi|405961498 & Uncharacterized protein C7orf62 [Crassostrea gigas] \\
\hline gi|405961675 & Cytosolic carboxypeptidase 6 [Crassostrea gigas] \\
\hline gi|405961892 & Vesicle transport protein GOT1B [Crassostrea gigas] \\
\hline gi|405962074 & AP-1 complex subunit sigma-2 [Crassostrea gigas] \\
\hline gi|405962625 & 5'-nucleotidase [Crassostrea gigas] \\
\hline gi|405962686 & Proteasome subunit beta type-7 [Crassostrea gigas] \\
\hline gi|405963072 & Tubulin alpha-3 chain [Crassostrea gigas] \\
\hline gi|405963426 & Serine/threonine/tyrosine-interacting-like protein 1 [Crassostrea gigas] \\
\hline gi|405963797 & Eukaryotic translation initiation factor 2 subunit 2 [Crassostrea gigas] \\
\hline gi|405963874 & Derlin-1 [Crassostrea gigas] \\
\hline gi|405964543 & Isocitrate dehydrogenase [NAD] subunit gamma, mitochondrial [Crassostrea gigas] \\
\hline gi|405964782 & Uridine phosphorylase 2 [Crassostrea gigas] \\
\hline gi|405964852 & Replication factor C subunit 2 [Crassostrea gigas] \\
\hline gi|405965641 & Mu-crystallin-like protein [Crassostrea gigas] \\
\hline gi|405965839 & Serine/threonine-protein phosphatase PP1-beta catalytic subunit [Crassostrea gigas] \\
\hline gi|405965865 & Proteasome subunit beta type-8 [Crassostrea gigas] \\
\hline gi|405966069 & Protein YIPF4 [Crassostrea gigas] \\
\hline gi|405968083 & Selenide, water dikinase [Crassostrea gigas] \\
\hline gi|405968134 & Trafficking protein particle complex subunit 3 [Crassostrea gigas] \\
\hline gi|405968449 & Phosphoenolpyruvate phosphomutase [Crassostrea gigas] \\
\hline gi|405969174 & S-adenosylmethionine synthetase isoform type-2 [Crassostrea gigas] \\
\hline gi|405969386 & U6 snRNA-associated Sm-like protein LSm2, partial [Crassostrea gigas] \\
\hline gi|405969501 & TIP41-like protein [Crassostrea gigas] \\
\hline gi|405969755 & Actin-3 [Crassostrea gigas] \\
\hline gi|405969997 & hypothetical protein CGI_10016221, partial [Crassostrea gigas] \\
\hline gi|405970150 & Sodium- and chloride-dependent glycine transporter 2 [Crassostrea gigas] \\
\hline gi|405971019 & Acetolactate synthase-like protein [Crassostrea gigas] \\
\hline gi|405971103 & Gamma-aminobutyric acid receptor-associated protein-like 2 [Crassostrea gigas] \\
\hline gi|405973607 & Synaptobrevin-like protein YKT6 [Crassostrea gigas] \\
\hline gi|405973976 & Copine-8 [Crassostrea gigas] \\
\hline gi|405975346 & Uncharacterized protein CXorf65-like protein [Crassostrea gigas] \\
\hline gi|405975388 & 2-acylglycerol O-acyltransferase 2-A [Crassostrea gigas] \\
\hline gi|405976100 & Annexin A7 [Crassostrea gigas] \\
\hline gi|405976287 & Beta-catenin-like protein 1 [Crassostrea gigas] \\
\hline gi|405976657 & Hemicentin-1 [Crassostrea gigas] \\
\hline
\end{tabular}




\begin{tabular}{|l|l|}
\hline \multicolumn{1}{|c|}{ Accession } & \multicolumn{1}{c|}{ Name } \\
\hline gi|405977337 & 60S ribosomal protein L18a [Crassostrea gigas] \\
\hline gi|405977844 & Excitatory amino acid transporter 1 [Crassostrea gigas] \\
\hline gi|405977994 & Myosin-VIla [Crassostrea gigas] \\
\hline gi|405978488 & hypothetical protein CGI_10028835 [Crassostrea gigas] \\
\hline gi|84782834 & LMPX protein [Crassostrea gigas] \\
\hline RRgi|405967181 & REVERSED Multidrug resistance-associated protein 1 [Crassostrea gigas] \\
\hline gi|405951234 & Innexin unc-9 [Crassostrea gigas] \\
\hline gi|405973883 & transport protein Sec24C [Crassostrea gigas] \\
\hline gi|405964639 & Phosphopantothenate--cysteine ligase [Crassostrea gigas] \\
\hline RRgi|405972453 & REVERSED Leucine-rich repeat-containing protein 7 [Crassostrea gigas] \\
\hline gi|405977545 & hypothetical protein CGI_10028170 [Crassostrea gigas] \\
\hline gi|405977688 & Kalirin [Crassostrea gigas] \\
\hline gi|405968555 & 26S proteasome non-ATPase regulatory subunit 5 [Crassostrea gigas] \\
\hline gi|405974250 & TP53RK-binding protein [Crassostrea gigas] \\
\hline gi|405971642 & ORM1-like protein 1 [Crassostrea gigas] \\
\hline gi|405973446 & Bardet-Biedl syndrome 1 protein [Crassostrea gigas] \\
\hline gi|405971762 & hypothetical protein CGI_10020122 [Crassostrea gigas] \\
\hline gi|405964272 & 15-hydroxyprostaglandin dehydrogenase [NAD+] [Crassostrea gigas] \\
\hline gi|405950208 & Protein FAM18A [Crassostrea gigas] \\
\hline gi|405972078 & Ganglioside-induced differentiation-associated protein 1 [Crassostrea gigas] \\
\hline gi|405975694 & Tripartite motif-containing protein 3 [Crassostrea gigas] \\
\hline gi|405951502 & Serine dehydratase-like protein [Crassostrea gigas] \\
\hline gi|405966735 & D-2-hydroxyglutarate dehydrogenase, mitochondrial [Crassostrea gigas] \\
\hline gi|405975474 & spinster-like protein 1 [Crassostrea gigas] \\
\hline gi|405971981 & Sodium-dependent phosphate transport protein 2B [Crassostrea gigas] \\
\hline gi|405972380 & Cytoplasmic FMR1-interacting protein [Crassostrea gigas] \\
\hline gi|405977557 & Myosin-lb [Crassostrea gigas] \\
\hline
\end{tabular}


Supplementary Table S2: Sydney Rock oyster proteins with fold change values.

\begin{tabular}{|c|c|c|c|}
\hline Accession & Name & GeoMean & $\begin{array}{c}\text { Stouffers } P \\
\text { value }\end{array}$ \\
\hline gi|405959701 & Aldo-keto reductase family 1 member B10 & 1.2 & 0.5630 \\
\hline gi|405951729 & Vesicle-fusing atpase 1 & 1.2 & 0.1161 \\
\hline gi|405958893 & Betaine--homocysteine S-methyltransferase 2 & 1.2 & 0.4964 \\
\hline gi|405945303 & Rhomboid-related protein 2 & 1.2 & \\
\hline gi|405969599 & Exportin-1 & 1.2 & 0.0994 \\
\hline gi|405951580 & Vesicle transport protein SEC20 & 1.3 & 0.2412 \\
\hline gi|405953454 & Mitochondrial glutamate carrier 2 & 1.3 & 0.4983 \\
\hline gi|405953048 & Hypothetical protein CGI_10005386 & 1.3 & \\
\hline gi|405961498 & Uncharacterized protein c7orf62 & 1.3 & \\
\hline gi|405978441 & Peroxisomal acyl-coenzyme A oxidase 1 & 1.3 & 0.2307 \\
\hline gi|405973112 & Aspartate aminotransferase, mitochondrial & 1.3 & \\
\hline gi|405971103 & $\begin{array}{l}\text { Gamma-aminobutyric acid receptor-associated protein-like } \\
2\end{array}$ & 1.3 & \\
\hline gi|405967896 & Developmentally-regulated GTP-binding protein 1 & 1.3 & 0.2413 \\
\hline gi|405971269 & Intraflagellar transport protein 52-like protein & 1.4 & 0.5150 \\
\hline gi|405951856 & Glucose-6-phosphate isomerase & 1.4 & 0.0567 \\
\hline gi|405973883 & Transport protein Sec24C & 1.4 & \\
\hline gi|405977162 & Hypothetical protein CGI_10022027, partial & 1.4 & 0.0886 \\
\hline gi|405977338 & Copine-8 & 1.4 & 0.0134 \\
\hline gi|405959766 & DNA polymerase epsilon catalytic subunit $A$ & 1.4 & \\
\hline gi|405966634 & Actin, adductor muscle & 1.5 & 0.1818 \\
\hline gi|46359622 & Polyubiquitin & 1.5 & 0.0023 \\
\hline gi|405959057 & Glutaryl-CoA dehydrogenase, mitochondrial & 1.5 & \\
\hline gi|405953685 & Regulator of differentiation 1 & 1.5 & 0.0322 \\
\hline gi|405978488 & Hypothetical protein CGI_10028835 & 1.5 & \\
\hline gi|405963789 & Cysteine desulfurase, mitochondrial & 1.5 & 0.0601 \\
\hline gi|405968449 & Phosphoenolpyruvate phosphomutase & 1.5 & \\
\hline gi|405954119 & Hypothetical protein CGI_10003535 & 1.5 & \\
\hline gi|22758854 & Ribosomal protein L11 & 1.5 & 0.0214 \\
\hline gi|405951746 & Transmembrane 9 superfamily member 2 & 1.6 & \\
\hline gi|405953925 & Hypothetical protein CGI_10003843 & 1.6 & \\
\hline gi|405959608 & Importin subunit alpha-7 & 1.6 & 0.1012 \\
\hline gi|405977337 & $60 S$ ribosomal protein $\mathrm{L} 18 \mathrm{a}$ & 1.6 & \\
\hline gi|405977265 & $\begin{array}{l}\text { Long-chain specific acyl- CoA dehydrogenase, } \\
\text { mitochondrial }\end{array}$ & 1.6 & 0.0150 \\
\hline gi|405960556 & Acyl- CoA dehydrogenase family member 10 & 1.6 & \\
\hline gi|405964852 & Replication factor C subunit 2 & 1.7 & \\
\hline gi|15419048 & Tropomyosin & 1.7 & \\
\hline gi|405965302 & Acyl- CoA dehydrogenase family member 9 , mitochondrial & 1.8 & 0.0071 \\
\hline gi|443787 & Actin & 1.8 & \\
\hline gi|405965590 & Tubulin beta chain & 1.9 & \\
\hline gi|405977672 & $\begin{array}{l}\text { 2-amino-3-ketobutyrate coenzyme A ligase, mitochondrial, } \\
\text { partial }\end{array}$ & 1.9 & 0.0186 \\
\hline gi|405975474 & Spinster-like protein 1 & 1.9 & \\
\hline gi|405964579 & Actin & 1.9 & 0.0000 \\
\hline gi|405957422 & Phosphatidylinositol 4-kinase type 2-beta & 2.0 & \\
\hline
\end{tabular}




\begin{tabular}{|c|c|c|c|}
\hline Accession & Name & GeoMean & $\begin{array}{c}\text { Stouffers } P \\
\text { value }\end{array}$ \\
\hline gi|405962781 & $26 \mathrm{~S}$ proteasome non-ATPase regulatory subunit 3 & 2.0 & 0.1076 \\
\hline gi|405953774 & Tyrosyl-tRNA synthetase, cytoplasmic & 2.0 & \\
\hline gi|405961934 & Ectoine hydroxylase, partial & 2.0 & \\
\hline gi|405967201 & Guanine nucleotide-binding protein G(s) subunit alpha & 2.1 & \\
\hline gi|405954301 & MAP kinase-activated protein kinase 2 & 2.1 & 0.0000 \\
\hline gi|405969174 & S-adenosylmethionine synthetase isoform type-2 & 2.2 & \\
\hline gi|405968465 & Cytochrome P450 20A1 & 2.4 & \\
\hline gi|42494887 & Heat shock protein 70 & 2.4 & 0.0147 \\
\hline gi|405971443 & UDP-N-acetylhexosamine pyrophosphorylase & 2.5 & \\
\hline gi|405963796 & Hypothetical protein CGI_10010422 & 2.6 & 0.0002 \\
\hline gi|405952130 & Mitochondrial 2-oxoglutarate/malate carrier protein & 2.6 & \\
\hline gi|405976952 & Nck-associated protein 1 & 2.8 & \\
\hline gi|405950746 & ATP-binding cassette sub-family E member 1 & 2.9 & \\
\hline gi|405960244 & Cytosolic purine 5'-nucleotidase & 2.9 & \\
\hline gi|44885727 & Arginine kinase & 2.9 & \\
\hline gi|48476117 & Isocitrate dehydrogenase & 3.0 & \\
\hline gi|405959789 & 60S ribosomal protein $\mathrm{L} 6$ & 3.0 & 0.0019 \\
\hline gi|405976100 & Annexin A7 & 3.0 & 0.0011 \\
\hline gi|405952227 & Pre-mRNA-processing factor 39 & 3.0 & \\
\hline gi|206814475 & Calmodulin & 3.1 & \\
\hline gi|405972789 & $60 S$ ribosomal protein $\mathrm{L} 7 \mathrm{a}$ & 3.3 & 0.0020 \\
\hline gi|405952182 & $40 S$ ribosomal protein $\mathrm{S} 8$ & 3.4 & 0.1139 \\
\hline gi|405963253 & Fumarate hydratase class I, aerobic & 3.4 & 0.0013 \\
\hline gi|405962622 & Protein henna & 3.5 & \\
\hline gi|27363131 & Ribosomal protein S19 & 3.6 & \\
\hline gi|405952237 & Sorting nexin- 6 & 3.7 & 0.0006 \\
\hline gi|405970698 & Multidrug resistance protein 1 & 3.8 & \\
\hline gi|405957442 & $40 S$ ribosomal protein S26 & 3.9 & \\
\hline gi|405970027 & Actin-related protein $2 / 3$ complex subunit 2 & 3.9 & 0.0000 \\
\hline gi|405958450 & $\begin{array}{l}\text { Serine/threonine-protein phosphatase } 2 \mathrm{~A} 56 \mathrm{kDa} \\
\text { regulatory subunit alpha isoform }\end{array}$ & 4.4 & 0.0007 \\
\hline gi|34484249 & Sodium/potassium ATPase alpha subunit & 4.7 & \\
\hline gi|405976874 & Peroxisomal 3,2-trans-enoyl- CoA isomerase & 4.8 & 0.0000 \\
\hline gi|116282657 & Heat shock protein 70 & 4.9 & \\
\hline gi|405963072 & Tubulin alpha-3 chain & 5.4 & \\
\hline gi|223364534 & Ferritin & 5.8 & \\
\hline gi|405954837 & Tryptophanyl-tRNA synthetase, cytoplasmic & 6.0 & 0.0003 \\
\hline gi|405976287 & Beta-catenin-like protein 1 & 6.3 & \\
\hline gi|194068377 & Tektin & 6.9 & 0.0000 \\
\hline gi|405977557 & Myosin-lb & 7.0 & \\
\hline gi|405955604 & $26 S$ protease regulatory subunit 7 & 7.9 & 0.1075 \\
\hline gi|22758864 & Ribosomal protein L7 & 8.5 & \\
\hline gi|405975470 & Sec1 family domain-containing protein 1 & 9.7 & \\
\hline gi|405958790 & Arginine kinase & 10.1 & 0.0000 \\
\hline gi|40642992 & Ribosomal protein L18 & 10.2 & 0.0026 \\
\hline gi|405965637 & Tubulin alpha-1C chain & 14.2 & 0.0035 \\
\hline
\end{tabular}




\begin{tabular}{|c|c|c|c|}
\hline Accession & Name & GeoMean & $\begin{array}{c}\text { Stouffers } P \\
\text { value }\end{array}$ \\
\hline gi|405971150 & Voltage-dependent anion-selective channel protein 2 & 0.3 & 0.0000 \\
\hline gi|405975587 & D-beta-hydroxybutyrate dehydrogenase & 0.4 & \\
\hline gi|51701468 & Recname: Full=Histone $\mathrm{H} 2 \mathrm{~A}$ & 0.5 & 0.0068 \\
\hline gi|40643018 & Ribosomal protein S27-1 & 0.5 & 0.0244 \\
\hline gi|405974250 & TP53RK-binding protein & 0.5 & \\
\hline gi|405978304 & Carbohydrate kinase domain-containing protein & 0.5 & \\
\hline gi|405975869 & Proteasome subunit alpha type- 6 & 0.5 & 0.0000 \\
\hline gi|405965788 & 3,2-trans-enoyl-CoA isomerase, mitochondrial & 0.5 & 0.1071 \\
\hline gi|405971276 & Syntenin-1 & 0.5 & \\
\hline gi|405969386 & U6 snRNA-associated Sm-like protein Ism2, partial & 0.5 & \\
\hline gi|405973300 & Small nuclear ribonucleoprotein Sm D1 & 0.5 & \\
\hline gi|405969501 & TIP41-like protein & 0.5 & \\
\hline gi|405951234 & Innexin unc-9 & 0.5 & \\
\hline gi|405977571 & UPF0632 protein $A$ & 0.5 & 0.0941 \\
\hline gi|405961757 & Citrate lyase subunit beta-like protein, mitochondrial & 0.5 & 0.1567 \\
\hline gi|405977688 & Kalirin & 0.5 & \\
\hline gi|405963980 & Mitogen-activated protein kinase 14 & 0.6 & 0.0001 \\
\hline gi|405969077 & Proteasome subunit beta type- 4 & 0.6 & 0.0096 \\
\hline gi|405961892 & Vesicle transport protein GOT1B & 0.6 & \\
\hline gi|405954117 & Alpha-1,3-mannosyltransferase ALG2 & 0.6 & \\
\hline gi|405970768 & $26 S$ proteasome non-ATPase regulatory subunit 14 & 0.6 & 0.0000 \\
\hline gi|405964143 & GTP-binding protein SAR1b & 0.6 & 0.0015 \\
\hline gi|405971901 & Protein I(2)37Cc & 0.6 & 0.0047 \\
\hline gi|405951502 & Serine dehydratase-like protein & 0.6 & \\
\hline gi|405963182 & Ras-related protein Rab-14 & 0.6 & 0.1055 \\
\hline gi|116008297 & Mitochondrial H+ ATPase a subunit & 0.6 & \\
\hline gi|405975730 & Cleavage and polyadenylation specificity factor subunit 5 & 0.6 & 0.0000 \\
\hline gi|405973770 & 3-oxoacyl-[acyl-carrier-protein] reductase & 0.6 & \\
\hline gi|51315709 & Recname: Full=Histone $\mathrm{H} 4$ & 0.6 & 0.0012 \\
\hline gi|405972078 & Ganglioside-induced differentiation-associated protein 1 & 0.6 & \\
\hline gi|405962074 & AP-1 complex subunit sigma-2 & 0.6 & \\
\hline gi|405963874 & Derlin-1 & 0.6 & \\
\hline gi|405970811 & Sushi repeat-containing protein SRPX2 & 0.6 & \\
\hline gi|405951430 & Protein muscleblind & 0.6 & 0.0363 \\
\hline gi|405957660 & Proteasome subunit beta type-1 & 0.6 & 0.0844 \\
\hline gi|405972959 & Choline transporter-like protein 1 & 0.6 & 0.0802 \\
\hline gi|7212448 & Cytochrome c oxidase subunit II & 0.6 & 0.0110 \\
\hline gi|405973607 & Synaptobrevin-like protein YKT6 & 0.6 & \\
\hline gi|405963071 & ADP-ribosylation factor-like protein 3 & 0.6 & 0.0056 \\
\hline gi|405976235 & Uroporphyrinogen decarboxylase & 0.6 & \\
\hline gi|405950783 & Alpha-soluble NSF attachment protein & 0.6 & 0.0005 \\
\hline gi|405964869 & Hypothetical protein CGI_10024545 & 0.6 & 0.0003 \\
\hline gi|405963331 & $\begin{array}{l}\text { Succinyl-CoA ligase [ADP-forming] subunit beta, } \\
\text { mitochondrial }\end{array}$ & 0.6 & 0.2507 \\
\hline gi|405964636 & Estradiol 17-beta-dehydrogenase 11 & 0.6 & \\
\hline gi|229485193 & Peroxiredoxin 6 & 0.6 & 0.0000 \\
\hline
\end{tabular}




\begin{tabular}{|c|c|c|c|}
\hline Accession & Name & GeoMean & $\begin{array}{c}\text { Stouffers } P \\
\text { value }\end{array}$ \\
\hline gi|405950969 & Ras-related protein Rab-2 & 0.6 & 0.0029 \\
\hline gi|405968616 & Hypothetical protein CGI_10015501 & 0.6 & 0.0091 \\
\hline gi|405954501 & ADP-ribosylation factor-like protein 1 & 0.6 & \\
\hline gi|405965667 & Aldehyde dehydrogenase family 8 member A1 & 0.6 & 0.0561 \\
\hline gi|405971091 & Serine--pyruvate aminotransferase, mitochondrial & 0.6 & 0.0246 \\
\hline gi|405963797 & Eukaryotic translation initiation factor 2 subunit 2 & 0.6 & \\
\hline gi|405950848 & Inositol monophosphatase & 0.6 & \\
\hline gi|405976041 & Ras-related C3 botulinum toxin substrate 1 & 0.6 & 0.0000 \\
\hline gi|40642998 & Actin related protein $2 / 3$ complex, $21 \mathrm{kDa}$ subunit & 0.6 & 0.0037 \\
\hline gi|405968786 & $\begin{array}{l}\text { Succinyl-CoA ligase [GDP-forming] subunit beta, } \\
\text { mitochondrial }\end{array}$ & 0.6 & \\
\hline gi|405946263 & Dihydropteridine reductase & 0.6 & 0.0000 \\
\hline gi|405976110 & $60 S$ ribosomal protein $\mathrm{L} 13 \mathrm{a}$ & 0.6 & 0.0005 \\
\hline gi|405955167 & Microsomal glutathione S-transferase 1 & 0.6 & \\
\hline gi|405970601 & Ras-related protein Rab-18-B & 0.6 & 0.0215 \\
\hline gi|405954457 & $\begin{array}{l}\text { Isochorismatase domain-containing protein } 2 \text {, } \\
\text { mitochondrial }\end{array}$ & 0.6 & 0.0031 \\
\hline gi|405950725 & Electron transfer flavoprotein subunit beta & 0.7 & 0.0052 \\
\hline gi|405971642 & ORM1-like protein 1 & 0.7 & \\
\hline gi|51989573 & Cytoplasmic aspartate aminotransferase & 0.7 & 0.0553 \\
\hline gi|405973652 & Hypothetical protein CGI_10021791 & 0.7 & \\
\hline gi|405966123 & 4-hydroxybutyrate coenzyme A transferase & 0.7 & 0.2789 \\
\hline gi|405967675 & Stomatin-like protein 2, partial & 0.7 & 0.3965 \\
\hline gi|46909219 & Fructose-bisphosphate aldolase & 0.7 & \\
\hline gi|405973157 & Prohibitin & 0.7 & 0.0272 \\
\hline gi|405959423 & Putative D-lactate dehydrogenase, mitochondrial & 0.7 & 0.2901 \\
\hline gi|405977994 & Myosin-VIla & 0.7 & \\
\hline gi|22203717 & Ribosomal protein S2 & 0.7 & 0.0000 \\
\hline gi|405977545 & Hypothetical protein CGI_10028170 & 0.7 & \\
\hline gi|405953900 & $60 S$ ribosomal protein L38, partial & 0.7 & 0.0011 \\
\hline gi|405972861 & $\begin{array}{l}\text { Isocitrate dehydrogenase [NAD] subunit beta, } \\
\text { mitochondrial }\end{array}$ & 0.7 & 0.0014 \\
\hline gi|405956929 & Putative deoxyribose-phosphate aldolase & 0.7 & 0.0011 \\
\hline gi|405964272 & 15-hydroxyprostaglandin dehydrogenase [NAD+] & 0.7 & \\
\hline gi|405978445 & Epidermal retinal dehydrogenase 2 & 0.7 & 0.0940 \\
\hline gi|405969997 & Hypothetical protein CGI_10016221, partial & 0.7 & \\
\hline gi|405978187 & Glycerol kinase & 0.7 & \\
\hline gi|405965397 & Rap1 GTPase-GDP dissociation stimulator 1-A & 0.7 & 0.0351 \\
\hline gi|405967886 & Ras-related protein Rab-32 & 0.7 & 0.0449 \\
\hline gi|405965053 & $\begin{array}{l}\text { Succinate dehydrogenase cytochrome b560 subunit, } \\
\text { mitochondrial }\end{array}$ & 0.7 & 0.0731 \\
\hline gi|405974697 & C-terminal-binding protein & 0.7 & 0.0972 \\
\hline gi|405971690 & Pre-mRNA branch site p14-like protein & 0.7 & 0.0712 \\
\hline gi|405964639 & Phosphopantothenate--cysteine ligase & 0.7 & 0.2946 \\
\hline gi|405968988 & Fatty acid-binding protein, heart & 0.7 & 0.1551 \\
\hline gi|405973846 & ADP-ribosylation factor-like protein 2 & 0.7 & 0.0060 \\
\hline gi|33114086 & Histone H2B & 0.7 & 0.0000 \\
\hline gi|405965399 & Glutaredoxin-1 & 0.8 & 0.1002 \\
\hline
\end{tabular}




\begin{tabular}{|c|c|c|c|}
\hline Accession & Name & GeoMean & $\begin{array}{c}\text { Stouffers } P \\
\text { value }\end{array}$ \\
\hline gi|405975744 & Eukaryotic translation initiation factor 3 subunit $F$ & 0.8 & \\
\hline gi|405973432 & COP9 signalosome complex subunit 4 & 0.8 & 0.0143 \\
\hline gi|405950913 & $\begin{array}{l}\text { Bifunctional ATP-dependent dihydroxyacetone } \\
\text { kinase/FAD-AMP Iyase (cyclizing) }\end{array}$ & 0.8 & \\
\hline gi|405962568 & Ruvb-like 2 & 0.8 & 0.0004 \\
\hline gi|405975219 & Ras-related protein Rab-4B & 0.8 & \\
\hline gi|405977015 & Ras-related protein Rab-11B & 0.8 & 0.0000 \\
\hline gi|405965641 & Mu-crystallin-like protein & 0.8 & \\
\hline gi|405957104 & U1 small nuclear ribonucleoprotein C & 0.8 & \\
\hline gi|405963426 & Serine/threonine/tyrosine-interacting-like protein 1 & 0.8 & \\
\hline gi|84782834 & LMPX protein & 0.8 & \\
\hline gi|405970761 & Phosphotriesterase-related protein & 0.8 & 0.0975 \\
\hline gi|405954518 & COP9 signalosome complex subunit 5 & 0.8 & 0.0161 \\
\hline gi|405977621 & Dehydrogenase/reductase SDR family member 1 & 0.8 & \\
\hline gi|405964782 & Uridine phosphorylase 2 & 0.8 & \\
\hline gi|405961648 & Developmentally-regulated GTP-binding protein 2 & 0.8 & 0.1741 \\
\hline gi|405963194 & Ras-related protein Rab-6B & 0.8 & 0.0359 \\
\hline gi|405953377 & Hypothetical protein CGI_10004678 & 0.8 & \\
\hline gi|40643020 & Ribosomal protein S3 & 0.8 & \\
\hline gi|405973446 & Bardet-Biedl syndrome 1 protein & 0.8 & \\
\hline gi|405950901 & Cysteine synthase & 0.8 & 0.2824 \\
\hline gi|405958267 & Zinc finger MYND domain-containing protein 12 & 0.8 & 0.7527 \\
\hline gi|405965865 & Proteasome subunit beta type-8 & 0.8 & \\
\hline gi|405966181 & Aquaporin-4 & 0.8 & 0.6074 \\
\hline gi|405964718 & Transmembrane and coiled-coil domains protein 1 & 0.8 & \\
\hline gi|405952265 & Omega-Amidase NIT2-B & 0.9 & \\
\hline gi|405962822 & Vesicle-trafficking protein SEC22b & 0.9 & \\
\hline gi|405950208 & Protein FAM18A & 0.9 & \\
\hline gi|405966177 & Cytochrome b5 & 0.9 & 0.5555 \\
\hline gi|405960626 & Interleukin enhancer-binding factor 2-like protein & 0.9 & 0.7722 \\
\hline gi|405963876 & Ribose-phosphate pyrophosphokinase 3, mitochondrial & 0.9 & 0.7306 \\
\hline gi|405967210 & Signal peptidase complex catalytic subunit SEC11A & 0.9 & 0.6063 \\
\hline gi|405959422 & $60 S$ ribosomal protein $L 14$ & 0.9 & 0.1654 \\
\hline gi|405953427 & Putative saccharopine dehydrogenase & 0.9 & 0.9453 \\
\hline gi|405968134 & Trafficking protein particle complex subunit 3 & 0.9 & \\
\hline gi|405955497 & L-threonine 3-dehydrogenase, mitochondrial & 0.9 & 0.5219 \\
\hline gi|405976266 & Eukaryotic translation initiation factor 3 subunit $\mathrm{E}$ & 0.9 & 0.5200 \\
\hline gi|405952874 & Vacuolar protein sorting-associated protein 45 & 0.9 & 0.7682 \\
\hline gi|405965384 & Cytosolic Fe-S cluster assembly factor nubp2 & 0.9 & 0.3537 \\
\hline gi|405965226 & $\begin{array}{l}\text { DNA-directed RNA polymerases I, II, and III subunit } \\
\text { RPABC1 }\end{array}$ & 0.9 & \\
\hline gi|405950619 & RNA-binding protein Raly & 0.9 & \\
\hline gi|405975643 & $\begin{array}{l}\text { Solute carrier family } 2 \text {, facilitated glucose transporter } \\
\text { member } 1\end{array}$ & 0.9 & 0.9422 \\
\hline gi|405968330 & Tetratricopeptide repeat protein 26 & 0.9 & 0.9835 \\
\hline gi|405972380 & Cytoplasmic FMR1-interacting protein & 0.9 & \\
\hline gi|405962827 & Ribose-phosphate pyrophosphokinase 1 & 0.9 & 0.8080 \\
\hline
\end{tabular}




\begin{tabular}{|l|l|c|c|}
\hline \multicolumn{1}{|c|}{ Accession } & \multicolumn{1}{|c|}{ Name } & GeoMean & $\begin{array}{c}\text { Stouffers P } \\
\text { value }\end{array}$ \\
\hline gi|405949952 & GDP-mannose 4,6 dehydratase & 1.0 & 0.9934 \\
\hline gi|405973910 & Lamin-B receptor & 1.0 & 0.9236 \\
\hline gi|405966735 & D-2-hydroxyglutarate dehydrogenase, mitochondrial & 1.0 & \\
\hline gi|405958861 & Carnitinyl-CoA dehydratase & 1.0 & \\
\hline gi|405971019 & Acetolactate synthase-like protein & 1.0 & \\
\hline gi|405954068 & Pyruvate kinase isozymes M1/M2 & 1.0 & \\
\hline gi|405950187 & Protein arginine N-methyltransferase 1 & 1.0 & 0.9933 \\
\hline gi|405968555 & 26S proteasome non-ATPase regulatory subunit 5 & 1.0 & \\
\hline gi|405970171 & T-complex protein 1 subunit epsilon & 1.0 & 0.9965 \\
\hline gi|405964543 & $\begin{array}{l}\text { Isocitrate dehydrogenase [NAD] subunit gamma, } \\
\text { mitochondrial }\end{array}$ & 1.0 & \\
\hline gi|405959509 & AP-1 complex subunit mu-1 & 1.0 & 0.9680 \\
\hline gi|405969319 & Hypothetical protein CGI_10023395, partial & 1.0 & 0.3430 \\
\hline gi|405961146 & $\begin{array}{l}\text { Solute carrier family 2, facilitated glucose transporter } \\
\text { member 8 }\end{array}$ & 1.0 & \\
\hline gi|405962686 & Proteasome subunit beta type-7 & 1.0 & \\
\hline gi|405950612 & DDI1-like protein 2 & 1.0 & \\
\hline gi|405974400 & Carbonyl reductase [NADPH] 1 & 1.1 & 0.6168 \\
\hline gi|405972655 & Calcineurin subunit B type 1 & 1.1 & 0.9553 \\
\hline gi|405964296 & Casein kinase I isoform alpha & 1.1 & 0.8256 \\
\hline gi|405965839 & $\begin{array}{l}\text { Serine/threonine-protein phosphatase PP1-beta catalytic } \\
\text { subunit }\end{array}$ & 1.1 & \\
\hline gi|405958322 & Exportin-7 & 1.1 & 0.4445 \\
\hline gi|405971018 & Hypothetical protein CGI_10016017 & 1.1 & \\
\hline gi|405963530 & Transmembrane protein 49 & 1.1 & \\
\hline gi|405971281 & Leucine-rich repeat-containing protein 40 & 1.2 & \\
\hline gi|405970150 & Sodium- and chloride-dependent glycine transporter 2 & \\
\hline gi|405956182 & 40S ribosomal protein S29 & 1.1 & \\
\hline & & & \\
\hline
\end{tabular}


Supplementary Table 3: All Pacific oyster proteins.

\begin{tabular}{|c|c|}
\hline Accession & Name \\
\hline gi|405974790 & ATP synthase subunit beta, mitochondrial [Crassostrea gigas] \\
\hline gi|405974703 & ATP synthase subunit alpha, mitochondrial [Crassostrea gigas] \\
\hline gi|405978716 & Alpha-actinin, sarcomeric [Crassostrea gigas] \\
\hline gi|405977961 & T-complex protein 1 subunit delta, partial [Crassostrea gigas] \\
\hline gi|405964948 & Fructose-bisphosphate aldolase [Crassostrea gigas] \\
\hline gi|405978809 & $\begin{array}{l}\text { Serine/threonine-protein phosphatase } 2 \mathrm{~A} 65 \mathrm{kDa} \text { regulatory subunit } \mathrm{A} \text { alpha isoform } \\
\text { [Crassostrea gigas] }\end{array}$ \\
\hline gi|405959695 & Clathrin heavy chain 1 [Crassostrea gigas] \\
\hline gi|405957058 & Glyceraldehyde-3-phosphate dehydrogenase [Crassostrea gigas] \\
\hline gi|405950190 & Vinculin [Crassostrea gigas] \\
\hline gi|405972882 & T-complex protein 1 subunit beta [Crassostrea gigas] \\
\hline gi|405974681 & Major vault protein [Crassostrea gigas] \\
\hline gi|405974443 & Adenosylhomocysteinase A [Crassostrea gigas] \\
\hline gi|405963584 & 14-3-3 protein epsilon [Crassostrea gigas] \\
\hline gi|405978369 & T-complex protein 1 subunit alpha [Crassostrea gigas] \\
\hline gi|405957859 & $26 \mathrm{~S}$ protease regulatory subunit $6 \mathrm{~A}$ [Crassostrea gigas] \\
\hline gi|405959600 & T-complex protein 1 subunit eta [Crassostrea gigas] \\
\hline gi|405963058 & T-complex protein 1 subunit gamma [Crassostrea gigas] \\
\hline gi|405973892 & Guanine nucleotide-binding protein subunit beta-2-like 1 [Crassostrea gigas] \\
\hline gi|405970867 & Enolase [Crassostrea gigas] \\
\hline gi|405961849 & Ras-related protein Rab-7a [Crassostrea gigas] \\
\hline gi|405957582 & Serine/threonine-protein phosphatase PP1-alpha catalytic subunit [Crassostrea gigas] \\
\hline gi|405965075 & Aldehyde dehydrogenase, mitochondrial [Crassostrea gigas] \\
\hline gi|405970598 & Citrate synthase, mitochondrial [Crassostrea gigas] \\
\hline gi|405959090 & Malate dehydrogenase, cytoplasmic, partial [Crassostrea gigas] \\
\hline gi|405950834 & Sperm-associated antigen 6 [Crassostrea gigas] \\
\hline gi|405959540 & Transaldolase [Crassostrea gigas] \\
\hline gi|405950430 & 14-3-3 protein gamma [Crassostrea gigas] \\
\hline gi|405965040 & Glycogen phosphorylase, muscle form [Crassostrea gigas] \\
\hline gi|405973142 & Actin-related protein 3 [Crassostrea gigas] \\
\hline gi|405961646 & ADP,ATP carrier protein [Crassostrea gigas] \\
\hline gi|405963233 & Phosphoglycerate kinase 1 [Crassostrea gigas] \\
\hline gi|405960081 & $60 S$ acidic ribosomal protein P0 [Crassostrea gigas] \\
\hline gi|405976088 & 40 S ribosomal protein SA [Crassostrea gigas] \\
\hline gi|405971611 & V-type proton ATPase subunit B [Crassostrea gigas] \\
\hline gi|405957821 & Mechanosensory protein 2 [Crassostrea gigas] \\
\hline gi|405972837 & Retinal dehydrogenase 1 [Crassostrea gigas] \\
\hline gi|405963427 & Malate dehydrogenase, mitochondrial [Crassostrea gigas] \\
\hline gi|405976915 & Proteasome subunit alpha type-7-like protein [Crassostrea gigas] \\
\hline gi|405957820 & Mechanosensory protein 2, partial [Crassostrea gigas] \\
\hline gi|405974897 & Peroxiredoxin-5, mitochondrial [Crassostrea gigas] \\
\hline gi|405973893 & $\begin{array}{l}\text { Serine/threonine-protein phosphatase } 2 \mathrm{~A} \text { catalytic subunit beta isoform [Crassostrea } \\
\text { gigas] }\end{array}$ \\
\hline gi|405977322 & Polyadenylate-binding protein 4 [Crassostrea gigas] \\
\hline gi|405970566 & Guanine nucleotide-binding protein $\mathrm{G}(\mathrm{o})$ subunit alpha [Crassostrea gigas] \\
\hline gi|405961263 & Phosphoenolpyruvate carboxykinase [GTP] [Crassostrea gigas] \\
\hline
\end{tabular}




\begin{tabular}{|c|c|}
\hline Accession & Name \\
\hline gi|405965244 & $\begin{array}{l}\text { Dolichyl-diphosphooligosaccharide--protein glycosyltransferase subunit } 2 \text { [Crassostrea } \\
\text { gigas] }\end{array}$ \\
\hline gi|405971056 & Flotillin-2 [Crassostrea gigas] \\
\hline gi|405962453 & Cdc42-like protein [Crassostrea gigas] \\
\hline gi|405957088 & $33 \mathrm{kDa}$ inner dynein arm light chain, axonemal [Crassostrea gigas] \\
\hline gi|405976231 & Protein FAM49B [Crassostrea gigas] \\
\hline gi|405969917 & Ras-related protein Rab-1A [Crassostrea gigas] \\
\hline gi|405961968 & Actin-related protein 2 [Crassostrea gigas] \\
\hline gi|405964525 & Proteasome subunit alpha type-2 [Crassostrea gigas] \\
\hline gi|405950795 & Non-neuronal cytoplasmic intermediate filament protein [Crassostrea gigas] \\
\hline gi|405975835 & $\mathrm{NAD}(\mathrm{P})$ transhydrogenase, mitochondrial [Crassostrea gigas] \\
\hline gi|405977168 & Signal recognition particle $54 \mathrm{kDa}$ protein [Crassostrea gigas] \\
\hline gi|405964445 & Cystathionine gamma-lyase [Crassostrea gigas] \\
\hline gi|405967540 & $60 S$ ribosomal protein L23 [Crassostrea gigas] \\
\hline gi|405973252 & Fructose-bisphosphate aldolase [Crassostrea gigas] \\
\hline gi|405971602 & hypothetical protein CGI_10010586 [Crassostrea gigas] \\
\hline gi|405969654 & Sodium/potassium-transporting ATPase subunit alpha [Crassostrea gigas] \\
\hline gi|405966599 & $60 \mathrm{kDa}$ heat shock protein, mitochondrial [Crassostrea gigas] \\
\hline gi|405959640 & Transitional endoplasmic reticulum ATPase [Crassostrea gigas] \\
\hline gi|405964519 & Glycerol-3-phosphate dehydrogenase [NAD+], cytoplasmic [Crassostrea gigas] \\
\hline gi|405953549 & T-complex protein 1 subunit zeta [Crassostrea gigas] \\
\hline gi|405973024 & Glutaredoxin-3 [Crassostrea gigas] \\
\hline gi|405954435 & Proteasome subunit beta type-2 [Crassostrea gigas] \\
\hline gi|405950385 & Programmed cell death 6-interacting protein [Crassostrea gigas] \\
\hline gi|405950098 & 14-3-3 protein zeta [Crassostrea gigas] \\
\hline gi|405959157 & Ornithine aminotransferase, mitochondrial [Crassostrea gigas] \\
\hline gi|405965429 & RNA-binding motif, single-stranded-interacting protein 3 [Crassostrea gigas] \\
\hline gi|405961548 & T-complex protein 1 subunit theta [Crassostrea gigas] \\
\hline gi|405965726 & NADP-dependent malic enzyme [Crassostrea gigas] \\
\hline gi|405952673 & Myophilin [Crassostrea gigas] \\
\hline gi|405972993 & Ras-like GTP-binding protein Rho1 [Crassostrea gigas] \\
\hline gi|405959086 & UTP--glucose-1-phosphate uridylyltransferase [Crassostrea gigas] \\
\hline gi|405961802 & ADP-ribosylation factor [Crassostrea gigas] \\
\hline gi|405969358 & ATPase family AAA domain-containing protein $2 \mathrm{~B}$ [Crassostrea gigas] \\
\hline gi|405962772 & Ras suppressor protein 1 [Crassostrea gigas] \\
\hline gi|405971077 & AP-2 complex subunit beta [Crassostrea gigas] \\
\hline gi|405968861 & UDP-glucose 4-epimerase [Crassostrea gigas] \\
\hline gi|405972952 & Plastin-3 [Crassostrea gigas] \\
\hline gi|405951837 & Hydroxyacyl-coenzyme A dehydrogenase, mitochondrial [Crassostrea gigas] \\
\hline gi|405966326 & $40 \mathrm{~S}$ ribosomal protein S13 [Crassostrea gigas] \\
\hline gi|405971745 & GTP-binding nuclear protein Ran [Crassostrea gigas] \\
\hline gi|405965548 & Adenylyl cyclase-associated protein 1 [Crassostrea gigas] \\
\hline gi|405960861 & Protein quaking-B [Crassostrea gigas] \\
\hline gi|405978782 & Nucleoside diphosphate kinase B [Crassostrea gigas] \\
\hline gi|405952674 & Myophilin [Crassostrea gigas] \\
\hline gi|405954743 & C-Myc-binding protein [Crassostrea gigas] \\
\hline gi|405977299 & Putative sodium/potassium-transporting ATPase subunit beta-2 [Crassostrea gigas] \\
\hline
\end{tabular}




\begin{tabular}{|c|c|}
\hline Accession & Name \\
\hline gi|405950079 & Tektin-2 [Crassostrea gigas] \\
\hline gi|405952464 & Spliceosome RNA helicase BAT1 [Crassostrea gigas] \\
\hline gi|405968311 & Isocitrate dehydrogenase [NAD] subunit alpha, mitochondrial [Crassostrea gigas] \\
\hline gi|405961297 & Coatomer subunit gamma-2 [Crassostrea gigas] \\
\hline gi|405958345 & $26 \mathrm{~S}$ protease regulatory subunit $6 \mathrm{~B}$ [Crassostrea gigas] \\
\hline gi|405972312 & Myosin-2 essential light chain [Crassostrea gigas] \\
\hline gi|405958969 & $40 S$ ribosomal protein S16 [Crassostrea gigas] \\
\hline gi|405973339 & Actin-2 [Crassostrea gigas] \\
\hline gi|405961918 & Ras-related protein Rab-5C [Crassostrea gigas] \\
\hline gi|405954717 & Tryptophanyl-tRNA synthetase, cytoplasmic [Crassostrea gigas] \\
\hline gi|405966318 & Ropporin-1-like protein [Crassostrea gigas] \\
\hline gi|405969074 & Spermatogenesis-associated protein 18-like protein [Crassostrea gigas] \\
\hline gi|405962126 & rRNA 2'-O-methyltransferase fibrillarin [Crassostrea gigas] \\
\hline gi|46359620 & elongation factor 1 alpha [Crassostrea gigas] \\
\hline gi|405971643 & Proteasome subunit beta type-3 [Crassostrea gigas] \\
\hline gi|405970995 & Transcription factor BTF3-like protein 4 [Crassostrea gigas] \\
\hline gi|405952733 & Glycerol-3-phosphate dehydrogenase, mitochondrial [Crassostrea gigas] \\
\hline gi|405960271 & Putative phosphoglycerate mutase [Crassostrea gigas] \\
\hline gi|405972127 & Eukaryotic translation initiation factor 3 subunit M, partial [Crassostrea gigas] \\
\hline gi|405970124 & Dynein light chain 1, axonemal, partial [Crassostrea gigas] \\
\hline gi|405967947 & Transgelin-2 [Crassostrea gigas] \\
\hline gi|405968450 & $\begin{array}{l}\text { Calcium-transporting ATPase sarcoplasmic/endoplasmic reticulum type [Crassostrea } \\
\text { gigas] }\end{array}$ \\
\hline gi|40643036 & ribosomal protein S5 [Crassostrea gigas] \\
\hline gi|405976932 & Synaptobrevin, partial [Crassostrea gigas] \\
\hline gi|405950221 & V-type proton ATPase catalytic subunit A [Crassostrea gigas] \\
\hline gi|405972954 & $40 S$ ribosomal protein S7 [Crassostrea gigas] \\
\hline gi|405964515 & Proteasome subunit alpha type- 4 [Crassostrea gigas] \\
\hline gi|405965232 & $60 S$ ribosomal protein L12 [Crassostrea gigas] \\
\hline gi|405978739 & Putative small nuclear ribonucleoprotein Sm D2 [Crassostrea gigas] \\
\hline gi|405977575 & $40 \mathrm{~S}$ ribosomal protein S12 [Crassostrea gigas] \\
\hline gi|405966541 & Fructose-1,6-bisphosphatase 1 [Crassostrea gigas] \\
\hline gi|405951393 & Cullin-associated NEDD8-dissociated protein 1 [Crassostrea gigas] \\
\hline gi|405976470 & Rab GDP dissociation inhibitor beta [Crassostrea gigas] \\
\hline gi|405946008 & Actin-related protein $2 / 3$ complex subunit 5 [Crassostrea gigas] \\
\hline gi|405967516 & Ubiquitin-conjugating enzyme E2 N [Crassostrea gigas] \\
\hline gi|56603670 & beta-tubulin [Crassostrea gigas] \\
\hline gi|405954742 & 26S proteasome non-ATPase regulatory subunit 13 [Crassostrea gigas] \\
\hline gi|405962672 & $\begin{array}{l}\text { Pyruvate dehydrogenase E1 component subunit beta, mitochondrial [Crassostrea } \\
\text { gigas] }\end{array}$ \\
\hline gi|405968084 & Alanine aminotransferase 2 [Crassostrea gigas] \\
\hline gi|405956161 & Annexin A7 [Crassostrea gigas] \\
\hline gi|405959655 & $26 S$ proteasome non-ATPase regulatory subunit 11 [Crassostrea gigas] \\
\hline gi|405976181 & Transcription elongation factor B polypeptide 2 [Crassostrea gigas] \\
\hline gi|405960811 & Phosphate carrier protein, mitochondrial [Crassostrea gigas] \\
\hline gi|405964308 & Carbonyl reductase [NADPH] 1 [Crassostrea gigas] \\
\hline gi|405962500 & V-type proton ATPase subunit $\mathrm{H}$ [Crassostrea gigas] \\
\hline
\end{tabular}




\begin{tabular}{|c|c|}
\hline Accession & Name \\
\hline gi|405973023 & Glycogenin-1 [Crassostrea gigas] \\
\hline gi|405975453 & $N(G), N(G)$-dimethylarginine dimethylaminohydrolase 1 [Crassostrea gigas] \\
\hline gi|405964154 & $40 S$ ribosomal protein S9 [Crassostrea gigas] \\
\hline gi|405969330 & Cytosolic non-specific dipeptidase [Crassostrea gigas] \\
\hline gi|405978353 & Ubiquitin-conjugating enzyme E2-17 kDa [Crassostrea gigas] \\
\hline gi|405973036 & Ribose-5-phosphate isomerase [Crassostrea gigas] \\
\hline gi|405964798 & Coatomer subunit beta [Crassostrea gigas] \\
\hline gi|405964569 & Alpha-centractin [Crassostrea gigas] \\
\hline gi|405958175 & Calcium-binding protein 39 [Crassostrea gigas] \\
\hline gi|405970587 & Universal stress protein A-like protein [Crassostrea gigas] \\
\hline gi|405961963 & Spectrin beta chain [Crassostrea gigas] \\
\hline gi|405970367 & Piwi-like protein 1 [Crassostrea gigas] \\
\hline gi|405974492 & $40 S$ ribosomal protein S14 [Crassostrea gigas] \\
\hline gi|405965163 & Beta-hexosaminidase subunit beta [Crassostrea gigas] \\
\hline gi|405962319 & Histone H3 [Crassostrea gigas] \\
\hline gi|405952804 & 40S ribosomal protein S17 [Crassostrea gigas] \\
\hline gi|405973257 & ATP-citrate synthase [Crassostrea gigas] \\
\hline gi|405976315 & Small nuclear ribonucleoprotein Sm D3 [Crassostrea gigas] \\
\hline gi|405972488 & Protein DJ-1 [Crassostrea gigas] \\
\hline gi|405960103 & Guanine nucleotide-binding protein G(i) subunit alpha [Crassostrea gigas] \\
\hline gi|405971692 & Tumor protein D54 [Crassostrea gigas] \\
\hline gi|405949998 & Fatty acid-binding protein, adipocyte [Crassostrea gigas] \\
\hline gi|405967288 & $40 \mathrm{~S}$ ribosomal protein $\mathrm{S} 4, \mathrm{X}$ isoform [Crassostrea gigas] \\
\hline gi|405957468 & Dynein light chain roadblock-type 2 [Crassostrea gigas] \\
\hline gi|405955110 & Programmed cell death protein 10 [Crassostrea gigas] \\
\hline gi|405960115 & Actin-related protein $2 / 3$ complex subunit 4 [Crassostrea gigas] \\
\hline gi|405968525 & Calcium-binding mitochondrial carrier protein SCaMC-2 [Crassostrea gigas] \\
\hline gi|405964683 & Ras-related protein Rab-3 [Crassostrea gigas] \\
\hline gi|405952808 & EH domain-containing protein 1 [Crassostrea gigas] \\
\hline gi|84619356 & soma ferritin [Crassostrea gigas] \\
\hline gi|405954100 & Triosephosphate isomerase [Crassostrea gigas] \\
\hline gi|405968443 & 4-hydroxyphenylpyruvate dioxygenase [Crassostrea gigas] \\
\hline gi|405976318 & 6-phosphogluconate dehydrogenase, decarboxylating [Crassostrea gigas] \\
\hline gi|405963183 & hypothetical protein CGI_10018075 [Crassostrea gigas] \\
\hline gi|405953650 & Cleavage stimulation factor $64 \mathrm{kDa}$ subunit [Crassostrea gigas] \\
\hline gi|405970739 & Dynein light chain 2, cytoplasmic [Crassostrea gigas] \\
\hline gi|405968618 & Integrin-linked protein kinase [Crassostrea gigas] \\
\hline gi|405966986 & Paramyosin [Crassostrea gigas] \\
\hline gi|405954084 & Pyrroline-5-carboxylate reductase 2 [Crassostrea gigas] \\
\hline gi|405967058 & Glutathione S-transferase P 1 [Crassostrea gigas] \\
\hline gi|405957470 & Small nuclear ribonucleoprotein-associated protein B' [Crassostrea gigas] \\
\hline gi|405978471 & F-box only protein 36 [Crassostrea gigas] \\
\hline gi|405951090 & CAP-Gly domain-containing linker protein 3 [Crassostrea gigas] \\
\hline gi|405963114 & Hydroxysteroid dehydrogenase-like protein 2 [Crassostrea gigas] \\
\hline gi|405966026 & Alanine--glyoxylate aminotransferase 2, mitochondrial [Crassostrea gigas] \\
\hline gi|405958990 & Lin-7-like protein B [Crassostrea gigas] \\
\hline
\end{tabular}




\begin{tabular}{|c|c|}
\hline Accession & Name \\
\hline gi|405975810 & ALK tyrosine kinase receptor [Crassostrea gigas] \\
\hline gi|405962570 & AP-2 complex subunit alpha-2 [Crassostrea gigas] \\
\hline gi|405967909 & $26 \mathrm{~S}$ proteasome non-ATPase regulatory subunit 8 [Crassostrea gigas] \\
\hline gi|405958300 & GDP-L-fucose synthetase [Crassostrea gigas] \\
\hline gi|405967652 & hypothetical protein CGI_10017178 [Crassostrea gigas] \\
\hline gi|405968843 & Peptidyl-prolyl cis-trans isomerase E [Crassostrea gigas] \\
\hline gi|405978785 & Nucleoside diphosphate kinase-like protein 5 [Crassostrea gigas] \\
\hline gi|405978693 & Uncharacterized protein yfeX [Crassostrea gigas] \\
\hline gi|405975002 & Eukaryotic translation initiation factor 6 [Crassostrea gigas] \\
\hline gi|40642988 & ribosomal protein S3a [Crassostrea gigas] \\
\hline gi|405959764 & Phospholipid scramblase 2 [Crassostrea gigas] \\
\hline gi|405959092 & Radial spoke head protein 9-like protein [Crassostrea gigas] \\
\hline gi|405965704 & Muscle-specific protein 20 [Crassostrea gigas] \\
\hline gi|405957970 & Sjoegren syndrome nuclear autoantigen 1 [Crassostrea gigas] \\
\hline gi|405961702 & Myosin regulatory light chain A, smooth adductor muscle [Crassostrea gigas] \\
\hline gi|405966837 & dpy-30-like protein [Crassostrea gigas] \\
\hline gi|405971996 & Glutathione S-transferase A [Crassostrea gigas] \\
\hline gi|405964668 & Ras-related protein Rab-8A [Crassostrea gigas] \\
\hline gi|405953653 & Sorting nexin-12 [Crassostrea gigas] \\
\hline gi|405954434 & Microtubule-associated protein RP/EB family member 3 [Crassostrea gigas] \\
\hline gi|405970591 & Universal stress protein A-like protein [Crassostrea gigas] \\
\hline gi|405972489 & Isocitrate dehydrogenase [NADP] cytoplasmic [Crassostrea gigas] \\
\hline gi|405975469 & Tektin-3 [Crassostrea gigas] \\
\hline gi|405968528 & hypothetical protein CGI_10017744 [Crassostrea gigas] \\
\hline gi|405960099 & $\begin{array}{l}\text { Dolichyl-diphosphooligosaccharide--protein glycosyltransferase subunit } 1 \text { [Crassostrea } \\
\text { gigas] }\end{array}$ \\
\hline gi|405962950 & Mitogen-activated protein kinase 1 [Crassostrea gigas] \\
\hline gi|405962264 & Peroxisomal NADH pyrophosphatase NUDT12 [Crassostrea gigas] \\
\hline gi|405947958 & $\begin{array}{l}\text { Succinate dehydrogenase [ubiquinone] iron-sulfur subunit, mitochondrial [Crassostrea } \\
\text { gigas] }\end{array}$ \\
\hline gi|405960192 & EF-hand calcium-binding domain-containing protein 1 [Crassostrea gigas] \\
\hline gi|405950642 & Guanine nucleotide-binding protein $\mathrm{G}(\mathrm{q})$ subunit alpha [Crassostrea gigas] \\
\hline gi|405950538 & Talin-1 [Crassostrea gigas] \\
\hline gi|405975242 & Calponin-2 [Crassostrea gigas] \\
\hline gi|405959519 & Succinate-semialdehyde dehydrogenase, mitochondrial [Crassostrea gigas] \\
\hline gi|405975056 & Myosin heavy chain, striated muscle [Crassostrea gigas] \\
\hline gi|405963909 & Lactoylglutathione lyase [Crassostrea gigas] \\
\hline gi|405971552 & $\begin{array}{l}\text { Vesicle-associated membrane protein/synaptobrevin-binding protein [Crassostrea } \\
\text { gigas] }\end{array}$ \\
\hline gi|405972843 & Obg-like ATPase 1 [Crassostrea gigas] \\
\hline gi|405960672 & 40 S ribosomal protein S28 [Crassostrea gigas] \\
\hline gi|405967409 & Vacuolar protein sorting-associated protein 35 , partial [Crassostrea gigas] \\
\hline gi|405963565 & Septin-2 [Crassostrea gigas] \\
\hline gi|405969967 & Thymidine phosphorylase [Crassostrea gigas] \\
\hline gi|405958510 & hypothetical protein CGI_10014543 [Crassostrea gigas] \\
\hline gi|405970772 & Growth factor receptor-bound protein 2 [Crassostrea gigas] \\
\hline gi|405961149 & Phospholipid scramblase 2 [Crassostrea gigas] \\
\hline gi|405965140 & Alpha-endosulfine [Crassostrea gigas] \\
\hline
\end{tabular}




\begin{tabular}{|c|c|}
\hline Accession & Name \\
\hline gi|405971658 & Cathepsin B [Crassostrea gigas] \\
\hline gi|405969953 & Allograft inflammatory factor 1 [Crassostrea gigas] \\
\hline gi|405962800 & Inorganic pyrophosphatase [Crassostrea gigas] \\
\hline gi|350663 & calmodulin \\
\hline gi|405945238 & Eukaryotic initiation factor 4A-II, partial [Crassostrea gigas] \\
\hline gi|405963212 & 1,2-dihydroxy-3-keto-5-methylthiopentene dioxygenase [Crassostrea gigas] \\
\hline gi|405963786 & Annexin A7 [Crassostrea gigas] \\
\hline gi|405964873 & DNA-directed RNA polymerase II subunit RPB4 [Crassostrea gigas] \\
\hline gi|405968787 & Dynamin-1-like protein [Crassostrea gigas] \\
\hline gi|40642982 & putative ribosomal protein S25 [Crassostrea gigas] \\
\hline gi|405957124 & hypothetical protein CGI_10008733 [Crassostrea gigas] \\
\hline gi|405957021 & Splicing factor 3 subunit 1 [Crassostrea gigas] \\
\hline gi|405966810 & Peroxiredoxin-1 [Crassostrea gigas] \\
\hline gi|156915032 & calmodulin [Crassostrea gigas] \\
\hline gi|405970999 & Acyl-protein thioesterase 2 [Crassostrea gigas] \\
\hline gi|405958519 & hypothetical protein CGI_10014553, partial [Crassostrea gigas] \\
\hline gi|405967706 & Alpha-parvin [Crassostrea gigas] \\
\hline gi|405974926 & Ras-related protein Rap-1b [Crassostrea gigas] \\
\hline gi|405951162 & Surfeit locus protein 4 [Crassostrea gigas] \\
\hline gi|405965410 & $40 S$ ribosomal protein S15 [Crassostrea gigas] \\
\hline gi|405952104 & Ubiquitin-conjugating enzyme E2-17 kDa, partial [Crassostrea gigas] \\
\hline gi|405962441 & UPF0468 protein C16orf80-like protein [Crassostrea gigas] \\
\hline gi|405972166 & $60 S$ ribosomal protein L30 [Crassostrea gigas] \\
\hline gi|46909259 & ATP synthase beta subunit [Modiolus americanus] \\
\hline gi|405977845 & hypothetical protein CGI_10017842 [Crassostrea gigas] \\
\hline gi|405960426 & 4-aminobutyrate aminotransferase, mitochondrial [Crassostrea gigas] \\
\hline gi|405969211 & Calcium-binding mitochondrial carrier protein Aralar1 [Crassostrea gigas] \\
\hline gi|405957003 & Core histone macro-H2A.1 [Crassostrea gigas] \\
\hline gi|405960404 & Transmembrane protein Tmp21 [Crassostrea gigas] \\
\hline gi|405973201 & hypothetical protein CGI_10009700 [Crassostrea gigas] \\
\hline gi|405959361 & Tubulin beta chain [Crassostrea gigas] \\
\hline gi|405964694 & Myosin regulatory light chain sqh [Crassostrea gigas] \\
\hline gi|405962936 & Ubiquitin-conjugating enzyme E2 G2 [Crassostrea gigas] \\
\hline gi|405957219 & CutA-like protein [Crassostrea gigas] \\
\hline gi|405968728 & hypothetical protein CGI_10023309 [Crassostrea gigas] \\
\hline gi|405972698 & Inosine-5'-monophosphate dehydrogenase 2 [Crassostrea gigas] \\
\hline gi|405962104 & Pancreatic triacylglycerol lipase [Crassostrea gigas] \\
\hline gi|405951454 & Outer dense fiber protein 3 [Crassostrea gigas] \\
\hline gi|405968170 & Endophilin-B1 [Crassostrea gigas] \\
\hline gi|71040621 & ribosomal protein S18 [Crassostrea gigas] \\
\hline gi|405952901 & Myosin catalytic light chain LC-1, mantle muscle [Crassostrea gigas] \\
\hline gi|405950779 & Stress-induced-phosphoprotein 1 [Crassostrea gigas] \\
\hline gi|405951840 & $40 \mathrm{~S}$ ribosomal protein $\mathrm{S} 19$ [Crassostrea gigas] \\
\hline gi|40642980 & ribosomal protein S10 [Crassostrea gigas] \\
\hline gi|405974984 & Glutamate dehydrogenase 1, mitochondrial [Crassostrea gigas] \\
\hline gi|40643004 & ribosomal protein S20 [Crassostrea gigas] \\
\hline
\end{tabular}




\begin{tabular}{|c|c|}
\hline Accession & Name \\
\hline gi|405972362 & Heterogeneous nuclear ribonucleoprotein Q [Crassostrea gigas] \\
\hline gi|405953394 & Dynein heavy chain, cytoplasmic [Crassostrea gigas] \\
\hline gi|405970294 & $\begin{array}{l}\text { Putative methylmalonate-semialdehyde dehydrogenase [acylating], mitochondrial } \\
\text { [Crassostrea gigas] }\end{array}$ \\
\hline gi|405977799 & S-phase kinase-associated protein 1 [Crassostrea gigas] \\
\hline gi|405965094 & Chloride intracellular channel exc-4 [Crassostrea gigas] \\
\hline gi|405950284 & Peptidyl-prolyl cis-trans isomerase B [Crassostrea gigas] \\
\hline gi|405964938 & Coactosin-like protein [Crassostrea gigas] \\
\hline gi|405947472 & hypothetical protein CGI_10000124, partial [Crassostrea gigas] \\
\hline gi|405962281 & Sacsin [Crassostrea gigas] \\
\hline gi|163637081 & $\mathrm{H} 2 \mathrm{~A}$ histone family member $\mathrm{V}$ [Crassostrea gigas] \\
\hline gi|405951735 & Multidrug resistance-associated protein 1 [Crassostrea gigas] \\
\hline gi|260424007 & Rieske-like apoprotein [Crassostrea gigas] \\
\hline gi|405974628 & Calcium-dependent protein kinase isoform 2 [Crassostrea gigas] \\
\hline gi|405973144 & Importin subunit beta-1 [Crassostrea gigas] \\
\hline gi|405976712 & hypothetical protein CGI_10006577 [Crassostrea gigas] \\
\hline gi|405974805 & Muscle LIM protein Mlp84B [Crassostrea gigas] \\
\hline gi|405977525 & Puromycin-sensitive aminopeptidase [Crassostrea gigas] \\
\hline gi|405975462 & Adenylate kinase 2, mitochondrial [Crassostrea gigas] \\
\hline gi|405962873 & Filamin-C [Crassostrea gigas] \\
\hline gi|405971206 & Small nuclear ribonucleoprotein E [Crassostrea gigas] \\
\hline gi|405952287 & Glycerol-3-phosphate dehydrogenase [NAD+], cytoplasmic [Crassostrea gigas] \\
\hline gi|405950753 & StAR-related lipid transfer protein 5 [Crassostrea gigas] \\
\hline gi|405972836 & Retinal dehydrogenase 1 [Crassostrea gigas] \\
\hline gi|405967101 & $60 S$ ribosomal protein L13 [Crassostrea gigas] \\
\hline gi|32169292 & ribosomal protein L7 [Crassostrea gigas] \\
\hline gi|405959617 & hypothetical protein CGI_10004941 [Crassostrea gigas] \\
\hline gi|405965653 & Adenosine kinase 1 [Crassostrea gigas] \\
\hline gi|405967050 & Tektin-4 [Crassostrea gigas] \\
\hline gi|405977927 & $60 S$ ribosomal protein L9 [Crassostrea gigas] \\
\hline gi|405975708 & Succinyl-CoA:3-ketoacid-coenzyme A transferase 1, mitochondrial [Crassostrea gigas] \\
\hline gi|405964146 & Protein disulfide-isomerase [Crassostrea gigas] \\
\hline gi|405950429 & 14-3-3 protein zeta [Crassostrea gigas] \\
\hline gi|405976085 & CDGSH iron sulfur domain-containing protein 2 [Crassostrea gigas] \\
\hline gi|405959643 & Thimet oligopeptidase [Crassostrea gigas] \\
\hline gi|405954888 & Ganglioside-induced differentiation-associated protein 1 [Crassostrea gigas] \\
\hline gi|405971092 & Rootletin [Crassostrea gigas] \\
\hline gi|405963773 & ATP synthase subunit gamma, mitochondrial [Crassostrea gigas] \\
\hline gi|405953044 & Dynein beta chain, ciliary [Crassostrea gigas] \\
\hline gi|405963279 & Leukocyte elastase inhibitor [Crassostrea gigas] \\
\hline gi|405962295 & Radixin [Crassostrea gigas] \\
\hline gi|405953320 & hypothetical protein CGI_10004855 [Crassostrea gigas] \\
\hline gi|405961366 & Dynactin subunit 2 [Crassostrea gigas] \\
\hline gi|405975080 & hypothetical protein CGI_10025135 [Crassostrea gigas] \\
\hline gi|405952544 & Leucine-rich repeat-containing protein 48 [Crassostrea gigas] \\
\hline gi|405961865 & Ubiquitin-like modifier-activating enzyme 1 [Crassostrea gigas] \\
\hline gi|405956988 & Uncharacterized protein C11D3.13 [Crassostrea gigas] \\
\hline
\end{tabular}




\begin{tabular}{|c|c|}
\hline Accession & Name \\
\hline gi|405977689 & Pre-mRNA-splicing factor SPF27 [Crassostrea gigas] \\
\hline gi|405973723 & Peptidyl-prolyl cis-trans isomerase FKBP1A [Crassostrea gigas] \\
\hline gi|405955347 & 3-ketoacyl-CoA thiolase, mitochondrial [Crassostrea gigas] \\
\hline gi|405973481 & Catenin beta [Crassostrea gigas] \\
\hline gi|405971478 & S-formylglutathione hydrolase [Crassostrea gigas] \\
\hline gi|405977878 & Phosphatidylinositol-binding clathrin assembly protein [Crassostrea gigas] \\
\hline gi|405953092 & Asparaginyl-tRNA synthetase, cytoplasmic [Crassostrea gigas] \\
\hline gi|405958080 & Calmodulin [Crassostrea gigas] \\
\hline gi|405953134 & hypothetical protein CGI_10005248 [Crassostrea gigas] \\
\hline gi|405962156 & Alpha-aminoadipic semialdehyde synthase, mitochondrial [Crassostrea gigas] \\
\hline gi|405970434 & $60 \mathrm{~S}$ acidic ribosomal protein $\mathrm{P} 1$ [Crassostrea gigas] \\
\hline gi|405963559 & Sarcoplasmic calcium-binding protein [Crassostrea gigas] \\
\hline gi|405973830 & Enkurin [Crassostrea gigas] \\
\hline gi|405969027 & Glycolipid transfer protein [Crassostrea gigas] \\
\hline gi|405966068 & Dipeptidyl-peptidase 3 [Crassostrea gigas] \\
\hline gi|405953142 & Dihydropyrimidinase [Crassostrea gigas] \\
\hline gi|405955335 & hypothetical protein CGI_10002180 [Crassostrea gigas] \\
\hline gi|405973087 & SH3 domain-binding glutamic acid-rich protein [Crassostrea gigas] \\
\hline gi|405975424 & Calcium-dependent protein kinase 31 [Crassostrea gigas] \\
\hline gi|405962967 & Ribosomal protein S6 kinase 2 alpha [Crassostrea gigas] \\
\hline gi|405976037 & Charged multivesicular body protein 5 [Crassostrea gigas] \\
\hline gi|405973234 & $40 S$ ribosomal protein S3 [Crassostrea gigas] \\
\hline gi|405950169 & Vacuolar protein sorting-associated protein 28-like protein [Crassostrea gigas] \\
\hline gi|405963288 & Membrane-associated progesterone receptor component 2 [Crassostrea gigas] \\
\hline gi|405959669 & Synaptojanin-2-binding protein [Crassostrea gigas] \\
\hline gi|405966380 & Tropomodulin [Crassostrea gigas] \\
\hline gi|405978438 & N-terminal EF-hand calcium-binding protein 1 [Crassostrea gigas] \\
\hline gi|29119645 & paramyosin protein [Crassostrea gigas] \\
\hline gi|405952417 & Calmodulin [Crassostrea gigas] \\
\hline gi|405955698 & hypothetical protein CGI_10001640 [Crassostrea gigas] \\
\hline gi|405970121 & Transcription initiation factor IIA subunit 1 [Crassostrea gigas] \\
\hline gi|405970507 & hypothetical protein CGI_10021010 [Crassostrea gigas] \\
\hline gi|405977412 & Protein-L-isoaspartate(D-aspartate) O-methyltransferase [Crassostrea gigas] \\
\hline gi|405967713 & 4-coumarate--CoA ligase [Crassostrea gigas] \\
\hline gi|405971207 & Histone deacetylase complex subunit SAP18 [Crassostrea gigas] \\
\hline gi|405951773 & Reticulocyte-binding protein 2-like protein a [Crassostrea gigas] \\
\hline gi|405968526 & Coactosin [Crassostrea gigas] \\
\hline gi|405954309 & Constitutive coactivator of PPAR-gamma-like protein 1-like protein [Crassostrea gigas] \\
\hline gi|405961591 & Cell differentiation protein RCD1-like protein [Crassostrea gigas] \\
\hline gi|405966073 & Glia maturation factor beta [Crassostrea gigas] \\
\hline gi|405972793 & Uncharacterized protein y4mH [Crassostrea gigas] \\
\hline gi|405955817 & 40 S ribosomal protein S24 [Crassostrea gigas] \\
\hline gi|405968514 & Mannose-6-phosphate isomerase [Crassostrea gigas] \\
\hline gi|405976150 & Purine nucleoside phosphorylase [Crassostrea gigas] \\
\hline gi|405947752 & $60 S$ ribosomal protein L17 [Crassostrea gigas] \\
\hline gi|405960908 & hypothetical protein CGI_10000618 [Crassostrea gigas] \\
\hline
\end{tabular}




\begin{tabular}{|c|c|}
\hline Accession & Name \\
\hline gi|405971282 & Histone H1.2 [Crassostrea gigas] \\
\hline gi|405958681 & Programmed cell death protein 6 [Crassostrea gigas] \\
\hline gi|405950001 & Transmembrane emp24 domain-containing protein 2 [Crassostrea gigas] \\
\hline gi|405975439 & Golgi SNAP receptor complex member 1 [Crassostrea gigas] \\
\hline gi|405951631 & Ras-related protein Rab-21 [Crassostrea gigas] \\
\hline gi|405952677 & Enhancer of yellow 2 transcription factor-like protein [Crassostrea gigas] \\
\hline gi|405957535 & Putative ATP-dependent RNA helicase DDX6 [Crassostrea gigas] \\
\hline gi|405958773 & HBXIP-like protein [Crassostrea gigas] \\
\hline gi|405959601 & T-complex protein 1 subunit eta [Crassostrea gigas] \\
\hline gi|405962679 & Allene oxide synthase-lipoxygenase protein [Crassostrea gigas] \\
\hline gi|405963508 & GMP reductase 2 [Crassostrea gigas] \\
\hline gi|405965375 & WD repeat-containing protein 82 [Crassostrea gigas] \\
\hline gi|405965856 & mago nashi-like protein 2 [Crassostrea gigas] \\
\hline gi|405972780 & Putative D-tyrosyl-tRNA(Tyr) deacylase 2 [Crassostrea gigas] \\
\hline gi|405972966 & Mps one binder kinase activator-like 2B [Crassostrea gigas] \\
\hline gi|405974200 & COP9 signalosome complex subunit 7a [Crassostrea gigas] \\
\hline gi|405974406 & NipSnap-like protein 2 [Crassostrea gigas] \\
\hline gi|405976506 & Counting factor associated protein D [Crassostrea gigas] \\
\hline gi|405974087 & hypothetical protein CGI_10020432 [Crassostrea gigas] \\
\hline gi|405978156 & Plasma membrane calcium-transporting ATPase 3 [Crassostrea gigas] \\
\hline gi|405966464 & Guanine nucleotide-binding protein subunit gamma-1 [Crassostrea gigas] \\
\hline gi|405957004 & Heterogeneous nuclear ribonucleoprotein A/B [Crassostrea gigas] \\
\hline gi|405977625 & Glutathione S-transferase omega-1 [Crassostrea gigas] \\
\hline gi|405973516 & Spectrin alpha chain [Crassostrea gigas] \\
\hline gi|405952370 & hypothetical protein CGI_10006610 [Crassostrea gigas] \\
\hline gi|405954419 & Collagen alpha-3(VI) chain [Crassostrea gigas] \\
\hline gi|219806594 & tropomyosin [Crassostrea gigas] \\
\hline gi|405971145 & Myosin heavy chain, non-muscle, partial [Crassostrea gigas] \\
\hline gi|405951822 & Collagen alpha-2(I) chain [Crassostrea gigas] \\
\hline gi|405964567 & Tubulin beta chain [Crassostrea gigas] \\
\hline gi|405975057 & Myosin heavy chain, striated muscle [Crassostrea gigas] \\
\hline gi|405951942 & Tubulin alpha-1C chain [Crassostrea gigas] \\
\hline gi|405973340 & Actin [Crassostrea gigas] \\
\hline gi|405969780 & Far upstream element-binding protein 3 [Crassostrea gigas] \\
\hline gi|405969480 & LIM domain and actin-binding protein 1 [Crassostrea gigas] \\
\hline gi|405967105 & Golgi apparatus protein 1 [Crassostrea gigas] \\
\hline gi|405951824 & Collagen alpha-2(I) chain [Crassostrea gigas] \\
\hline gi|148717307 & calreticulin [Crassostrea gigas] \\
\hline gi|405972828 & Collagen alpha-5(VI) chain [Crassostrea gigas] \\
\hline gi|46359618 & 78kDa glucose regulated protein [Crassostrea gigas] \\
\hline gi|405974739 & hypothetical protein CGI_10019003 [Crassostrea gigas] \\
\hline gi|405974721 & $\mathrm{Na}(+) / \mathrm{H}(+)$ exchange regulatory cofactor NHE-RF1 [Crassostrea gigas] \\
\hline gi|405952353 & Calumenin-B [Crassostrea gigas] \\
\hline gi|405958707 & Collagen alpha-2(I) chain [Crassostrea gigas] \\
\hline gi|405953442 & Signal peptide, CUB and EGF-like domain-containing protein 1 [Crassostrea gigas] \\
\hline gi|405975636 & Tektin-1 [Crassostrea gigas] \\
\hline
\end{tabular}




\begin{tabular}{|c|c|}
\hline Accession & Name \\
\hline gi|405957670 & Peroxiredoxin-6 [Crassostrea gigas] \\
\hline gi|405954235 & Adipophilin [Crassostrea gigas] \\
\hline gi|405964921 & Proactivator polypeptide [Crassostrea gigas] \\
\hline gi|405953430 & Ribosome-binding protein 1 [Crassostrea gigas] \\
\hline gi|405978630 & S-crystallin SL11 [Crassostrea gigas] \\
\hline gi|405967637 & Tropomyosin [Crassostrea gigas] \\
\hline gi|405974270 & 5'-AMP-activated protein kinase subunit beta-2 [Crassostrea gigas] \\
\hline gi|405968440 & Collagen alpha-6(VI) chain [Crassostrea gigas] \\
\hline gi|405957087 & Calumenin [Crassostrea gigas] \\
\hline gi|405972504 & hypothetical protein CGI_10018585 [Crassostrea gigas] \\
\hline gi|405975834 & Isocitrate dehydrogenase [NADP], mitochondrial [Crassostrea gigas] \\
\hline gi|405969715 & Short-chain collagen C4 [Crassostrea gigas] \\
\hline gi|157169145 & histone $\mathrm{H} 4$ [Venerupis philippinarum] \\
\hline gi|405972180 & Tetratricopeptide repeat protein 25 [Crassostrea gigas] \\
\hline gi|405978272 & Calmodulin [Crassostrea gigas] \\
\hline gi|40642994 & myosin essential light chain [Crassostrea gigas] \\
\hline gi|405963558 & Sarcoplasmic calcium-binding protein [Crassostrea gigas] \\
\hline gi|44885729 & arginine kinase [Crassostrea gigas] \\
\hline gi|405971719 & hypothetical protein CGI_10004063 [Crassostrea gigas] \\
\hline gi|405967698 & Protein disulfide-isomerase A3 [Crassostrea gigas] \\
\hline gi|405972818 & Myosin heavy chain, striated muscle [Crassostrea gigas] \\
\hline gi|405967541 & LIM and SH3 domain protein Lasp [Crassostrea gigas] \\
\hline gi|405975466 & hypothetical protein CGI_10010025 [Crassostrea gigas] \\
\hline gi|405977320 & Neural cell adhesion molecule 1 [Crassostrea gigas] \\
\hline gi|405959947 & Calmodulin [Crassostrea gigas] \\
\hline gi|405972892 & Protein SPATIAL [Crassostrea gigas] \\
\hline gi|405958088 & Calmodulin [Crassostrea gigas] \\
\hline gi|405971561 & Zonadhesin [Crassostrea gigas] \\
\hline gi|405953483 & Sarcoplasmic calcium-binding protein [Crassostrea gigas] \\
\hline gi|4838561 & heat shock protein 70 [Crassostrea gigas] \\
\hline gi|405957528 & hypothetical protein CGI_10021888 [Crassostrea gigas] \\
\hline gi|405954824 & Severin [Crassostrea gigas] \\
\hline gi|405952543 & Target of Myb protein 1 [Crassostrea gigas] \\
\hline gi|405961832 & Heat shock protein beta- 1 [Crassostrea gigas] \\
\hline gi|405954690 & Hsc70-interacting protein [Crassostrea gigas] \\
\hline gi|48476115 & cyclophilin [Crassostrea gigas] \\
\hline gi|405962321 & Histone H2B.3 [Crassostrea gigas] \\
\hline gi|405976099 & Annexin A7 [Crassostrea gigas] \\
\hline gi|405950403 & hypothetical protein CGI_10012758 [Crassostrea gigas] \\
\hline gi|405952420 & Calmodulin [Crassostrea gigas] \\
\hline gi|405963739 & EF-hand calcium-binding domain-containing protein 6 [Crassostrea gigas] \\
\hline gi|405953431 & Enolase-phosphatase E1 [Crassostrea gigas] \\
\hline gi|405953127 & Allene oxide synthase-lipoxygenase protein, partial [Crassostrea gigas] \\
\hline gi|405976546 & Dynein heavy chain 10 , axonemal [Crassostrea gigas] \\
\hline gi|405959945 & Calmodulin-like protein [Crassostrea gigas] \\
\hline gi|405957423 & Transcription elongation regulator 1 [Crassostrea gigas] \\
\hline
\end{tabular}




\begin{tabular}{|c|c|}
\hline Accession & Name \\
\hline gi|405958653 & hypothetical protein CGI_10006272 [Crassostrea gigas] \\
\hline gi|405958669 & Ankyrin-2 [Crassostrea gigas] \\
\hline gi|89520693 & histone H2A [Chlamys farreri] \\
\hline gi|405974086 & Coiled-coil domain-containing protein 63 [Crassostrea gigas] \\
\hline gi|405963883 & hypothetical protein CGI_10023805 [Crassostrea gigas] \\
\hline gi|405977356 & hypothetical protein CGI_10026431 [Crassostrea gigas] \\
\hline gi|405963229 & Laminin subunit gamma-1 [Crassostrea gigas] \\
\hline gi|405978483 & hypothetical protein CGI_10028829 [Crassostrea gigas] \\
\hline gi|405974545 & Collagen alpha-1(IX) chain [Crassostrea gigas] \\
\hline gi|405975181 & S-crystallin SL11 [Crassostrea gigas] \\
\hline gi|405974348 & Extracellular superoxide dismutase [Cu-Zn] [Crassostrea gigas] \\
\hline gi|405952740 & Latrophilin-3 [Crassostrea gigas] \\
\hline gi|405963180 & Protein SET [Crassostrea gigas] \\
\hline gi|405962553 & hypothetical protein CGI_10009086 [Crassostrea gigas] \\
\hline gi|405961240 & Sperm surface protein Sp17 [Crassostrea gigas] \\
\hline gi|405950944 & Phospholipase D1 [Crassostrea gigas] \\
\hline gi|405962702 & $60 S$ acidic ribosomal protein P2 [Crassostrea gigas] \\
\hline gi|405955680 & Nucleobindin-2 [Crassostrea gigas] \\
\hline gi|405964737 & Signal peptide, CUB and EGF-like domain-containing protein 3 [Crassostrea gigas] \\
\hline gi|405960381 & Monocarboxylate transporter 12 [Crassostrea gigas] \\
\hline gi|405973812 & Coiled-coil domain-containing protein 19, mitochondrial [Crassostrea gigas] \\
\hline gi|405977042 & Elongation factor 1-beta [Crassostrea gigas] \\
\hline gi|405977513 & High mobility group protein B3 [Crassostrea gigas] \\
\hline gi|405969523 & Catalase [Crassostrea gigas] \\
\hline gi|405961344 & Transforming acidic coiled-coil-containing protein 1 [Crassostrea gigas] \\
\hline gi|405961157 & Profilin [Crassostrea gigas] \\
\hline gi|405969360 & hypothetical protein CGI_10023442 [Crassostrea gigas] \\
\hline gi|405977380 & Radial spoke head protein 3-like protein [Crassostrea gigas] \\
\hline gi|405958383 & hypothetical protein CGI_10007870 [Crassostrea gigas] \\
\hline gi|405975282 & Cytochrome $\mathrm{c}$ oxidase subunit 6B [Crassostrea gigas] \\
\hline gi|405978204 & Tubulin-specific chaperone A [Crassostrea gigas] \\
\hline gi|405965141 & Ubiquilin-1 [Crassostrea gigas] \\
\hline gi|405965618 & hypothetical protein CGI_10024978 [Crassostrea gigas] \\
\hline gi|405963849 & RIB43A-like with coiled-coils protein 2 [Crassostrea gigas] \\
\hline gi|405960153 & Neural/ectodermal development factor IMP-L2 [Crassostrea gigas] \\
\hline gi|405950627 & hypothetical protein CGI_10011730 [Crassostrea gigas] \\
\hline gi|405976955 & Zonadhesin [Crassostrea gigas] \\
\hline gi|405970996 & Nuclear autoantigenic sperm protein [Crassostrea gigas] \\
\hline gi|405951359 & Leucine-rich repeat flightless-interacting protein 2 [Crassostrea gigas] \\
\hline gi|405959178 & hypothetical protein CGI_10014271 [Crassostrea gigas] \\
\hline gi|405962190 & Collagen alpha-3(VI) chain [Crassostrea gigas] \\
\hline gi|405963940 & Reticulon-4 [Crassostrea gigas] \\
\hline gi|405950809 & Protocadherin Fat 4 [Crassostrea gigas] \\
\hline gi|405959691 & Cytochrome c oxidase subunit 5A, mitochondrial [Crassostrea gigas] \\
\hline gi|405971250 & Glucosidase 2 subunit beta [Crassostrea gigas] \\
\hline gi|405953525 & Endophilin-A2 [Crassostrea gigas] \\
\hline
\end{tabular}




\begin{tabular}{|c|c|}
\hline Accession & Name \\
\hline gi|405977608 & Lymphocyte cytosolic protein 2 [Crassostrea gigas] \\
\hline gi|405969875 & $\begin{array}{l}\text { Succinate dehydrogenase [ubiquinone] flavoprotein subunit B, mitochondrial } \\
\text { [Crassostrea gigas] }\end{array}$ \\
\hline gi|405957909 & hypothetical protein CGI_10015176 [Crassostrea gigas] \\
\hline gi|405955982 & Kyphoscoliosis peptidase [Crassostrea gigas] \\
\hline gi|405960949 & hypothetical protein CGI_10013854 [Crassostrea gigas] \\
\hline gi|405966436 & Rho GDP-dissociation inhibitor 1 [Crassostrea gigas] \\
\hline gi|405966470 & Cytochrome b-c1 complex subunit 6, mitochondrial [Crassostrea gigas] \\
\hline gi|405964761 & Aconitate hydratase, mitochondrial [Crassostrea gigas] \\
\hline gi|405972391 & Nuclear pore glycoprotein p62 [Crassostrea gigas] \\
\hline gi|405973146 & Annexin A7 [Crassostrea gigas] \\
\hline gi|405959268 & Synaptosomal-associated protein 25 [Crassostrea gigas] \\
\hline gi|405957584 & hypothetical protein CGI_10013948 [Crassostrea gigas] \\
\hline gi|405965909 & Prohormone-4 [Crassostrea gigas] \\
\hline gi|405969964 & Metalloproteinase inhibitor 3 [Crassostrea gigas] \\
\hline gi|405974349 & Extracellular superoxide dismutase [Cu-Zn] [Crassostrea gigas] \\
\hline gi|405965301 & Mitochondrial-processing peptidase subunit beta [Crassostrea gigas] \\
\hline gi|405955147 & Plasminogen [Crassostrea gigas] \\
\hline gi|405955681 & Elongation factor 1-beta [Crassostrea gigas] \\
\hline gi|405976463 & Transketolase-like protein 2 [Crassostrea gigas] \\
\hline gi|405952266 & Protein hu-li tai shao [Crassostrea gigas] \\
\hline gi|405958225 & Protein C20orf11 [Crassostrea gigas] \\
\hline gi|405969458 & $\begin{array}{l}\text { NADH dehydrogenase [ubiquinone] flavoprotein 2, mitochondrial, partial [Crassostrea } \\
\text { gigas] }\end{array}$ \\
\hline gi|405962705 & Golgi phosphoprotein 3 [Crassostrea gigas] \\
\hline gi|405951006 & EF-hand domain-containing protein D2 [Crassostrea gigas] \\
\hline gi|405976128 & Coiled-coil domain-containing protein 6 [Crassostrea gigas] \\
\hline gi|405971621 & Selenium-binding protein 1, partial [Crassostrea gigas] \\
\hline gi|405950693 & V-type proton ATPase subunit E [Crassostrea gigas] \\
\hline gi|405978841 & Voltage-dependent anion-selective channel protein 2 [Crassostrea gigas] \\
\hline gi|405954593 & Calbindin-32 [Crassostrea gigas] \\
\hline gi|405967580 & Calnexin [Crassostrea gigas] \\
\hline gi|405961403 & Epsin-2 [Crassostrea gigas] \\
\hline gi|405951402 & $\begin{array}{l}\text { KH domain-containing, RNA-binding, signal transduction-associated protein } 2 \\
\text { [Crassostrea gigas] }\end{array}$ \\
\hline gi|405951541 & Fatty acid-binding protein, heart [Crassostrea gigas] \\
\hline gi|2833326 & RecName: Full=Actin, adductor muscle \\
\hline gi|405952165 & hypothetical protein CGI_10007068 [Crassostrea gigas] \\
\hline gi|405950130 & hypothetical protein CGI_10015025 [Crassostrea gigas] \\
\hline gi|405965518 & hypothetical protein CGI_10028568 [Crassostrea gigas] \\
\hline gi|405976084 & Tubulin polymerization-promoting protein family member 3 [Crassostrea gigas] \\
\hline gi|405961662 & Neurocalcin-like protein [Crassostrea gigas] \\
\hline gi|405961012 & Superoxide dismutase [Cu-Zn] [Crassostrea gigas] \\
\hline gi|405975706 & Band 4.1-like protein 3 [Crassostrea gigas] \\
\hline gi|405973281 & Drebrin-like protein [Crassostrea gigas] \\
\hline gi|405968720 & hypothetical protein CGI_10023300 [Crassostrea gigas] \\
\hline gi|405975742 & High mobility group protein DSP1 [Crassostrea gigas] \\
\hline gi|405954092 & Mitochondrial fission factor-like protein B [Crassostrea gigas] \\
\hline
\end{tabular}




\begin{tabular}{|c|c|}
\hline Accession & Name \\
\hline gi|405952492 & hypothetical protein CGI_10006329 [Crassostrea gigas] \\
\hline gi|15004986 & integrin beta cgh [Crassostrea gigas] \\
\hline gi|405964355 & Calpain-A [Crassostrea gigas] \\
\hline gi|405973827 & Cytochrome c [Crassostrea gigas] \\
\hline gi|405962020 & GrpE-like protein 1, mitochondrial [Crassostrea gigas] \\
\hline gi|405958006 & hypothetical protein CGI_10007020 [Crassostrea gigas] \\
\hline gi|405971451 & Dynein heavy chain 5 , axonemal [Crassostrea gigas] \\
\hline gi|405950251 & Golgi integral membrane protein 4 [Crassostrea gigas] \\
\hline gi|405968237 & Putative 10-formyltetrahydrofolate dehydrogenase ALDH1L2 [Crassostrea gigas] \\
\hline gi|405957445 & Tyrosine-protein phosphatase non-receptor type 6 [Crassostrea gigas] \\
\hline gi|405970056 & Kyphoscoliosis peptidase [Crassostrea gigas] \\
\hline gi|405952872 & Splicing factor 3B subunit 2 [Crassostrea gigas] \\
\hline gi|405967137 & Ubiquitin-conjugating enzyme E2 L3 [Crassostrea gigas] \\
\hline gi|405971969 & Glutaredoxin-C6 [Crassostrea gigas] \\
\hline gi|405965620 & hypothetical protein CGI_10024980 [Crassostrea gigas] \\
\hline gi|405965276 & Neurocalcin-like protein [Crassostrea gigas] \\
\hline gi|405946542 & Charged multivesicular body protein $4 \mathrm{~b}$ [Crassostrea gigas] \\
\hline gi|405965308 & Troponin T, skeletal muscle [Crassostrea gigas] \\
\hline gi|405954918 & hypothetical protein CGI_10002631 [Crassostrea gigas] \\
\hline gi|405963782 & Nucleoredoxin [Crassostrea gigas] \\
\hline gi|405975785 & Filamin-A [Crassostrea gigas] \\
\hline gi|148717309 & hypothetical protein [Crassostrea gigas] \\
\hline gi|405951087 & $\begin{array}{l}\text { Small glutamine-rich tetratricopeptide repeat-containing protein beta [Crassostrea } \\
\text { gigas] }\end{array}$ \\
\hline gi|405977975 & Synapse-associated protein 1 [Crassostrea gigas] \\
\hline gi|405968521 & Prefoldin subunit 6 [Crassostrea gigas] \\
\hline gi|405968301 & hypothetical protein CGI_10025906 [Crassostrea gigas] \\
\hline gi|405978518 & Plasminogen activator inhibitor 1 RNA-binding protein [Crassostrea gigas] \\
\hline gi|405964925 & Ankyrin repeat domain-containing protein 45 [Crassostrea gigas] \\
\hline gi|405961624 & hypothetical protein CGI_10005225 [Crassostrea gigas] \\
\hline gi|405959798 & Dipeptidase 1 [Crassostrea gigas] \\
\hline gi|405966920 & Clathrin interactor 1 [Crassostrea gigas] \\
\hline gi|405950888 & Armadillo repeat-containing protein 4 [Crassostrea gigas] \\
\hline gi|405961245 & Heat shock $70 \mathrm{kDa}$ protein 12B [Crassostrea gigas] \\
\hline gi|405977263 & Heterogeneous nuclear ribonucleoprotein A2-like protein 1 [Crassostrea gigas] \\
\hline gi|405957035 & Microtubule-associated protein futsch [Crassostrea gigas] \\
\hline gi|405955275 & Kyphoscoliosis peptidase [Crassostrea gigas] \\
\hline gi|405972803 & Radial spoke head protein 4-like protein A [Crassostrea gigas] \\
\hline gi|405953094 & Eukaryotic translation initiation factor 3 subunit J [Crassostrea gigas] \\
\hline gi|405954012 & Thioredoxin [Crassostrea gigas] \\
\hline gi|405957913 & Calmodulin-like protein 12 [Crassostrea gigas] \\
\hline gi|405975838 & kinase $\mathrm{C}$ and casein kinase substrate in neurons protein 2 [Crassostrea gigas] \\
\hline gi|385843206 & ubiquitin/ribosomal protein S27 precursor [Crassostrea gigas] \\
\hline gi|405970175 & hypothetical protein CGI_10015122 [Crassostrea gigas] \\
\hline gi|405969112 & Protein dodo [Crassostrea gigas] \\
\hline gi|405970776 & Troponin C [Crassostrea gigas] \\
\hline gi|405952827 & PERQ amino acid-rich with GYF domain-containing protein 1 [Crassostrea gigas] \\
\hline
\end{tabular}




\begin{tabular}{|c|c|}
\hline Accession & Name \\
\hline gi|405971352 & Disks large-like protein 1 [Crassostrea gigas] \\
\hline gi|405960503 & Peroxisomal biogenesis factor 19 [Crassostrea gigas] \\
\hline gi|405978599 & Glutamate receptor U1 [Crassostrea gigas] \\
\hline gi|405956520 & Putative aminopeptidase W07G4.4 [Crassostrea gigas] \\
\hline gi|405974068 & $\begin{array}{l}\text { Glucosamine--fructose-6-phosphate aminotransferase [isomerizing] } 1 \text { [Crassostrea } \\
\text { gigas] }\end{array}$ \\
\hline gi|405970177 & Eukaryotic translation initiation factor 4B [Crassostrea gigas] \\
\hline gi|405970266 & Methylmalonyl-CoA mutase, mitochondrial [Crassostrea gigas] \\
\hline gi|405978223 & BAG family molecular chaperone regulator 4 [Crassostrea gigas] \\
\hline gi|405950507 & Integrin beta-3 [Crassostrea gigas] \\
\hline gi|405964118 & Talin-1 [Crassostrea gigas] \\
\hline gi|7573639 & calcineurin B [Mizuhopecten yessoensis] \\
\hline gi|405975071 & Coronin-1B [Crassostrea gigas] \\
\hline gi|405958084 & Calmodulin [Crassostrea gigas] \\
\hline gi|405952922 & Calmodulin-5/6/7/8 [Crassostrea gigas] \\
\hline gi|405972778 & Protein phosphatase 1B [Crassostrea gigas] \\
\hline gi|405977464 & Protein DEK [Crassostrea gigas] \\
\hline gi|405974726 & U1 small nuclear ribonucleoprotein A [Crassostrea gigas] \\
\hline gi|405959611 & Cystatin-B [Crassostrea gigas] \\
\hline gi|405976028 & canopy-like protein 3 [Crassostrea gigas] \\
\hline gi|405970262 & DnaJ-like protein subfamily B member 4 [Crassostrea gigas] \\
\hline gi|405950905 & Syntaxin-5 [Crassostrea gigas] \\
\hline gi|405964593 & hypothetical protein CGI_10018739 [Crassostrea gigas] \\
\hline gi|405962626 & Serine-threonine kinase receptor-associated protein [Crassostrea gigas] \\
\hline gi|405966001 & Non-specific lipid-transfer protein [Crassostrea gigas] \\
\hline gi|405969168 & hypothetical protein CGI_10007637 [Crassostrea gigas] \\
\hline gi|113207856 & pyruvate kinase [Crassostrea gigas] \\
\hline gi|405976502 & Uncharacterized protein C17orf98 [Crassostrea gigas] \\
\hline gi|405957984 & Apolipoprotein D [Crassostrea gigas] \\
\hline gi|405967433 & hypothetical protein CGI_10008200 [Crassostrea gigas] \\
\hline gi|405950863 & hypothetical protein CGI_10010851 [Crassostrea gigas] \\
\hline gi|405965382 & Soma ferritin [Crassostrea gigas] \\
\hline gi|405971954 & hypothetical protein CGI_10014227 [Crassostrea gigas] \\
\hline gi|405952344 & $60 S$ ribosomal protein L4 [Crassostrea gigas] \\
\hline gi|405977264 & Chromobox-like protein 5 [Crassostrea gigas] \\
\hline gi|405973525 & Endoplasmin [Crassostrea gigas] \\
\hline gi|405962294 & Pre-mRNA-splicing regulator female-lethal(2)D, partial [Crassostrea gigas] \\
\hline gi|405962502 & hypothetical protein CGI_10014339 [Crassostrea gigas] \\
\hline gi|405978738 & hypothetical protein CGI_10022305 [Crassostrea gigas] \\
\hline gi|405963691 & Cofilin [Crassostrea gigas] \\
\hline gi|405966392 & Dystroglycan [Crassostrea gigas] \\
\hline gi|405969114 & Thioredoxin domain-containing protein 3-like protein [Crassostrea gigas] \\
\hline gi|405973356 & Glutathione-requiring prostaglandin D synthase [Crassostrea gigas] \\
\hline gi|405958466 & Putative calcium-binding protein CML13 [Crassostrea gigas] \\
\hline gi|405957375 & hypothetical protein CGI_10009294 [Crassostrea gigas] \\
\hline gi|405978649 & Laminin-like protein epi-1 [Crassostrea gigas] \\
\hline gi|405965398 & Sorbin and $\mathrm{SH} 3$ domain-containing protein 1 [Crassostrea gigas] \\
\hline
\end{tabular}




\begin{tabular}{|c|c|}
\hline Accession & Name \\
\hline gi|405970994 & Calcyphosin-like protein [Crassostrea gigas] \\
\hline gi|405971603 & Cathepsin L [Crassostrea gigas] \\
\hline gi|405963900 & Formin-binding protein 1-like protein [Crassostrea gigas] \\
\hline gi|405958424 & Cytochrome c oxidase subunit 5B, mitochondrial [Crassostrea gigas] \\
\hline gi|405960078 & hypothetical protein CGI_10010679 [Crassostrea gigas] \\
\hline gi|405958039 & Acidic leucine-rich nuclear phosphoprotein 32 family member A [Crassostrea gigas] \\
\hline gi|405975234 & Dual oxidase 2, partial [Crassostrea gigas] \\
\hline gi|405962439 & 26S proteasome non-ATPase regulatory subunit 7 [Crassostrea gigas] \\
\hline gi|405968717 & Programmed cell death protein 6 [Crassostrea gigas] \\
\hline gi|405956277 & Nuclear distribution protein nudE-like protein 1 [Crassostrea gigas] \\
\hline gi|405961302 & Cystatin-B [Crassostrea gigas] \\
\hline gi|405953867 & Septin-7 [Crassostrea gigas] \\
\hline gi|405962247 & Complement C1q-like protein 4, partial [Crassostrea gigas] \\
\hline gi|405961595 & Anosmin-1 [Crassostrea gigas] \\
\hline gi|405951461 & V-type proton ATPase subunit F [Crassostrea gigas] \\
\hline gi|405972364 & IST1-like protein [Crassostrea gigas] \\
\hline gi|405959607 & Coiled-coil domain-containing protein 58 [Crassostrea gigas] \\
\hline gi|405966309 & Annulin [Crassostrea gigas] \\
\hline gi|405974168 & Titin [Crassostrea gigas] \\
\hline gi|405966484 & hypothetical protein CGI_10016704 [Crassostrea gigas] \\
\hline gi|405969229 & NSFL1 cofactor p47 [Crassostrea gigas] \\
\hline gi|405970439 & BAG family molecular chaperone regulator 1 [Crassostrea gigas] \\
\hline gi|405976897 & LSM14-like protein A [Crassostrea gigas] \\
\hline gi|405951160 & Endoplasmic reticulum resident protein ERp44 [Crassostrea gigas] \\
\hline gi|405969732 & Laminin subunit alpha [Crassostrea gigas] \\
\hline gi|405963030 & hypothetical protein CGI_10025157 [Crassostrea gigas] \\
\hline gi|405957249 & Src substrate cortactin [Crassostrea gigas] \\
\hline gi|405974767 & Splicing factor 4 [Crassostrea gigas] \\
\hline gi|405957005 & hypothetical protein CGI_10020924 [Crassostrea gigas] \\
\hline gi|405957436 & Forkhead box protein $\mathrm{O}$ [Crassostrea gigas] \\
\hline gi|405963261 & Guanine nucleotide-binding protein subunit beta [Crassostrea gigas] \\
\hline gi|405977358 & hypothetical protein CGI_10026433 [Crassostrea gigas] \\
\hline gi|405950254 & Tyrosine-protein kinase PR2 [Crassostrea gigas] \\
\hline gi|405974423 & hypothetical protein CGI_10018548 [Crassostrea gigas] \\
\hline gi|405976040 & Acyl carrier protein, mitochondrial [Crassostrea gigas] \\
\hline gi|405971628 & Coiled-coil domain-containing protein 39 [Crassostrea gigas] \\
\hline gi|405945610 & hypothetical protein CGI_10000903 [Crassostrea gigas] \\
\hline gi|405977606 & Astacin [Crassostrea gigas] \\
\hline gi|405970837 & Uncharacterized protein C7orf57-like protein [Crassostrea gigas] \\
\hline gi|405969437 & THO complex subunit 4-A [Crassostrea gigas] \\
\hline gi|405974949 & cAMP-dependent protein kinase regulatory subunit [Crassostrea gigas] \\
\hline gi|405951437 & hypothetical protein CGI_10008571 [Crassostrea gigas] \\
\hline gi|405953522 & Nucleolin [Crassostrea gigas] \\
\hline gi|405976533 & Hsp90 co-chaperone Cdc37 [Crassostrea gigas] \\
\hline gi|405952912 & $65 \mathrm{kDa}$ Yes-associated protein [Crassostrea gigas] \\
\hline gi|405970297 & V-type proton ATPase subunit D [Crassostrea gigas] \\
\hline
\end{tabular}




\begin{tabular}{|c|c|}
\hline Accession & Name \\
\hline gi|405975334 & Apoptosis inhibitor 5 [Crassostrea gigas] \\
\hline gi|405951796 & hypothetical protein CGI_10007922 [Crassostrea gigas] \\
\hline gi|405957236 & Collagen-like protein 2 [Crassostrea gigas] \\
\hline gi|405959294 & Paxillin [Crassostrea gigas] \\
\hline gi|405959327 & hypothetical protein CGI_10005346 [Crassostrea gigas] \\
\hline gi|405960379 & hypothetical protein CGI_10012583 [Crassostrea gigas] \\
\hline gi|405961405 & hypothetical protein CGI_10005085 [Crassostrea gigas] \\
\hline gi|405962468 & Calmodulin-like protein 3 [Crassostrea gigas] \\
\hline gi|405962821 & hypothetical protein CGI_10027749 [Crassostrea gigas] \\
\hline gi|405965271 & Caspase-2 [Crassostrea gigas] \\
\hline gi|405967081 & Myotrophin-like protein [Crassostrea gigas] \\
\hline gi|405969783 & hypothetical protein CGI_10021716 [Crassostrea gigas] \\
\hline gi|405971215 & MAGUK p55 subfamily member 2 [Crassostrea gigas] \\
\hline gi|405976518 & Syntaxin-7 [Crassostrea gigas] \\
\hline gi|405977935 & hypothetical protein CGI_10018270 [Crassostrea gigas] \\
\hline gi|405978690 & Propionyl-CoA carboxylase beta chain, mitochondrial [Crassostrea gigas] \\
\hline gi|40643000 & ribosomal protein S8 [Crassostrea gigas] \\
\hline gi|84619354 & cytochrome b5 [Crassostrea gigas] \\
\hline gi|405965139 & Sorting nexin-2 [Crassostrea gigas] \\
\hline gi|405973521 & Death-associated protein 1 [Crassostrea gigas] \\
\hline gi|405952506 & hypothetical protein CGI_10006312 [Crassostrea gigas] \\
\hline gi|405959343 & Blastula protease 10 [Crassostrea gigas] \\
\hline gi|405960037 & Serine/threonine-protein phosphatase 6 regulatory subunit 3 [Crassostrea gigas] \\
\hline gi|405951067 & Lysosomal aspartic protease [Crassostrea gigas] \\
\hline gi|405951327 & Protein G7c [Crassostrea gigas] \\
\hline gi|405957279 & $\begin{array}{l}\text { NADH dehydrogenase [ubiquinone] iron-sulfur protein } 4 \text {, mitochondrial [Crassostrea } \\
\text { gigas] }\end{array}$ \\
\hline gi|405958470 & Papilin [Crassostrea gigas] \\
\hline gi|405974066 & Eukaryotic translation initiation factor 4E-binding protein 1 [Crassostrea gigas] \\
\hline gi|405967363 & $\begin{array}{l}\text { Putative NADH dehydrogenase [ubiquinone] } 1 \text { alpha subcomplex subunit } 12 \\
\text { [Crassostrea gigas] }\end{array}$ \\
\hline gi|405959948 & hypothetical protein CGI_10013422 [Crassostrea gigas] \\
\hline gi|405976016 & Villin-1 [Crassostrea gigas] \\
\hline gi|405963725 & Sarcoplasmic reticulum histidine-rich calcium-binding protein [Crassostrea gigas] \\
\hline gi|405973406 & SAP domain-containing ribonucleoprotein [Crassostrea gigas] \\
\hline gi|405954900 & Pinin [Crassostrea gigas] \\
\hline gi|405960314 & hypothetical protein CGI_10005509 [Crassostrea gigas] \\
\hline gi|405976093 & DPY30 domain-containing protein 1 [Crassostrea gigas] \\
\hline gi|405978588 & hypothetical protein CGI_10023566 [Crassostrea gigas] \\
\hline gi|405973348 & SH3 domain-containing kinase-binding protein 1 [Crassostrea gigas] \\
\hline gi|405976947 & hypothetical protein CGI_10017528 [Crassostrea gigas] \\
\hline gi|405970946 & Fatty acid-binding protein, brain [Crassostrea gigas] \\
\hline gi|405977361 & hypothetical protein CGI_10026436 [Crassostrea gigas] \\
\hline gi|405953995 & hypothetical protein CGI_10003794 [Crassostrea gigas] \\
\hline gi|405976591 & bicaudal D-like protein 2 [Crassostrea gigas] \\
\hline gi|405978696 & Alpha-aminoadipic semialdehyde dehydrogenase [Crassostrea gigas] \\
\hline gi|405966927 & Cytochrome P450 3A29 [Crassostrea gigas] \\
\hline
\end{tabular}




\begin{tabular}{|c|c|}
\hline Accession & Name \\
\hline gi|405975720 & Endoplasmic reticulum protein ERp29 [Crassostrea gigas] \\
\hline gi|405957441 & hypothetical protein CGI_10007985 [Crassostrea gigas] \\
\hline gi|405962684 & hypothetical protein CGI_10011556 [Crassostrea gigas] \\
\hline gi|405975577 & Fibrillin-1 [Crassostrea gigas] \\
\hline gi|405977399 & Metallothionein [Crassostrea gigas] \\
\hline gi|405974686 & hypothetical protein CGI_10024481 [Crassostrea gigas] \\
\hline gi|405959675 & Heat shock protein HSP 90-alpha 1 [Crassostrea gigas] \\
\hline gi|405968273 & Blastula protease 10 [Crassostrea gigas] \\
\hline gi|405968529 & hypothetical protein CGI_10017745 [Crassostrea gigas] \\
\hline gi|405959517 & Uncharacterized protein in QAH/OAS sulfhydrylase 3'region, partial [Crassostrea gigas] \\
\hline gi|405975946 & hypothetical protein CGI_10013510 [Crassostrea gigas] \\
\hline gi|405970485 & Ganglioside GM2 activator [Crassostrea gigas] \\
\hline gi|405971647 & hypothetical protein CGI_10027007 [Crassostrea gigas] \\
\hline gi|405958886 & hypothetical protein CGI_10024026 [Crassostrea gigas] \\
\hline gi|405960477 & Laminin subunit beta-2 [Crassostrea gigas] \\
\hline gi|405972019 & hypothetical protein CGI_10022767 [Crassostrea gigas] \\
\hline gi|405960046 & Protein OSCP1 [Crassostrea gigas] \\
\hline gi|405974732 & hypothetical protein CGI_10018996 [Crassostrea gigas] \\
\hline gi|405961475 & Pre-mRNA-processing factor 40-like protein A [Crassostrea gigas] \\
\hline gi|405977780 & Calmodulin [Crassostrea gigas] \\
\hline gi|405958119 & Gamma-interferon-inducible lysosomal thiol reductase [Crassostrea gigas] \\
\hline gi|405971057 & Actin-related protein $2 / 3$ complex subunit 3 [Crassostrea gigas] \\
\hline gi|405975053 & Epididymal secretory glutathione peroxidase [Crassostrea gigas] \\
\hline gi|405969172 & S-adenosylmethionine synthetase isoform type-1 [Crassostrea gigas] \\
\hline gi|405959274 & hypothetical protein CGI_10015606 [Crassostrea gigas] \\
\hline gi|405963192 & von Willebrand factor D and EGF domain-containing protein [Crassostrea gigas] \\
\hline gi|405977958 & hypothetical protein CGI_10005753 [Crassostrea gigas] \\
\hline gi|405957947 & 3-hydroxyisobutyrate dehydrogenase, mitochondrial [Crassostrea gigas] \\
\hline gi|405958997 & Charged multivesicular body protein 3 [Crassostrea gigas] \\
\hline gi|405977720 & Charged multivesicular body protein 1a [Crassostrea gigas] \\
\hline gi|405953302 & $\begin{array}{l}\text { Complement component } 1 \mathrm{Q} \text { subcomponent-binding protein, mitochondrial } \\
\text { [Crassostrea gigas] }\end{array}$ \\
\hline gi|405965772 & hypothetical protein CGI_10028757 [Crassostrea gigas] \\
\hline gi|405952290 & $\begin{array}{l}\text { Armadillo repeat protein deleted in velo-cardio-facial syndrome-like protein [Crassostrea } \\
\text { gigas] }\end{array}$ \\
\hline gi|405967549 & ATP-dependent DNA helicase 2 subunit 2 [Crassostrea gigas] \\
\hline gi|405973865 & Actin-1/3 [Crassostrea gigas] \\
\hline gi|405976121 & WD repeat-containing protein C2orf44-like protein [Crassostrea gigas] \\
\hline gi|405972492 & Kinesin-related protein 1 [Crassostrea gigas] \\
\hline gi|405957013 & B-cell linker protein [Crassostrea gigas] \\
\hline gi|405967527 & Nesprin-1 [Crassostrea gigas] \\
\hline gi|405946277 & hypothetical protein CGI_10000492 [Crassostrea gigas] \\
\hline gi|405962871 & Metallothionein [Crassostrea gigas] \\
\hline gi|405957373 & Sulfotransferase $1 \mathrm{~A} 1$ [Crassostrea gigas] \\
\hline gi|405967714 & Basigin [Crassostrea gigas] \\
\hline gi|405971179 & NADH dehydrogenase [ubiquinone] 1 alpha subcomplex subunit 8 [Crassostrea gigas] \\
\hline gi|405959335 & Serine/threonine-protein kinase Nek4 [Crassostrea gigas] \\
\hline
\end{tabular}




\begin{tabular}{|c|c|}
\hline Accession & Name \\
\hline gi|405972497 & Natterin-3 [Crassostrea gigas] \\
\hline gi|58219308 & small cardioactive peptide precursor [Crassostrea gigas] \\
\hline gi|405972408 & Shootin-1 [Crassostrea gigas] \\
\hline gi|405956300 & Phosducin-like protein 3, partial [Crassostrea gigas] \\
\hline gi|405973292 & Protein cappuccino [Crassostrea gigas] \\
\hline gi|405953479 & hypothetical protein CGI_10004540 [Crassostrea gigas] \\
\hline gi|405954063 & hypothetical protein CGI_10003636 [Crassostrea gigas] \\
\hline gi|48476119 & fatty acid binding protein [Crassostrea gigas] \\
\hline gi|405970386 & hypothetical protein CGI_10017976 [Crassostrea gigas] \\
\hline gi|405960951 & hypothetical protein CGI_10013856, partial [Crassostrea gigas] \\
\hline gi|405957030 & Ras GTPase-activating-like protein IQGAP1 [Crassostrea gigas] \\
\hline gi|405958083 & Calmodulin [Crassostrea gigas] \\
\hline gi|405963257 & Protein LZIC [Crassostrea gigas] \\
\hline gi|405971784 & hypothetical protein CGI_10018185 [Crassostrea gigas] \\
\hline gi|405965635 & Coiled-coil domain-containing protein 40 [Crassostrea gigas] \\
\hline gi|405967615 & 4-hydroxybutyrate coenzyme A transferase [Crassostrea gigas] \\
\hline gi|405951408 & Proteasome subunit alpha type- 1 [Crassostrea gigas] \\
\hline gi|405953053 & Echinoderm microtubule-associated protein-like 1 [Crassostrea gigas] \\
\hline gi|405956965 & TRAF3-interacting protein 1 [Crassostrea gigas] \\
\hline gi|405961233 & Alpha-crystallin B chain [Crassostrea gigas] \\
\hline gi|405972618 & Peptidyl-prolyl cis-trans isomerase C [Crassostrea gigas] \\
\hline gi|405975170 & CUB and sushi domain-containing protein 1 [Crassostrea gigas] \\
\hline gi|405949969 & Centrosomal protein of $72 \mathrm{kDa}$ [Crassostrea gigas] \\
\hline gi|405952731 & Lupus La-like protein [Crassostrea gigas] \\
\hline gi|405957238 & Collagen alpha-5(VI) chain [Crassostrea gigas] \\
\hline gi|405963352 & Signal transducing adapter molecule 2 [Crassostrea gigas] \\
\hline gi|405975722 & Polyamine-modulated factor 1-binding protein 1 [Crassostrea gigas] \\
\hline gi|405952111 & Transcription factor E2F5 [Crassostrea gigas] \\
\hline gi|405952454 & Epidermal growth factor receptor substrate 15-like 1 [Crassostrea gigas] \\
\hline gi|405956952 & LIM domain-binding protein 3 [Crassostrea gigas] \\
\hline gi|405967397 & Calmodulin [Crassostrea gigas] \\
\hline gi|405968887 & Epidermal growth factor receptor kinase substrate 8-like protein 1 [Crassostrea gigas] \\
\hline gi|405970058 & Eukaryotic translation initiation factor 3 subunit A [Crassostrea gigas] \\
\hline gi|405962056 & hypothetical protein CGI_10002715 [Crassostrea gigas] \\
\hline gi|405971400 & Paired box protein Pax-2-A [Crassostrea gigas] \\
\hline gi|405952884 & hypothetical protein CGI_10005680 [Crassostrea gigas] \\
\hline gi|405965171 & hypothetical protein CGI_10017255 [Crassostrea gigas] \\
\hline gi|405968992 & IQ domain-containing protein $\mathrm{D}$ [Crassostrea gigas] \\
\hline gi|405978684 & Collagen alpha-1(IV) chain [Crassostrea gigas] \\
\hline gi|405952542 & hypothetical protein CGI_10006212 [Crassostrea gigas] \\
\hline gi|405959180 & Protein SET [Crassostrea gigas] \\
\hline gi|405963398 & hypothetical protein CGI_10011849 [Crassostrea gigas] \\
\hline gi|405975467 & hypothetical protein CGI_10010026 [Crassostrea gigas] \\
\hline gi|405976672 & Programmed cell death protein 5 [Crassostrea gigas] \\
\hline gi|405957864 & Prominin-1 [Crassostrea gigas] \\
\hline gi|405965699 & hypothetical protein CGI_10020257 [Crassostrea gigas] \\
\hline
\end{tabular}




\begin{tabular}{|c|c|}
\hline Accession & Name \\
\hline gi|405967888 & NGFI-A-binding-like protein [Crassostrea gigas] \\
\hline gi|405968442 & Collagen alpha-1(XII) chain [Crassostrea gigas] \\
\hline gi|405970532 & Septin-2 [Crassostrea gigas] \\
\hline gi|405975672 & Long-chain-fatty-acid--CoA ligase 4 [Crassostrea gigas] \\
\hline gi|405977916 & UPF0556 protein C19orf10-like protein [Crassostrea gigas] \\
\hline gi|405945552 & 2,4-dienoyl-CoA reductase, mitochondrial [Crassostrea gigas] \\
\hline gi|405950871 & hypothetical protein CGI_10010860 [Crassostrea gigas] \\
\hline gi|405951163 & Putative adenylate kinase-like protein C9orf98-like protein [Crassostrea gigas] \\
\hline gi|405951960 & F-actin-capping protein subunit alpha [Crassostrea gigas] \\
\hline gi|405952395 & WD repeat-containing protein 27 [Crassostrea gigas] \\
\hline gi|405953462 & ATP synthase subunit delta, mitochondrial [Crassostrea gigas] \\
\hline gi|405953722 & Calmodulin-like protein 12 [Crassostrea gigas] \\
\hline gi|405956092 & DNA-directed RNA polymerases I, II, and III subunit RPABC2 [Crassostrea gigas] \\
\hline gi|405961313 & Actin Cyl, cytoplasmic [Crassostrea gigas] \\
\hline gi|405963726 & Dynactin subunit 3 [Crassostrea gigas] \\
\hline gi|405963822 & UPF0663 transmembrane protein C17orf28 [Crassostrea gigas] \\
\hline gi|405964056 & hypothetical protein CGI_10027362 [Crassostrea gigas] \\
\hline gi|405964670 & Histidine triad nucleotide-binding protein 1 [Crassostrea gigas] \\
\hline gi|405965638 & Tubulin alpha-1C chain [Crassostrea gigas] \\
\hline gi|405965844 & Dynamin-1 [Crassostrea gigas] \\
\hline gi|405966160 & UPF0369 protein C6orf57 [Crassostrea gigas] \\
\hline gi|405966779 & Cytochrome b-c1 complex subunit 2, mitochondrial [Crassostrea gigas] \\
\hline gi|405968662 & hypothetical protein CGI_10020740 [Crassostrea gigas] \\
\hline gi|405968719 & hypothetical protein CGI_10023299 [Crassostrea gigas] \\
\hline gi|405968984 & Fatty acid-binding protein, heart [Crassostrea gigas] \\
\hline gi|405969560 & Globin [Crassostrea gigas] \\
\hline gi|405969642 & NADH dehydrogenase [ubiquinone] 1 alpha subcomplex subunit 7 [Crassostrea gigas] \\
\hline gi|405969643 & hypothetical protein CGI_10012952 [Crassostrea gigas] \\
\hline gi|405970031 & Receptor-type tyrosine-protein phosphatase N2 [Crassostrea gigas] \\
\hline gi|405971248 & NFU1 iron-sulfur cluster scaffold-like protein, mitochondrial [Crassostrea gigas] \\
\hline gi|405972257 & hypothetical protein CGI_10014350 [Crassostrea gigas] \\
\hline gi|405974405 & Coiled-coil domain-containing protein 42-like protein [Crassostrea gigas] \\
\hline gi|405975737 & Proteasome activator complex subunit 3 [Crassostrea gigas] \\
\hline gi|68655616 & aspartate aminotransferase [Crassostrea gigas] \\
\hline gi|405967247 & Sulfide:quinone oxidoreductase, mitochondrial [Crassostrea gigas] \\
\hline gi|405945673 & Natterin-1 [Crassostrea gigas] \\
\hline gi|405961556 & hypothetical protein CGI_10010367 [Crassostrea gigas] \\
\hline gi|405963174 & MORN repeat-containing protein 5 [Crassostrea gigas] \\
\hline gi|405969487 & Protein phosphatase inhibitor 2 [Crassostrea gigas] \\
\hline gi|405963687 & Peptidyl-prolyl cis-trans isomerase B [Crassostrea gigas] \\
\hline gi|405960124 & hypothetical protein CGI_10023375 [Crassostrea gigas] \\
\hline gi|405973124 & hypothetical protein CGI_10019404 [Crassostrea gigas] \\
\hline gi|405978645 & Low-density lipoprotein receptor-related protein 6 [Crassostrea gigas] \\
\hline gi|405963560 & Sarcoplasmic calcium-binding protein [Crassostrea gigas] \\
\hline gi|405972343 & Calmodulin-like protein 4 [Crassostrea gigas] \\
\hline gi|405972110 & hypothetical protein CGI_10027089 [Crassostrea gigas] \\
\hline
\end{tabular}




\begin{tabular}{|c|c|}
\hline Accession & Name \\
\hline gi|405955617 & 3-hydroxyanthranilate 3,4-dioxygenase [Crassostrea gigas] \\
\hline gi|405961227 & Serine/threonine-protein kinase phg2 [Crassostrea gigas] \\
\hline gi|405959264 & Heterogeneous nuclear ribonucleoprotein U-like protein 1 [Crassostrea gigas] \\
\hline gi|405967851 & hypothetical protein CGI_10011344 [Crassostrea gigas] \\
\hline gi|405956544 & Small ubiquitin-related modifier 3 [Crassostrea gigas] \\
\hline gi|405978177 & Polyadenylate-binding protein 2 [Crassostrea gigas] \\
\hline gi|405962619 & Hsp90 co-chaperone Cdc37 [Crassostrea gigas] \\
\hline gi|405958268 & Mitochondrial import inner membrane translocase subunit Tim10 [Crassostrea gigas] \\
\hline gi|405977353 & DNA fragmentation factor subunit alpha, partial [Crassostrea gigas] \\
\hline gi|405962751 & RNA-binding protein 8A [Crassostrea gigas] \\
\hline gi|405963809 & Vacuolar protein sorting-associated protein 4B [Crassostrea gigas] \\
\hline gi|405969502 & hypothetical protein CGI_10015393 [Crassostrea gigas] \\
\hline gi|405950592 & Phosphoglucomutase-1 [Crassostrea gigas] \\
\hline gi|405976946 & hypothetical protein CGI_10017526 [Crassostrea gigas] \\
\hline gi|405975655 & transport protein Sec23A [Crassostrea gigas] \\
\hline gi|405958762 & Transcription factor SOX-2 [Crassostrea gigas] \\
\hline gi|405977054 & Kinesin heavy chain [Crassostrea gigas] \\
\hline gi|405968923 & LDLR chaperone MESD [Crassostrea gigas] \\
\hline gi|405952153 & Heterogeneous nuclear ribonucleoprotein $\mathrm{H}$ [Crassostrea gigas] \\
\hline gi|405964350 & Centrin-3 [Crassostrea gigas] \\
\hline gi|405950756 & JmjC domain-containing protein 5 [Crassostrea gigas] \\
\hline gi|405952424 & Tubulin-folding cofactor B [Crassostrea gigas] \\
\hline gi|405970417 & Titin [Crassostrea gigas] \\
\hline gi|405975381 & Huntingtin-interacting protein $\mathrm{K}$ [Crassostrea gigas] \\
\hline gi|405978104 & Afadin [Crassostrea gigas] \\
\hline gi|405966210 & Collectin-12 [Crassostrea gigas] \\
\hline gi|405965784 & Leucine-rich repeat-containing protein C10orf11-like protein [Crassostrea gigas] \\
\hline gi|405975180 & Glutathione S-transferase [Crassostrea gigas] \\
\hline gi|405959994 & TP53-regulated inhibitor of apoptosis 1 [Crassostrea gigas] \\
\hline gi|405959171 & Glucose-6-phosphate 1-dehydrogenase [Crassostrea gigas] \\
\hline gi|405974851 & Neurocalcin-like protein [Crassostrea gigas] \\
\hline gi|405961393 & RNA-binding protein 25 [Crassostrea gigas] \\
\hline gi|405966530 & hypothetical protein CGI_10010194 [Crassostrea gigas] \\
\hline gi|405953955 & hypothetical protein CGI_10003801 [Crassostrea gigas] \\
\hline gi|405954140 & $\begin{array}{l}\text { SWI/SNF-related matrix-associated actin-dependent regulator chromatin subfamily E } \\
\text { member } 1 \text { [Crassostrea gigas] }\end{array}$ \\
\hline gi|405964918 & WW domain-binding protein 11 [Crassostrea gigas] \\
\hline gi|405975484 & Protein lethal(2)essential for life [Crassostrea gigas] \\
\hline gi|405962914 & Synaptosomal-associated protein 29 [Crassostrea gigas] \\
\hline gi|405958072 & Sperm-associated antigen 8 [Crassostrea gigas] \\
\hline gi|405954086 & Severin [Crassostrea gigas] \\
\hline gi|405975958 & Heat shock $70 \mathrm{kDa}$ protein $12 \mathrm{~A}$ [Crassostrea gigas] \\
\hline gi|405972862 & Adenylate kinase isoenzyme 5 [Crassostrea gigas] \\
\hline gi|405978465 & Delta-1-pyrroline-5-carboxylate dehydrogenase, mitochondrial [Crassostrea gigas] \\
\hline gi|405966603 & Mitochondrial import inner membrane translocase subunit Tim13-B [Crassostrea gigas] \\
\hline gi|405972167 & hypothetical protein CGI_10023100 [Crassostrea gigas] \\
\hline gi|405969710 & NADH dehydrogenase [ubiquinone] flavoprotein 3, mitochondrial [Crassostrea gigas] \\
\hline
\end{tabular}




\begin{tabular}{|c|c|}
\hline Accession & Name \\
\hline gi|405951048 & $45 \mathrm{kDa}$ calcium-binding protein [Crassostrea gigas] \\
\hline gi|405978470 & Mitochondrial fission 1 protein [Crassostrea gigas] \\
\hline gi|405971733 & Formimidoyltransferase-cyclodeaminase [Crassostrea gigas] \\
\hline gi|405949997 & Serine/arginine repetitive matrix protein 2 [Crassostrea gigas] \\
\hline gi|238768474 & peptidoglycan recognition protein L [Crassostrea gigas] \\
\hline gi|405969928 & von Willebrand factor D and EGF domain-containing protein [Crassostrea gigas] \\
\hline gi|405975485 & Heat shock protein beta-1 [Crassostrea gigas] \\
\hline gi|405965288 & hypothetical protein CGI_10002263 [Crassostrea gigas] \\
\hline gi|405956633 & Eukaryotic translation initiation factor 4E [Crassostrea gigas] \\
\hline gi|405966125 & Glutathione S-transferase 3 [Crassostrea gigas] \\
\hline gi|405961262 & Phosphoenolpyruvate carboxykinase, cytosolic [GTP] [Crassostrea gigas] \\
\hline gi|405971329 & Spectrin beta chain, brain 4 [Crassostrea gigas] \\
\hline gi|405964277 & $26 S$ protease regulatory subunit 4 [Crassostrea gigas] \\
\hline gi|405967570 & Fibropellin-1 [Crassostrea gigas] \\
\hline gi|405970298 & Melanoma inhibitory activity protein 3 [Crassostrea gigas] \\
\hline gi|405975553 & Putative ferric-chelate reductase 1 [Crassostrea gigas] \\
\hline gi|405964721 & EF-hand domain-containing protein 1 [Crassostrea gigas] \\
\hline gi|405965402 & hypothetical protein CGI_10021684 [Crassostrea gigas] \\
\hline gi|405952433 & Sodium- and chloride-dependent GABA transporter ine [Crassostrea gigas] \\
\hline gi|405961806 & GRIP1-associated protein 1 [Crassostrea gigas] \\
\hline gi|405978082 & Myosin-le [Crassostrea gigas] \\
\hline gi|405960636 & Leucine-rich repeat-containing protein $16 \mathrm{~A}$ [Crassostrea gigas] \\
\hline gi|405962196 & ADAM family mig-17 [Crassostrea gigas] \\
\hline gi|405952419 & Calmodulin [Crassostrea gigas] \\
\hline gi|405960313 & Putative uncharacterized protein yghX [Crassostrea gigas] \\
\hline gi|405966525 & Neuroligin-4, X-linked [Crassostrea gigas] \\
\hline gi|405966818 & Putative ATP-dependent RNA helicase DDX5 [Crassostrea gigas] \\
\hline gi|40642990 & ribosomal protein L5 [Crassostrea gigas] \\
\hline gi|405966631 & Deleted in malignant brain tumors 1 protein [Crassostrea gigas] \\
\hline gi|405952218 & DnaJ-like protein subfamily B member 13 [Crassostrea gigas] \\
\hline gi|405962106 & diaphanous-like protein 2 [Crassostrea gigas] \\
\hline gi|405975217 & CD2 antigen cytoplasmic tail-binding protein 2 [Crassostrea gigas] \\
\hline gi|405966825 & Hepatocyte growth factor-regulated tyrosine kinase substrate [Crassostrea gigas] \\
\hline gi|405957461 & Putative thiopurine S-methyltransferase [Crassostrea gigas] \\
\hline gi|405961917 & EF-hand domain-containing family member B [Crassostrea gigas] \\
\hline gi|405973194 & Mitochondrial import receptor subunit TOM70 [Crassostrea gigas] \\
\hline gi|405958177 & DnaJ-like protein subfamily C member 3 [Crassostrea gigas] \\
\hline gi|405968899 & Putative beta-D-xylosidase 5 [Crassostrea gigas] \\
\hline gi|405972383 & Coiled-coil domain-containing protein 91 [Crassostrea gigas] \\
\hline gi|405957571 & hypothetical protein CGI_10013933 [Crassostrea gigas] \\
\hline gi|405960658 & Plastin-1 [Crassostrea gigas] \\
\hline gi|405975550 & Eukaryotic translation initiation factor $1 \mathrm{~A}, \mathrm{X}$-chromosomal [Crassostrea gigas] \\
\hline gi|405969535 & hypothetical protein CGI_10016269 [Crassostrea gigas] \\
\hline gi|405965785 & Heterochromatin protein 1-binding protein 3 [Crassostrea gigas] \\
\hline gi|405972517 & Coiled-coil domain-containing protein 37 [Crassostrea gigas] \\
\hline gi|405974007 & Protein FAM21A [Crassostrea gigas] \\
\hline
\end{tabular}




\begin{tabular}{|c|c|}
\hline Accession & Name \\
\hline gi|405969388 & Gamma-glutamyltranspeptidase 1, partial [Crassostrea gigas] \\
\hline gi|405960427 & PDZ and LIM domain protein 5 [Crassostrea gigas] \\
\hline gi|405965168 & Pyruvate carboxylase, mitochondrial [Crassostrea gigas] \\
\hline gi|405956597 & hypothetical protein CGI_10000542 [Crassostrea gigas] \\
\hline gi|405974486 & Long-chain-fatty-acid--CoA ligase 1 [Crassostrea gigas] \\
\hline gi|405955658 & hypothetical protein CGI_10001712 [Crassostrea gigas] \\
\hline gi|405953907 & hypothetical protein CGI_10003856 [Crassostrea gigas] \\
\hline gi|405966381 & Dynein heavy chain 6 , axonemal [Crassostrea gigas] \\
\hline gi|405960639 & Deoxyuridine 5'-triphosphate nucleotidohydrolase [Crassostrea gigas] \\
\hline gi|405964242 & hypothetical protein CGI_10009344 [Crassostrea gigas] \\
\hline gi|405964353 & Uncharacterized protein C3orf30 [Crassostrea gigas] \\
\hline gi|405967712 & Ubiquitin thioesterase OTUB1 [Crassostrea gigas] \\
\hline gi|405970778 & IQ domain-containing protein $\mathrm{K}$ [Crassostrea gigas] \\
\hline gi|405954158 & Lachesin [Crassostrea gigas] \\
\hline gi|405961169 & Stress-induced protein 1 [Crassostrea gigas] \\
\hline gi|405961593 & MORN repeat-containing protein 4 [Crassostrea gigas] \\
\hline gi|405967643 & Bromodomain testis-specific protein [Crassostrea gigas] \\
\hline gi|405973078 & EF-hand calcium-binding domain-containing protein 6 [Crassostrea gigas] \\
\hline gi|405975833 & Doublecortin domain-containing protein 2 [Crassostrea gigas] \\
\hline gi|113928362 & dominin precursor [Crassostrea virginica] \\
\hline gi|405947710 & Barrier-to-autointegration factor [Crassostrea gigas] \\
\hline gi|405951115 & Dynein intermediate chain 2, ciliary [Crassostrea gigas] \\
\hline gi|405953641 & hypothetical protein CGI_10004231 [Crassostrea gigas] \\
\hline gi|405966072 & Putative adenylate kinase 7 [Crassostrea gigas] \\
\hline gi|405973805 & Mitochondrial inner membrane protein [Crassostrea gigas] \\
\hline gi|405976491 & PRKC apoptosis WT1 regulator protein [Crassostrea gigas] \\
\hline gi|405957059 & Caprin-1 [Crassostrea gigas] \\
\hline gi|405958293 & hypothetical protein CGI_10016401 [Crassostrea gigas] \\
\hline gi|405960204 & Hypoxia up-regulated protein 1 [Crassostrea gigas] \\
\hline gi|405960935 & High mobility group protein $20 \mathrm{~A}$ [Crassostrea gigas] \\
\hline gi|405961983 & Splicing factor 3B subunit 4 [Crassostrea gigas] \\
\hline gi|405966870 & Actin-interacting protein 1 [Crassostrea gigas] \\
\hline gi|405967124 & Sjoegren syndrome/scleroderma autoantigen 1 [Crassostrea gigas] \\
\hline gi|405967494 & hypothetical protein CGI_10011463 [Crassostrea gigas] \\
\hline gi|405968619 & 40 kDa peptidyl-prolyl cis-trans isomerase [Crassostrea gigas] \\
\hline gi|405969883 & Thioredoxin domain-containing protein $\mathrm{C} 2 \mathrm{~F} 3.12 \mathrm{c}$ [Crassostrea gigas] \\
\hline gi|405973425 & Dynein intermediate chain 3, ciliary [Crassostrea gigas] \\
\hline gi|405951159 & Valyl-tRNA synthetase [Crassostrea gigas] \\
\hline gi|405951799 & hypothetical protein CGI_10007925 [Crassostrea gigas] \\
\hline gi|405952725 & hypothetical protein CGI_10005976 [Crassostrea gigas] \\
\hline gi|405952962 & Galectin-4 [Crassostrea gigas] \\
\hline gi|405964031 & Sodium channel and clathrin linker 1 [Crassostrea gigas] \\
\hline gi|405964596 & hypothetical protein CGI_10018742 [Crassostrea gigas] \\
\hline gi|405965776 & LisH domain-containing protein C16orf63-like protein [Crassostrea gigas] \\
\hline gi|405966565 & Putative glycogen [starch] synthase [Crassostrea gigas] \\
\hline gi|405969366 & Syntaxin-6 [Crassostrea gigas] \\
\hline
\end{tabular}




\begin{tabular}{|c|c|}
\hline Accession & Name \\
\hline gi|405971538 & Synaptophysin [Crassostrea gigas] \\
\hline gi|405975257 & T-complex-associated testis-expressed protein 1 [Crassostrea gigas] \\
\hline gi|405976108 & Iron-sulfur cluster assembly enzyme ISCU, mitochondrial [Crassostrea gigas] \\
\hline gi|405976336 & hypothetical protein CGI_10026535 [Crassostrea gigas] \\
\hline gi|405978043 & $\begin{array}{l}\text { Sushi, von Willebrand factor type A, EGF and pentraxin domain-containing protein } 1 \\
\text { [Crassostrea gigas] }\end{array}$ \\
\hline gi|405978198 & canopy-like protein 2 [Crassostrea gigas] \\
\hline gi|405978205 & Dual oxidase [Crassostrea gigas] \\
\hline gi|144228241 & tubulin A [Hyriopsis cumingii] \\
\hline gi|3990959 & Sequence 3 from patent US 5736356 \\
\hline gi|405950308 & hypothetical protein CGI_10013719 [Crassostrea gigas] \\
\hline gi|405950353 & Excitatory amino acid transporter 3 [Crassostrea gigas] \\
\hline gi|405950378 & GSK3-beta interaction protein [Crassostrea gigas] \\
\hline gi|405950556 & Copine-7 [Crassostrea gigas] \\
\hline gi|405950685 & Allene oxide synthase-lipoxygenase protein [Crassostrea gigas] \\
\hline gi|405951130 & Protein TFG [Crassostrea gigas] \\
\hline gi|405951471 & Serine hydroxymethyltransferase, mitochondrial [Crassostrea gigas] \\
\hline gi|405951638 & Coiled-coil domain-containing protein 43 [Crassostrea gigas] \\
\hline gi|405951707 & 6-phosphofructokinase [Crassostrea gigas] \\
\hline gi|405952176 & hypothetical protein CGI_10007080 [Crassostrea gigas] \\
\hline gi|405952590 & Phospholipid scramblase 2, partial [Crassostrea gigas] \\
\hline gi|405952732 & Protein CASC3 [Crassostrea gigas] \\
\hline gi|405952828 & PERQ amino acid-rich with GYF domain-containing protein 2 [Crassostrea gigas] \\
\hline gi|405953908 & Putative peptidyl-tRNA hydrolase 2 [Crassostrea gigas] \\
\hline gi|405954148 & Calpain-9 [Crassostrea gigas] \\
\hline gi|405955229 & hypothetical protein CGI_10002317 [Crassostrea gigas] \\
\hline gi|405955564 & Cytoplasmic aconitate hydratase [Crassostrea gigas] \\
\hline gi|405957338 & hypothetical protein CGI_10011960 [Crassostrea gigas] \\
\hline gi|405957573 & hypothetical protein CGI_10013935 [Crassostrea gigas] \\
\hline gi|405957739 & hypothetical protein CGI_10004557 [Crassostrea gigas] \\
\hline gi|405958243 & hypothetical protein CGI_10013387 [Crassostrea gigas] \\
\hline gi|405958465 & Calmodulin [Crassostrea gigas] \\
\hline gi|405958778 & hypothetical protein CGI_10021467 [Crassostrea gigas] \\
\hline gi|405958912 & hypothetical protein CGI_10024053 [Crassostrea gigas] \\
\hline gi|405958940 & Phospholipid scramblase 2 [Crassostrea gigas] \\
\hline gi|405959119 & $60 S$ ribosomal protein L3, partial [Crassostrea gigas] \\
\hline gi|405959244 & FGFR1 oncogene partner 2-like protein [Crassostrea gigas] \\
\hline gi|405959582 & hypothetical protein CGI_10010386 [Crassostrea gigas] \\
\hline gi|405959834 & Catalase [Crassostrea gigas] \\
\hline gi|405960652 & $60 S$ ribosomal protein L17 [Crassostrea gigas] \\
\hline gi|405960767 & hypothetical protein CGI_10017882 [Crassostrea gigas] \\
\hline gi|405960824 & Thioredoxin domain-containing protein 16 [Crassostrea gigas] \\
\hline gi|405961084 & $\begin{array}{l}\text { NADH dehydrogenase [ubiquinone] iron-sulfur protein 6, mitochondrial [Crassostrea } \\
\text { gigas] }\end{array}$ \\
\hline gi|405961406 & Ras GTPase-activating protein-binding protein 2 [Crassostrea gigas] \\
\hline gi|405961414 & Uncharacterized protein C8orf34 [Crassostrea gigas] \\
\hline gi|405961725 & Alpha-tocopherol transfer-like protein [Crassostrea gigas] \\
\hline
\end{tabular}




\begin{tabular}{|c|c|}
\hline Accession & Name \\
\hline gi|405962051 & Importin subunit alpha-3 [Crassostrea gigas] \\
\hline gi|405962293 & Superoxide dismutase [Mn], mitochondrial [Crassostrea gigas] \\
\hline gi|405962701 & Malectin [Crassostrea gigas] \\
\hline gi|405962799 & Tyrosine-protein kinase transforming protein Src [Crassostrea gigas] \\
\hline gi|405963880 & CDK5 regulatory subunit-associated protein 3 [Crassostrea gigas] \\
\hline gi|405963947 & PDZ and LIM domain protein 1 [Crassostrea gigas] \\
\hline gi|405964042 & Coatomer subunit alpha [Crassostrea gigas] \\
\hline gi|405964054 & $\mathrm{NADH}$-cytochrome b5 reductase 2 [Crassostrea gigas] \\
\hline gi|405965049 & Nucleolar protein 58 [Crassostrea gigas] \\
\hline gi|405965135 & hypothetical protein CGI_10012662 [Crassostrea gigas] \\
\hline gi|405965147 & Apoptosis regulator $\mathrm{Bcl}-2$ [Crassostrea gigas] \\
\hline gi|405965273 & Putative WAS protein family-like protein 4 [Crassostrea gigas] \\
\hline gi|405965662 & Protein lap4 [Crassostrea gigas] \\
\hline gi|405965665 & Survival of motor neuron-related-splicing factor 30 [Crassostrea gigas] \\
\hline gi|405965826 & Programmed cell death protein 4 [Crassostrea gigas] \\
\hline gi|405966174 & Ubiquitin-conjugating enzyme E2 variant 1 [Crassostrea gigas] \\
\hline gi|405966762 & UPF0582 protein C13orf37-like protein [Crassostrea gigas] \\
\hline gi|405966819 & Serine hydroxymethyltransferase, cytosolic [Crassostrea gigas] \\
\hline gi|405966886 & hypothetical protein CGI_10025210 [Crassostrea gigas] \\
\hline gi|405967992 & hypothetical protein CGI_10024002 [Crassostrea gigas] \\
\hline gi|405969532 & hypothetical protein CGI_10016266 [Crassostrea gigas] \\
\hline gi|405969853 & NADP-dependent malic enzyme, mitochondrial [Crassostrea gigas] \\
\hline gi|405970315 & Mitochondrial import inner membrane translocase subunit Tim8 [Crassostrea gigas] \\
\hline gi|405970483 & $\begin{array}{l}\text { Aminoacyl tRNA synthetase complex-interacting multifunctional protein } 1 \text { [Crassostrea } \\
\text { gigas] }\end{array}$ \\
\hline gi|405970531 & Neurobeachin [Crassostrea gigas] \\
\hline gi|405970889 & Cleavage and polyadenylation specificity factor subunit 6 [Crassostrea gigas] \\
\hline gi|405971298 & Pallidin [Crassostrea gigas] \\
\hline gi|405971641 & Fibropellin-3 [Crassostrea gigas] \\
\hline gi|405972053 & Sarcoplasmic calcium-binding protein [Crassostrea gigas] \\
\hline gi|405972424 & cAMP-dependent protein kinase type II regulatory subunit [Crassostrea gigas] \\
\hline gi|405973130 & UDP-glucose:glycoprotein glucosyltransferase 1 [Crassostrea gigas] \\
\hline gi|405973352 & Glucose-repressible alcohol dehydrogenase transcriptional effector [Crassostrea gigas] \\
\hline gi|405973443 & Protein CEPU-1 [Crassostrea gigas] \\
\hline gi|405973802 & Peptidyl-prolyl cis-trans isomerase NIMA-interacting 4 [Crassostrea gigas] \\
\hline gi|405974458 & E3 ubiquitin-protein ligase MIB2 [Crassostrea gigas] \\
\hline gi|405974500 & $\begin{array}{l}\text { Eukaryotic peptide chain release factor GTP-binding subunit ERF3B [Crassostrea } \\
\text { gigas] }\end{array}$ \\
\hline gi|405974565 & RNA-binding protein 4 [Crassostrea gigas] \\
\hline gi|405974579 & Splicing factor 1 [Crassostrea gigas] \\
\hline gi|405974595 & Vacuolar protein sorting-associated protein VTA1-like protein [Crassostrea gigas] \\
\hline gi|405974727 & Transcriptional activator protein Pur-alpha [Crassostrea gigas] \\
\hline gi|405975243 & Protein unc-87 [Crassostrea gigas] \\
\hline gi|405975507 & Disks large-associated protein 1 [Crassostrea gigas] \\
\hline gi|405975922 & Replication protein A $14 \mathrm{kDa}$ subunit [Crassostrea gigas] \\
\hline gi|405976454 & hypothetical protein CGI_10028684 [Crassostrea gigas] \\
\hline gi|405976908 & $\begin{array}{l}\text { Coiled-coil-helix-coiled-coil-helix domain-containing protein 2, mitochondrial } \\
\text { [Crassostrea gigas] }\end{array}$ \\
\hline
\end{tabular}




\begin{tabular}{|c|c|}
\hline Accession & Name \\
\hline gi|405976926 & Dihydroorotase [Crassostrea gigas] \\
\hline gi|405976943 & hypothetical protein CGI_10017522 [Crassostrea gigas] \\
\hline gi|405977043 & NADH-ubiquinone oxidoreductase $75 \mathrm{kDa}$ subunit, mitochondrial [Crassostrea gigas] \\
\hline gi|405977312 & Heterogeneous nuclear ribonucleoprotein $27 \mathrm{C}$ [Crassostrea gigas] \\
\hline gi|405977599 & LETM1 and EF-hand domain-containing protein 1, mitochondrial [Crassostrea gigas] \\
\hline gi|405978116 & D-erythrulose reductase [Crassostrea gigas] \\
\hline gi|405978275 & EF-hand calcium-binding domain-containing protein 2 [Crassostrea gigas] \\
\hline gi|405953996 & hypothetical protein CGI_10003795 [Crassostrea gigas] \\
\hline gi|405961967 & Eukaryotic translation initiation factor 5 [Crassostrea gigas] \\
\hline gi|405961385 & Glutamine synthetase [Crassostrea gigas] \\
\hline gi|405972082 & Aspartate aminotransferase, mitochondrial [Crassostrea gigas] \\
\hline gi|405966303 & hypothetical protein CGI_10009847 [Crassostrea gigas] \\
\hline gi|405950508 & Integrin beta-6 [Crassostrea gigas] \\
\hline gi|405974528 & hypothetical protein CGI_10024564 [Crassostrea gigas] \\
\hline gi|405977348 & Histone H5 [Crassostrea gigas] \\
\hline gi|405952292 & Fibrillin-3 [Crassostrea gigas] \\
\hline gi|405961965 & Kinesin light chain [Crassostrea gigas] \\
\hline gi|405974626 & CD82 antigen [Crassostrea gigas] \\
\hline gi|405968755 & Mammalian ependymin-related protein 1 [Crassostrea gigas] \\
\hline gi|405976455 & hypothetical protein CGI_10028685 [Crassostrea gigas] \\
\hline gi|405976865 & Translocon-associated protein subunit alpha [Crassostrea gigas] \\
\hline gi|405964650 & Extended synaptotagmin-2 [Crassostrea gigas] \\
\hline gi|405952451 & Sperm flagellar protein 2 [Crassostrea gigas] \\
\hline gi|405955674 & hypothetical protein CGI_10001667 [Crassostrea gigas] \\
\hline gi|405968987 & Fatty acid-binding-like protein 5 [Crassostrea gigas] \\
\hline gi|405968991 & BolA-like protein 2 [Crassostrea gigas] \\
\hline gi|405951994 & hypothetical protein CGI_10007416 [Crassostrea gigas] \\
\hline gi|405957661 & Large proline-rich protein BAT3 [Crassostrea gigas] \\
\hline gi|405958864 & hypothetical protein CGI_10010933 [Crassostrea gigas] \\
\hline gi|405978643 & hypothetical protein CGI_10013193 [Crassostrea gigas] \\
\hline gi|405975575 & Calmodulin [Crassostrea gigas] \\
\hline gi|405972513 & $\begin{array}{l}\text { NADH dehydrogenase [ubiquinone] } 1 \text { beta subcomplex subunit 11, mitochondrial } \\
\text { [Crassostrea gigas] }\end{array}$ \\
\hline gi|405951857 & Cytochrome c1, heme protein, mitochondrial [Crassostrea gigas] \\
\hline gi|405958682 & 2-oxoglutarate dehydrogenase E1 component, mitochondrial [Crassostrea gigas] \\
\hline gi|405969429 & Plasma alpha-L-fucosidase [Crassostrea gigas] \\
\hline gi|405963555 & hypothetical protein CGI_10006803 [Crassostrea gigas] \\
\hline gi|405952289 & Microtubule-associated serine/threonine-protein kinase-like protein [Crassostrea gigas] \\
\hline gi|405965483 & Dihydrolipoyl dehydrogenase, mitochondrial [Crassostrea gigas] \\
\hline gi|405978546 & hypothetical protein CGI_10028902 [Crassostrea gigas] \\
\hline gi|405971322 & hypothetical protein CGI_10020230 [Crassostrea gigas] \\
\hline gi|405963184 & hypothetical protein CGI_10018076 [Crassostrea gigas] \\
\hline gi|405953851 & Alpha-2-macroglobulin receptor-associated protein [Crassostrea gigas] \\
\hline gi|405952159 & Vesicular integral-membrane protein VIP36 [Crassostrea gigas] \\
\hline gi|405960600 & Vasodilator-stimulated phosphoprotein [Crassostrea gigas] \\
\hline gi|405960674 & hypothetical protein CGI_10010476 [Crassostrea gigas] \\
\hline gi|405963145 & Integrin alpha-4 [Crassostrea gigas] \\
\hline
\end{tabular}




\begin{tabular}{|c|c|}
\hline Accession & Name \\
\hline gi|405965494 & DnaJ-like protein subfamily B member 11 [Crassostrea gigas] \\
\hline gi|405971676 & Tumor necrosis factor, alpha-induced protein 8 [Crassostrea gigas] \\
\hline gi|405959131 & Uncharacterized protein C5orf48-like protein [Crassostrea gigas] \\
\hline gi|405970751 & WD repeat-containing protein 65 [Crassostrea gigas] \\
\hline gi|405952131 & SH3 domain-binding glutamic acid-rich-like protein 3 [Crassostrea gigas] \\
\hline gi|405977154 & Exonuclease $3^{\prime}-5^{\prime}$ domain-containing protein 2 [Crassostrea gigas] \\
\hline gi|405972240 & V-type proton ATPase subunit G [Crassostrea gigas] \\
\hline gi|405973648 & Pericentriolar material 1 protein [Crassostrea gigas] \\
\hline gi|405969301 & hypothetical protein CGI_10019990 [Crassostrea gigas] \\
\hline gi|405969278 & Putative ATP-dependent RNA helicase an3 [Crassostrea gigas] \\
\hline gi|405964475 & hypothetical protein CGI_10015378 [Crassostrea gigas] \\
\hline gi|405970115 & Cytochrome b-c1 complex subunit 7 [Crassostrea gigas] \\
\hline gi|405977537 & Otoancorin [Crassostrea gigas] \\
\hline gi|405974476 & Laminin subunit beta-1 [Crassostrea gigas] \\
\hline gi|405977985 & hypothetical protein CGI_10015704 [Crassostrea gigas] \\
\hline gi|405973981 & Calcium-dependent protein kinase C [Crassostrea gigas] \\
\hline gi|405977993 & Arfaptin-1 [Crassostrea gigas] \\
\hline gi|46518245 & glutathione S-transferase [Crassostrea gigas] \\
\hline gi|405969843 & Protein FAM21 [Crassostrea gigas] \\
\hline gi|405957717 & Neural cell adhesion molecule L1 [Crassostrea gigas] \\
\hline gi|405973520 & UPF0449 protein C19orf25-like protein [Crassostrea gigas] \\
\hline gi|405964691 & Acetyl-coenzyme A synthetase [Crassostrea gigas] \\
\hline gi|405953771 & Proapoptotic caspase adapter protein [Crassostrea gigas] \\
\hline gi|405966811 & Intraflagellar transport protein 74-like protein [Crassostrea gigas] \\
\hline gi|405950170 & FYN-binding protein [Crassostrea gigas] \\
\hline gi|405959794 & Leucine-zipper-like transcriptional regulator 1 [Crassostrea gigas] \\
\hline gi|405964978 & hypothetical protein CGI_10003651 [Crassostrea gigas] \\
\hline gi|405965419 & Tetraspanin-3 [Crassostrea gigas] \\
\hline gi|405964391 & Calmodulin [Crassostrea gigas] \\
\hline gi|405975921 & Clathrin light chain A [Crassostrea gigas] \\
\hline gi|405965328 & Deoxyuridine 5'-triphosphate nucleotidohydrolase [Crassostrea gigas] \\
\hline gi|405974530 & Mediator of RNA polymerase II transcription subunit 8-B [Crassostrea gigas] \\
\hline gi|405969159 & hypothetical protein CGI_10002917 [Crassostrea gigas] \\
\hline gi|405961408 & hypothetical protein CGI_10005088 [Crassostrea gigas] \\
\hline gi|405969235 & DDRGK domain-containing protein 1 [Crassostrea gigas] \\
\hline gi|405960879 & hypothetical protein CGI_10028292 [Crassostrea gigas] \\
\hline gi|405974075 & hypothetical protein CGI_10020417 [Crassostrea gigas] \\
\hline gi|405964909 & Poly [ADP-ribose] polymerase 1 [Crassostrea gigas] \\
\hline gi|405965903 & Major egg antigen [Crassostrea gigas] \\
\hline gi|405973965 & hypothetical protein CGI_10016182 [Crassostrea gigas] \\
\hline gi|405960149 & Blastula protease 10 [Crassostrea gigas] \\
\hline gi|405961655 & Fascin [Crassostrea gigas] \\
\hline gi|353191 & myosin,regulatory La \\
\hline gi|405951265 & hypothetical protein CGI_10009262 [Crassostrea gigas] \\
\hline gi|405970545 & hypothetical protein CGI_10022572 [Crassostrea gigas] \\
\hline gi|405976269 & hypothetical protein CGI_10021273 [Crassostrea gigas] \\
\hline
\end{tabular}




\begin{tabular}{|c|c|}
\hline Accession & Name \\
\hline gi|405955782 & Coiled-coil domain-containing protein 12 [Crassostrea gigas] \\
\hline gi|405957910 & FMRFamide neuropeptide [Crassostrea gigas] \\
\hline gi|405962486 & hypothetical protein CGI_10015800, partial [Crassostrea gigas] \\
\hline gi|405969553 & Translin-associated factor X-interacting protein 1 [Crassostrea gigas] \\
\hline gi|405972436 & Cystatin-A2 [Crassostrea gigas] \\
\hline gi|405964482 & hypothetical protein CGI_10003076 [Crassostrea gigas] \\
\hline gi|405964165 & Calcium/calmodulin-dependent protein kinase type II delta chain [Crassostrea gigas] \\
\hline gi|405977877 & Dysferlin [Crassostrea gigas] \\
\hline gi|405970462 & mRNA-decapping enzyme 1B [Crassostrea gigas] \\
\hline gi|405966050 & Zinc finger RNA-binding protein [Crassostrea gigas] \\
\hline gi|405966265 & hypothetical protein CGI_10027684 [Crassostrea gigas] \\
\hline gi|405969898 & Tight junction protein ZO-1, partial [Crassostrea gigas] \\
\hline gi|405972973 & hypothetical protein CGI_10020471 [Crassostrea gigas] \\
\hline gi|405965901 & $60 S$ ribosomal protein L27a [Crassostrea gigas] \\
\hline gi|405977841 & Partner of Y14 and mago [Crassostrea gigas] \\
\hline gi|405959111 & WW domain-binding protein 4, partial [Crassostrea gigas] \\
\hline gi|405976464 & Transcription cofactor vestigial-like protein 4 [Crassostrea gigas] \\
\hline gi|405957027 & Heterogeneous nuclear ribonucleoprotein K [Crassostrea gigas] \\
\hline gi|405978819 & Leucine-rich repeat-containing protein 59 [Crassostrea gigas] \\
\hline gi|405977455 & Glyoxalase domain-containing protein 5 , partial [Crassostrea gigas] \\
\hline gi|405959015 & Tetraspanin-7 [Crassostrea gigas] \\
\hline gi|405966449 & hypothetical protein CGI_10008992 [Crassostrea gigas] \\
\hline gi|405967012 & hypothetical protein CGI_10026212 [Crassostrea gigas] \\
\hline gi|405959513 & hypothetical protein CGI_10009216, partial [Crassostrea gigas] \\
\hline gi|405957242 & Group XIIA secretory phospholipase A2 [Crassostrea gigas] \\
\hline gi|405966738 & Eukaryotic translation initiation factor 4 gamma 3 [Crassostrea gigas] \\
\hline gi|405969345 & Ubiquitin-associated protein 2 [Crassostrea gigas] \\
\hline gi|405970334 & IgGFc-binding protein [Crassostrea gigas] \\
\hline gi|405957161 & TAR DNA-binding protein 43 [Crassostrea gigas] \\
\hline gi|405965517 & Neurocalcin [Crassostrea gigas] \\
\hline gi|405950583 & Fermitin family-like protein 2 [Crassostrea gigas] \\
\hline gi|405973684 & Calcium-regulated heat stable protein 1 [Crassostrea gigas] \\
\hline gi|405952027 & Lethal(2) giant larvae-like protein 1 [Crassostrea gigas] \\
\hline gi|405972487 & CDV3-like protein [Crassostrea gigas] \\
\hline gi|405966511 & ELKS/RAB6-interacting/CAST family member 1 [Crassostrea gigas] \\
\hline gi|405968105 & Receptor-type tyrosine-protein phosphatase T [Crassostrea gigas] \\
\hline gi|405966284 & Upstream activation factor subunit spp27 [Crassostrea gigas] \\
\hline gi|405975727 & L-rhamnose-binding lectin CSL3, partial [Crassostrea gigas] \\
\hline gi|405945995 & Laminin subunit beta-2 [Crassostrea gigas] \\
\hline gi|405953620 & hypothetical protein CGI_10004281 [Crassostrea gigas] \\
\hline gi|405959751 & $28 \mathrm{kDa}$ heat- and acid-stable phosphoprotein [Crassostrea gigas] \\
\hline gi|405971402 & Coiled-coil domain-containing protein 96 [Crassostrea gigas] \\
\hline gi|405961430 & Docking protein 1 [Crassostrea gigas] \\
\hline gi|405961156 & Myosin-XVI [Crassostrea gigas] \\
\hline gi|405972434 & Galectin-4 [Crassostrea gigas] \\
\hline gi|405974267 & Halomucin [Crassostrea gigas] \\
\hline
\end{tabular}




\begin{tabular}{|c|c|}
\hline Accession & Name \\
\hline gi|405952521 & Apoptosis-inducing factor 3 [Crassostrea gigas] \\
\hline gi|241913774 & ribosomal protein S6 [Pinctada maxima] \\
\hline gi|405950559 & hypothetical protein CGI_10011903 [Crassostrea gigas] \\
\hline gi|405964587 & Hemagglutinin/amebocyte aggregation factor [Crassostrea gigas] \\
\hline gi|405951401 & Prefoldin subunit 1 [Crassostrea gigas] \\
\hline gi|405958822 & hypothetical protein CGI_10008262 [Crassostrea gigas] \\
\hline gi|405960203 & Upstream stimulatory factor 2 [Crassostrea gigas] \\
\hline gi|405964580 & Actin, cytoplasmic [Crassostrea gigas] \\
\hline gi|405970733 & Lysosome-associated membrane glycoprotein 1 [Crassostrea gigas] \\
\hline gi|405951108 & Homeobox protein SIX1 [Crassostrea gigas] \\
\hline gi|405958298 & Centrin-1 [Crassostrea gigas] \\
\hline gi|405967554 & hypothetical protein CGI_10024080 [Crassostrea gigas] \\
\hline gi|405976087 & Splicing factor U2AF 50 kDa subunit [Crassostrea gigas] \\
\hline gi|405970092 & $26 S$ proteasome non-ATPase regulatory subunit 2 [Crassostrea gigas] \\
\hline gi|405968537 & Actin [Crassostrea gigas] \\
\hline gi|405973713 & Serine/threonine-protein kinase PAK 3 [Crassostrea gigas] \\
\hline gi|405946926 & CD63 antigen [Crassostrea gigas] \\
\hline gi|405973510 & Transcription initiation factor TFIID subunit 10 [Crassostrea gigas] \\
\hline gi|405958081 & Calmodulin [Crassostrea gigas] \\
\hline gi|405972165 & $\begin{array}{l}\text { NADH dehydrogenase [ubiquinone] } 1 \text { alpha subcomplex subunit 4-like } 2 \text { [Crassostrea } \\
\text { gigas] }\end{array}$ \\
\hline gi|405960968 & hypothetical protein CGI_10007397 [Crassostrea gigas] \\
\hline gi|405966618 & Carbonic anhydrase 2 [Crassostrea gigas] \\
\hline gi|405965490 & hypothetical protein CGI_10028537 [Crassostrea gigas] \\
\hline gi|405978849 & Rho GTPase-activating protein 17 [Crassostrea gigas] \\
\hline gi|405961598 & U6 snRNA-associated Sm-like protein LSm1 [Crassostrea gigas] \\
\hline gi|405963411 & Forkhead-associated domain-containing protein 1 [Crassostrea gigas] \\
\hline gi|405967055 & Xaa-Pro aminopeptidase 1 [Crassostrea gigas] \\
\hline gi|405969117 & Dynein heavy chain 7 , axonemal [Crassostrea gigas] \\
\hline gi|405963737 & hypothetical protein CGI_10014599 [Crassostrea gigas] \\
\hline gi|328905054 & caspase-1 [Crassostrea gigas] \\
\hline gi|405951452 & T-complex protein 11-like protein 1 [Crassostrea gigas] \\
\hline gi|405951213 & Threonine synthase-like 1 [Crassostrea gigas] \\
\hline gi|405975959 & hypothetical protein CGI_10013526 [Crassostrea gigas] \\
\hline gi|405961473 & Thioredoxin domain-containing protein 12 [Crassostrea gigas] \\
\hline gi|405961926 & hypothetical protein CGI_10016949 [Crassostrea gigas] \\
\hline gi|405968439 & Collagen alpha-1(XII) chain [Crassostrea gigas] \\
\hline gi|405969503 & hypothetical protein CGI_10015394 [Crassostrea gigas] \\
\hline gi|405952295 & hypothetical protein CGI_10006782 [Crassostrea gigas] \\
\hline gi|405974815 & Glutamate receptor U1 [Crassostrea gigas] \\
\hline gi|405959253 & Myosin-VI [Crassostrea gigas] \\
\hline gi|405959946 & Uncharacterized protein C10orf67 [Crassostrea gigas] \\
\hline gi|405960179 & hypothetical protein CGI_10010255 [Crassostrea gigas] \\
\hline gi|405967115 & Peptidyl-prolyl cis-trans isomerase 6 [Crassostrea gigas] \\
\hline gi|405967434 & Fibropellin-1 [Crassostrea gigas] \\
\hline gi|405974669 & $39 S$ ribosomal protein L12, mitochondrial [Crassostrea gigas] \\
\hline gi|405976351 & Neurogenic locus Notch protein [Crassostrea gigas] \\
\hline
\end{tabular}




\begin{tabular}{|c|c|}
\hline Accession & Name \\
\hline gi|405964046 & hypothetical protein CGI_10027351 [Crassostrea gigas] \\
\hline gi|405965044 & Neutral and basic amino acid transport protein rBAT [Crassostrea gigas] \\
\hline gi|405969083 & hypothetical protein CGI_10018964 [Crassostrea gigas] \\
\hline gi|405970502 & Glutathione reductase, mitochondrial [Crassostrea gigas] \\
\hline gi|405977152 & Putative ferric-chelate reductase 1 [Crassostrea gigas] \\
\hline gi|405970038 & ATP-dependent DNA helicase 2 subunit 1 [Crassostrea gigas] \\
\hline gi|405972170 & Rho guanine nucleotide exchange factor 12 [Crassostrea gigas] \\
\hline gi|405974543 & Serrate RNA effector molecule-like protein [Crassostrea gigas] \\
\hline gi|405978151 & Nuclear protein MDM1 [Crassostrea gigas] \\
\hline gi|405955246 & hypothetical protein CGI_10002291 [Crassostrea gigas] \\
\hline gi|405960601 & Coiled-coil domain-containing protein 46 [Crassostrea gigas] \\
\hline gi|405973025 & Coatomer subunit delta [Crassostrea gigas] \\
\hline gi|405974623 & 26S proteasome non-ATPase regulatory subunit 12 [Crassostrea gigas] \\
\hline gi|405954191 & hypothetical protein CGI_10003464 [Crassostrea gigas] \\
\hline gi|405960113 & Ubiquitin carboxyl-terminal hydrolase 15 [Crassostrea gigas] \\
\hline gi|405976122 & Putative RNA-binding protein 16 [Crassostrea gigas] \\
\hline gi|405978773 & hypothetical protein CGI_10012933 [Crassostrea gigas] \\
\hline gi|405954083 & COX assembly mitochondrial-like protein [Crassostrea gigas] \\
\hline gi|405962113 & hypothetical protein CGI_10023942 [Crassostrea gigas] \\
\hline gi|405970435 & Thioredoxin domain-containing protein 5 [Crassostrea gigas] \\
\hline gi|405972200 & Coiled-coil domain-containing protein 9 [Crassostrea gigas] \\
\hline gi|405972230 & Growth arrest-specific protein 8 [Crassostrea gigas] \\
\hline gi|405952178 & Transcriptional adapter 3-like B [Crassostrea gigas] \\
\hline gi|405960226 & Cell adhesion molecule 3 [Crassostrea gigas] \\
\hline gi|405970718 & Cytochrome c oxidase subunit 6A1, mitochondrial [Crassostrea gigas] \\
\hline gi|405977715 & Katanin p80 WD40-containing subunit B1 [Crassostrea gigas] \\
\hline gi|328905046 & FAS-associating death domain-containing protein [Crassostrea gigas] \\
\hline gi|405952805 & Osteoclast-stimulating factor 1 [Crassostrea gigas] \\
\hline gi|405954222 & Importin-9 [Crassostrea gigas] \\
\hline gi|405958935 & L-ascorbate oxidase [Crassostrea gigas] \\
\hline gi|405970128 & Nucleolar protein 56 [Crassostrea gigas] \\
\hline gi|405970293 & Neuronal acetylcholine receptor subunit non-alpha-2 [Crassostrea gigas] \\
\hline gi|405972109 & hypothetical protein CGI_10027088 [Crassostrea gigas] \\
\hline gi|405975171 & Crumbs-like protein 2 [Crassostrea gigas] \\
\hline gi|405976453 & MICAL-like protein 2 [Crassostrea gigas] \\
\hline gi|405978261 & Hexokinase type 2 [Crassostrea gigas] \\
\hline gi|405950742 & Vascular endothelial growth factor D [Crassostrea gigas] \\
\hline gi|405953933 & Tetratricopeptide repeat protein 29 [Crassostrea gigas] \\
\hline gi|405954099 & Triosephosphate isomerase B [Crassostrea gigas] \\
\hline gi|405957091 & Proteasome inhibitor PI31 subunit [Crassostrea gigas] \\
\hline gi|405960444 & AP-3 complex subunit delta-1 [Crassostrea gigas] \\
\hline gi|405963003 & Splicing factor, arginine/serine-rich 4 [Crassostrea gigas] \\
\hline gi|405963604 & $60 S$ ribosomal protein L31 [Crassostrea gigas] \\
\hline gi|405964679 & Neurexin-4 [Crassostrea gigas] \\
\hline gi|405965593 & E3 ubiquitin-protein ligase HECTD1 [Crassostrea gigas] \\
\hline gi|405965813 & Williams-Beuren syndrome chromosomal region 27 protein [Crassostrea gigas] \\
\hline
\end{tabular}




\begin{tabular}{|c|c|}
\hline Accession & Name \\
\hline gi|405966615 & COP9 signalosome complex subunit 2 [Crassostrea gigas] \\
\hline gi|405971116 & Hydroxyacylglutathione hydrolase, mitochondrial [Crassostrea gigas] \\
\hline gi|405976226 & Inosine triphosphate pyrophosphatase [Crassostrea gigas] \\
\hline gi|405976309 & Kinesin-related protein 1 [Crassostrea gigas] \\
\hline gi|405976820 & Tripartite motif-containing protein 3 [Crassostrea gigas] \\
\hline gi|163637085 & coiled-coil-helix-coiled-coil-helix domain containing 3 [Crassostrea gigas] \\
\hline gi|405952082 & Extracellular sulfatase Sulf-1 [Crassostrea gigas] \\
\hline gi|405952388 & Spermatogenesis-associated protein 4 [Crassostrea gigas] \\
\hline gi|405958832 & 3-ketoacyl-CoA thiolase A, peroxisomal [Crassostrea gigas] \\
\hline gi|405960231 & Vigilin [Crassostrea gigas] \\
\hline gi|405960597 & $\begin{array}{l}\text { Phytanoyl-CoA dioxygenase domain-containing protein 1-like protein [Crassostrea } \\
\text { gigas] }\end{array}$ \\
\hline gi|405961544 & Plexin-A4 [Crassostrea gigas] \\
\hline gi|405964001 & Transcription initiation factor TFIID subunit 8 [Crassostrea gigas] \\
\hline gi|405964228 & Coiled-coil domain-containing protein 13 [Crassostrea gigas] \\
\hline gi|405965462 & Elongation factor Tu, mitochondrial [Crassostrea gigas] \\
\hline gi|405966992 & hypothetical protein CGI_10007491 [Crassostrea gigas] \\
\hline gi|405967002 & Linear gramicidin synthetase subunit D [Crassostrea gigas] \\
\hline gi|405969505 & Toll-interacting protein [Crassostrea gigas] \\
\hline gi|405969708 & hypothetical protein CGI_10023205 [Crassostrea gigas] \\
\hline gi|405969759 & Vacuolar protein sorting-associated protein 13C [Crassostrea gigas] \\
\hline gi|405972709 & Integrin beta-1 [Crassostrea gigas] \\
\hline gi|40643028 & ribosomal protein L19 [Crassostrea gigas] \\
\hline RRRRRgi|405973078 & REVERSED EF-hand calcium-binding domain-containing protein 6 [Crassostrea gigas] \\
\hline gi|405947434 & hypothetical protein CGI_10000134 [Crassostrea gigas] \\
\hline gi|405950813 & GPI inositol-deacylase [Crassostrea gigas] \\
\hline gi|405950980 & Caltractin [Crassostrea gigas] \\
\hline gi|405951312 & UPF0638 protein B [Crassostrea gigas] \\
\hline gi|405951329 & CLIP-associating protein 1 [Crassostrea gigas] \\
\hline gi|405951422 & Eukaryotic translation initiation factor 3 subunit G-A [Crassostrea gigas] \\
\hline gi|405951651 & 2-amino-3-carboxymuconate-6-semialdehyde decarboxylase [Crassostrea gigas] \\
\hline gi|405952183 & Serine/threonine-protein kinase 3 [Crassostrea gigas] \\
\hline gi|405952378 & Eukaryotic translation initiation factor 4 gamma 2 [Crassostrea gigas] \\
\hline gi|405953624 & hypothetical protein CGI_10004246 [Crassostrea gigas] \\
\hline gi|405953892 & Serine/threonine-protein kinase 25 [Crassostrea gigas] \\
\hline gi|405955211 & hypothetical protein CGI_10002332 [Crassostrea gigas] \\
\hline gi|405955495 & hypothetical protein CGI_10001933 [Crassostrea gigas] \\
\hline gi|405955957 & Death domain-containing protein CRADD [Crassostrea gigas] \\
\hline gi|405957466 & Dynein heavy chain 5 , axonemal [Crassostrea gigas] \\
\hline gi|405959699 & Aldo-keto reductase family 1 member B10 [Crassostrea gigas] \\
\hline gi|405960206 & Frizzled-7 [Crassostrea gigas] \\
\hline gi|405960423 & Cadherin-23 [Crassostrea gigas] \\
\hline gi|405960660 & Protein disulfide-isomerase A5 [Crassostrea gigas] \\
\hline gi|405960769 & Lysyl oxidase-like protein 2 [Crassostrea gigas] \\
\hline gi|405961151 & Xaa-Pro aminopeptidase 1 [Crassostrea gigas] \\
\hline gi|405961193 & Coatomer subunit beta', partial [Crassostrea gigas] \\
\hline gi|405962443 & hypothetical protein CGI_10009681 [Crassostrea gigas] \\
\hline
\end{tabular}




\begin{tabular}{|c|c|}
\hline Accession & Name \\
\hline gi|405962829 & LIM domain only protein 7 [Crassostrea gigas] \\
\hline gi|405963190 & Alpha-aspartyl dipeptidase [Crassostrea gigas] \\
\hline gi|405963573 & hypothetical protein CGI_10024254 [Crassostrea gigas] \\
\hline gi|405963576 & FACT complex subunit SSRP1 [Crassostrea gigas] \\
\hline gi|405965351 & Uncharacterized protein C2orf77 [Crassostrea gigas] \\
\hline gi|405966835 & hypothetical protein CGI_10013436 [Crassostrea gigas] \\
\hline gi|405967052 & WD repeat-containing protein 16 [Crassostrea gigas] \\
\hline gi|405967117 & Apoptotic chromatin condensation inducer in the nucleus [Crassostrea gigas] \\
\hline gi|405967749 & Catenin alpha-2 [Crassostrea gigas] \\
\hline gi|405968797 & Methenyltetrahydrofolate synthetase domain-containing protein [Crassostrea gigas] \\
\hline gi|405968910 & Gephyrin [Crassostrea gigas] \\
\hline gi|405970161 & Uncharacterized protein yqjG [Crassostrea gigas] \\
\hline gi|405970210 & Myosin-XVIIIa [Crassostrea gigas] \\
\hline gi|405970302 & PDZ domain-containing protein 2 [Crassostrea gigas] \\
\hline gi|405970476 & Pleckstrin-like protein domain family B member 2 [Crassostrea gigas] \\
\hline gi|405971245 & Eukaryotic translation initiation factor 3 subunit D [Crassostrea gigas] \\
\hline gi|405971472 & Ankyrin-2 [Crassostrea gigas] \\
\hline gi|405971620 & ES1-like protein, mitochondrial [Crassostrea gigas] \\
\hline gi|405971821 & Heat shock $70 \mathrm{kDa}$ protein $12 \mathrm{~A}$ [Crassostrea gigas] \\
\hline gi|405972083 & hypothetical protein CGI_10027060 [Crassostrea gigas] \\
\hline gi|405972124 & Cysteinyl-tRNA synthetase, cytoplasmic [Crassostrea gigas] \\
\hline gi|405972154 & hypothetical protein CGI_10023087 [Crassostrea gigas] \\
\hline gi|405972605 & Nuclear transcription factor $Y$ subunit alpha [Crassostrea gigas] \\
\hline gi|405972696 & hypothetical protein CGI_10011429 [Crassostrea gigas] \\
\hline gi|405972975 & Deleted in malignant brain tumors 1 protein [Crassostrea gigas] \\
\hline gi|405973051 & Neuron navigator 2 [Crassostrea gigas] \\
\hline gi|405973442 & Nicotinamide riboside kinase 1 [Crassostrea gigas] \\
\hline gi|405973879 & Zinc metalloproteinase nas-36 [Crassostrea gigas] \\
\hline gi|405974461 & E3 ubiquitin-protein ligase MIB2 [Crassostrea gigas] \\
\hline gi|405974711 & Serine/threonine-protein phosphatase 2A regulatory subunit B' [Crassostrea gigas] \\
\hline gi|405975201 & SH3 domain-containing guanine exchange factor [Crassostrea gigas] \\
\hline gi|405976936 & Leucine-rich repeat-containing protein 23 [Crassostrea gigas] \\
\hline gi|405977373 & Dynein heavy chain 1 , axonemal [Crassostrea gigas] \\
\hline gi|405977572 & Calcyphosin-like protein [Crassostrea gigas] \\
\hline gi|405977790 & hypothetical protein CGI_10028023 [Crassostrea gigas] \\
\hline gi|405978332 & Golgi membrane protein 1 [Crassostrea gigas] \\
\hline gi|405978371 & Leucine-rich repeat-containing protein 51 , partial [Crassostrea gigas] \\
\hline gi|405978774 & hypothetical protein CGI_10012934, partial [Crassostrea gigas] \\
\hline gi|47076115 & mu class glutathione S-transferase [Crassostrea gigas] \\
\hline gi|157154401 & IK cytokine [Crassostrea gigas] \\
\hline gi|157154403 & sodium/potassium-transporting ATPase alpha chain [Crassostrea gigas] \\
\hline gi|22758866 & ribosomal protein L23a [Argopecten irradians] \\
\hline gi|22758874 & ribosomal protein L [Argopecten irradians] \\
\hline gi|26892108 & LBP/BPI [Crassostrea gigas] \\
\hline gi|33337627 & astacin metalloprotease [Crassostrea gigas] \\
\hline gi|405946057 & Talin-2 [Crassostrea gigas] \\
\hline
\end{tabular}




\begin{tabular}{|c|c|}
\hline Accession & Name \\
\hline gi|405950138 & Glutamate receptor 3 [Crassostrea gigas] \\
\hline gi|405950245 & Cation-dependent mannose-6-phosphate receptor [Crassostrea gigas] \\
\hline gi|405950455 & Sperm-associated antigen 7-like protein [Crassostrea gigas] \\
\hline gi|405950532 & Uncharacterized protein yieF [Crassostrea gigas] \\
\hline gi|405950548 & Surfeit locus protein 1 [Crassostrea gigas] \\
\hline gi|405950755 & hypothetical protein CGI_10011395 [Crassostrea gigas] \\
\hline gi|405950869 & Dynein heavy chain 3 , axonemal [Crassostrea gigas] \\
\hline gi|405950870 & hypothetical protein CGI_10010859 [Crassostrea gigas] \\
\hline gi|405950946 & Phospholipase A2 inhibitor subunit B [Crassostrea gigas] \\
\hline gi|405951040 & Eukaryotic translation initiation factor 3 subunit C [Crassostrea gigas] \\
\hline gi|405951043 & Serine protease inhibitor dipetalogastin [Crassostrea gigas] \\
\hline gi|405951089 & Neuronal calcium sensor 2 [Crassostrea gigas] \\
\hline gi|405951151 & hypothetical protein CGI_10009743 [Crassostrea gigas] \\
\hline gi|405951326 & Protein G7c [Crassostrea gigas] \\
\hline gi|405951433 & Tubulin beta chain [Crassostrea gigas] \\
\hline gi|405951501 & Serine dehydratase-like protein [Crassostrea gigas] \\
\hline gi|405951532 & CAP-Gly domain-containing linker protein 1 [Crassostrea gigas] \\
\hline gi|405951570 & 15-hydroxyprostaglandin dehydrogenase [NAD+] [Crassostrea gigas] \\
\hline gi|405951710 & Protein argonaute-2 [Crassostrea gigas] \\
\hline gi|405951825 & Nidogen-2 [Crassostrea gigas] \\
\hline gi|405951873 & Transcription initiation factor TFIID subunit 11 [Crassostrea gigas] \\
\hline gi|405952064 & hypothetical protein CGI_10007259 [Crassostrea gigas] \\
\hline gi|405952065 & hypothetical protein CGI_10007261 [Crassostrea gigas] \\
\hline gi|405952500 & Vacuolar-sorting protein SNF8 [Crassostrea gigas] \\
\hline gi|405952501 & DnaJ-like protein subfamily B member 3 [Crassostrea gigas] \\
\hline gi|405952883 & Ankyrin repeat domain-containing protein 49 [Crassostrea gigas] \\
\hline gi|405952907 & hypothetical protein CGI_10005641 [Crassostrea gigas] \\
\hline gi|405953045 & PDZ domain-containing protein GIPC1 [Crassostrea gigas] \\
\hline gi|405953328 & Protein kinase $\mathrm{C}$ delta type [Crassostrea gigas] \\
\hline gi|405953339 & Mid1-interacting protein 1 [Crassostrea gigas] \\
\hline gi|405953465 & Tether containing UBX domain for GLUT4 [Crassostrea gigas] \\
\hline gi|405953564 & PC4 and SFRS1-interacting protein [Crassostrea gigas] \\
\hline gi|405953565 & HD domain-containing protein 3 [Crassostrea gigas] \\
\hline gi|405953593 & Double-stranded RNA-specific editase 1 [Crassostrea gigas] \\
\hline gi|405953772 & Renalase [Crassostrea gigas] \\
\hline gi|405953918 & hypothetical protein CGI_10003872 [Crassostrea gigas] \\
\hline gi|405954337 & hypothetical protein CGI_10003282 [Crassostrea gigas] \\
\hline gi|405954612 & Fucolectin-5 [Crassostrea gigas] \\
\hline gi|405954851 & Intermediate filament tail domain-containing protein 1 [Crassostrea gigas] \\
\hline gi|405955148 & Plasminogen [Crassostrea gigas] \\
\hline gi|405955166 & hypothetical protein CGI_10002360 [Crassostrea gigas] \\
\hline gi|405955398 & Proline-rich protein PRCC [Crassostrea gigas] \\
\hline gi|405955543 & Fumarylacetoacetate hydrolase domain-containing protein 2 [Crassostrea gigas] \\
\hline gi|405955753 & Elongation factor 1-gamma [Crassostrea gigas] \\
\hline gi|405955811 & Annexin A4 [Crassostrea gigas] \\
\hline gi|405956062 & hypothetical protein CGI_10001256 [Crassostrea gigas] \\
\hline
\end{tabular}




\begin{tabular}{|c|c|}
\hline Accession & Name \\
\hline gi|405956360 & Multidrug resistance protein 1, partial [Crassostrea gigas] \\
\hline gi|405956668 & LSM domain-containing protein 1 [Crassostrea gigas] \\
\hline gi|405956722 & Putative ATP-dependent RNA helicase DDX58 [Crassostrea gigas] \\
\hline gi|405957186 & RNA-binding protein Nova-1 [Crassostrea gigas] \\
\hline gi|405957246 & Excitatory amino acid transporter 2 [Crassostrea gigas] \\
\hline gi|405957331 & Interferon-induced protein 44-like protein [Crassostrea gigas] \\
\hline gi|405957372 & Sulfotransferase 1A1, partial [Crassostrea gigas] \\
\hline gi|405957477 & Putative thiopurine S-methyltransferase [Crassostrea gigas] \\
\hline gi|405957603 & Dysferlin-interacting protein 1 [Crassostrea gigas] \\
\hline gi|405957619 & hypothetical protein CGI_10020198 [Crassostrea gigas] \\
\hline gi|405957632 & hypothetical protein CGI_10020214 [Crassostrea gigas] \\
\hline gi|405957828 & Cytochrome P450 3A24 [Crassostrea gigas] \\
\hline gi|405957837 & CCR4-NOT transcription complex subunit 2 [Crassostrea gigas] \\
\hline gi|405957905 & $\mathrm{N}$-acylethanolamine-hydrolyzing acid amidase [Crassostrea gigas] \\
\hline gi|405957935 & hypothetical protein CGI_10016657 [Crassostrea gigas] \\
\hline gi|405957950 & SH3 domain-binding protein 5-like protein [Crassostrea gigas] \\
\hline gi|405958005 & hypothetical protein CGI_10007019 [Crassostrea gigas] \\
\hline gi|405958091 & hypothetical protein CGI_10002445 [Crassostrea gigas] \\
\hline gi|405958107 & Poly [ADP-ribose] polymerase 1 [Crassostrea gigas] \\
\hline gi|405958174 & Pyruvate kinase isozymes M1/M2 [Crassostrea gigas] \\
\hline gi|405958269 & hypothetical protein CGI_10014060 [Crassostrea gigas] \\
\hline gi|405958347 & Putative RNA-binding protein EIF1AD [Crassostrea gigas] \\
\hline gi|405958389 & Protein-glutamine gamma-glutamyltransferase K [Crassostrea gigas] \\
\hline gi|405958414 & U2 small nuclear ribonucleoprotein A' [Crassostrea gigas] \\
\hline gi|405958608 & Transmembrane BAX inhibitor motif-containing protein 4 [Crassostrea gigas] \\
\hline gi|405958647 & Ectoine hydroxylase [Crassostrea gigas] \\
\hline gi|405958692 & hypothetical protein CGI_10019555 [Crassostrea gigas] \\
\hline gi|405958743 & Prostaglandin reductase 1 [Crassostrea gigas] \\
\hline gi|405958791 & Arginine kinase [Crassostrea gigas] \\
\hline gi|405958828 & BTB/POZ domain-containing protein 9 [Crassostrea gigas] \\
\hline gi|405959058 & hypothetical protein CGI_10008488 [Crassostrea gigas] \\
\hline gi|405959151 & hypothetical protein CGI_10003818 [Crassostrea gigas] \\
\hline gi|405959173 & PRA1 family protein 3 [Crassostrea gigas] \\
\hline gi|405959219 & Mitogen-activated protein kinase kinase kinase kinase 3, partial [Crassostrea gigas] \\
\hline gi|405959230 & Membrane metallo-endopeptidase-like 1 [Crassostrea gigas] \\
\hline gi|405959291 & Serum paraoxonase/arylesterase 1 [Crassostrea gigas] \\
\hline gi|405959304 & Smoothelin-like protein 1 [Crassostrea gigas] \\
\hline gi|405959342 & Putative aminopeptidase W07G4.4 [Crassostrea gigas] \\
\hline gi|405959589 & Golgi-associated plant pathogenesis-related protein 1 [Crassostrea gigas] \\
\hline gi|405959696 & RPE-spondin [Crassostrea gigas] \\
\hline gi|405960133 & hypothetical protein CGI_10023385 [Crassostrea gigas] \\
\hline gi|405960169 & Cytoplasmic dynein 1 intermediate chain 2 [Crassostrea gigas] \\
\hline gi|405960263 & Mediator of RNA polymerase II transcription subunit 10 [Crassostrea gigas] \\
\hline gi|405960428 & PDZ and LIM domain protein 1 [Crassostrea gigas] \\
\hline gi|405960581 & Bile salt sulfotransferase [Crassostrea gigas] \\
\hline gi|405960587 & Proteasomal ubiquitin receptor ADRM1 [Crassostrea gigas] \\
\hline
\end{tabular}




\begin{tabular}{|c|c|}
\hline Accession & Name \\
\hline gi|405960605 & Uncharacterized protein C20orf26 [Crassostrea gigas] \\
\hline gi|405960640 & Cysteine-rich with EGF-like domain protein 2 [Crassostrea gigas] \\
\hline gi|405960911 & Ninjurin-1 [Crassostrea gigas] \\
\hline gi|405961035 & Engulfment and cell motility protein 2 [Crassostrea gigas] \\
\hline gi|405961051 & Protein FAM21 [Crassostrea gigas] \\
\hline gi|405961124 & Dynein beta chain, flagellar outer arm [Crassostrea gigas] \\
\hline gi|405961165 & 26S proteasome non-ATPase regulatory subunit 11 [Crassostrea gigas] \\
\hline gi|405961167 & Uncharacterized protein C21orf59-like protein [Crassostrea gigas] \\
\hline gi|405961266 & hypothetical protein CGI_10014919 [Crassostrea gigas] \\
\hline gi|405961687 & Nucleoredoxin [Crassostrea gigas] \\
\hline gi|405961689 & UPF0631 protein [Crassostrea gigas] \\
\hline gi|405961885 & Rab5 GDP/GTP exchange factor [Crassostrea gigas] \\
\hline gi|405961952 & Importin subunit alpha-2 [Crassostrea gigas] \\
\hline gi|405962092 & Protein disabled [Crassostrea gigas] \\
\hline gi|405962165 & Thioredoxin reductase 3 [Crassostrea gigas] \\
\hline gi|405962300 & Frizzled-5 [Crassostrea gigas] \\
\hline gi|405962442 & Casein kinase II subunit alpha [Crassostrea gigas] \\
\hline gi|405962528 & Double-strand-break repair protein rad21-like protein [Crassostrea gigas] \\
\hline gi|405962530 & Uncharacterized protein C2orf50 [Crassostrea gigas] \\
\hline gi|405962717 & Low-density lipoprotein receptor-related protein 1B [Crassostrea gigas] \\
\hline gi|405962828 & Ubiquitin-conjugating enzyme E2-22 kDa [Crassostrea gigas] \\
\hline gi|405962844 & Protein ETHE1, mitochondrial [Crassostrea gigas] \\
\hline gi|405962913 & $\begin{array}{l}\text { NADH dehydrogenase [ubiquinone] iron-sulfur protein 3, mitochondrial [Crassostrea } \\
\text { gigas] }\end{array}$ \\
\hline gi|405962986 & hypothetical protein CGI_10003439 [Crassostrea gigas] \\
\hline gi|405963074 & hypothetical protein CGI_10018932 [Crassostrea gigas] \\
\hline gi|405963175 & $60 \mathrm{kDa}$ neurofilament protein [Crassostrea gigas] \\
\hline gi|405963205 & Heat shock $70 \mathrm{kDa}$ protein $12 \mathrm{~A}$ [Crassostrea gigas] \\
\hline gi|405963248 & MTO1-like protein, mitochondrial [Crassostrea gigas] \\
\hline gi|405963300 & $\begin{array}{l}\text { Serine/threonine-protein phosphatase } 2 \mathrm{~A} 56 \mathrm{kDa} \text { regulatory subunit delta isoform } \\
\text { [Crassostrea gigas] }\end{array}$ \\
\hline gi|405963599 & Endonuclease VIII-like 1 [Crassostrea gigas] \\
\hline gi|405963692 & Neuroendocrine convertase 2 [Crassostrea gigas] \\
\hline gi|405963740 & U4/U6.U5 tri-snRNP-associated protein 2 [Crassostrea gigas] \\
\hline gi|405964229 & Golgi SNAP receptor complex member 2 [Crassostrea gigas] \\
\hline gi|405964311 & Ankyrin repeat domain-containing protein 29 , partial [Crassostrea gigas] \\
\hline gi|405964463 & hypothetical protein CGI_10015364 [Crassostrea gigas] \\
\hline gi|405964511 & $\begin{array}{l}\text { Ras-associated and pleckstrin-like protein domains-containing protein } 1 \text { [Crassostrea } \\
\text { gigas] }\end{array}$ \\
\hline gi|405964597 & hypothetical protein CGI_10018743 [Crassostrea gigas] \\
\hline gi|405964764 & Putative RNA-binding protein Luc7-like 2 [Crassostrea gigas] \\
\hline gi|405964769 & Putative ATP-dependent RNA helicase DDX47 [Crassostrea gigas] \\
\hline gi|405965007 & DNA-directed RNA polymerase II subunit RPB1 [Crassostrea gigas] \\
\hline gi|405965146 & hypothetical protein CGI_10006541 [Crassostrea gigas] \\
\hline gi|405965289 & Adenine phosphoribosyltransferase [Crassostrea gigas] \\
\hline gi|405965316 & Synaptic vesicle membrane protein VAT-1-like protein [Crassostrea gigas] \\
\hline gi|405965394 & Eukaryotic translation initiation factor 3 subunit B [Crassostrea gigas] \\
\hline gi|405965406 & Aldehyde dehydrogenase [Crassostrea gigas] \\
\hline
\end{tabular}




\begin{tabular}{|c|c|}
\hline Accession & Name \\
\hline gi|405965431 & Fatty acyl-CoA hydrolase precursor, medium chain [Crassostrea gigas] \\
\hline gi|405965493 & Alpha-N-acetylgalactosaminidase [Crassostrea gigas] \\
\hline gi|405965566 & hypothetical protein CGI_10022503 [Crassostrea gigas] \\
\hline gi|405965899 & Pleckstrin-like protein domain-containing family A member 7 [Crassostrea gigas] \\
\hline gi|405966054 & AP-3 complex subunit beta-2 [Crassostrea gigas] \\
\hline gi|405966314 & Lysyl-tRNA synthetase [Crassostrea gigas] \\
\hline gi|405966783 & Myosin-11 [Crassostrea gigas] \\
\hline gi|405966888 & Collagen alpha-3(VI) chain [Crassostrea gigas] \\
\hline gi|405967030 & hypothetical protein CGI_10026232 [Crassostrea gigas] \\
\hline gi|405967042 & Splicing factor, arginine/serine-rich 2 [Crassostrea gigas] \\
\hline gi|405967062 & Sulfotransferase family cytosolic 1B member 1 [Crassostrea gigas] \\
\hline gi|405967381 & Cysteinyl-tRNA synthetase, cytoplasmic [Crassostrea gigas] \\
\hline gi|405967393 & Calmodulin [Crassostrea gigas] \\
\hline gi|405967555 & $\mathrm{NADH}$ dehydrogenase [ubiquinone] flavoprotein 1, mitochondrial [Crassostrea gigas] \\
\hline gi|405967567 & hypothetical protein CGI_10024094 [Crassostrea gigas] \\
\hline gi|405967668 & Homer-like protein 2 [Crassostrea gigas] \\
\hline gi|405967835 & Methylglutaconyl-CoA hydratase, mitochondrial [Crassostrea gigas] \\
\hline gi|405968071 & U6 snRNA-associated Sm-like protein LSm7, partial [Crassostrea gigas] \\
\hline gi|405968088 & WD repeat-containing protein 19 [Crassostrea gigas] \\
\hline gi|405968446 & hypothetical protein CGI_10022012 [Crassostrea gigas] \\
\hline gi|405968707 & hypothetical protein CGI_10023287 [Crassostrea gigas] \\
\hline gi|405968826 & hypothetical protein CGI_10026345, partial [Crassostrea gigas] \\
\hline gi|405968884 & Epithelial splicing regulatory protein 2 [Crassostrea gigas] \\
\hline gi|405968888 & BET1-like protein [Crassostrea gigas] \\
\hline gi|405968916 & Coiled-coil domain-containing protein 55 [Crassostrea gigas] \\
\hline gi|405968925 & hypothetical protein CGI_10004918 [Crassostrea gigas] \\
\hline gi|405969084 & Small acidic protein [Crassostrea gigas] \\
\hline gi|405969198 & Tyrosine-protein kinase Yes, partial [Crassostrea gigas] \\
\hline gi|405969368 & Tetratricopeptide repeat protein 19 [Crassostrea gigas] \\
\hline gi|405969389 & DNA-directed RNA polymerases I, II, and III subunit RPABC3 [Crassostrea gigas] \\
\hline gi|405969488 & hypothetical protein CGI_10012737 [Crassostrea gigas] \\
\hline gi|405969600 & hypothetical protein CGI_10021126 [Crassostrea gigas] \\
\hline gi|405969789 & hypothetical protein CGI_10021722 [Crassostrea gigas] \\
\hline gi|405969881 & Synaptobrevin [Crassostrea gigas] \\
\hline gi|405969955 & hypothetical protein CGI_10027607 [Crassostrea gigas] \\
\hline gi|405969966 & Thymidine phosphorylase [Crassostrea gigas] \\
\hline gi|405970025 & hypothetical protein CGI_10018000 [Crassostrea gigas] \\
\hline gi|405970214 & Ataxin-2 [Crassostrea gigas] \\
\hline gi|405970312 & Alpha-N-acetylgalactosaminidase [Crassostrea gigas] \\
\hline gi|405970440 & BAG family molecular chaperone regulator 1 [Crassostrea gigas] \\
\hline gi|405970444 & Acid ceramidase [Crassostrea gigas] \\
\hline gi|405970446 & Sodium- and chloride-dependent glycine transporter 2 [Crassostrea gigas] \\
\hline gi|405970487 & Glutaminyl-tRNA synthetase, partial [Crassostrea gigas] \\
\hline gi|405970539 & Uncharacterized protein C13orf26-like protein [Crassostrea gigas] \\
\hline gi|405970695 & Receptor-type tyrosine-protein phosphatase beta [Crassostrea gigas] \\
\hline gi|405970741 & Translocon-associated protein subunit delta [Crassostrea gigas] \\
\hline
\end{tabular}




\begin{tabular}{|c|c|}
\hline Accession & Name \\
\hline gi|405970915 & $\begin{array}{l}\text { Serine/threonine-protein phosphatase } 2 \text { A } 55 \text { kDa regulatory subunit B alpha isoform } \\
\text { [Crassostrea gigas] }\end{array}$ \\
\hline gi|405970941 & hypothetical protein CGI_10011199 [Crassostrea gigas] \\
\hline gi|405971114 & Talin-1 [Crassostrea gigas] \\
\hline gi|405971130 & Anaphase-promoting complex subunit CDC26 [Crassostrea gigas] \\
\hline gi|405971204 & E3 ubiquitin-protein ligase HECTD1 [Crassostrea gigas] \\
\hline gi|405971277 & Phosphatase and actin regulator 1 [Crassostrea gigas] \\
\hline gi|405971344 & Mitochondrial carrier-like protein 2 [Crassostrea gigas] \\
\hline gi|405971414 & hypothetical protein CGI_10024180 [Crassostrea gigas] \\
\hline gi|405971541 & 4-coumarate--CoA ligase 1 [Crassostrea gigas] \\
\hline gi|405971818 & Myosin-ld [Crassostrea gigas] \\
\hline gi|405971858 & Acetyl-CoA acetyltransferase [Crassostrea gigas] \\
\hline gi|405971875 & Hemicentin-1 [Crassostrea gigas] \\
\hline gi|405971953 & hypothetical protein CGI_10014226 [Crassostrea gigas] \\
\hline gi|405972179 & hypothetical protein CGI_10023112 [Crassostrea gigas] \\
\hline gi|405972323 & EGF-like domain-containing protein 8 [Crassostrea gigas] \\
\hline gi|405972400 & Dual oxidase 2 [Crassostrea gigas] \\
\hline gi|405972486 & Putative malate dehydrogenase 1B [Crassostrea gigas] \\
\hline gi|405972528 & hypothetical protein CGI_10020633 [Crassostrea gigas] \\
\hline gi|405972553 & Dual oxidase maturation factor 1 [Crassostrea gigas] \\
\hline gi|405972660 & Nucleosome assembly protein 1-like 4 [Crassostrea gigas] \\
\hline gi|405972759 & hypothetical protein CGI_10018124 [Crassostrea gigas] \\
\hline gi|405972774 & Aldose 1-epimerase [Crassostrea gigas] \\
\hline gi|405972779 & hypothetical protein CGI_10013979 [Crassostrea gigas] \\
\hline gi|405972819 & Golgin subfamily A member 2 [Crassostrea gigas] \\
\hline gi|405972821 & Heterogeneous nuclear ribonucleoprotein L [Crassostrea gigas] \\
\hline gi|405972826 & Collagen alpha-5(VI) chain [Crassostrea gigas] \\
\hline gi|405972926 & Peroxiredoxin-4 [Crassostrea gigas] \\
\hline gi|405973002 & Vesicle transport through interaction with t-SNAREs-like protein 1B [Crassostrea gigas] \\
\hline gi|405973085 & Serine protease inhibitor dipetalogastin [Crassostrea gigas] \\
\hline gi|405973349 & CD2-associated protein [Crassostrea gigas] \\
\hline gi|405973433 & Epoxide hydrolase 4 [Crassostrea gigas] \\
\hline gi|405973524 & Thrombospondin-3b [Crassostrea gigas] \\
\hline gi|405973546 & Sodium-driven chloride bicarbonate exchanger [Crassostrea gigas] \\
\hline gi|405973843 & DNA-binding protein P3A2 [Crassostrea gigas] \\
\hline gi|405973904 & Spermatogenesis-associated protein 6 [Crassostrea gigas] \\
\hline gi|405974017 & hypothetical protein CGI_10020808 [Crassostrea gigas] \\
\hline gi|405974166 & Titin [Crassostrea gigas] \\
\hline gi|405974308 & Protein deltex-3-like protein [Crassostrea gigas] \\
\hline gi|405974452 & Adenylate kinase isoenzyme 6 [Crassostrea gigas] \\
\hline gi|405974485 & $13 \mathrm{kDa}$ ribonucleoprotein-associated protein [Crassostrea gigas] \\
\hline gi|405974510 & hypothetical protein CGI_10002394 [Crassostrea gigas] \\
\hline gi|405974522 & E3 ubiquitin-protein ligase MIB2 [Crassostrea gigas] \\
\hline gi|405974531 & MRG-binding protein [Crassostrea gigas] \\
\hline gi|405974556 & Thioredoxin-like protein 1 [Crassostrea gigas] \\
\hline gi|405974768 & Survival motor neuron protein [Crassostrea gigas] \\
\hline gi|405975073 & GMP synthase [glutamine-hydrolyzing] [Crassostrea gigas] \\
\hline
\end{tabular}




\begin{tabular}{|c|c|}
\hline Accession & Name \\
\hline gi|405975437 & ARF GTPase-activating protein GIT2 [Crassostrea gigas] \\
\hline gi|405975468 & hypothetical protein CGI_10010027 [Crassostrea gigas] \\
\hline gi|405975638 & hypothetical protein CGI_10027837 [Crassostrea gigas] \\
\hline gi|405975656 & Calcium-binding protein p22 [Crassostrea gigas] \\
\hline gi|405975707 & hypothetical protein CGI_10015240 [Crassostrea gigas] \\
\hline gi|405975797 & NCK-interacting protein with $\mathrm{SH} 3$ domain [Crassostrea gigas] \\
\hline gi|405975901 & Uncharacterized protein C3orf32 [Crassostrea gigas] \\
\hline gi|405976018 & DnaJ-like protein subfamily $\mathrm{C}$ member 7 [Crassostrea gigas] \\
\hline gi|405976102 & Omega-crystallin [Crassostrea gigas] \\
\hline gi|405976227 & Annexin A6 [Crassostrea gigas] \\
\hline gi|405976256 & Ribonuclease H1 [Crassostrea gigas] \\
\hline gi|405976274 & hypothetical protein CGI_10021278 [Crassostrea gigas] \\
\hline gi|405976588 & Serine/threonine-protein kinase PAK 1 [Crassostrea gigas] \\
\hline gi|405976598 & hypothetical protein CGI_10026559 [Crassostrea gigas] \\
\hline gi|405976912 & Syntaxin [Crassostrea gigas] \\
\hline gi|405976919 & MORN repeat-containing protein 3 [Crassostrea gigas] \\
\hline gi|405976945 & hypothetical protein CGI_10017525 [Crassostrea gigas] \\
\hline gi|405977262 & hypothetical protein CGI_10028468 [Crassostrea gigas] \\
\hline gi|405977321 & hypothetical protein CGI_10021646 [Crassostrea gigas] \\
\hline gi|405977416 & U4/U6.U5 tri-snRNP-associated protein 1 [Crassostrea gigas] \\
\hline gi|405977517 & $40 S$ ribosomal protein S23 [Crassostrea gigas] \\
\hline gi|405977633 & 1,4-alpha-glucan-branching enzyme [Crassostrea gigas] \\
\hline gi|405977783 & hypothetical protein CGI_10028016 [Crassostrea gigas] \\
\hline gi|405977875 & hypothetical protein CGI_10024758 [Crassostrea gigas] \\
\hline gi|405977889 & Putative adenosylhomocysteinase 3 [Crassostrea gigas] \\
\hline gi|405977894 & Dynactin subunit 1 [Crassostrea gigas] \\
\hline gi|405978006 & hypothetical protein CGI_10016337 [Crassostrea gigas] \\
\hline gi|405978143 & hypothetical protein CGI_10023670 [Crassostrea gigas] \\
\hline gi|405978279 & AP-2 complex subunit sigma [Crassostrea gigas] \\
\hline gi|405978442 & hypothetical protein CGI_10010069 [Crassostrea gigas] \\
\hline gi|405978482 & Sushi domain-containing protein 2 [Crassostrea gigas] \\
\hline gi|405978602 & Calcium-binding protein NCS-1 [Crassostrea gigas] \\
\hline gi|405978625 & Metaxin-2 [Crassostrea gigas] \\
\hline gi|405978703 & Dynactin subunit 1 [Crassostrea gigas] \\
\hline gi|405978742 & $\mathrm{N}$-acetyltransferase 11 [Crassostrea gigas] \\
\hline gi|405978806 & Caspase-7 [Crassostrea gigas] \\
\hline gi|405978866 & Four and a half LIM domains protein 2 [Crassostrea gigas] \\
\hline gi|405978868 & Uncharacterized protein C1orf93-like protein [Crassostrea gigas] \\
\hline gi|68989137 & cytochrome c oxidase subunit II [Crassostrea virginica] \\
\hline gi|22090632 & Se-cadherin [Sexostrea echinata] \\
\hline gi|405969995 & Choline-phosphate cytidylyltransferase B [Crassostrea gigas] \\
\hline gi|405970769 & hypothetical protein CGI_10020336 [Crassostrea gigas] \\
\hline gi|405960755 & Ras-related protein Rab-11A [Crassostrea gigas] \\
\hline gi|405975372 & hypothetical protein CGI_10026945 [Crassostrea gigas] \\
\hline gi|29134776 & galectin-4 (lectin, galactoside-binding, soluble 4) [Crassostrea gigas] \\
\hline gi|405951379 & Amidase [Crassostrea gigas] \\
\hline
\end{tabular}




\begin{tabular}{|c|c|}
\hline Accession & Name \\
\hline gi|405958253 & hypothetical protein CGI_10014044 [Crassostrea gigas] \\
\hline gi|405969739 & Tankyrase-1 [Crassostrea gigas] \\
\hline gi|71040623 & ribosomal protein S27 [Crassostrea gigas] \\
\hline gi|405959472 & AFG3-like protein 2 [Crassostrea gigas] \\
\hline gi|405964692 & Alpha-N-acetylglucosaminidase [Crassostrea gigas] \\
\hline gi|405955461 & hypothetical protein CGI_10002011 [Crassostrea gigas] \\
\hline gi|405971580 & Transcription elongation factor B polypeptide 1 [Crassostrea gigas] \\
\hline gi|13194854 & metallothionein [Crassostrea angulata] \\
\hline gi|405960075 & Legumain [Crassostrea gigas] \\
\hline gi|405960921 & hypothetical protein CGI_10013223 [Crassostrea gigas] \\
\hline gi|405963289 & $\begin{array}{l}\text { Electron transfer flavoprotein-ubiquinone oxidoreductase, mitochondrial [Crassostrea } \\
\text { gigas] }\end{array}$ \\
\hline gi|405964820 & ERO1-like protein beta [Crassostrea gigas] \\
\hline gi|405966302 & Heterogeneous nuclear ribonucleoprotein C [Crassostrea gigas] \\
\hline gi|405972911 & Latrophilin-1 [Crassostrea gigas] \\
\hline gi|405975332 & $60 S$ ribosomal protein L15 [Crassostrea gigas] \\
\hline gi|405950078 & Nucleoprotein TPR [Crassostrea gigas] \\
\hline gi|405957146 & Splicing factor, proline- and glutamine-rich [Crassostrea gigas] \\
\hline gi|405975593 & hypothetical protein CGI_10027787 [Crassostrea gigas] \\
\hline gi|296524486 & unnamed protein product [Crassostrea gigas] \\
\hline gi|405957467 & Laminin subunit alpha-3 [Crassostrea gigas] \\
\hline gi|405960954 & hypothetical protein CGI_10013860 [Crassostrea gigas] \\
\hline gi|405977536 & Protein Dr1 [Crassostrea gigas] \\
\hline gi|405952800 & hypothetical protein CGI_10005804 [Crassostrea gigas] \\
\hline gi|405953897 & Guanine nucleotide-binding protein subunit gamma-e [Crassostrea gigas] \\
\hline gi|405972495 & Aldehyde dehydrogenase family 3 member B1 [Crassostrea gigas] \\
\hline gi|405965222 & Centrosome and spindle pole-associated protein 1 [Crassostrea gigas] \\
\hline gi|405961376 & hypothetical protein CGI_10015417 [Crassostrea gigas] \\
\hline gi|405969597 & Dipeptidyl peptidase family member 6 [Crassostrea gigas] \\
\hline gi|405967048 & Scaffold attachment factor B1 [Crassostrea gigas] \\
\hline gi|405975566 & $60 S$ ribosomal protein L36 [Crassostrea gigas] \\
\hline gi|405954502 & Splicing factor, arginine/serine-rich 6 [Crassostrea gigas] \\
\hline gi|405967707 & Transcriptional enhancer factor TEF-1 [Crassostrea gigas] \\
\hline gi|405952357 & Protein daughter of sevenless [Crassostrea gigas] \\
\hline gi|405957329 & hypothetical protein CGI_10005495 [Crassostrea gigas] \\
\hline gi|405959795 & A-kinase anchor protein 9 [Crassostrea gigas] \\
\hline gi|405965290 & hypothetical protein CGI_10002265 [Crassostrea gigas] \\
\hline gi|405953035 & Cysteine-rich protein 1 [Crassostrea gigas] \\
\hline gi|405975724 & hypothetical protein CGI_10023706 [Crassostrea gigas] \\
\hline gi|405976693 & Coiled-coil and C2 domain-containing protein 1-like protein [Crassostrea gigas] \\
\hline gi|405965333 & Deoxyuridine 5'-triphosphate nucleotidohydrolase, mitochondrial [Crassostrea gigas] \\
\hline gi|405977713 & Regulation of nuclear pre-mRNA domain-containing protein 1B [Crassostrea gigas] \\
\hline gi|405974916 & hypothetical protein CGI_10027938 [Crassostrea gigas] \\
\hline gi|405970006 & hypothetical protein CGI_10016230 [Crassostrea gigas] \\
\hline gi|405961287 & Collagen alpha- $5(\mathrm{VI})$ chain [Crassostrea gigas] \\
\hline gi|405950782 & Golgin subfamily A member 5 [Crassostrea gigas] \\
\hline gi|405977511 & hypothetical protein CGI_10028134 [Crassostrea gigas] \\
\hline
\end{tabular}




\begin{tabular}{|l|l|}
\hline \multicolumn{1}{|c|}{ Accession } & \multicolumn{1}{c|}{ Name } \\
\hline gi|405963046 & Myomodulin neuropeptide 2 [Crassostrea gigas] \\
\hline gi|405950030 & Stress-70 protein, mitochondrial [Crassostrea gigas] \\
\hline gi|405966858 & 3-hydroxyacyl-CoA dehydrogenase type-2 [Crassostrea gigas] \\
\hline gi|405969341 & Glycyl-tRNA synthetase [Crassostrea gigas] \\
\hline gi|405970197 & Dysbindin [Crassostrea gigas] \\
\hline gi|405950484 & hypothetical protein CGI_10012368 [Crassostrea gigas] \\
\hline gi|405963231 & hypothetical protein CGI_10019048 [Crassostrea gigas] \\
\hline
\end{tabular}


Supplementary Table S4: Pacific oyster proteins with fold change values.

\begin{tabular}{|c|c|c|c|}
\hline Accession & Name & Geomean & $\begin{array}{l}\text { Stouffers } \\
P \text { value }\end{array}$ \\
\hline gi|405973078 & EF-hand calcium-binding domain-containing protein 6 & 1.2 & 0.4532 \\
\hline gi|405969360 & Hypothetical protein CGI_10023442 & 1.2 & 0.0001 \\
\hline gi|405958006 & Hypothetical protein CGI_10007020 & 1.2 & 0.0036 \\
\hline gi|405959274 & Hypothetical protein CGI_10015606 & 1.2 & 0.6438 \\
\hline gi|405963257 & Protein LZIC & 1.2 & 0.2970 \\
\hline gi|405968071 & U6 snRNA-associated Sm-like protein Ism7, partial & 1.2 & \\
\hline gi|405958298 & Centrin-1 & 1.2 & 0.3072 \\
\hline gi|405967992 & Hypothetical protein CGI_10024002 & 1.2 & 0.1413 \\
\hline gi|405965699 & Hypothetical protein CGI_10020257 & 1.2 & 0.0194 \\
\hline gi|405974007 & Protein FAM21A & 1.2 & \\
\hline gi|405977361 & Hypothetical protein CGI_10026436 & 1.2 & 0.0305 \\
\hline gi|405974732 & Hypothetical protein CGI_10018996 & 1.2 & 0.0981 \\
\hline gi|405955681 & Elongation factor 1-beta & 1.2 & 0.4939 \\
\hline gi|58219308 & Small cardioactive peptide precursor & 1.2 & 0.0843 \\
\hline gi|405968619 & $40 \mathrm{kDa}$ peptidyl-prolyl cis-trans isomerase & 1.2 & 0.2453 \\
\hline gi|405970262 & DNAj-like protein subfamily B member 4 & 1.2 & 0.3592 \\
\hline gi|405968923 & LDLR chaperone MESD & 1.2 & 0.1430 \\
\hline gi|405951359 & Leucine-rich repeat flightless-interacting protein 2 & 1.2 & 0.0216 \\
\hline gi|405962553 & Hypothetical protein CGI_10009086 & 1.2 & 0.1478 \\
\hline gi|405952131 & SH3 domain-binding glutamic acid-rich-like protein 3 & 1.2 & 0.0384 \\
\hline gi|405950946 & Phospholipase A2 inhibitor subunit B & 1.2 & \\
\hline gi|405957739 & Hypothetical protein CGI_10004557 & 1.2 & 0.6588 \\
\hline gi|405952424 & Tubulin-folding cofactor B & 1.2 & 0.2307 \\
\hline gi|405964511 & $\begin{array}{l}\text { Ras-associated and pleckstrin-like protein domains-containing } \\
\text { protein } 1\end{array}$ & 1.2 & \\
\hline gi|405952111 & Transcription factor E2F5 & 1.2 & 0.3309 \\
\hline gi|405962871 & Metallothionein & 1.2 & 0.0827 \\
\hline gi|405972892 & Protein SPATIAL & 1.2 & 0.0000 \\
\hline gi|405969487 & Protein phosphatase inhibitor 2 & 1.2 & 0.0395 \\
\hline gi|405953933 & Tetratricopeptide repeat protein 29 & 1.2 & 0.2394 \\
\hline gi|405967567 & Hypothetical protein CGI_10024094 & 1.2 & \\
\hline gi|405958762 & Transcription factor SOX-2 & 1.2 & 0.1119 \\
\hline gi|405968719 & Hypothetical protein CGI_10023299 & 1.2 & 0.2162 \\
\hline gi|405974545 & Collagen alpha- $1(\mathrm{IX})$ chain & 1.2 & 0.1843 \\
\hline gi|405965618 & Hypothetical protein CGI_10024978 & 1.2 & 0.0007 \\
\hline gi|405958465 & Calmodulin & 1.2 & 0.5047 \\
\hline gi|405974579 & Splicing factor 1 & 1.2 & 0.7105 \\
\hline gi|405971954 & Hypothetical protein CGI_10014227 & 1.2 & 0.0783 \\
\hline gi|405975636 & Tektin-1 & 1.2 & 0.0000 \\
\hline gi|405952176 & Hypothetical protein CGI_10007080 & 1.2 & 0.4197 \\
\hline gi|405951043 & Serine protease inhibitor dipetalogastin & 1.2 & \\
\hline gi|405959111 & WW domain-binding protein 4 , partial & 1.2 & 0.1321 \\
\hline gi|405952165 & Hypothetical protein CGI_10007068 & 1.2 & 0.1690 \\
\hline gi|405965899 & Pleckstrin-like protein domain-containing family A member 7 & 1.2 & \\
\hline
\end{tabular}




\begin{tabular}{|c|c|c|c|}
\hline Accession & Name & Geomean & $\begin{array}{c}\text { Stouffers } \\
P \text { value }\end{array}$ \\
\hline gi|405960206 & Frizzled-7 & 1.2 & \\
\hline gi|405958608 & Transmembrane BAX inhibitor motif-containing protein 4 & 1.2 & \\
\hline gi|405964918 & WW domain-binding protein 11 & 1.2 & 0.0506 \\
\hline gi|405975243 & Protein unc-87 & 1.2 & 0.5019 \\
\hline gi|405958828 & BTB/POZ domain-containing protein 9 & 1.2 & \\
\hline gi|405965351 & Uncharacterized protein c2orf77 & 1.2 & \\
\hline gi|405975171 & Crumbs-like protein 2 & 1.2 & \\
\hline gi|405967124 & Sjoegren syndrome/scleroderma autoantigen 1 & 1.2 & 0.0263 \\
\hline gi|405953897 & Guanine nucleotide-binding protein subunit gamma-e & 1.2 & 0.3306 \\
\hline gi|405960879 & Hypothetical protein CGI_10028292 & 1.2 & 0.0698 \\
\hline gi|405967541 & LIM and SH3 domain protein LASP & 1.2 & 0.0004 \\
\hline gi|405969168 & Hypothetical protein CGI_10007637 & 1.2 & 0.1780 \\
\hline gi|405957445 & Tyrosine-protein phosphatase non-receptor type 6 & 1.2 & 0.0042 \\
\hline gi|405971676 & Tumor necrosis factor, alpha-induced protein 8 & 1.2 & 0.3928 \\
\hline gi|405965271 & Caspase-2 & 1.2 & 0.0277 \\
\hline gi|405953565 & HD domain-containing protein 3 & 1.2 & \\
\hline gi|405950455 & Sperm-associated antigen 7 -like protein & 1.2 & \\
\hline gi|405973802 & Peptidyl-prolyl cis-trans isomerase NIMA-interacting 4 & 1.2 & 0.4314 \\
\hline gi|405956544 & Small ubiquitin-related modifier 3 & 1.2 & 0.0178 \\
\hline gi|405960600 & Vasodilator-stimulated phosphoprotein & 1.2 & 0.5675 \\
\hline gi|405962619 & Hsp90 co-chaperone Cdc37 & 1.2 & 0.3249 \\
\hline gi|405973349 & CD2-associated protein & 1.2 & \\
\hline gi|405957375 & Hypothetical protein CGI_10009294 & 1.2 & \\
\hline gi|405951437 & Hypothetical protein CGI_10008571 & 1.2 & 0.0402 \\
\hline gi|405968662 & Hypothetical protein CGI_10020740 & 1.2 & \\
\hline gi|405968984 & Fatty acid-binding protein, heart & 1.2 & 0.2777 \\
\hline gi|405978104 & Afadin & 1.2 & 0.3717 \\
\hline gi|405967363 & $\begin{array}{l}\text { Putative NADH dehydrogenase [ubiquinone] } 1 \text { alpha } \\
\text { subcomplex subunit } 12\end{array}$ & 1.2 & 0.0232 \\
\hline gi|405953483 & Sarcoplasmic calcium-binding protein & 1.2 & 0.0780 \\
\hline gi|405973406 & SAP domain-containing ribonucleoprotein & 1.2 & 0.0078 \\
\hline gi|405951312 & UPF0638 protein B & 1.2 & \\
\hline gi|405962502 & Hypothetical protein CGI_10014339 & 1.2 & 0.1624 \\
\hline gi|405958997 & Charged multivesicular body protein 3 & 1.2 & 0.2295 \\
\hline gi|405978043 & $\begin{array}{l}\text { Sushi, von Willebrand factor type A, EGF and pentraxin } \\
\text { domain-containing protein } 1\end{array}$ & 1.2 & \\
\hline gi|405955782 & Coiled-coil domain-containing protein 12 & 1.2 & 0.2999 \\
\hline gi|405966054 & AP-3 complex subunit beta- 2 & 1.2 & \\
\hline gi|405973281 & Drebrin-like protein & 1.2 & 0.0743 \\
\hline gi|405972391 & Nuclear pore glycoprotein $p 62$ & 1.3 & 0.0020 \\
\hline gi|48476119 & Fatty acid binding protein & 1.3 & 0.0090 \\
\hline gi|405960640 & Cysteine-rich with EGF-like domain protein 2 & 1.3 & \\
\hline gi|405951087 & $\begin{array}{l}\text { Small glutamine-rich tetratricopeptide repeat-containing protein } \\
\text { beta }\end{array}$ & 1.3 & 0.0007 \\
\hline gi|405973812 & Coiled-coil domain-containing protein 19, mitochondrial & 1.3 & 0.0014 \\
\hline gi|405975181 & S-crystallin SL11 & 1.3 & 0.0000 \\
\hline gi|405960263 & Mediator of RNA polymerase II transcription subunit 10 & 1.3 & \\
\hline
\end{tabular}




\begin{tabular}{|c|c|c|c|}
\hline Accession & Name & Geomean & $\begin{array}{c}\text { Stouffers } \\
\text { P value }\end{array}$ \\
\hline gi|40642994 & Myosin essential light chain & 1.3 & 0.0136 \\
\hline gi|405957584 & Hypothetical protein CGI_10013948 & 1.3 & 0.0002 \\
\hline gi|405978198 & Canopy-like protein 2 & 1.3 & 0.2984 \\
\hline gi|405976502 & Uncharacterized protein c17orf98 & 1.3 & 0.0384 \\
\hline gi|405968273 & Blastula protease 10 & 1.3 & 0.1437 \\
\hline gi|405962626 & Serine-threonine kinase receptor-associated protein & 1.3 & 0.0160 \\
\hline gi|405971647 & Hypothetical protein CGI_10027007 & 1.3 & 0.0148 \\
\hline gi|405958005 & Hypothetical protein CGI_10007019 & 1.3 & \\
\hline gi|405963883 & Hypothetical protein CGI_10023805 & 1.3 & 0.0467 \\
\hline gi|405959794 & Leucine-zipper-like transcriptional regulator 1 & 1.3 & 0.1776 \\
\hline gi|405972180 & Tetratricopeptide repeat protein 25 & 1.3 & 0.0006 \\
\hline gi|405978588 & Hypothetical protein CGI_10023566 & 1.3 & 0.0089 \\
\hline gi|405963560 & Sarcoplasmic calcium-binding protein & 1.3 & 0.0786 \\
\hline gi|405959327 & Hypothetical protein CGI_10005346 & 1.3 & 0.0574 \\
\hline gi|405977511 & Hypothetical protein CGI_10028134 & 1.3 & 0.2307 \\
\hline gi|405961165 & $26 \mathrm{~S}$ proteasome non-ATPase regulatory subunit 11 & 1.3 & \\
\hline gi|405977606 & Astacin & 1.3 & 0.1926 \\
\hline gi|405955147 & Plasminogen & 1.3 & 0.0059 \\
\hline gi|405962751 & RNA-binding protein $8 \mathrm{~A}$ & 1.3 & 0.1580 \\
\hline gi|405978866 & Four and a half LIM domains protein 2 & 1.3 & \\
\hline gi|405977916 & UPF0556 protein c19orf10-like protein & 1.3 & 0.2907 \\
\hline gi|405950871 & Hypothetical protein CGI_10010860 & 1.3 & 0.1289 \\
\hline gi|405960153 & Neural/ectodermal development factor IMP-L2 & 1.3 & 0.0576 \\
\hline gi|405965635 & Coiled-coil domain-containing protein 40 & 1.3 & \\
\hline gi|405970545 & Hypothetical protein CGI_10022572 & 1.3 & 0.6108 \\
\hline gi|405970946 & Fatty acid-binding protein, brain & 1.3 & 0.2157 \\
\hline gi|405977975 & Synapse-associated protein 1 & 1.3 & 0.0074 \\
\hline gi|353191 & Myosin, regulatory la & 1.3 & 0.3961 \\
\hline gi|405965909 & Prohormone-4 & 1.3 & 0.0001 \\
\hline gi|405970837 & Uncharacterized protein c7orf57-like protein & 1.3 & 0.0444 \\
\hline gi|405957423 & Transcription elongation regulator 1 & 1.3 & 0.0000 \\
\hline gi|405968105 & Receptor-type tyrosine-protein phosphatase $\mathrm{T}$ & 1.3 & 0.2063 \\
\hline gi|405955398 & Proline-rich protein PRCC & 1.3 & \\
\hline gi|405970386 & Hypothetical protein CGI_10017976 & 1.3 & 0.0576 \\
\hline gi|405961983 & Splicing factor 3B subunit 4 & 1.3 & \\
\hline gi|405970741 & Translocon-associated protein subunit delta & 1.3 & \\
\hline gi|405962196 & ADAM family mig-17 & 1.3 & 0.2656 \\
\hline gi|22090632 & Se-cadherin [Sexostrea echinata] & 1.3 & \\
\hline gi|405970733 & Lysosome-associated membrane glycoprotein 1 & 1.3 & 0.1723 \\
\hline gi|405971250 & Glucosidase 2 subunit beta & 1.3 & 0.0004 \\
\hline gi|405969368 & Tetratricopeptide repeat protein 19 & 1.3 & \\
\hline gi|405975577 & Fibrillin-1 & 1.3 & 0.0493 \\
\hline gi|405953094 & Eukaryotic translation initiation factor 3 subunit $\mathrm{J}$ & 1.3 & 0.0667 \\
\hline gi|405978332 & Golgi membrane protein 1 & 1.3 & \\
\hline gi|405975553 & Putative ferric-chelate reductase 1 & 1.3 & 0.3122 \\
\hline gi|405966927 & Cytochrome P450 3A29 & 1.3 & 0.0290 \\
\hline
\end{tabular}




\begin{tabular}{|c|c|c|c|}
\hline Accession & Name & Geomean & $\begin{array}{c}\text { Stouffers } \\
\text { P value }\end{array}$ \\
\hline gi|405966811 & Intraflagellar transport protein 74-like protein & 1.3 & 0.0057 \\
\hline gi|405969503 & Hypothetical protein CGI_10015394 & 1.3 & 0.4036 \\
\hline gi|405960769 & Lysyl oxidase-like protein 2 & 1.3 & 0.2132 \\
\hline gi|405978738 & Hypothetical protein CGI_10022305 & 1.3 & 0.2138 \\
\hline gi|405977399 & Metallothionein & 1.3 & 0.1332 \\
\hline gi|405969789 & Hypothetical protein CGI_10021722 & 1.3 & \\
\hline gi|405976897 & LSM14-like protein A & 1.3 & 0.0033 \\
\hline gi|405965308 & Troponin T, skeletal muscle & 1.3 & 0.0176 \\
\hline gi|405969739 & Tankyrase-1 & 1.3 & \\
\hline gi|405953722 & Calmodulin-like protein 12 & 1.3 & 0.0149 \\
\hline gi|405962468 & Calmodulin-like protein 3 & 1.3 & 0.3286 \\
\hline gi|405958778 & Hypothetical protein CGI_10021467 & 1.3 & 0.7819 \\
\hline gi|405966001 & Non-specific lipid-transfer protein & 1.3 & 0.0020 \\
\hline gi|405959472 & AFG3-like protein 2 & 1.3 & \\
\hline gi|405968529 & Hypothetical protein CGI_10017745 & 1.3 & 0.0053 \\
\hline gi|405978272 & Calmodulin & 1.3 & 0.0004 \\
\hline gi|405975550 & Eukaryotic translation initiation factor $1 \mathrm{~A}, \mathrm{X}$-chromosomal & 1.3 & 0.3250 \\
\hline gi|405970197 & Dysbindin & 1.3 & 0.0997 \\
\hline gi|405973524 & Thrombospondin-3b & 1.3 & \\
\hline gi|405964593 & Hypothetical protein CGI_10018739 & 1.4 & 0.0021 \\
\hline gi|405970776 & Troponin C & 1.4 & 0.0131 \\
\hline gi|405969229 & NSFL1 cofactor $p 47$ & 1.4 & 0.0041 \\
\hline gi|405968925 & Hypothetical protein CGI_10004918 & 1.4 & \\
\hline gi|405959994 & TP53-regulated inhibitor of apoptosis 1 & 1.4 & 0.0037 \\
\hline gi|405963180 & Protein SET & 1.4 & 0.0140 \\
\hline gi|405965328 & Deoxyuridine 5'-triphosphate nucleotidohydrolase & 1.4 & 0.1070 \\
\hline gi|405960921 & Hypothetical protein CGI_10013223 & 1.4 & \\
\hline gi|405972179 & Hypothetical protein CGI_10023112 & 1.4 & \\
\hline gi|405958084 & Calmodulin & 1.4 & 0.1367 \\
\hline gi|405954690 & Hsc70-interacting protein & 1.4 & 0.0000 \\
\hline gi|405972528 & Hypothetical protein CGI_10020633 & 1.4 & \\
\hline gi|405971784 & Hypothetical protein CGI_10018185 & 1.4 & 0.1715 \\
\hline gi|405955246 & Hypothetical protein CGI_10002291 & 1.4 & 0.0901 \\
\hline gi|405959131 & Uncharacterized protein c5orf48-like protein & 1.4 & 0.0071 \\
\hline gi|405972975 & Deleted in malignant brain tumors 1 protein & 1.4 & 0.1003 \\
\hline gi|405952353 & Calumenin-B & 1.4 & 0.0001 \\
\hline gi|405977780 & Calmodulin & 1.4 & \\
\hline gi|405965382 & Soma ferritin & 1.4 & 0.0070 \\
\hline gi|405978177 & Polyadenylate-binding protein 2 & 1.4 & 0.0147 \\
\hline gi|405970440 & BAG family molecular chaperone regulator 1 & 1.4 & \\
\hline gi|405957935 & Hypothetical protein CGI_10016657 & 1.4 & \\
\hline gi|405951401 & Prefoldin subunit 1 & 1.4 & \\
\hline gi|405973521 & Death-associated protein 1 & 1.4 & 0.0618 \\
\hline gi|405959947 & Calmodulin & 1.4 & 0.0571 \\
\hline gi|405952370 & Hypothetical protein CGI_10006610 & 1.4 & 0.0000 \\
\hline
\end{tabular}




\begin{tabular}{|c|c|c|c|}
\hline Accession & Name & Geomean & $\begin{array}{l}\text { Stouffers } \\
\text { P value }\end{array}$ \\
\hline gi|405969710 & $\begin{array}{l}\text { NADH dehydrogenase [ubiquinone] flavoprotein 3, } \\
\text { mitochondrial }\end{array}$ & 1.4 & 0.0745 \\
\hline gi|405960503 & Peroxisomal biogenesis factor 19 & 1.4 & 0.0125 \\
\hline gi|405976121 & WD repeat-containing protein c2orf44-like protein & 1.4 & 0.1562 \\
\hline gi|405957059 & Caprin-1 & 1.4 & 0.3680 \\
\hline gi|405973684 & Calcium-regulated heat stable protein 1 & 1.4 & 0.5222 \\
\hline gi|405971204 & E3 ubiquitin-protein ligase HECTD1 & 1.4 & \\
\hline gi|405978649 & Laminin-like protein epi-1 & 1.4 & 0.0000 \\
\hline gi|405973965 & Hypothetical protein CGI_10016182 & 1.4 & 0.1026 \\
\hline gi|148717307 & Calreticulin & 1.4 & 0.0000 \\
\hline gi|405965406 & Aldehyde dehydrogenase & 1.4 & \\
\hline gi|405959948 & Hypothetical protein CGI_10013422 & 1.5 & 0.2817 \\
\hline gi|405957913 & Calmodulin-like protein 12 & 1.5 & 0.0091 \\
\hline gi|405968717 & Programmed cell death protein 6 & 1.5 & 0.0244 \\
\hline gi|405964391 & Calmodulin & 1.5 & \\
\hline gi|405967012 & Hypothetical protein CGI_10026212 & 1.5 & \\
\hline gi|405978204 & Tubulin-specific chaperone A & 1.5 & 0.1713 \\
\hline gi|405952922 & Calmodulin-5/6/7/8 & 1.5 & 0.0095 \\
\hline gi|405975575 & Calmodulin & 1.5 & 0.0057 \\
\hline gi|405952740 & Latrophilin-3 & 1.5 & 0.3069 \\
\hline gi|405977513 & High mobility group protein B3 & 1.5 & 0.0002 \\
\hline gi|405951638 & Coiled-coil domain-containing protein 43 & 1.5 & 0.3364 \\
\hline gi|405968720 & Hypothetical protein CGI_10023300 & 1.5 & 0.0001 \\
\hline gi|385843206 & Ubiquitin/ribosomal protein S27 precursor & 1.5 & 0.0090 \\
\hline gi|405963558 & Sarcoplasmic calcium-binding protein & 1.5 & 0.0000 \\
\hline gi|405975466 & Hypothetical protein CGI_10010025 & 1.5 & 0.0011 \\
\hline gi|405977042 & Elongation factor 1-beta & 1.5 & 0.0000 \\
\hline gi|405976084 & Tubulin polymerization-promoting protein family member 3 & 1.5 & 0.0007 \\
\hline gi|405973827 & Cytochrome c & 1.5 & 0.0001 \\
\hline gi|405951402 & $\begin{array}{l}\text { KH domain-containing, RNA-binding, signal transduction- } \\
\text { associated protein } 2\end{array}$ & 1.6 & 0.0001 \\
\hline gi|405974452 & Adenylate kinase isoenzyme 6 & 1.6 & \\
\hline gi|405957087 & Calumenin & 1.6 & 0.0000 \\
\hline gi|405965135 & Hypothetical protein CGI_10012662 & 1.6 & 0.0709 \\
\hline gi|405976946 & Hypothetical protein CGI_10017526 & 1.6 & 0.0158 \\
\hline gi|405969780 & Far upstream element-binding protein 3 & 1.6 & 0.0000 \\
\hline gi|405958088 & Calmodulin & 1.6 & 0.0006 \\
\hline gi|405955680 & Nucleobindin-2 & 1.6 & 0.0156 \\
\hline gi|405972759 & Hypothetical protein CGI_10018124 & 1.7 & \\
\hline gi|405975467 & Hypothetical protein CGI_10010026 & 1.7 & 0.2697 \\
\hline gi|405960639 & Deoxyuridine 5'-triphosphate nucleotidohydrolase & 1.7 & 0.0428 \\
\hline gi|405946277 & Hypothetical protein CGI_10000492 & 1.7 & 0.2095 \\
\hline gi|405970177 & Eukaryotic translation initiation factor $4 \mathrm{~B}$ & 1.7 & 0.0000 \\
\hline gi|405968888 & BET1-like protein & 1.7 & \\
\hline gi|405975921 & Clathrin light chain $A$ & 1.7 & 0.0020 \\
\hline gi|405958383 & Hypothetical protein CGI_10007870 & 1.8 & 0.0035 \\
\hline gi|405969535 & Hypothetical protein CGI_10016269 & 1.8 & 0.3226 \\
\hline
\end{tabular}




\begin{tabular}{|c|c|c|c|}
\hline Accession & Name & Geomean & $\begin{array}{l}\text { Stouffers } \\
\text { P value }\end{array}$ \\
\hline gi|405957603 & Dysferlin-interacting protein 1 & 1.8 & \\
\hline gi|405958091 & Hypothetical protein CGI_10002445 & 1.9 & \\
\hline gi|405956668 & LSM domain-containing protein 1 & 1.9 & \\
\hline gi|405978742 & $\mathrm{N}$-acetyltransferase 11 & 2.0 & \\
\hline gi|405969759 & Vacuolar protein sorting-associated protein $13 \mathrm{C}$ & 2.0 & \\
\hline gi|405978518 & Plasminogen activator inhibitor 1 RNA-binding protein & 2.2 & 0.0000 \\
\hline gi|405974686 & Hypothetical protein CGI_10024481 & 6.2 & 0.3448 \\
\hline gi|405977783 & Hypothetical protein CGI_10028016 & 0.4 & \\
\hline gi|405952065 & Hypothetical protein CGI_10007261 & 0.5 & \\
\hline gi|405976102 & Omega-crystallin & 0.5 & \\
\hline gi|405960078 & Hypothetical protein CGI_10010679 & 0.5 & 0.0092 \\
\hline gi|405960444 & AP-3 complex subunit delta- 1 & 0.5 & \\
\hline gi|405952183 & Serine/threonine-protein kinase 3 & 0.6 & \\
\hline gi|405951710 & Protein argonaute-2 & 0.6 & \\
\hline gi|405951433 & Tubulin beta chain & 0.6 & \\
\hline gi|405950782 & Golgin subfamily A member 5 & 0.6 & \\
\hline gi|405963599 & Endonuclease VIII-like 1 & 0.6 & \\
\hline gi|405969198 & Tyrosine-protein kinase Yes, partial & 0.6 & \\
\hline gi|405956722 & Putative ATP-dependent RNA helicase DDX58 & 0.6 & \\
\hline gi|405954012 & Thioredoxin & 0.6 & 0.4928 \\
\hline gi|405957910 & FMRFamide neuropeptide & 0.6 & 0.3243 \\
\hline gi|405962092 & Protein disabled & 0.6 & \\
\hline gi|405969643 & Hypothetical protein CGI_10012952 & 0.6 & \\
\hline gi|405956360 & Multidrug resistance protein 1 , partial & 0.6 & \\
\hline gi|405957477 & Putative thiopurine S-methyltransferase & 0.6 & \\
\hline gi|405959119 & $60 S$ ribosomal protein $\mathrm{L} 3$, partial & 0.6 & 0.3909 \\
\hline gi|405969117 & Dynein heavy chain 7 , axonemal & 0.6 & 0.1315 \\
\hline gi|405970293 & Neuronal acetylcholine receptor subunit non-alpha- 2 & 0.6 & 0.0649 \\
\hline gi|405973130 & UDP-glucose:glycoprotein glucosyltransferase 1 & 0.6 & \\
\hline gi|405978806 & Caspase-7 & 0.7 & \\
\hline gi|405971116 & Hydroxyacylglutathione hydrolase, mitochondrial & 0.7 & \\
\hline gi|405978371 & Leucine-rich repeat-containing protein 51 , partial & 0.7 & \\
\hline gi|405966302 & Heterogeneous nuclear ribonucleoprotein C & 0.7 & \\
\hline gi|405965638 & Tubulin alpha-1C chain & 0.7 & \\
\hline gi|405975073 & GMP synthase [glutamine-hydrolyzing] & 0.7 & \\
\hline gi|405972926 & Peroxiredoxin-4 & 0.7 & \\
\hline gi|405962986 & Hypothetical protein CGI_10003439 & 0.7 & \\
\hline gi|405965431 & Fatty acyl-CoA hydrolase precursor, medium chain & 0.7 & \\
\hline gi|405964596 & Hypothetical protein CGI_10018742 & 0.7 & \\
\hline gi|405972696 & Hypothetical protein CGI_10011429 & 0.7 & \\
\hline gi|405970915 & $\begin{array}{l}\text { Serine/threonine-protein phosphatase } 2 \mathrm{~A} 55 \mathrm{kDa} \text { regulatory } \\
\text { subunit B alpha isoform }\end{array}$ & 0.7 & \\
\hline gi|2833326 & Recname: Full=Actin, adductor muscle & 0.7 & 0.2013 \\
\hline gi|405960911 & Ninjurin-1 & 0.7 & \\
\hline gi|405961952 & Importin subunit alpha-2 & 0.7 & \\
\hline gi|405965044 & Neutral and basic amino acid transport protein RBAT & 0.7 & \\
\hline
\end{tabular}




\begin{tabular}{|c|c|c|c|}
\hline Accession & Name & Geomean & $\begin{array}{l}\text { Stouffers } \\
\text { P value }\end{array}$ \\
\hline gi|405971541 & 4-coumarate--CoA ligase 1 & 0.7 & \\
\hline gi|405955166 & Hypothetical protein CGI_10002360 & 0.7 & \\
\hline gi|405973425 & Dynein intermediate chain 3 , ciliary & 0.7 & \\
\hline gi|405953996 & Hypothetical protein CGI_10003795 & 0.7 & 0.1677 \\
\hline gi|405971953 & Hypothetical protein CGI_10014226 & 0.7 & \\
\hline gi|405968884 & Epithelial splicing regulatory protein 2 & 0.7 & \\
\hline gi|405964580 & Actin, cytoplasmic & 0.7 & \\
\hline gi|405966618 & Carbonic anhydrase 2 & 0.7 & 0.0958 \\
\hline gi|405958743 & Prostaglandin reductase 1 & 0.7 & \\
\hline gi|405951379 & Amidase & 0.7 & \\
\hline gi|405973433 & Epoxide hydrolase 4 & 0.7 & \\
\hline gi|405975332 & $60 S$ ribosomal protein $L 15$ & 0.7 & \\
\hline gi|405950556 & Copine-7 & 0.7 & 0.1801 \\
\hline gi|405966783 & Myosin-11 & 0.7 & \\
\hline gi|405978774 & Hypothetical protein CGI_10012934, partial & 0.7 & \\
\hline gi|405975257 & T-complex-associated testis-expressed protein 1 & 0.7 & \\
\hline gi|405972803 & Radial spoke head protein 4-like protein A & 0.7 & 0.0004 \\
\hline gi|405973865 & Actin-1/3 & 0.7 & 0.0224 \\
\hline gi|405978703 & Dynactin subunit 1 & 0.7 & \\
\hline gi|405963300 & $\begin{array}{l}\text { Serine/threonine-protein phosphatase 2A } 56 \mathrm{kDa} \text { regulatory } \\
\text { subunit delta isoform }\end{array}$ & 0.7 & \\
\hline gi|405952433 & Sodium- and chloride-dependent GABA transporter INE & 0.7 & 0.1237 \\
\hline gi|405971621 & Selenium-binding protein 1 , partial & 0.7 & 0.0166 \\
\hline gi|405974066 & Eukaryotic translation initiation factor $4 \mathrm{E}$-binding protein 1 & 0.7 & 0.1116 \\
\hline gi|405976463 & Transketolase-like protein 2 & 0.7 & 0.0015 \\
\hline gi|405960423 & Cadherin-23 & 0.7 & \\
\hline gi|405972486 & Putative malate dehydrogenase $1 \mathrm{~B}$ & 0.7 & \\
\hline gi|405964311 & Ankyrin repeat domain-containing protein 29 , partial & 0.7 & \\
\hline gi|405966284 & Upstream activation factor subunit spp27 & 0.7 & 0.1182 \\
\hline gi|405969083 & Hypothetical protein CGI_10018964 & 0.7 & \\
\hline gi|405963205 & Heat shock $70 \mathrm{kDa}$ protein $12 \mathrm{~A}$ & 0.8 & \\
\hline gi|405955982 & Kyphoscoliosis peptidase & 0.8 & 0.0000 \\
\hline gi|405964054 & $\mathrm{NADH}$-cytochrome b5 reductase 2 & 0.8 & 0.4340 \\
\hline gi|405963691 & Cofilin & 0.8 & 0.0263 \\
\hline gi|405971245 & Eukaryotic translation initiation factor 3 subunit $D$ & 0.8 & \\
\hline gi|405965289 & Adenine phosphoribosyltransferase & 0.8 & \\
\hline gi|405975727 & L-rhamnose-binding lectin CSL3, partial & 0.8 & 0.3835 \\
\hline gi|405964567 & Tubulin beta chain & 0.8 & 0.0003 \\
\hline gi|405961313 & Actin Cyl, cytoplasmic & 0.8 & 0.1776 \\
\hline gi|405971057 & Actin-related protein $2 / 3$ complex subunit 3 & 0.8 & 0.0037 \\
\hline gi|405965394 & Eukaryotic translation initiation factor 3 subunit $B$ & 0.8 & \\
\hline gi|405969278 & Putative ATP-dependent RNA helicase an3 & 0.8 & 0.1980 \\
\hline gi|405969523 & Catalase & 0.8 & 0.1174 \\
\hline gi|405953522 & Nucleolin & 0.8 & 0.8253 \\
\hline gi|405964042 & Coatomer subunit alpha & 0.8 & 0.1012 \\
\hline gi|405963190 & Alpha-aspartyl dipeptidase & 0.8 & \\
\hline
\end{tabular}




\begin{tabular}{|c|c|c|c|}
\hline Accession & Name & Geomean & $\begin{array}{l}\text { Stouffers } \\
\text { P value }\end{array}$ \\
\hline gi|405961262 & Phosphoenolpyruvate carboxykinase, cytosolic [GTP] & 0.8 & 0.1182 \\
\hline gi|405962165 & Thioredoxin reductase 3 & 0.8 & \\
\hline gi|405972778 & Protein phosphatase 1B & 0.8 & 0.1687 \\
\hline gi|405951532 & CAP-Gly domain-containing linker protein 1 & 0.8 & \\
\hline gi|405952292 & Fibrillin-3 & 0.8 & 0.3843 \\
\hline gi|405968910 & Gephyrin & 0.8 & \\
\hline gi|405960133 & Hypothetical protein CGI_10023385 & 0.8 & \\
\hline gi|405946057 & Talin-2 & 0.8 & \\
\hline gi|405965007 & DNA-directed RNA polymerase II subunit RPB1 & 0.8 & \\
\hline gi|405968439 & Collagen alpha-1(XII) chain & 0.8 & 0.4208 \\
\hline gi|405978645 & Low-density lipoprotein receptor-related protein 6 & 0.8 & \\
\hline gi|405955753 & Elongation factor 1-gamma & 0.8 & \\
\hline gi|405967247 & Sulfide:quinone oxidoreductase, mitochondrial & 0.8 & 0.1003 \\
\hline gi|405952290 & $\begin{array}{l}\text { Armadillo repeat protein deleted in velo-cardio-facial } \\
\text { syndrome-like protein }\end{array}$ & 0.8 & 0.6182 \\
\hline gi|405975958 & Heat shock $70 \mathrm{kDa}$ protein $12 \mathrm{~A}$ & 0.8 & 0.1754 \\
\hline gi|405960652 & $60 S$ ribosomal protein $\mathrm{L} 17$ & 0.8 & \\
\hline gi|405972862 & Adenylate kinase isoenzyme 5 & 0.8 & 0.0441 \\
\hline gi|405972436 & Cystatin-A2 & 0.8 & 0.7273 \\
\hline gi|405975234 & Dual oxidase 2, partial & 0.8 & \\
\hline gi|405959180 & Protein SET & 0.8 & 0.0132 \\
\hline gi|405963822 & UPF0663 transmembrane protein c17orf28 & 0.8 & 0.0747 \\
\hline gi|405963573 & Hypothetical protein CGI_10024254 & 0.8 & \\
\hline gi|405960428 & PDZ and LIM domain protein 1 & 0.8 & \\
\hline gi|405968887 & $\begin{array}{l}\text { Epidermal growth factor receptor kinase substrate 8-like } \\
\text { protein } 1\end{array}$ & 0.8 & 0.0762 \\
\hline gi|405971344 & Mitochondrial carrier-like protein 2 & 0.8 & \\
\hline gi|405973648 & Pericentriolar material 1 protein & 0.8 & 0.3047 \\
\hline gi|405961193 & Coatomer subunit beta', partial & 0.8 & \\
\hline gi|405953995 & Hypothetical protein CGI_10003794 & 0.8 & 0.0653 \\
\hline gi|405967835 & Methylglutaconyl-CoA hydratase, mitochondrial & 0.8 & \\
\hline gi|405953465 & Tether containing UBX domain for GLUT4 & 0.8 & \\
\hline gi|405978602 & Calcium-binding protein NCS-1 & 0.8 & \\
\hline gi|405971875 & Hemicentin-1 & 0.8 & \\
\hline gi|405961385 & Glutamine synthetase & 0.8 & 0.0572 \\
\hline gi|405951942 & Tubulin alpha- $1 \mathrm{C}$ chain & 0.8 & 0.5045 \\
\hline gi|405965290 & Hypothetical protein CGI_10002265 & 0.8 & \\
\hline gi|405973146 & Annexin A7 & 0.8 & 0.0002 \\
\hline gi|157154403 & Sodium/potassium-transporting ATPase alpha chain & 0.8 & \\
\hline gi|405953624 & Hypothetical protein CGI_10004246 & 0.8 & \\
\hline gi|405966819 & Serine hydroxymethyltransferase, cytosolic & 0.8 & 0.3721 \\
\hline gi|405973340 & Actin & 0.8 & 0.0208 \\
\hline gi|405962300 & Frizzled-5 & 0.8 & \\
\hline gi|405978690 & Propionyl-CoA carboxylase beta chain, mitochondrial & 0.8 & 0.0778 \\
\hline gi|405963030 & Hypothetical protein CGI_10025157 & 0.8 & 0.0588 \\
\hline gi|405956092 & DNA-directed RNA polymerases I, II, and III subunit RPABC2 & 0.8 & 0.2201 \\
\hline gi|405966314 & Lysyl-tRNA synthetase & 0.8 & \\
\hline
\end{tabular}




\begin{tabular}{|c|c|c|c|}
\hline Accession & Name & Geomean & $\begin{array}{c}\text { Stouffers } \\
P \text { value }\end{array}$ \\
\hline gi|405965049 & Nucleolar protein 58 & 0.8 & 0.4175 \\
\hline gi|405951327 & Protein G7c & 0.8 & 0.6167 \\
\hline gi|47076115 & Mu class glutathione S-transferase & 0.8 & \\
\hline gi|405977043 & $\begin{array}{l}\text { NADH-ubiquinone oxidoreductase } 75 \text { kDa subunit, } \\
\text { mitochondrial }\end{array}$ & 0.8 & \\
\hline gi|405952907 & Hypothetical protein CGI_10005641 & 0.8 & \\
\hline gi|405959253 & Myosin-VI & 0.8 & 0.4115 \\
\hline gi|405974168 & Titin & 0.8 & 0.0203 \\
\hline gi|405954612 & Fucolectin-5 & 0.8 & \\
\hline gi|405960204 & Hypoxia up-regulated protein 1 & 0.8 & \\
\hline gi|405970532 & Septin-2 & 0.8 & \\
\hline gi|405950592 & Phosphoglucomutase-1 & 0.8 & 0.0982 \\
\hline gi|405960597 & $\begin{array}{l}\text { Phytanoyl-CoA dioxygenase domain-containing protein 1-like } \\
\text { protein }\end{array}$ & 0.8 & 0.3204 \\
\hline gi|405969341 & Glycyl-tRNA synthetase & 0.8 & \\
\hline gi|405975071 & Coronin-1B & 0.8 & 0.0008 \\
\hline gi|405960605 & Uncharacterized protein c20orf26 & 0.8 & \\
\hline gi|405972553 & Dual oxidase maturation factor 1 & 0.8 & \\
\hline gi|40643028 & Ribosomal protein L19 & 0.8 & 0.2355 \\
\hline gi|405960660 & Protein disulfide-isomerase A5 & 0.8 & \\
\hline gi|405967381 & Cysteinyl-tRNA synthetase, cytoplasmic & 0.8 & \\
\hline gi|405970695 & Receptor-type tyrosine-protein phosphatase beta & 0.8 & \\
\hline gi|405974068 & $\begin{array}{l}\text { Glucosamine--fructose-6-phosphate aminotransferase } \\
\text { [isomerizing] } 1\end{array}$ & 0.8 & 0.0033 \\
\hline gi|405951651 & 2-amino-3-carboxymuconate-6-semialdehyde decarboxylase & 0.8 & \\
\hline gi|405959219 & Mitogen-activated protein kinase kinase kinase kinase 3 , partial & 0.8 & \\
\hline gi|405964691 & Acetyl-coenzyme A synthetase & 0.8 & 0.2508 \\
\hline gi|405959335 & Serine/threonine-protein kinase Nek4 & 0.8 & 0.0682 \\
\hline gi|405971561 & Zonadhesin & 0.8 & 0.0077 \\
\hline gi|405966858 & 3-hydroxyacyl-CoA dehydrogenase type-2 & 0.8 & \\
\hline gi|405966303 & Hypothetical protein CGI_10009847 & 0.8 & 0.1231 \\
\hline gi|405964597 & Hypothetical protein CGI_10018743 & 0.8 & \\
\hline gi|405968446 & Hypothetical protein CGI_10022012 & 0.8 & \\
\hline gi|405970058 & Eukaryotic translation initiation factor 3 subunit $A$ & 0.8 & 0.0806 \\
\hline gi|405955211 & Hypothetical protein CGI_10002332 & 0.8 & 0.4132 \\
\hline gi|405954502 & Splicing factor, arginine/serine-rich 6 & 0.8 & \\
\hline gi|405960477 & Laminin subunit beta-2 & 0.8 & \\
\hline gi|405966886 & Hypothetical protein CGI_10025210 & 0.8 & \\
\hline gi|405978465 & Delta-1-pyrroline-5-carboxylate dehydrogenase, mitochondrial & 0.8 & \\
\hline gi|405956520 & Putative aminopeptidase W07G4.4 & 0.8 & 0.0552 \\
\hline gi|405950078 & Nucleoprotein TPR & 0.8 & \\
\hline gi|405975672 & Long-chain-fatty-acid--CoA ligase 4 & 0.8 & 0.0875 \\
\hline gi|405976274 & Hypothetical protein CGI_10021278 & 0.8 & \\
\hline gi|405953328 & Protein kinase $C$ delta type & 0.8 & \\
\hline gi|405970941 & Hypothetical protein CGI_10011199 & 0.8 & \\
\hline gi|405978868 & Uncharacterized protein c1orf93-like protein & 0.8 & \\
\hline gi|405976016 & Villin-1 & 0.8 & 0.0779 \\
\hline
\end{tabular}




\begin{tabular}{|c|c|c|c|}
\hline Accession & Name & Geomean & $\begin{array}{l}\text { Stouffers } \\
\text { P value }\end{array}$ \\
\hline gi|405953593 & Double-stranded RNA-specific editase 1 & 0.8 & \\
\hline gi|405972492 & Kinesin-related protein 1 & 0.8 & \\
\hline gi|405974500 & $\begin{array}{l}\text { Eukaryotic peptide chain release factor GTP-binding subunit } \\
\text { ERF3B }\end{array}$ & 0.8 & 0.2727 \\
\hline gi|405952027 & Lethal(2) giant larvae-like protein 1 & 0.8 & 0.2618 \\
\hline gi|405967527 & Nesprin-1 & 0.8 & 0.0121 \\
\hline gi|405975484 & Protein lethal(2)essential for life & 0.8 & 0.0154 \\
\hline gi|405951040 & Eukaryotic translation initiation factor 3 subunit $\mathrm{C}$ & 0.8 & 0.7591 \\
\hline gi|405960037 & Serine/threonine-protein phosphatase 6 regulatory subunit 3 & 0.8 & 0.1371 \\
\hline gi|405964650 & Extended synaptotagmin-2 & 0.8 & 0.2952 \\
\hline gi|405977935 & Hypothetical protein CGI_10018270 & 0.8 & 0.3434 \\
\hline gi|405976336 & Hypothetical protein CGI_10026535 & 0.8 & 0.5951 \\
\hline gi|71040623 & Ribosomal protein S27 & 0.8 & \\
\hline gi|405966565 & Putative glycogen [starch] synthase & 0.8 & \\
\hline gi|405975901 & Uncharacterized protein c3orf32 & 0.8 & \\
\hline gi|405973981 & Calcium-dependent protein kinase $\mathrm{C}$ & 0.8 & \\
\hline gi|405978279 & AP-2 complex subunit sigma & 0.8 & \\
\hline gi|405975834 & Isocitrate dehydrogenase [NADP], mitochondrial & 0.8 & 0.0000 \\
\hline gi|405950813 & GPI inositol-deacylase & 0.8 & \\
\hline gi|405953127 & Allene oxide synthase-lipoxygenase protein, partial & 0.8 & 0.0001 \\
\hline gi|405952800 & Hypothetical protein CGI_10005804 & 0.8 & \\
\hline gi|405966125 & Glutathione S-transferase 3 & 0.8 & 0.1176 \\
\hline gi|405962701 & Malectin & 0.8 & \\
\hline gi|405970446 & Sodium- and chloride-dependent glycine transporter 2 & 0.8 & \\
\hline gi|405975785 & Filamin-A & 0.8 & 0.0415 \\
\hline gi|405969429 & Plasma alpha-L-fucosidase & 0.8 & 0.1322 \\
\hline gi|405964482 & Hypothetical protein CGI_10003076 & 0.8 & 0.3253 \\
\hline gi|405966210 & Collectin-12 & 0.8 & 0.5845 \\
\hline gi|405964165 & $\begin{array}{l}\text { Calcium/calmodulin-dependent protein kinase type II delta } \\
\text { chain }\end{array}$ & 0.8 & 0.2548 \\
\hline gi|405966818 & Putative ATP-dependent RNA helicase DDX5 & 0.8 & \\
\hline gi|405971733 & Formimidoyltransferase-cyclodeaminase & 0.8 & 0.5047 \\
\hline gi|405945552 & 2,4-dienoyl-CoA reductase, mitochondrial & 0.8 & 0.5527 \\
\hline gi|405955564 & Cytoplasmic aconitate hydratase & 0.8 & 0.2590 \\
\hline gi|405977889 & Putative adenosylhomocysteinase 3 & 0.8 & \\
\hline gi|405978819 & Leucine-rich repeat-containing protein 59 & 0.8 & 0.5226 \\
\hline gi|405959699 & Aldo-keto reductase family 1 member B10 & 0.8 & \\
\hline gi|405965483 & Dihydrolipoyl dehydrogenase, mitochondrial & 0.8 & 0.3794 \\
\hline gi|405971538 & Synaptophysin & 0.8 & 0.3616 \\
\hline gi|405972424 & Camp-dependent protein kinase type II regulatory subunit & 0.8 & 0.3822 \\
\hline gi|405951265 & Hypothetical protein CGI_10009262 & 0.8 & \\
\hline gi|405977348 & Histone H5 & 0.8 & 0.3119 \\
\hline gi|405957950 & SH3 domain-binding protein 5-like protein & 0.8 & \\
\hline gi|405969389 & DNA-directed RNA polymerases I, II, and III subunit RPABC3 & 0.8 & \\
\hline gi|405969881 & Synaptobrevin & 0.8 & \\
\hline gi|405974166 & Titin & 0.8 & \\
\hline gi|405953053 & Echinoderm microtubule-associated protein-like 1 & 0.8 & 0.4557 \\
\hline
\end{tabular}




\begin{tabular}{|c|c|c|c|}
\hline Accession & Name & Geomean & $\begin{array}{c}\text { Stouffers } \\
\text { P value }\end{array}$ \\
\hline gi|405960113 & Ubiquitin carboxyl-terminal hydrolase 15 & 0.8 & \\
\hline gi|405978625 & Metaxin-2 & 0.8 & \\
\hline gi|405961544 & Plexin-A4 & 0.8 & \\
\hline gi|405978696 & Alpha-aminoadipic semialdehyde dehydrogenase & 0.8 & 0.0071 \\
\hline gi|405973025 & Coatomer subunit delta & 0.8 & 0.4564 \\
\hline gi|405964355 & Calpain-A & 0.8 & 0.0263 \\
\hline gi|405970056 & Kyphoscoliosis peptidase & 0.8 & 0.0112 \\
\hline gi|22758874 & Ribosomal protein $\mathrm{L}$ & 0.8 & \\
\hline gi|405970435 & Thioredoxin domain-containing protein 5 & 0.8 & 0.6454 \\
\hline gi|405971145 & Myosin heavy chain, non-muscle, partial & 0.8 & 0.0000 \\
\hline gi|405975057 & Myosin heavy chain, striated muscle & 0.8 & 0.0024 \\
\hline gi|405960658 & Plastin-1 & 0.8 & 0.6109 \\
\hline gi|405966381 & Dynein heavy chain 6 , axonemal & 0.8 & 0.4499 \\
\hline gi|405977321 & Hypothetical protein CGI_10021646 & 0.8 & \\
\hline gi|405965776 & LISH domain-containing protein c16orf63-like protein & 0.8 & \\
\hline gi|405956597 & Hypothetical protein CGI_10000542 & 0.8 & 0.3625 \\
\hline gi|405970128 & Nucleolar protein 56 & 0.8 & \\
\hline gi|405964721 & EF-hand domain-containing protein 1 & 0.8 & 0.1079 \\
\hline gi|405975707 & Hypothetical protein CGI_10015240 & 0.8 & \\
\hline gi|405974485 & $13 \mathrm{kDa}$ ribonucleoprotein-associated protein & 0.8 & \\
\hline gi|405977320 & Neural cell adhesion molecule 1 & 0.8 & 0.0000 \\
\hline gi|157154401 & IK cytokine & 0.8 & \\
\hline gi|405972660 & Nucleosome assembly protein 1 -like 4 & 0.8 & \\
\hline gi|405960169 & Cytoplasmic dynein 1 intermediate chain 2 & 0.8 & \\
\hline gi|405973904 & Spermatogenesis-associated protein 6 & 0.8 & \\
\hline gi|405958791 & Arginine kinase & 0.8 & \\
\hline gi|405958081 & Calmodulin & 0.8 & \\
\hline gi|405960314 & Hypothetical protein CGI_10005509 & 0.9 & 0.8697 \\
\hline gi|405969732 & Laminin subunit alpha & 0.9 & 0.0188 \\
\hline gi|405951570 & 15-hydroxyprostaglandin dehydrogenase [NAD+] & 0.9 & \\
\hline gi|405960674 & Hypothetical protein CGI_10010476 & 0.9 & 0.1742 \\
\hline gi|405967698 & Protein disulfide-isomerase $\mathrm{A} 3$ & 0.9 & 0.0000 \\
\hline gi|405963261 & Guanine nucleotide-binding protein subunit beta & 0.9 & 0.4306 \\
\hline gi|405968440 & Collagen alpha- $6(\mathrm{VI})$ chain & 0.9 & 0.0278 \\
\hline gi|405963184 & Hypothetical protein CGI_10018076 & 0.9 & 0.7710 \\
\hline gi|405957246 & Excitatory amino acid transporter 2 & 0.9 & \\
\hline gi|405976919 & MORN repeat-containing protein 3 & 0.9 & \\
\hline gi|405957573 & Hypothetical protein CGI_10013935 & 0.9 & 0.3525 \\
\hline gi|405966072 & Putative adenylate kinase 7 & 0.9 & 0.0940 \\
\hline gi|405964761 & Aconitate hydratase, mitochondrial & 0.9 & 0.0029 \\
\hline gi|405961151 & Xaa-Pro aminopeptidase 1 & 0.9 & 0.9001 \\
\hline gi|405972826 & Collagen alpha- $5(\mathrm{VI})$ chain & 0.9 & \\
\hline gi|405957027 & Heterogeneous nuclear ribonucleoprotein $\mathrm{K}$ & 0.9 & 0.6010 \\
\hline gi|405973442 & Nicotinamide riboside kinase 1 & 0.9 & \\
\hline gi|405965813 & Williams-Beuren syndrome chromosomal region 27 protein & 0.9 & \\
\hline gi|405961227 & Serine/threonine-protein kinase phg2 & 0.9 & 0.4331 \\
\hline
\end{tabular}




\begin{tabular}{|c|c|c|c|}
\hline Accession & Name & Geomean & $\begin{array}{c}\text { Stouffers } \\
\mathrm{P} \text { value }\end{array}$ \\
\hline gi|405971329 & Spectrin beta chain, brain 4 & 0.9 & 0.2480 \\
\hline gi|405952521 & Apoptosis-inducing factor 3 & 0.9 & 0.6100 \\
\hline gi|405969159 & Hypothetical protein CGI_10002917 & 0.9 & 0.4630 \\
\hline gi|405962828 & Ubiquitin-conjugating enzyme E2-22 kDa & 0.9 & \\
\hline gi|405978082 & Myosin-le & 0.9 & 0.0785 \\
\hline gi|46359618 & $78 \mathrm{kda}$ glucose regulated protein & 0.9 & 0.0001 \\
\hline gi|241913774 & Ribosomal protein S6 & 0.9 & 0.2316 \\
\hline gi|405961245 & Heat shock $70 \mathrm{kDa}$ protein $12 \mathrm{~B}$ & 0.9 & 0.0260 \\
\hline gi|405964764 & Putative RNA-binding protein Luc7-like 2 & 0.9 & \\
\hline gi|405968088 & WD repeat-containing protein 19 & 0.9 & \\
\hline gi|405957571 & Hypothetical protein CGI_10013933 & 0.9 & 0.1949 \\
\hline gi|405972497 & Natterin-3 & 0.9 & 0.3838 \\
\hline gi|405957372 & Sulfotransferase $1 \mathrm{~A} 1$, partial & 0.9 & \\
\hline gi|405970487 & Glutaminyl-tRNA synthetase, partial & 0.9 & \\
\hline gi|405970444 & Acid ceramidase & 0.9 & \\
\hline gi|405954824 & Severin & 0.9 & 0.0000 \\
\hline gi|405953892 & Serine/threonine-protein kinase 25 & 0.9 & \\
\hline gi|405959582 & Hypothetical protein CGI_10010386 & 0.9 & 0.3630 \\
\hline gi|405950254 & Tyrosine-protein kinase PR2 & 0.9 & 0.2042 \\
\hline gi|405969875 & $\begin{array}{l}\text { Succinate dehydrogenase [ubiquinone] flavoprotein subunit B, } \\
\text { mitochondrial }\end{array}$ & 0.9 & 0.0177 \\
\hline gi|296524486 & Unnamed protein product & 0.9 & \\
\hline gi|405974623 & $26 \mathrm{~S}$ proteasome non-ATPase regulatory subunit 12 & 0.9 & 0.5922 \\
\hline gi|405973352 & $\begin{array}{l}\text { Glucose-repressible alcohol dehydrogenase transcriptional } \\
\text { effector }\end{array}$ & 0.9 & 0.5888 \\
\hline gi|405972154 & Hypothetical protein CGI_10023087 & 0.9 & \\
\hline gi|405975593 & Hypothetical protein CGI_10027787 & 0.9 & \\
\hline gi|405965171 & Hypothetical protein CGI_10017255 & 0.9 & 0.6147 \\
\hline gi|405962443 & Hypothetical protein CGI_10009681 & 0.9 & 0.6682 \\
\hline gi|405958174 & Pyruvate kinase isozymes M1/M2 & 0.9 & \\
\hline gi|405978205 & Dual oxidase & 0.9 & \\
\hline gi|405976926 & Dihydroorotase & 0.9 & 0.8375 \\
\hline gi|405977599 & $\begin{array}{l}\text { LETM1 and EF-hand domain-containing protein } 1 \text {, } \\
\text { mitochondrial }\end{array}$ & 0.9 & \\
\hline gi|405968797 & Methenyltetrahydrofolate synthetase domain-containing protein & 0.9 & \\
\hline gi|405977154 & Exonuclease $3^{\prime}-5^{\prime}$ domain-containing protein 2 & 0.9 & 0.8040 \\
\hline gi|405967052 & WD repeat-containing protein 16 & 0.9 & 0.2496 \\
\hline gi|113207856 & Pyruvate kinase & 0.9 & 0.1841 \\
\hline gi|405961414 & Uncharacterized protein c8orf34 & 0.9 & 0.6822 \\
\hline gi|405959264 & Heterogeneous nuclear ribonucleoprotein U-like protein 1 & 0.9 & 0.9295 \\
\hline gi|405959171 & Glucose-6-phosphate 1-dehydrogenase & 0.9 & 0.2854 \\
\hline gi|405964118 & Talin-1 & 0.9 & 0.4291 \\
\hline gi|405978841 & Voltage-dependent anion-selective channel protein 2 & 0.9 & 0.0048 \\
\hline gi|405967555 & $\begin{array}{l}\text { NADH dehydrogenase [ubiquinone] flavoprotein } 1 \text {, } \\
\text { mitochondrial }\end{array}$ & 0.9 & \\
\hline gi|405961430 & Docking protein 1 & 0.9 & 0.4221 \\
\hline gi|405973194 & Mitochondrial import receptor subunit TOM70 & 0.9 & 0.3494 \\
\hline gi|405969783 & Hypothetical protein CGI_10021716 & 0.9 & 0.0709 \\
\hline
\end{tabular}




\begin{tabular}{|c|c|c|c|}
\hline Accession & Name & Geomean & $\begin{array}{c}\text { Stouffers } \\
\mathrm{P} \text { value }\end{array}$ \\
\hline gi|405976908 & $\begin{array}{l}\text { Coiled-coil-helix-coiled-coil-helix domain-containing protein } 2 \text {, } \\
\text { mitochondrial }\end{array}$ & 0.9 & \\
\hline gi|405972082 & Aspartate aminotransferase, mitochondrial & 0.9 & 0.5197 \\
\hline gi|405956062 & Hypothetical protein CGI_10001256 & 0.9 & \\
\hline gi|405955275 & Kyphoscoliosis peptidase & 0.9 & 0.2376 \\
\hline gi|22758866 & Ribosomal protein L23a & 0.9 & \\
\hline gi|405959834 & Catalase & 0.9 & 0.6786 \\
\hline gi|405965301 & Mitochondrial-processing peptidase subunit beta & 0.9 & 0.0122 \\
\hline gi|405978151 & Nuclear protein MDM1 & 0.9 & \\
\hline gi|405958886 & Hypothetical protein CGI_10024026 & 0.9 & 0.7904 \\
\hline gi|405957238 & Collagen alpha- $5(\mathrm{VI})$ chain & 0.9 & 0.5339 \\
\hline gi|405970115 & Cytochrome b-c1 complex subunit 7 & 0.9 & 0.7687 \\
\hline gi|405958243 & Hypothetical protein CGI_10013387 & 0.9 & 0.6828 \\
\hline gi|405966870 & Actin-interacting protein 1 & 0.9 & 0.2336 \\
\hline gi|405959946 & Uncharacterized protein c10orf67 & 0.9 & \\
\hline gi|405963604 & $60 S$ ribosomal protein $\mathrm{L} 31$ & 0.9 & \\
\hline gi|3990959 & Sequence 3 from patent US 5736356 & 0.9 & \\
\hline gi|405956300 & Phosducin-like protein 3 , partial & 0.9 & 0.1657 \\
\hline gi|405951824 & Collagen alpha-2(I) chain & 0.9 & 0.4710 \\
\hline gi|405975638 & Hypothetical protein CGI_10027837 & 0.9 & \\
\hline gi|405965316 & Synaptic vesicle membrane protein VAT-1-like protein & 0.9 & \\
\hline gi|405970476 & Pleckstrin-like protein domain family B member 2 & 0.9 & \\
\hline gi|405952266 & Protein Hu-Li Tai Shao & 0.9 & 0.0892 \\
\hline gi|405970417 & Titin & 0.9 & 0.6658 \\
\hline gi|405972513 & $\begin{array}{l}\text { NADH dehydrogenase [ubiquinone] } 1 \text { beta subcomplex subunit } \\
11 \text {, mitochondrial }\end{array}$ & 0.9 & 0.4377 \\
\hline gi|405960046 & Protein OSCP1 & 0.9 & 0.6096 \\
\hline gi|405968537 & Actin & 0.9 & 0.8451 \\
\hline gi|405977790 & Hypothetical protein CGI_10028023 & 0.9 & 0.6319 \\
\hline gi|405962913 & $\begin{array}{l}\text { NADH dehydrogenase [ubiquinone] iron-sulfur protein } 3 \text {, } \\
\text { mitochondrial }\end{array}$ & 0.9 & \\
\hline gi|405972434 & Galectin-4 & 0.9 & 0.0990 \\
\hline gi|405958935 & L-ascorbate oxidase & 0.9 & \\
\hline gi|405960954 & Hypothetical protein CGI_10013860 & 0.9 & \\
\hline gi|405954148 & Calpain-9 & 0.9 & 0.4163 \\
\hline gi|405950685 & Allene oxide synthase-lipoxygenase protein & 0.9 & \\
\hline gi|405970038 & ATP-dependent DNA helicase 2 subunit 1 & 0.9 & 0.4138 \\
\hline gi|405978116 & D-erythrulose reductase & 0.9 & 0.9016 \\
\hline gi|405953918 & Hypothetical protein CGI_10003872 & 0.9 & \\
\hline gi|405961655 & Fascin & 0.9 & 0.5874 \\
\hline gi|405971451 & Dynein heavy chain 5 , axonemal & 0.9 & 0.1075 \\
\hline gi|405973805 & Mitochondrial inner membrane protein & 0.9 & 0.6076 \\
\hline gi|405978599 & Glutamate receptor U1 & 0.9 & 0.8089 \\
\hline gi|405965844 & Dynamin-1 & 0.9 & 0.0793 \\
\hline gi|405954419 & Collagen alpha-3(VI) chain & 0.9 & 0.0001 \\
\hline gi|405959611 & Cystatin-B & 0.9 & 0.3827 \\
\hline gi|405970266 & Methylmalonyl-CoA mutase, mitochondrial & 0.9 & 0.2293 \\
\hline
\end{tabular}




\begin{tabular}{|c|c|c|c|}
\hline Accession & Name & Geomean & $\begin{array}{c}\text { Stouffers } \\
P \text { value }\end{array}$ \\
\hline gi|405972170 & Rho guanine nucleotide exchange factor 12 & 0.9 & 0.1444 \\
\hline gi|405950888 & Armadillo repeat-containing protein 4 & 0.9 & 0.3467 \\
\hline gi|405951857 & Cytochrome $\mathrm{c} 1$, heme protein, mitochondrial & 0.9 & 0.7188 \\
\hline gi|405951408 & Proteasome subunit alpha type-1 & 0.9 & 0.0088 \\
\hline gi|405966436 & Rho GDP-dissociation inhibitor 1 & 0.9 & 0.0168 \\
\hline gi|405975655 & Transport protein Sec23A & 0.9 & 0.8868 \\
\hline gi|68989137 & Cytochrome c oxidase subunit II & 0.9 & \\
\hline gi|405963692 & Neuroendocrine convertase 2 & 0.9 & \\
\hline gi|405953302 & $\begin{array}{l}\text { Complement component } 1 \mathrm{Q} \text { subcomponent-binding protein, } \\
\text { mitochondrial }\end{array}$ & 0.9 & 0.3158 \\
\hline gi|405968237 & Putative 10-formyltetrahydrofolate dehydrogenase ALDH1L2 & 0.9 & 0.0004 \\
\hline gi|405978261 & Hexokinase type 2 & 0.9 & 0.8691 \\
\hline gi|405972774 & Aldose 1-epimerase & 0.9 & \\
\hline gi|405950532 & Uncharacterized protein YIEF & 0.9 & \\
\hline gi|405972165 & $\begin{array}{l}\text { NADH dehydrogenase [ubiquinone] } 1 \text { alpha subcomplex } \\
\text { subunit 4-like } 2\end{array}$ & 0.9 & 0.5052 \\
\hline gi|405953620 & Hypothetical protein CGI_10004281 & 0.9 & \\
\hline gi|405957005 & Hypothetical protein CGI_10020924 & 0.9 & 0.2585 \\
\hline gi|144228241 & Tubulin A & 0.9 & 0.6704 \\
\hline gi|405952732 & Protein CASC3 & 0.9 & 0.5894 \\
\hline gi|405965490 & Hypothetical protein CGI_10028537 & 0.9 & \\
\hline gi|405978849 & Rho GTPase-activating protein 17 & 0.9 & 0.1096 \\
\hline gi|405962051 & Importin subunit alpha-3 & 0.9 & 0.5210 \\
\hline gi|405955148 & Plasminogen & 0.9 & \\
\hline gi|405965333 & $\begin{array}{l}\text { Deoxyuridine 5'-triphosphate nucleotidohydrolase, } \\
\text { mitochondrial }\end{array}$ & 0.9 & \\
\hline gi|405965398 & Sorbin and $\mathrm{SH} 3$ domain-containing protein 1 & 0.9 & 0.2873 \\
\hline gi|405965462 & Elongation factor Tu, mitochondrial & 0.9 & 0.6593 \\
\hline gi|405966309 & Annulin & 0.9 & 0.9598 \\
\hline gi|405972828 & Collagen alpha- $5(\mathrm{VI})$ chain & 0.9 & 0.3562 \\
\hline gi|405963145 & Integrin alpha-4 & 0.9 & 0.4349 \\
\hline gi|405969843 & Protein FAM21 & 0.9 & 0.6310 \\
\hline gi|405970297 & V-type proton ATPase subunit D & 0.9 & 0.5585 \\
\hline gi|405957035 & Microtubule-associated protein FUTSCH & 0.9 & 0.4010 \\
\hline gi|405950809 & Protocadherin fat 4 & 0.9 & 0.9230 \\
\hline gi|405967637 & Tropomyosin & 0.9 & 0.6045 \\
\hline gi|405951089 & Neuronal calcium sensor 2 & 0.9 & \\
\hline gi|405966050 & Zinc finger RNA-binding protein & 0.9 & 0.8616 \\
\hline gi|405960824 & Thioredoxin domain-containing protein 16 & 0.9 & 0.8455 \\
\hline gi|405955957 & Death domain-containing protein CRADD & 0.9 & 0.2375 \\
\hline gi|405976351 & Neurogenic locus Notch protein & 0.9 & \\
\hline gi|405957331 & Interferon-induced protein 44-like protein & 0.9 & \\
\hline gi|405955811 & Annexin A4 & 0.9 & \\
\hline gi|405977572 & Calcyphosin-like protein & 0.9 & 0.7496 \\
\hline gi|405975485 & Heat shock protein beta-1 & 0.9 & 0.7752 \\
\hline gi|405969084 & Small acidic protein & 0.9 & \\
\hline gi|405970161 & Uncharacterized protein YGIG & 0.9 & 0.5171 \\
\hline
\end{tabular}




\begin{tabular}{|c|c|c|c|}
\hline Accession & Name & Geomean & $\begin{array}{c}\text { Stouffers } \\
P \text { value }\end{array}$ \\
\hline gi|405969597 & Dipeptidyl peptidase family member 6 & 0.9 & 0.2660 \\
\hline gi|405952451 & Sperm flagellar protein 2 & 0.9 & 0.8052 \\
\hline gi|405976269 & Hypothetical protein CGI_10021273 & 0.9 & 0.3893 \\
\hline gi|405975053 & Epididymal secretory glutathione peroxidase & 0.9 & 0.2890 \\
\hline gi|405957661 & Large proline-rich protein BAT3 & 0.9 & 0.8511 \\
\hline gi|405977373 & Dynein heavy chain 1 , axonemal & 0.9 & \\
\hline gi|405958832 & 3-ketoacyl-CoA thiolase A, peroxisomal & 0.9 & \\
\hline gi|405967668 & Homer-like protein 2 & 0.9 & \\
\hline gi|405951994 & Hypothetical protein CGI_10007416 & 0.9 & 0.0423 \\
\hline gi|405951501 & Serine dehydratase-like protein & 0.9 & \\
\hline gi|405957717 & Neural cell adhesion molecule L1 & 0.9 & 0.7126 \\
\hline gi|405953867 & Septin-7 & 0.9 & 0.5856 \\
\hline gi|405977054 & Kinesin heavy chain & 0.9 & 0.4168 \\
\hline gi|405976693 & Coiled-coil and C2 domain-containing protein 1-like protein & 0.9 & \\
\hline gi|405951159 & Valyl-tRNA synthetase & 0.9 & 0.8598 \\
\hline gi|405964277 & $26 S$ protease regulatory subunit 4 & 0.9 & 0.6140 \\
\hline gi|405974543 & Serrate RNA effector molecule-like protein & 0.9 & \\
\hline gi|405965493 & Alpha- $\mathrm{N}$-acetylgalactosaminidase & 0.9 & \\
\hline gi|405959173 & PRA1 family protein 3 & 0.9 & \\
\hline gi|405963687 & Peptidyl-prolyl cis-trans isomerase B & 0.9 & 0.0170 \\
\hline gi|405966470 & Cytochrome b-c1 complex subunit 6 , mitochondrial & 0.9 & 0.9178 \\
\hline gi|405978482 & Sushi domain-containing protein 2 & 0.9 & \\
\hline gi|405962799 & Tyrosine-protein kinase transforming protein Src & 0.9 & \\
\hline gi|405977894 & Dynactin subunit 1 & 0.9 & \\
\hline gi|405976943 & Hypothetical protein CGI_10017522 & 0.9 & 0.8308 \\
\hline gi|405957030 & Ras GTPase-activating-like protein IQGAP1 & 0.9 & 0.5081 \\
\hline gi|405963940 & Reticulon-4 & 0.9 & 0.6957 \\
\hline gi|405965785 & Heterochromatin protein 1-binding protein 3 & 0.9 & 0.3605 \\
\hline gi|405960767 & Hypothetical protein CGI_10017882 & 0.9 & 0.5571 \\
\hline gi|405971818 & Myosin-id & 0.9 & \\
\hline gi|405964056 & Hypothetical protein CGI_10027362 & 0.9 & 0.6609 \\
\hline gi|405965419 & Tetraspanin-3 & 0.9 & 0.6511 \\
\hline gi|405967714 & Basigin & 0.9 & 0.8202 \\
\hline gi|405952344 & $60 S$ ribosomal protein $\mathrm{L} 4$ & 0.9 & 0.0112 \\
\hline gi|405977537 & Otoancorin & 0.9 & 0.4594 \\
\hline gi|405974461 & E3 ubiquitin-protein ligase MIB2 & 0.9 & 0.9640 \\
\hline gi|405966920 & Clathrin interactor 1 & 0.9 & 0.7854 \\
\hline gi|405960231 & Vigilin & 0.9 & 0.7746 \\
\hline gi|405971179 & $\begin{array}{l}\text { NADH dehydrogenase [ubiquinone] } 1 \text { alpha subcomplex } \\
\text { subunit } 8\end{array}$ & 0.9 & 0.3934 \\
\hline gi|405958669 & Ankyrin-2 & 0.9 & 0.3760 \\
\hline gi|405966888 & Collagen alpha-3(VI) chain & 0.9 & \\
\hline gi|405966449 & Hypothetical protein CGI_10008992 & 0.9 & \\
\hline gi|405976912 & Syntaxin & 0.9 & \\
\hline gi|405962190 & Collagen alpha-3(VI) chain & 0.9 & 0.0199 \\
\hline gi|405958293 & Hypothetical protein CGI_10016401 & 0.9 & 0.6051 \\
\hline
\end{tabular}




\begin{tabular}{|c|c|c|c|}
\hline Accession & Name & Geomean & $\begin{array}{l}\text { Stouffers } \\
\text { P value }\end{array}$ \\
\hline gi|405950742 & Vascular endothelial growth factor $\mathrm{D}$ & 0.9 & 0.9280 \\
\hline gi|405976820 & Tripartite motif-containing protein 3 & 0.9 & \\
\hline gi|405951960 & F-actin-capping protein subunit alpha & 0.9 & 0.4956 \\
\hline gi|405966762 & UPF0582 protein c13orf37-like protein & 0.9 & 0.3938 \\
\hline gi|405977713 & Regulation of nuclear pre-mRNA domain-containing protein 1B & 0.9 & \\
\hline gi|405974522 & E3 ubiquitin-protein ligase MIB2 & 0.9 & \\
\hline gi|29134776 & Galectin-4 (lectin, galactoside-binding, soluble 4) & 0.9 & \\
\hline gi|405970718 & Cytochrome $\mathrm{c}$ oxidase subunit $6 \mathrm{~A} 1$, mitochondrial & 0.9 & 0.8161 \\
\hline gi|4838561 & Heat shock protein 70 & 0.9 & 0.0040 \\
\hline gi|405958940 & Phospholipid scramblase 2 & 0.9 & 0.3687 \\
\hline gi|405962106 & Diaphanous-like protein 2 & 0.9 & 0.1961 \\
\hline gi|405976588 & Serine/threonine-protein kinase PAK 1 & 0.9 & \\
\hline gi|405969966 & Thymidine phosphorylase & 0.9 & \\
\hline gi|405967055 & Xaa-Pro aminopeptidase 1 & 0.9 & 0.3785 \\
\hline gi|405969853 & NADP-dependent malic enzyme, mitochondrial & 0.9 & 0.8931 \\
\hline gi|405974556 & Thioredoxin-like protein 1 & 0.9 & \\
\hline gi|405965826 & Programmed cell death protein 4 & 0.9 & 0.6912 \\
\hline gi|405974815 & Glutamate receptor U1 & 0.9 & \\
\hline gi|405951799 & Hypothetical protein CGI_10007925 & 0.9 & 0.5313 \\
\hline gi|328905054 & Caspase-1 & 0.9 & 0.8645 \\
\hline gi|405973356 & Glutathione-requiring prostaglandin D synthase & 0.9 & 0.2951 \\
\hline gi|405951163 & Putative adenylate kinase-like protein c9orf98-like protein & 0.9 & 0.1342 \\
\hline gi|405952064 & Hypothetical protein CGI_10007259 & 0.9 & \\
\hline gi|44885729 & Arginine kinase & 0.9 & 0.0001 \\
\hline gi|328905046 & FAS-associating death domain-containing protein & 0.9 & 0.9730 \\
\hline gi|405959675 & Heat shock protein HSP 90-alpha 1 & 0.9 & 0.0199 \\
\hline gi|405951160 & Endoplasmic reticulum resident protein erp44 & 0.9 & 0.0864 \\
\hline gi|405977517 & $40 S$ ribosomal protein $\mathrm{S} 23$ & 0.9 & \\
\hline gi|405960968 & Hypothetical protein CGI_10007397 & 0.9 & 0.9031 \\
\hline gi|405974510 & Hypothetical protein CGI_10002394 & 0.9 & \\
\hline gi|405969458 & $\begin{array}{l}\mathrm{NADH} \text { dehydrogenase [ubiquinone] flavoprotein } 2 \text {, } \\
\text { mitochondrial, partial }\end{array}$ & 0.9 & 0.2441 \\
\hline gi|405970751 & WD repeat-containing protein 65 & 0.9 & 0.1663 \\
\hline gi|405968916 & Coiled-coil domain-containing protein 55 & 0.9 & \\
\hline gi|405949969 & Centrosomal protein of $72 \mathrm{kDa}$ & 0.9 & 0.5935 \\
\hline gi|405962247 & Complement c1q-like protein 4, partial & 0.9 & 0.4242 \\
\hline gi|405965662 & Protein lap4 & 0.9 & \\
\hline gi|405974851 & Neurocalcin-like protein & 0.9 & 0.9082 \\
\hline gi|405967549 & ATP-dependent DNA helicase 2 subunit 2 & 0.9 & 0.7929 \\
\hline gi|405978442 & Hypothetical protein CGI_10010069 & 0.9 & \\
\hline gi|405972605 & Nuclear transcription factor $Y$ subunit alpha & 0.9 & 0.3630 \\
\hline gi|148717309 & Hypothetical protein & 0.9 & 0.7787 \\
\hline gi|405977262 & Hypothetical protein CGI_10028468 & 0.9 & \\
\hline gi|405963003 & Splicing factor, arginine/serine-rich 4 & 0.9 & \\
\hline gi|405975507 & Disks large-associated protein 1 & 0.9 & 0.8706 \\
\hline gi|405956277 & Nuclear distribution protein nude-like protein 1 & 0.9 & 0.3010 \\
\hline
\end{tabular}




\begin{tabular}{|c|c|c|c|}
\hline Accession & Name & Geomean & $\begin{array}{c}\text { Stouffers } \\
\text { P value }\end{array}$ \\
\hline gi|405974476 & Laminin subunit beta-1 & 0.9 & 0.8990 \\
\hline gi|405960124 & Hypothetical protein CGI_10023375 & 0.9 & \\
\hline gi|405965901 & $60 S$ ribosomal protein $\mathrm{L} 27 \mathrm{a}$ & 0.9 & 0.5076 \\
\hline gi|405965494 & DNAj-like protein subfamily B member 11 & 0.9 & 0.9258 \\
\hline gi|405971352 & Disks large-like protein 1 & 0.9 & 0.0557 \\
\hline gi|405961233 & Alpha-crystallin B chain & 0.9 & 0.2320 \\
\hline gi|405960313 & Putative uncharacterized protein YGXH & 0.9 & 0.2190 \\
\hline gi|405970334 & IgG Fc-binding protein & 0.9 & \\
\hline gi|405950583 & Fermitin family-like protein 2 & 0.9 & 0.5472 \\
\hline gi|405960601 & Coiled-coil domain-containing protein 46 & 0.9 & 0.9170 \\
\hline gi|405951115 & Dynein intermediate chain 2, ciliary & 0.9 & 0.5781 \\
\hline gi|405974727 & Transcriptional activator protein PUR-alpha & 0.9 & 0.2653 \\
\hline gi|405969532 & Hypothetical protein CGI_10016266 & 0.9 & \\
\hline gi|405952357 & Protein daughter of sevenless & 1.0 & \\
\hline gi|405961556 & Hypothetical protein CGI_10010367 & 1.0 & 0.7540 \\
\hline gi|405974531 & MRG-binding protein & 1.0 & \\
\hline gi|405947710 & Barrier-to-autointegration factor & 1.0 & 0.7054 \\
\hline gi|405970025 & Hypothetical protein CGI_10018000 & 1.0 & \\
\hline gi|405962844 & Protein ETHE1, mitochondrial & 1.0 & \\
\hline gi|405963555 & Hypothetical protein CGI_10006803 & 1.0 & 0.9733 \\
\hline gi|405953564 & PC4 and SFRS1-interacting protein & 1.0 & \\
\hline gi|405970502 & Glutathione reductase, mitochondrial & 1.0 & 0.9752 \\
\hline gi|405976598 & Hypothetical protein CGI_10026559 & 1.0 & \\
\hline gi|405961406 & Ras GTPase-activating protein-binding protein 2 & 1.0 & 0.8051 \\
\hline gi|405965288 & Hypothetical protein CGI_10002263 & 1.0 & \\
\hline gi|405969172 & S-adenosylmethionine synthetase isoform type-1 & 1.0 & 0.4182 \\
\hline gi|405976491 & PRKC apoptosis WT1 regulator protein & 1.0 & 0.7361 \\
\hline gi|405958414 & U2 small nuclear ribonucleoprotein $A^{\prime}$ & 1.0 & \\
\hline gi|405962829 & LIM domain only protein 7 & 1.0 & \\
\hline gi|68655616 & Aspartate aminotransferase & 1.0 & 0.9775 \\
\hline gi|405972230 & Growth arrest-specific protein 8 & 1.0 & 0.8607 \\
\hline gi|405974349 & Extracellular superoxide dismutase [Cu-Zn] & 1.0 & 0.7621 \\
\hline gi|405970539 & Uncharacterized protein c13orf26-like protein & 1.0 & \\
\hline gi|405959294 & Paxillin & 1.0 & 0.8869 \\
\hline gi|405957947 & 3-hydroxyisobutyrate dehydrogenase, mitochondrial & 1.0 & 0.1707 \\
\hline gi|405959798 & Dipeptidase 1 & 1.0 & 0.5144 \\
\hline gi|405976453 & MICAL-like protein 2 & 1.0 & \\
\hline gi|40643000 & Ribosomal protein S8 & 1.0 & 0.2898 \\
\hline gi|405975656 & Calcium-binding protein p22 & 1.0 & \\
\hline gi|405953442 & Signal peptide, CUB and EGF-like domain-containing protein 1 & 1.0 & 0.0941 \\
\hline gi|405959230 & Membrane metallo-endopeptidase-like 1 & 1.0 & \\
\hline gi|405978773 & Hypothetical protein CGI_10012933 & 1.0 & 0.7682 \\
\hline gi|405970092 & $26 \mathrm{~S}$ proteasome non-ATPase regulatory subunit 2 & 1.0 & 0.8663 \\
\hline gi|405971215 & MAGUK p55 subfamily member 2 & 1.0 & 0.8808 \\
\hline gi|405958039 & Acidic leucine-rich nuclear phosphoprotein 32 family member $A$ & 1.0 & 0.0509 \\
\hline gi|405950559 & Hypothetical protein CGI_10011903 & 1.0 & 0.7357 \\
\hline
\end{tabular}




\begin{tabular}{|c|c|c|c|}
\hline Accession & Name & Geomean & $\begin{array}{c}\text { Stouffers } \\
\text { P value }\end{array}$ \\
\hline gi|405964228 & Coiled-coil domain-containing protein 13 & 1.0 & \\
\hline gi|405966779 & Cytochrome b-c1 complex subunit 2, mitochondrial & 1.0 & 0.9627 \\
\hline gi|405963809 & Vacuolar protein sorting-associated protein 4B & 1.0 & 0.9465 \\
\hline gi|405969600 & Hypothetical protein CGI_10021126 & 1.0 & \\
\hline gi|405958470 & Papilin & 1.0 & 0.7916 \\
\hline gi|405961035 & Engulfment and cell motility protein 2 & 1.0 & \\
\hline gi|405968987 & Fatty acid-binding-like protein 5 & 1.0 & \\
\hline gi|405965566 & Hypothetical protein CGI_10022503 & 1.0 & \\
\hline gi|405961124 & Dynein beta chain, flagellar outer arm & 1.0 & \\
\hline gi|405963782 & Nucleoredoxin & 1.0 & 0.5042 \\
\hline gi|405971277 & Phosphatase and actin regulator 1 & 1.0 & \\
\hline gi|405968755 & Mammalian ependymin-related protein 1 & 1.0 & 0.7242 \\
\hline gi|405960951 & Hypothetical protein CGI_10013856, partial & 1.0 & 0.9391 \\
\hline gi|405969488 & Hypothetical protein CGI_10012737 & 1.0 & \\
\hline gi|405969708 & Hypothetical protein CGI_10023205 & 1.0 & 0.9039 \\
\hline gi|405978470 & Mitochondrial fission 1 protein & 1.0 & 0.9906 \\
\hline gi|405963248 & MTO1-like protein, mitochondrial & 1.0 & \\
\hline gi|405957828 & Cytochrome P450 3A24 & 1.0 & \\
\hline gi|405969553 & Translin-associated factor $\mathrm{X}$-interacting protein 1 & 1.0 & 0.8174 \\
\hline gi|405976122 & Putative RNA-binding protein 16 & 1.0 & 0.8800 \\
\hline gi|405969898 & Tight junction protein ZO-1, partial & 1.0 & 0.9966 \\
\hline gi|405965402 & Hypothetical protein CGI_10021684 & 1.0 & 0.5328 \\
\hline gi|405970531 & Neurobeachin & 1.0 & 0.9021 \\
\hline gi|405972124 & Cysteinyl-tRNA synthetase, cytoplasmic & 1.0 & \\
\hline gi|405952725 & Hypothetical protein CGI_10005976 & 1.0 & 0.9871 \\
\hline gi|405970175 & Hypothetical protein CGI_10015122 & 1.0 & 0.6229 \\
\hline gi|405974458 & E3 ubiquitin-protein ligase MIB2 & 1.0 & \\
\hline gi|40642990 & Ribosomal protein L5 & 1.0 & 0.0903 \\
\hline gi|405951422 & Eukaryotic translation initiation factor 3 subunit G-A & 1.0 & 0.5764 \\
\hline gi|405954222 & Importin-9 & 1.0 & \\
\hline gi|405966484 & Hypothetical protein CGI_10016704 & 1.0 & 0.3649 \\
\hline gi|405974626 & CD82 antigen & 1.0 & \\
\hline gi|405950508 & Integrin beta- 6 & 1.0 & 0.8694 \\
\hline gi|405960427 & PDZ and LIM domain protein 5 & 1.0 & 0.6966 \\
\hline gi|405952159 & Vesicular integral-membrane protein VIP36 & 1.0 & 0.9998 \\
\hline gi|405953772 & Renalase & 1.0 & \\
\hline gi|405975334 & Apoptosis inhibitor 5 & 1.0 & 0.6544 \\
\hline gi|405970298 & Melanoma inhibitory activity protein 3 & 1.0 & 0.9323 \\
\hline gi|405974528 & Hypothetical protein CGI_10024564 & 1.0 & 0.9193 \\
\hline gi|405957467 & Laminin subunit alpha-3 & 1.0 & \\
\hline gi|405965273 & Putative WAS protein family-like protein 4 & 1.0 & 0.7609 \\
\hline gi|405975706 & Band 4.1-like protein 3 & 1.0 & 0.6867 \\
\hline gi|405970889 & Cleavage and polyadenylation specificity factor subunit 6 & 1.0 & 0.8204 \\
\hline gi|405961157 & Profilin & 1.0 & 0.8468 \\
\hline gi|405977356 & Hypothetical protein CGI_10026431 & 1.0 & 0.7738 \\
\hline gi|405962684 & Hypothetical protein CGI_10011556 & 1.0 & 0.9930 \\
\hline
\end{tabular}




\begin{tabular}{|c|c|c|c|}
\hline Accession & Name & Geomean & $\begin{array}{c}\text { Stouffers } \\
\text { P value }\end{array}$ \\
\hline gi|405968442 & Collagen alpha- $1(\mathrm{XII})$ chain & 1.0 & 0.9907 \\
\hline gi|405970994 & Calcyphosin-like protein & 1.0 & 0.7774 \\
\hline gi|405972709 & Integrin beta-1 & 1.0 & \\
\hline gi|405965903 & Major egg antigen & 1.0 & 0.7731 \\
\hline gi|405969995 & Choline-phosphate cytidylyltransferase B & 1.0 & \\
\hline gi|405966825 & Hepatocyte growth factor-regulated tyrosine kinase substrate & 1.0 & 0.8906 \\
\hline gi|405950548 & Surfeit locus protein 1 & 1.0 & \\
\hline gi|405952501 & DNAj-like protein subfamily B member 3 & 1.0 & \\
\hline gi|405960581 & Bile salt sulfotransferase & 1.0 & \\
\hline gi|405957441 & Hypothetical protein CGI_10007985 & 1.0 & 0.6742 \\
\hline gi|405970210 & Myosin-XVIIIa & 1.0 & \\
\hline gi|405957864 & Prominin-1 & 1.0 & 0.7090 \\
\hline gi|405958253 & Hypothetical protein CGI_10014044 & 1.0 & \\
\hline gi|405958466 & Putative calcium-binding protein CML13 & 1.0 & 0.2660 \\
\hline gi|405968707 & Hypothetical protein CGI_10023287 & 1.0 & \\
\hline gi|405967580 & Calnexin & 1.0 & \\
\hline gi|405954086 & Severin & 1.0 & 0.6799 \\
\hline gi|405951067 & Lysosomal aspartic protease & 1.0 & 0.8783 \\
\hline gi|405974768 & Survival motor neuron protein & 1.0 & \\
\hline gi|405974486 & Long-chain-fatty-acid--CoA ligase 1 & 1.0 & 0.5664 \\
\hline gi|405952500 & Vacuolar-sorting protein SNF8 & 1.0 & \\
\hline gi|405965517 & Neurocalcin & 1.0 & 0.7044 \\
\hline gi|405961302 & Cystatin-B & 1.0 & 0.9130 \\
\hline gi|405967434 & Fibropellin-1 & 1.0 & \\
\hline gi|405961832 & Heat shock protein beta-1 & 1.0 & 0.2479 \\
\hline gi|405959945 & Calmodulin-like protein & 1.0 & 0.3098 \\
\hline gi|405973525 & Endoplasmin & 1.0 & 0.7671 \\
\hline gi|405969235 & DDRGK domain-containing protein 1 & 1.0 & 0.9628 \\
\hline gi|405972240 & V-type proton ATPase subunit G & 1.0 & 0.1277 \\
\hline gi|405958682 & 2-oxoglutarate dehydrogenase E1 component, mitochondrial & 1.0 & 0.9524 \\
\hline gi|405953641 & Hypothetical protein CGI_10004231 & 1.0 & 0.8715 \\
\hline gi|405975833 & Doublecortin domain-containing protein 2 & 1.0 & 0.9961 \\
\hline gi|405975959 & Hypothetical protein CGI_10013526 & 1.0 & 0.6360 \\
\hline gi|405962056 & Hypothetical protein CGI_10002715 & 1.0 & 0.4927 \\
\hline gi|405951471 & Serine hydroxymethyltransferase, mitochondrial & 1.0 & 0.7744 \\
\hline gi|405963411 & Forkhead-associated domain-containing protein 1 & 1.0 & 0.9835 \\
\hline gi|405956952 & LIM domain-binding protein 3 & 1.0 & 0.2701 \\
\hline gi|405971400 & Paired box protein Pax-2-A & 1.0 & 0.2072 \\
\hline gi|405973124 & Hypothetical protein CGI_10019404 & 1.0 & 0.1906 \\
\hline gi|405951326 & Protein G7c & 1.0 & \\
\hline gi|405976226 & Inosine triphosphate pyrophosphatase & 1.0 & 0.9174 \\
\hline gi|405958107 & Poly [ADP-ribose] polymerase 1 & 1.0 & \\
\hline gi|405966738 & Eukaryotic translation initiation factor 4 gamma 3 & 1.0 & 0.3159 \\
\hline gi|405961917 & EF-hand domain-containing family member B & 1.0 & 0.8122 \\
\hline gi|405973546 & Sodium-driven chloride bicarbonate exchanger & 1.0 & \\
\hline gi|405972495 & Aldehyde dehydrogenase family 3 member B1 & 1.0 & \\
\hline
\end{tabular}




\begin{tabular}{|c|c|c|c|}
\hline Accession & Name & Geomean & $\begin{array}{c}\text { Stouffers } \\
\text { P value }\end{array}$ \\
\hline gi|405951213 & Threonine synthase-like 1 & 1.0 & 0.9950 \\
\hline gi|405977152 & Putative ferric-chelate reductase 1 & 1.0 & \\
\hline gi|405952178 & Transcriptional adapter 3-like B & 1.0 & 0.9761 \\
\hline gi|405961403 & Epsin-2 & 1.0 & 0.2790 \\
\hline gi|405971641 & Fibropellin-3 & 1.0 & 0.7503 \\
\hline gi|405952805 & Osteoclast-stimulating factor 1 & 1.0 & 0.9997 \\
\hline gi|405967707 & Transcriptional enhancer factor TEF-1 & 1.0 & \\
\hline gi|405972818 & Myosin heavy chain, striated muscle & 1.0 & 0.6335 \\
\hline gi|405955617 & 3-hydroxyanthranilate 3,4-dioxygenase & 1.0 & 0.5086 \\
\hline gi|405956633 & Eukaryotic translation initiation factor $4 \mathrm{E}$ & 1.0 & 0.7919 \\
\hline gi|405970462 & mRNA-decapping enzyme 1B & 1.0 & 0.8515 \\
\hline gi|405977875 & Hypothetical protein CGI_10024758 & 1.0 & \\
\hline gi|405974530 & Mediator of RNA polymerase II transcription subunit 8-B & 1.0 & 0.9431 \\
\hline gi|405961266 & Hypothetical protein CGI_10014919 & 1.0 & \\
\hline gi|405953908 & Putative peptidyl-tRNA hydrolase 2 & 1.0 & 0.9351 \\
\hline gi|405975724 & Hypothetical protein CGI_10023706 & 1.0 & 0.0169 \\
\hline gi|405957461 & Putative thiopurine S-methyltransferase & 1.0 & 0.2710 \\
\hline gi|405958912 & Hypothetical protein CGI_10024053 & 1.0 & 0.6928 \\
\hline gi|405961051 & Protein FAM21 & 1.0 & \\
\hline gi|405964353 & Uncharacterized protein c3orf30 & 1.0 & \\
\hline gi|405976865 & Translocon-associated protein subunit alpha & 1.0 & 0.9959 \\
\hline gi|405978630 & S-crystallin SL11 & 1.0 & 0.8677 \\
\hline gi|405964587 & Hemagglutinin/amebocyte aggregation factor & 1.0 & \\
\hline gi|405960636 & Leucine-rich repeat-containing protein $16 \mathrm{~A}$ & 1.0 & 0.9715 \\
\hline gi|405975180 & Glutathione S-transferase & 1.0 & 0.6438 \\
\hline gi|405952295 & Hypothetical protein CGI_10006782 & 1.0 & \\
\hline gi|405960755 & Ras-related protein Rab-11A & 1.0 & \\
\hline gi|89520693 & Histone $\mathrm{H} 2 \mathrm{~A}$ & 1.0 & 0.7637 \\
\hline gi|405966160 & UPF0369 protein c6orf57 & 1.0 & 0.9442 \\
\hline gi|405959178 & Hypothetical protein CGI_10014271 & 1.0 & 0.9690 \\
\hline gi|405972821 & Heterogeneous nuclear ribonucleoprotein $L$ & 1.0 & \\
\hline gi|405955229 & Hypothetical protein CGI_10002317 & 1.0 & 0.6658 \\
\hline gi|405952420 & Calmodulin & 1.0 & 0.5131 \\
\hline gi|405952590 & Phospholipid scramblase 2, partial & 1.0 & 0.9775 \\
\hline gi|405954900 & Pinin & 1.0 & 0.3758 \\
\hline gi|405966174 & Ubiquitin-conjugating enzyme E2 variant 1 & 1.0 & \\
\hline gi|405960587 & Proteasomal ubiquitin receptor ADRM1 & 1.0 & \\
\hline gi|405970302 & PDZ domain-containing protein 2 & 1.0 & \\
\hline gi|405953462 & ATP synthase subunit delta, mitochondrial & 1.0 & 0.7018 \\
\hline gi|405975838 & Kinase $\mathrm{C}$ and casein kinase substrate in neurons protein 2 & 1.0 & 0.7796 \\
\hline gi|405971298 & Pallidin & 1.0 & 0.4869 \\
\hline gi|405964737 & Signal peptide, CUB and EGF-like domain-containing protein 3 & 1.0 & 0.4640 \\
\hline gi|405976018 & DNAj-like protein subfamily $\mathrm{C}$ member 7 & 1.0 & \\
\hline gi|405967048 & Scaffold attachment factor B1 & 1.0 & 0.6439 \\
\hline gi|405961393 & RNA-binding protein 25 & 1.0 & 0.9742 \\
\hline gi|405958389 & Protein-glutamine gamma-glutamyltransferase $\mathrm{K}$ & 1.0 & \\
\hline
\end{tabular}




\begin{tabular}{|c|c|c|c|}
\hline Accession & Name & Geomean & $\begin{array}{l}\text { Stouffers } \\
\text { P value }\end{array}$ \\
\hline gi|405953525 & Endophilin-A2 & 1.0 & 0.9272 \\
\hline gi|405969437 & THO complex subunit 4-A & 1.0 & 0.4572 \\
\hline gi|405967115 & Peptidyl-prolyl cis-trans isomerase 6 & 1.0 & 0.7636 \\
\hline gi|405977715 & Katanin $\mathrm{p} 80$ WD40-containing subunit B1 & 1.0 & \\
\hline gi|405967749 & Catenin alpha-2 & 1.0 & \\
\hline gi|405972911 & Latrophilin-1 & 1.0 & \\
\hline gi|405961473 & Thioredoxin domain-containing protein 12 & 1.0 & 0.7548 \\
\hline gi|405953479 & Hypothetical protein CGI_10004540 & 1.0 & 0.9795 \\
\hline gi|405975742 & High mobility group protein DSP1 & 1.0 & 0.1627 \\
\hline gi|405957373 & Sulfotransferase $1 \mathrm{~A} 1$ & 1.0 & 0.0916 \\
\hline gi|405961475 & Pre-mRNA-processing factor 40 -like protein A & 1.0 & 0.8747 \\
\hline gi|405954083 & COX assembly mitochondrial-like protein & 1.0 & \\
\hline gi|405961598 & U6 snRNA-associated Sm-like protein Ism1 & 1.0 & 0.7846 \\
\hline gi|405962293 & Superoxide dismutase [Mn], mitochondrial & 1.0 & 0.7728 \\
\hline gi|405959304 & Smoothelin-like protein 1 & 1.0 & \\
\hline gi|405958864 & Hypothetical protein CGI_10010933 & 1.0 & 0.9936 \\
\hline gi|405950245 & Cation-dependent mannose-6-phosphate receptor & 1.0 & \\
\hline gi|405958707 & Collagen alpha-2(I) chain & 1.0 & 0.4062 \\
\hline gi|405959517 & $\begin{array}{l}\text { Uncharacterized protein in QAH/OAS sulfhydrylase 3'region, } \\
\text { partial }\end{array}$ & 1.0 & 0.9562 \\
\hline gi|405954593 & Calbindin-32 & 1.0 & 0.3272 \\
\hline gi|405957905 & $\mathrm{N}$-acylethanolamine-hydrolyzing acid amidase & 1.0 & \\
\hline gi|405977416 & U4/U6.U5 tri-snRNP-associated protein 1 & 1.0 & \\
\hline gi|405966603 & $\begin{array}{l}\text { Mitochondrial import inner membrane translocase subunit } \\
\text { Tim13-B }\end{array}$ & 1.0 & 0.6022 \\
\hline gi|405957249 & Src substrate cortactin & 1.0 & 0.8239 \\
\hline gi|405967030 & Hypothetical protein CGI_10026232 & 1.0 & \\
\hline gi|405945995 & Laminin subunit beta- 2 & 1.0 & 0.9834 \\
\hline gi|405974075 & Hypothetical protein CGI_10020417 & 1.0 & 0.9682 \\
\hline gi|405974711 & Serine/threonine-protein phosphatase $2 \mathrm{~A}$ regulatory subunit B' & 1.0 & \\
\hline gi|405969928 & Von Willebrand factor D and EGF domain-containing protein & 1.0 & 0.9749 \\
\hline gi|405950130 & Hypothetical protein CGI_10015025 & 1.0 & 0.9747 \\
\hline gi|405976672 & Programmed cell death protein 5 & 1.0 & 0.3091 \\
\hline gi|405958653 & Hypothetical protein CGI_10006272 & 1.0 & 0.0650 \\
\hline gi|405967137 & Ubiquitin-conjugating enzyme E2 L3 & 1.0 & 0.7734 \\
\hline gi|405950755 & Hypothetical protein CGI_10011395 & 1.0 & \\
\hline gi|405972819 & Golgin subfamily A member 2 & 1.0 & \\
\hline gi|405962439 & $26 S$ proteasome non-ATPase regulatory subunit 7 & 1.0 & 0.9092 \\
\hline gi|405957146 & Splicing factor, proline- and glutamine-rich & 1.0 & \\
\hline gi|405972383 & Coiled-coil domain-containing protein 91 & 1.0 & 0.3898 \\
\hline gi|405964350 & Centrin-3 & 1.0 & 0.6783 \\
\hline gi|405966530 & Hypothetical protein CGI_10010194 & 1.0 & 0.7585 \\
\hline gi|405952828 & PERQ amino acid-rich with GYF domain-containing protein 2 & 1.0 & 0.8863 \\
\hline gi|405972109 & Hypothetical protein CGI_10027088 & 1.0 & 0.6777 \\
\hline gi|405967615 & 4-hydroxybutyrate coenzyme A transferase & 1.0 & 0.8395 \\
\hline gi|405954337 & Hypothetical protein CGI_10003282 & 1.0 & \\
\hline gi|405969715 & Short-chain collagen $\mathrm{C} 4$ & 1.0 & 0.0054 \\
\hline
\end{tabular}




\begin{tabular}{|c|c|c|c|}
\hline Accession & Name & Geomean & $\begin{array}{c}\text { Stouffers } \\
\text { P value }\end{array}$ \\
\hline gi|405967397 & Calmodulin & 1.0 & 0.9895 \\
\hline gi|405964692 & Alpha-N-acetylglucosaminidase & 1.0 & \\
\hline gi|405963352 & Signal transducing adapter molecule 2 & 1.0 & 0.1424 \\
\hline gi|405952542 & Hypothetical protein CGI_10006212 & 1.0 & 0.2341 \\
\hline gi|405975922 & Replication protein $\mathrm{A} 14 \mathrm{kDa}$ subunit & 1.0 & 0.7793 \\
\hline gi|405976955 & Zonadhesin & 1.0 & 0.3304 \\
\hline gi|405974949 & Camp-dependent protein kinase regulatory subunit & 1.0 & 0.5341 \\
\hline gi|405976936 & Leucine-rich repeat-containing protein 23 & 1.0 & \\
\hline gi|405959795 & A-kinase anchor protein 9 & 1.0 & \\
\hline gi|405952395 & WD repeat-containing protein 27 & 1.0 & \\
\hline gi|405953430 & Ribosome-binding protein 1 & 1.0 & 0.8685 \\
\hline gi|405961595 & Anosmin-1 & 1.0 & 0.1549 \\
\hline gi|405969345 & Ubiquitin-associated protein 2 & 1.0 & 0.9477 \\
\hline gi|405959696 & RPE-spondin & 1.0 & \\
\hline gi|405974916 & Hypothetical protein CGI_10027938 & 1.0 & 0.9710 \\
\hline gi|405977985 & Hypothetical protein CGI_10015704 & 1.0 & \\
\hline gi|405958347 & Putative RNA-binding protein EIF1AD & 1.0 & \\
\hline gi|405972504 & Hypothetical protein CGI_10018585 & 1.0 & 0.0968 \\
\hline gi|405969366 & Syntaxin-6 & 1.0 & 0.6791 \\
\hline gi|405968992 & IQ domain-containing protein $\mathrm{D}$ & 1.0 & 0.3979 \\
\hline gi|405952454 & Epidermal growth factor receptor substrate 15-like 1 & 1.0 & 0.5380 \\
\hline gi|405977720 & Charged multivesicular body protein $1 \mathrm{a}$ & 1.0 & 0.8441 \\
\hline gi|405965139 & Sorting nexin-2 & 1.0 & 0.2393 \\
\hline gi|405958822 & Hypothetical protein CGI_10008262 & 1.0 & 0.8549 \\
\hline gi|405966265 & Hypothetical protein CGI_10027684 & 1.0 & 0.4544 \\
\hline gi|405963175 & $60 \mathrm{kDa}$ neurofilament protein & 1.0 & \\
\hline gi|405957466 & Dynein heavy chain 5 , axonemal & 1.0 & \\
\hline gi|405976945 & Hypothetical protein CGI_10017525 & 1.0 & \\
\hline gi|405957909 & Hypothetical protein CGI_10015176 & 1.0 & 0.1139 \\
\hline gi|405965222 & Centrosome and spindle pole-associated protein 1 & 1.0 & \\
\hline gi|405978643 & Hypothetical protein CGI_10013193 & 1.0 & 0.6047 \\
\hline gi|405969114 & Thioredoxin domain-containing protein 3-like protein & 1.0 & 0.8185 \\
\hline gi|405965168 & Pyruvate carboxylase, mitochondrial & 1.0 & 0.9382 \\
\hline gi|405978684 & Collagen alpha-1(IV) chain & 1.0 & 0.9536 \\
\hline gi|405964475 & Hypothetical protein CGI_10015378 & 1.0 & 0.2798 \\
\hline gi|405977633 & 1,4-alpha-glucan-branching enzyme & 1.1 & \\
\hline gi|405967042 & Splicing factor, arginine/serine-rich 2 & 1.1 & \\
\hline gi|405964001 & Transcription initiation factor TFIID subunit 8 & 1.1 & 0.5416 \\
\hline gi|405972257 & Hypothetical protein CGI_10014350 & 1.1 & \\
\hline gi|405977877 & Dysferlin & 1.1 & 0.8549 \\
\hline gi|405961806 & GRIP1-associated protein 1 & 1.1 & 0.3400 \\
\hline gi|405962442 & Casein kinase II subunit alpha & 1.1 & \\
\hline gi|405959343 & Blastula protease 10 & 1.1 & 0.4406 \\
\hline gi|405971130 & Anaphase-promoting complex subunit CDC26 & 1.1 & \\
\hline gi|405950756 & JMJC domain-containing protein 5 & 1.1 & 0.1518 \\
\hline gi|405965772 & Hypothetical protein CGI_10028757 & 1.1 & 0.6051 \\
\hline
\end{tabular}




\begin{tabular}{|c|c|c|c|}
\hline Accession & Name & Geomean & $\begin{array}{l}\text { Stouffers } \\
\text { P value }\end{array}$ \\
\hline gi|405971580 & Transcription elongation factor B polypeptide 1 & 1.1 & 0.7794 \\
\hline gi|405964909 & Poly [ADP-ribose] polymerase 1 & 1.1 & 0.1626 \\
\hline gi|405976464 & Transcription cofactor vestigial-like protein 4 & 1.1 & 0.3724 \\
\hline gi|405964679 & Neurexin-4 & 1.1 & \\
\hline gi|405963849 & RIB43A-like with coiled-coils protein 2 & 1.1 & 0.1035 \\
\hline gi|15004986 & Integrin beta $\mathrm{CGH}$ & 1.1 & 0.4921 \\
\hline gi|405974565 & RNA-binding protein 4 & 1.1 & 0.8152 \\
\hline gi|405973443 & Protein CEPU-1 & 1.1 & 0.4590 \\
\hline gi|405951130 & Protein TFG & 1.1 & 0.9477 \\
\hline gi|405963074 & Hypothetical protein CGI_10018932 & 1.1 & \\
\hline gi|405950378 & GSK3-beta interaction protein & 1.1 & 0.8520 \\
\hline gi|405965141 & Ubiquilin-1 & 1.1 & 0.0011 \\
\hline gi|405952872 & Splicing factor 3B subunit 2 & 1.1 & 0.2734 \\
\hline gi|405961965 & Kinesin light chain & 1.1 & \\
\hline gi|405967393 & Calmodulin & 1.1 & \\
\hline gi|405977263 & Heterogeneous nuclear ribonucleoprotein A2-like protein 1 & 1.1 & 0.7094 \\
\hline gi|405969301 & Hypothetical protein CGI_10019990 & 1.1 & 0.8949 \\
\hline gi|405952827 & PERQ amino acid-rich with GYF domain-containing protein 1 & 1.1 & 0.9008 \\
\hline gi|405963192 & Von Willebrand factor D and EGF domain-containing protein & 1.1 & 0.3345 \\
\hline gi|405963398 & Hypothetical protein CGI_10011849 & 1.1 & 0.2019 \\
\hline gi|405945610 & Hypothetical protein CGI_10000903 & 1.1 & 0.7594 \\
\hline gi|405971628 & Coiled-coil domain-containing protein 39 & 1.1 & 0.7092 \\
\hline gi|405974595 & Vacuolar protein sorting-associated protein VTA1-like protein & 1.1 & 0.4855 \\
\hline gi|405950507 & Integrin beta-3 & 1.1 & 0.6829 \\
\hline gi|405963880 & CDK5 regulatory subunit-associated protein 3 & 1.1 & 0.9160 \\
\hline gi|405967570 & Fibropellin-1 & 1.1 & 0.9319 \\
\hline gi|405961169 & Stress-induced protein 1 & 1.1 & 0.7485 \\
\hline gi|405951108 & Homeobox protein SIX1 & 1.1 & 0.6405 \\
\hline gi|405957632 & Hypothetical protein CGI_10020214 & 1.1 & \\
\hline gi|405952506 & Hypothetical protein CGI_10006312 & 1.1 & 0.6205 \\
\hline gi|405956965 & TRAF3-interacting protein 1 & 1.1 & 0.6916 \\
\hline gi|405964670 & Histidine triad nucleotide-binding protein 1 & 1.1 & 0.7560 \\
\hline gi|405972487 & CDV3-like protein & 1.1 & 0.1907 \\
\hline gi|405970769 & Hypothetical protein CGI_10020336 & 1.1 & \\
\hline gi|405968899 & Putative beta-D-xylosidase 5 & 1.1 & 0.9659 \\
\hline gi|405977380 & Radial spoke head protein 3-like protein & 1.1 & 0.2924 \\
\hline gi|405974423 & Hypothetical protein CGI_10018548 & 1.1 & 0.8964 \\
\hline gi|405966835 & Hypothetical protein CGI_10013436 & 1.1 & 0.7628 \\
\hline gi|405969964 & Metalloproteinase inhibitor 3 & 1.1 & 0.0657 \\
\hline gi|405952218 & DNAj-like protein subfamily $B$ member 13 & 1.1 & 0.9847 \\
\hline gi|405953771 & Proapoptotic caspase adapter protein & 1.1 & 0.7509 \\
\hline gi|405960949 & Hypothetical protein CGI_10013854 & 1.1 & 0.2141 \\
\hline gi|405954140 & $\begin{array}{l}\text { SWI/SNF-related matrix-associated actin-dependent regulator } \\
\text { chromatin subfamily E member } 1\end{array}$ & 1.1 & 0.6172 \\
\hline gi|405972167 & Hypothetical protein CGI_10023100 & 1.1 & 0.8106 \\
\hline gi|405975201 & $\mathrm{SH} 3$ domain-containing guanine exchange factor & 1.1 & \\
\hline
\end{tabular}




\begin{tabular}{|c|c|c|c|}
\hline Accession & Name & Geomean & $\begin{array}{c}\text { Stouffers } \\
\text { P value }\end{array}$ \\
\hline gi|405974267 & Halomucin & 1.1 & 0.9756 \\
\hline gi|405954158 & Lachesin & 1.1 & 0.9061 \\
\hline gi|405971248 & NFU1 iron-sulfur cluster scaffold-like protein, mitochondrial & 1.1 & 0.5527 \\
\hline gi|405946542 & Charged multivesicular body protein $4 \mathrm{~b}$ & 1.1 & 0.1450 \\
\hline gi|405972110 & Hypothetical protein CGI_10027089 & 1.1 & 0.5546 \\
\hline gi|405950693 & V-type proton ATPase subunit E & 1.1 & 0.1167 \\
\hline gi|84619354 & Cytochrome b5 & 1.1 & 0.4510 \\
\hline gi|405959751 & $28 \mathrm{kDa}$ heat- and acid-stable phosphoprotein & 1.1 & 0.4727 \\
\hline gi|405977841 & Partner of $\mathrm{Y} 14$ and MAGO & 1.1 & 0.9778 \\
\hline gi|405965784 & Leucine-rich repeat-containing protein c10orf11-like protein & 1.1 & 0.9220 \\
\hline gi|405974726 & U1 small nuclear ribonucleoprotein A & 1.1 & 0.1225 \\
\hline gi|405950030 & Stress-70 protein, mitochondrial & 1.1 & 0.6808 \\
\hline gi|405957528 & Hypothetical protein CGI_10021888 & 1.1 & 0.4885 \\
\hline gi|405963739 & EF-hand calcium-binding domain-containing protein 6 & 1.1 & 0.0022 \\
\hline gi|405975722 & Polyamine-modulated factor 1-binding protein 1 & 1.1 & 0.4212 \\
\hline gi|405958647 & Ectoine hydroxylase & 1.1 & \\
\hline gi|13194854 & Metallothionein & 1.1 & \\
\hline gi|405974086 & Coiled-coil domain-containing protein 63 & 1.1 & 0.5182 \\
\hline gi|405969388 & Gamma-glutamyltranspeptidase 1, partial & 1.1 & 0.8475 \\
\hline gi|405970031 & Receptor-type tyrosine-protein phosphatase N2 & 1.1 & 0.3708 \\
\hline gi|405970778 & $\mathrm{IQ}$ domain-containing protein $\mathrm{K}$ & 1.1 & 0.4469 \\
\hline gi|405972779 & Hypothetical protein CGI_10013979 & 1.1 & \\
\hline gi|405964769 & Putative ATP-dependent RNA helicase DDX47 & 1.1 & \\
\hline gi|405952731 & Lupus La-like protein & 1.1 & 0.1593 \\
\hline gi|405975566 & $60 S$ ribosomal protein $\mathrm{L} 36$ & 1.1 & 0.9348 \\
\hline gi|405967712 & Ubiquitin thioesterase OTUB1 & 1.1 & 0.2381 \\
\hline gi|405972323 & EGF-like domain-containing protein 8 & 1.1 & \\
\hline gi|405973520 & UPF0449 protein c19orf25-like protein & 1.1 & 0.6261 \\
\hline gi|405954191 & Hypothetical protein CGI_10003464 & 1.1 & 0.2024 \\
\hline gi|405971603 & Cathepsin L & 1.1 & 0.5611 \\
\hline gi|405958119 & Gamma-interferon-inducible lysosomal thiol reductase & 1.1 & 0.4605 \\
\hline gi|405969505 & Toll-interacting protein & 1.1 & 0.9326 \\
\hline gi|405963740 & U4/U6.U5 tri-snRNP-associated protein 2 & 1.1 & \\
\hline gi|405957329 & Hypothetical protein CGI_10005495 & 1.1 & \\
\hline gi|405971821 & Heat shock $70 \mathrm{kDa}$ protein $12 \mathrm{~A}$ & 1.1 & \\
\hline gi|405950403 & Hypothetical protein CGI_10012758 & 1.1 & 0.0491 \\
\hline gi|405966511 & ELKS/RAB6-interacting/CAST family member 1 & 1.1 & 0.8196 \\
\hline gi|405959015 & Tetraspanin-7 & 1.1 & 0.7052 \\
\hline gi|405978546 & Hypothetical protein CGI_10028902 & 1.1 & \\
\hline gi|405964229 & Golgi SNAP receptor complex member 2 & 1.1 & \\
\hline gi|405967105 & Golgi apparatus protein 1 & 1.1 & 0.0013 \\
\hline gi|405967851 & Hypothetical protein CGI_10011344 & 1.1 & \\
\hline gi|405959151 & Hypothetical protein CGI_10003818 & 1.1 & \\
\hline gi|405957242 & Group XIIA secretory phospholipase A2 & 1.1 & \\
\hline gi|405969480 & LIM domain and actin-binding protein 1 & 1.1 & 0.0011 \\
\hline gi|405976518 & Syntaxin-7 & 1.1 & 0.3489 \\
\hline
\end{tabular}




\begin{tabular}{|c|c|c|c|}
\hline Accession & Name & Geomean & $\begin{array}{l}\text { Stouffers } \\
\text { P value }\end{array}$ \\
\hline gi|405974767 & Splicing factor 4 & 1.1 & 0.2034 \\
\hline gi|405946926 & CD63 antigen & 1.1 & 0.6226 \\
\hline gi|405950944 & Phospholipase D1 & 1.1 & 0.1266 \\
\hline gi|405969560 & Globin & 1.1 & 0.6011 \\
\hline gi|405974348 & Extracellular superoxide dismutase [Cu-Zn] & 1.1 & 0.4894 \\
\hline gi|405955658 & Hypothetical protein CGI_10001712 & 1.1 & 0.8552 \\
\hline gi|405974270 & 5'-AMP-activated protein kinase subunit beta-2 & 1.1 & 0.4907 \\
\hline gi|405953851 & Alpha-2-macroglobulin receptor-associated protein & 1.1 & 0.8492 \\
\hline gi|405971620 & ES1-like protein, mitochondrial & 1.1 & \\
\hline gi|405972618 & Peptidyl-prolyl cis-trans isomerase C & 1.1 & 0.2226 \\
\hline gi|405972364 & IST1-like protein & 1.1 & 0.2764 \\
\hline gi|405967002 & Linear gramicidin synthetase subunit $\mathrm{D}$ & 1.1 & \\
\hline gi|405966392 & Dystroglycan & 1.1 & 0.0993 \\
\hline gi|405952289 & $\begin{array}{l}\text { Microtubule-associated serine/threonine-protein kinase-like } \\
\text { protein }\end{array}$ & 1.1 & 0.6552 \\
\hline gi|405967433 & Hypothetical protein CGI_10008200 & 1.1 & 0.1956 \\
\hline gi|405968301 & Hypothetical protein CGI_10025906 & 1.1 & 0.0054 \\
\hline gi|405957186 & RNA-binding protein Nova-1 & 1.1 & \\
\hline gi|405975720 & Endoplasmic reticulum protein erp29 & 1.1 & 0.7811 \\
\hline gi|405950627 & Hypothetical protein CGI_10011730 & 1.1 & 0.1478 \\
\hline gi|405966631 & Deleted in malignant brain tumors 1 protein & 1.1 & 0.6577 \\
\hline gi|405967888 & NGFI-A-binding-like protein & 1.1 & 0.6097 \\
\hline gi|405972517 & Coiled-coil domain-containing protein 37 & 1.1 & 0.6304 \\
\hline gi|405961156 & Myosin-XVI & 1.1 & 0.2226 \\
\hline gi|405950251 & Golgi integral membrane protein 4 & 1.1 & 0.1430 \\
\hline gi|405976087 & Splicing factor U2AF $50 \mathrm{kDa}$ subunit & 1.1 & 0.8590 \\
\hline gi|405970006 & Hypothetical protein CGI_10016230 & 1.1 & \\
\hline gi|405971858 & Acetyl-CoA acetyltransferase & 1.1 & \\
\hline gi|405962705 & Golgi phosphoprotein 3 & 1.1 & 0.1277 \\
\hline gi|405959268 & Synaptosomal-associated protein 25 & 1.1 & 0.1560 \\
\hline gi|405950484 & Hypothetical protein CGI_10012368 & 1.1 & 0.8573 \\
\hline gi|405957161 & TAR DNA-binding protein 43 & 1.1 & 0.7842 \\
\hline gi|405960379 & Hypothetical protein CGI_10012583 & 1.1 & 0.4679 \\
\hline gi|405974721 & $\mathrm{Na}(+) / \mathrm{H}(+)$ exchange regulatory cofactor NHE-RF1 & 1.1 & 0.0023 \\
\hline gi|405959691 & Cytochrome $\mathrm{c}$ oxidase subunit $5 \mathrm{~A}$, mitochondrial & 1.1 & 0.1351 \\
\hline gi|405951707 & 6-phosphofructokinase & 1.1 & 0.8101 \\
\hline gi|405972200 & Coiled-coil domain-containing protein 9 & 1.1 & 0.8579 \\
\hline gi|405971114 & Talin-1 & 1.1 & \\
\hline gi|405959244 & FGFR1 oncogene partner 2-like protein & 1.1 & 0.6681 \\
\hline gi|405961689 & UPF0631 protein & 1.1 & \\
\hline gi|405973051 & Neuron navigator 2 & 1.1 & \\
\hline gi|405976108 & Iron-sulfur cluster assembly enzyme ISCU, mitochondrial & 1.1 & 0.4616 \\
\hline gi|405953955 & Hypothetical protein CGI_10003801 & 1.1 & 0.8487 \\
\hline gi|405969642 & $\begin{array}{l}\text { NADH dehydrogenase [ubiquinone] } 1 \text { alpha subcomplex } \\
\text { subunit } 7\end{array}$ & 1.1 & 0.1097 \\
\hline gi|405976128 & Coiled-coil domain-containing protein 6 & 1.1 & 0.0396 \\
\hline gi|405973510 & Transcription initiation factor TFIID subunit 10 & 1.1 & 0.7163 \\
\hline
\end{tabular}




\begin{tabular}{|c|c|c|c|}
\hline Accession & Name & Geomean & $\begin{array}{c}\text { Stouffers } \\
\text { P value }\end{array}$ \\
\hline gi|405967643 & Bromodomain testis-specific protein & 1.1 & 0.5691 \\
\hline gi|405967554 & Hypothetical protein CGI_10024080 & 1.1 & 0.7848 \\
\hline gi|405975437 & ARF GTPase-activating protein GIT2 & 1.1 & \\
\hline gi|405959607 & Coiled-coil domain-containing protein 58 & 1.1 & 0.0009 \\
\hline gi|405961593 & MORN repeat-containing protein 4 & 1.1 & 0.4488 \\
\hline gi|405952912 & $65 \mathrm{kDa}$ Yes-associated protein & 1.1 & 0.2140 \\
\hline gi|405951822 & Collagen alpha-2(I) chain & 1.1 & \\
\hline gi|405971414 & Hypothetical protein CGI_10024180 & 1.1 & \\
\hline gi|405966525 & Neuroligin-4, X-linked & 1.1 & 0.7197 \\
\hline gi|219806594 & Tropomyosin & 1.1 & 0.4079 \\
\hline gi|405972408 & Shootin-1 & 1.1 & 0.8392 \\
\hline gi|405953045 & PDZ domain-containing protein GIPC1 & 1.1 & \\
\hline gi|405952388 & Spermatogenesis-associated protein 4 & 1.1 & 0.7239 \\
\hline gi|405950308 & Hypothetical protein CGI_10013719 & 1.1 & 0.5712 \\
\hline gi|405950980 & Caltractin & 1.1 & \\
\hline gi|405965146 & Hypothetical protein CGI_10006541 & 1.1 & \\
\hline gi|405964925 & Ankyrin repeat domain-containing protein 45 & 1.1 & 0.0797 \\
\hline gi|405975170 & CUB and sushi domain-containing protein 1 & 1.1 & 0.2199 \\
\hline gi|405950170 & FYN-binding protein & 1.1 & 0.9392 \\
\hline gi|405965620 & Hypothetical protein CGI_10024980 & 1.1 & 0.0034 \\
\hline gi|405964242 & Hypothetical protein CGI_10009344 & 1.1 & 0.1969 \\
\hline gi|405957436 & Forkhead box protein $\mathrm{O}$ & 1.1 & 0.3522 \\
\hline gi|405970485 & Ganglioside GM2 activator & 1.1 & 0.7134 \\
\hline gi|405951541 & Fatty acid-binding protein, heart & 1.1 & 0.0709 \\
\hline gi|405961967 & Eukaryotic translation initiation factor 5 & 1.1 & 0.2865 \\
\hline gi|405962914 & Synaptosomal-associated protein 29 & 1.1 & 0.7173 \\
\hline gi|405952153 & Heterogeneous nuclear ribonucleoprotein $\mathrm{H}$ & 1.1 & 0.4213 \\
\hline gi|405957338 & Hypothetical protein CGI_10011960 & 1.1 & 0.2513 \\
\hline gi|405951873 & Transcription initiation factor TFIID subunit 11 & 1.1 & \\
\hline gi|405973085 & Serine protease inhibitor dipetalogastin & 1.1 & \\
\hline gi|405977464 & Protein DEK & 1.1 & 0.2668 \\
\hline gi|405953431 & Enolase-phosphatase E1 & 1.1 & 0.0467 \\
\hline gi|405975282 & Cytochrome $\mathrm{c}$ oxidase subunit $6 \mathrm{~B}$ & 1.1 & 0.0066 \\
\hline gi|405954092 & Mitochondrial fission factor-like protein B & 1.1 & 0.0314 \\
\hline gi|405957619 & Hypothetical protein CGI_10020198 & 1.1 & \\
\hline gi|405958225 & Protein c20orf11 & 1.1 & 0.0017 \\
\hline gi|405974739 & Hypothetical protein CGI_10019003 & 1.1 & 0.0000 \\
\hline gi|405964978 & Hypothetical protein CGI_10003651 & 1.1 & \\
\hline gi|405952962 & Galectin-4 & 1.1 & 0.3980 \\
\hline gi|405961167 & Uncharacterized protein c21orf59-like protein & 1.1 & \\
\hline gi|405976454 & Hypothetical protein CGI_10028684 & 1.1 & 0.6479 \\
\hline gi|405962321 & Histone H2B.3 & 1.1 & 0.1305 \\
\hline gi|405965147 & Apoptosis regulator $\mathrm{Bcl}-2$ & 1.1 & 0.7399 \\
\hline gi|405976533 & Hsp90 co-chaperone Cdc37 & 1.1 & 0.7213 \\
\hline gi|405963231 & Hypothetical protein CGI_10019048 & 1.1 & \\
\hline gi|405977993 & Arfaptin-1 & 1.1 & \\
\hline
\end{tabular}




\begin{tabular}{|c|c|c|c|}
\hline Accession & Name & Geomean & $\begin{array}{l}\text { Stouffers } \\
\mathrm{P} \text { value }\end{array}$ \\
\hline gi|405965276 & Neurocalcin-like protein & 1.1 & 0.0751 \\
\hline gi|405961084 & $\begin{array}{l}\text { NADH dehydrogenase [ubiquinone] iron-sulfur protein } 6 \text {, } \\
\text { mitochondrial }\end{array}$ & 1.1 & 0.4509 \\
\hline gi|405977536 & Protein dr1 & 1.1 & 0.6461 \\
\hline gi|405961926 & Hypothetical protein CGI_10016949 & 1.1 & 0.6184 \\
\hline gi|405952543 & Target of Myb protein 1 & 1.1 & 0.0050 \\
\hline gi|405959058 & Hypothetical protein CGI_10008488 & 1.1 & \\
\hline gi|405969502 & Hypothetical protein CGI_10015393 & 1.1 & 0.5110 \\
\hline gi|405968991 & Bola-like protein 2 & 1.1 & 0.2155 \\
\hline gi|405976099 & Annexin A7 & 1.1 & 0.1447 \\
\hline gi|163637085 & Coiled-coil-helix-coiled-coil-helix domain containing 3 & 1.1 & 0.8030 \\
\hline gi|405978275 & EF-hand calcium-binding domain-containing protein 2 & 1.1 & 0.4859 \\
\hline gi|157169145 & Histone $\mathrm{H} 4$ & 1.1 & 0.2266 \\
\hline gi|238768474 & Peptidoglycan recognition protein $\mathrm{L}$ & 1.1 & 0.1688 \\
\hline gi|405957670 & Peroxiredoxin-6 & 1.1 & 0.0272 \\
\hline gi|405963725 & Sarcoplasmic reticulum histidine-rich calcium-binding protein & 1.1 & 0.0244 \\
\hline gi|405977264 & Chromobox-like protein 5 & 1.1 & 0.0114 \\
\hline gi|405975372 & Hypothetical protein CGI_10026945 & 1.1 & 0.2350 \\
\hline gi|405964031 & Sodium channel and clathrin linker 1 & 1.1 & 0.2896 \\
\hline gi|405955495 & Hypothetical protein CGI_10001933 & 1.1 & \\
\hline gi|405973516 & Spectrin alpha chain & 1.1 & 0.0000 \\
\hline gi|405950353 & Excitatory amino acid transporter 3 & 1.1 & \\
\hline gi|405969112 & Protein dodo & 1.1 & 0.0337 \\
\hline gi|405977455 & Glyoxalase domain-containing protein 5 , partial & 1.1 & 0.6714 \\
\hline gi|405973843 & DNA-binding protein $\mathrm{P} 3 \mathrm{~A} 2$ & 1.1 & \\
\hline gi|405958072 & Sperm-associated antigen 8 & 1.1 & 0.3155 \\
\hline gi|405952419 & Calmodulin & 1.1 & \\
\hline gi|405955674 & Hypothetical protein CGI_10001667 & 1.1 & \\
\hline gi|405976040 & Acyl carrier protein, mitochondrial & 1.1 & 0.0726 \\
\hline gi|405974017 & Hypothetical protein CGI_10020808 & 1.1 & \\
\hline gi|405949997 & Serine/arginine repetitive matrix protein 2 & 1.1 & 0.8833 \\
\hline gi|405954918 & Hypothetical protein CGI_10002631 & 1.1 & 0.6528 \\
\hline gi|405977353 & DNA fragmentation factor subunit alpha, partial & 1.1 & 0.6201 \\
\hline gi|405976455 & Hypothetical protein CGI_10028685 & 1.1 & 0.3926 \\
\hline gi|405951461 & V-type proton ATPase subunit F & 1.1 & 0.1785 \\
\hline gi|405962717 & Low-density lipoprotein receptor-related protein 1B & 1.1 & \\
\hline gi|405961344 & Transforming acidic coiled-coil-containing protein 1 & 1.1 & 0.0018 \\
\hline gi|405963947 & PDZ and LIM domain protein 1 & 1.1 & 0.3413 \\
\hline gi|405970996 & Nuclear autoantigenic sperm protein & 1.1 & 0.0059 \\
\hline gi|405972053 & Sarcoplasmic calcium-binding protein & 1.1 & 0.5455 \\
\hline gi|405963289 & $\begin{array}{l}\text { Electron transfer flavoprotein-ubiquinone oxidoreductase, } \\
\text { mitochondrial }\end{array}$ & 1.1 & \\
\hline gi|405976093 & DPY30 domain-containing protein 1 & 1.1 & 0.0013 \\
\hline gi|405973002 & $\begin{array}{l}\text { Vesicle transport through interaction with t-snares-like protein } \\
\text { 1B }\end{array}$ & 1.1 & \\
\hline gi|405953907 & Hypothetical protein CGI_10003856 & 1.1 & 0.3376 \\
\hline gi|405963174 & MORN repeat-containing protein 5 & 1.1 & 0.4606 \\
\hline
\end{tabular}




\begin{tabular}{|c|c|c|c|}
\hline Accession & Name & Geomean & $\begin{array}{l}\text { Stouffers } \\
\text { P value }\end{array}$ \\
\hline gi|48476115 & Cyclophilin & 1.1 & 0.0887 \\
\hline gi|405961012 & Superoxide dismutase [Cu-Zn] & 1.1 & 0.0056 \\
\hline gi|405959513 & Hypothetical protein CGI_10009216, partial & 1.1 & \\
\hline gi|405967117 & Apoptotic chromatin condensation inducer in the nucleus & 1.1 & \\
\hline gi|405970439 & BAG family molecular chaperone regulator 1 & 1.1 & 0.0508 \\
\hline gi|405961662 & Neurocalcin-like protein & 1.1 & 0.1670 \\
\hline gi|405976028 & Canopy-like protein 3 & 1.1 & 0.0336 \\
\hline gi|405962821 & Hypothetical protein CGI_10027749 & 1.1 & 0.1338 \\
\hline gi|7573639 & Calcineurin B & 1.1 & 0.1067 \\
\hline gi|405967062 & Sulfotransferase family cytosolic 1B member 1 & 1.1 & \\
\hline gi|405976256 & Ribonuclease $\mathrm{H} 1$ & 1.2 & \\
\hline gi|33337627 & Astacin metalloprotease & 1.2 & \\
\hline gi|405974405 & Coiled-coil domain-containing protein 42 -like protein & 1.2 & 0.3040 \\
\hline gi|405975381 & Huntingtin-interacting protein $\mathrm{K}$ & 1.2 & 0.0638 \\
\hline gi|405971402 & Coiled-coil domain-containing protein 96 & 1.2 & 0.4192 \\
\hline gi|405961240 & Sperm surface protein Sp17 & 1.2 & 0.0000 \\
\hline gi|405970312 & Alpha- $\mathrm{N}$-acetylgalactosaminidase & 1.2 & \\
\hline gi|405973292 & Protein cappuccino & 1.2 & 0.0696 \\
\hline gi|405957984 & Apolipoprotein D & 1.2 & 0.0257 \\
\hline gi|405960381 & Monocarboxylate transporter 12 & 1.2 & 0.5221 \\
\hline gi|405950863 & Hypothetical protein CGI_10010851 & 1.2 & 0.0973 \\
\hline gi|405957279 & $\begin{array}{l}\text { NADH dehydrogenase [ubiquinone] iron-sulfur protein } 4 \text {, } \\
\text { mitochondrial }\end{array}$ & 1.2 & 0.0837 \\
\hline gi|405951006 & EF-hand domain-containing protein D2 & 1.2 & 0.0377 \\
\hline gi|405977358 & Hypothetical protein CGI_10026433 & 1.2 & 0.3336 \\
\hline gi|405961408 & Hypothetical protein CGI_10005088 & 1.2 & 0.0127 \\
\hline gi|405976591 & Bicaudal D-like protein 2 & 1.2 & 0.2629 \\
\hline gi|405967494 & Hypothetical protein CGI_10011463 & 1.2 & 0.7868 \\
\hline gi|405960203 & Upstream stimulatory factor 2 & 1.2 & 0.1142 \\
\hline gi|405971719 & Hypothetical protein CGI_10004063 & 1.2 & 0.0056 \\
\hline gi|405963900 & Formin-binding protein 1 -like protein & 1.2 & 0.5589 \\
\hline gi|405951825 & Nidogen-2 & 1.2 & \\
\hline gi|405958692 & Hypothetical protein CGI_10019555 & 1.2 & \\
\hline gi|26892108 & LBP/bpi & 1.2 & \\
\hline gi|405960179 & Hypothetical protein CGI_10010255 & 1.2 & \\
\hline gi|405977312 & Heterogeneous nuclear ribonucleoprotein $27 \mathrm{C}$ & 1.2 & 0.6941 \\
\hline gi|405954099 & Triosephosphate isomerase B & 1.2 & 0.5470 \\
\hline gi|405961725 & Alpha-tocopherol transfer-like protein & 1.2 & 0.3071 \\
\hline gi|405970214 & Ataxin-2 & 1.2 & \\
\hline gi|405973348 & SH3 domain-containing kinase-binding protein 1 & 1.2 & 0.1958 \\
\hline gi|405970315 & Mitochondrial import inner membrane translocase subunit Tim8 & 1.2 & 0.1299 \\
\hline gi|405973713 & Serine/threonine-protein kinase PAK 3 & 1.2 & 0.5136 \\
\hline gi|405958424 & Cytochrome c oxidase subunit $5 \mathrm{~B}$, mitochondrial & 1.2 & 0.2352 \\
\hline gi|405958268 & $\begin{array}{l}\text { Mitochondrial import inner membrane translocase subunit } \\
\text { Tim10 }\end{array}$ & 1.2 & 0.0375 \\
\hline gi|405963229 & Laminin subunit gamma-1 & 1.2 & 0.0001 \\
\hline gi|405962702 & $60 S$ acidic ribosomal protein $\mathrm{P} 2$ & 1.2 & 0.2628 \\
\hline
\end{tabular}




\begin{tabular}{|c|c|c|c|}
\hline Accession & Name & Geomean & $\begin{array}{l}\text { Stouffers } \\
\text { P value }\end{array}$ \\
\hline gi|405976546 & Dynein heavy chain 10 , axonemal & 1.2 & 0.0311 \\
\hline gi|405952884 & Hypothetical protein CGI_10005680 & 1.2 & 0.4391 \\
\hline gi|405965518 & Hypothetical protein CGI_10028568 & 1.2 & 0.0703 \\
\hline gi|405958269 & Hypothetical protein CGI_10014060 & 1.2 & \\
\hline gi|405970483 & $\begin{array}{l}\text { Aminoacyl tRNA synthetase complex-interacting multifunctional } \\
\text { protein } 1\end{array}$ & 1.2 & 0.5319 \\
\hline gi|405961405 & Hypothetical protein CGI_10005085 & 1.2 & \\
\hline gi|405954063 & Hypothetical protein CGI_10003636 & 1.2 & 0.1296 \\
\hline gi|405954235 & Adipophilin & 1.2 & 0.0000 \\
\hline gi|405978483 & Hypothetical protein CGI_10028829 & 1.2 & 0.0000 \\
\hline gi|405951151 & Hypothetical protein CGI_10009743 & 1.2 & \\
\hline gi|405952883 & Ankyrin repeat domain-containing protein 49 & 1.2 & \\
\hline gi|405964463 & Hypothetical protein CGI_10015364 & 1.2 & \\
\hline gi|405951796 & Hypothetical protein CGI_10007922 & 1.2 & 0.0486 \\
\hline gi|405974669 & $39 S$ ribosomal protein $\mathrm{L} 12$, mitochondrial & 1.2 & 0.4869 \\
\hline gi|405950870 & Hypothetical protein CGI_10010859 & 1.2 & \\
\hline gi|405975737 & Proteasome activator complex subunit 3 & 1.2 & 0.0648 \\
\hline gi|405960075 & Legumain & 1.2 & \\
\hline gi|405964046 & Hypothetical protein CGI_10027351 & 1.2 & 0.5823 \\
\hline gi|405950905 & Syntaxin-5 & 1.2 & 0.0303 \\
\hline gi|405972019 & Hypothetical protein CGI_10022767 & 1.2 & 0.1116 \\
\hline gi|405975217 & CD2 antigen cytoplasmic tail-binding protein 2 & 1.2 & 0.1943 \\
\hline gi|405964921 & Proactivator polypeptide & 1.2 & 0.1641 \\
\hline gi|405978223 & BAG family molecular chaperone regulator 4 & 1.2 & 0.1340 \\
\hline gi|405977958 & Hypothetical protein CGI_10005753 & 1.2 & 0.5605 \\
\hline gi|405951048 & $45 \mathrm{kDa}$ calcium-binding protein & 1.2 & 0.1508 \\
\hline gi|405961624 & Hypothetical protein CGI_10005225 & 1.2 & 0.0554 \\
\hline gi|46518245 & Glutathione S-transferase & 1.2 & \\
\hline gi|405966992 & Hypothetical protein CGI_10007491 & 1.2 & 0.3887 \\
\hline gi|405958083 & Calmodulin & 1.2 & 0.0128 \\
\hline gi|405962486 & Hypothetical protein CGI_10015800, partial & 1.2 & 0.2600 \\
\hline gi|405947434 & Hypothetical protein CGI_10000134 & 1.2 & 0.7257 \\
\hline gi|405954851 & Intermediate filament tail domain-containing protein 1 & 1.2 & \\
\hline gi|405973879 & Zinc metalloproteinase nas-36 & 1.2 & \\
\hline gi|405960935 & High mobility group protein $20 \mathrm{~A}$ & 1.2 & 0.3458 \\
\hline gi|405952492 & Hypothetical protein CGI_10006329 & 1.2 & 0.1098 \\
\hline gi|405962528 & Double-strand-break repair protein rad21-like protein & 1.2 & \\
\hline gi|405975946 & Hypothetical protein CGI_10013510 & 1.2 & 0.1741 \\
\hline gi|405953339 & Mid1-interacting protein 1 & 1.2 & \\
\hline gi|405977608 & Lymphocyte cytosolic protein 2 & 1.2 & 0.0402 \\
\hline gi|405972343 & Calmodulin-like protein 4 & 1.2 & 0.0358 \\
\hline gi|405960226 & Cell adhesion molecule 3 & 1.2 & 0.9023 \\
\hline gi|405965665 & Survival of motor neuron-related-splicing factor 30 & 1.2 & \\
\hline gi|405960149 & Blastula protease 10 & 1.2 & 0.1858 \\
\hline gi|405957013 & B-cell linker protein & 1.2 & 0.1385 \\
\hline gi|405962020 & GRPE-like protein 1, mitochondrial & 1.2 & 0.0201 \\
\hline
\end{tabular}




\begin{tabular}{|l|l|r|r|}
\hline \multicolumn{1}{|c|}{ Accession } & \multicolumn{1}{|c|}{ Name } & Geomean & \multicolumn{1}{|c|}{$\begin{array}{c}\text { Stouffers } \\
\text { P value }\end{array}$} \\
\hline gi|405967081 & Myotrophin-like protein & 1.2 & 0.5219 \\
\hline gi|405976947 & Hypothetical protein CGI_10017528 & 1.2 & 0.0774 \\
\hline gi|405952378 & Eukaryotic translation initiation factor 4 gamma 2 & 1.2 & 0.4660 \\
\hline gi|405958177 & DNAj-like protein subfamily C member 3 & 1.2 & 0.4865 \\
\hline gi|405966615 & COP9 signalosome complex subunit 2 & 1.2 & 0.4857 \\
\hline gi|405953035 & Cysteine-rich protein 1 & 1.2 & 0.4234 \\
\hline gi|405976309 & Kinesin-related protein 1 & 1.2 & \\
\hline gi|405969883 & Thioredoxin domain-containing protein C2F3.12c & 1.2 & 0.4732 \\
\hline gi|405945673 & Natterin-1 & 1.2 & 0.1102 \\
\hline gi|405957091 & Proteasome inhibitor PI31 subunit & 1.2 & \\
\hline gi|405957236 & Collagen-like protein 2 & 1.2 & 0.4967 \\
\hline gi|405962294 & Pre-mRNA-splicing regulator female-lethal(2)D, partial & 1.2 & 0.0011 \\
\hline gi|405963726 & Dynactin subunit 3 & 1.2 & 0.2978 \\
\hline gi|405951452 & T-complex protein 11-like protein 1 & 1.2 & 0.2471 \\
\hline gi|405971322 & Hypothetical protein CGI_10020230 & 1.2 & 0.4715 \\
\hline gi|405971969 & Glutaredoxin-C6 & 1.2 & 0.0050 \\
\hline gi|405972973 & Hypothetical protein CGI_10020471 & 1.2 & \\
\hline
\end{tabular}


Supplementary Table 5

A

\begin{tabular}{|c|c|c|c|c|c|c|c|}
\hline GO-ID & $\begin{array}{l}\text { GO Term } \\
\text { (Definition) }\end{array}$ & Category ${ }^{1}$ & FDR & P-Value & $\begin{array}{c}\# \\
\text { SRO }\end{array}$ & $\begin{array}{c}\# \\
\mathrm{PO}^{3}\end{array}$ & $\begin{array}{c}\text { Overl } \\
\text { Under }^{4}\end{array}$ \\
\hline GO:0019439 & $\begin{array}{c}\text { Aromatic } \\
\text { Compound } \\
\text { Catabolic Process }\end{array}$ & $\mathrm{P}$ & 1.69E-03 & $1.73 \mathrm{E}-04$ & 23 & 20 & OVER \\
\hline GO:0009058 & $\begin{array}{c}\text { Biosynthetic } \\
\text { Process }\end{array}$ & $P$ & $4.40 \mathrm{E}-03$ & $5.65 \mathrm{E}-04$ & 61 & 96 & OVER \\
\hline GO:0005975 & $\begin{array}{l}\text { Carbohydrate } \\
\text { Metabolic } \\
\text { Process }\end{array}$ & $P$ & 3.90E-03 & 4.64E-04 & 23 & 22 & OVER \\
\hline GO:0009056 & Catabolic Process & $P$ & $3.21 \mathrm{E}-04$ & 1.67E-05 & 47 & 55 & OVER \\
\hline GO:0003824 & Catalytic Activity & $\mathrm{F}$ & 2.27E-02 & $5.82 \mathrm{E}-03$ & 104 & 213 & OVER \\
\hline GO:0005623 & Cell & C & $4.12 \mathrm{E}-05$ & $7.16 \mathrm{E}-07$ & 166 & 318 & OVER \\
\hline GO:0007049 & Cell Cycle & $\mathrm{P}$ & $4.91 \mathrm{E}-02$ & $1.62 \mathrm{E}-02$ & 20 & 26 & OVER \\
\hline GO:0022402 & $\begin{array}{l}\text { Cell Cycle } \\
\text { Process }\end{array}$ & $P$ & 2.27E-02 & $6.31 \mathrm{E}-03$ & 6 & 2 & OVER \\
\hline GO:0044464 & Cell Part & C & $4.93 \mathrm{E}-05$ & 1.03E-06 & 163 & 312 & OVER \\
\hline GO:0071944 & Cell Periphery & C & $9.92 \mathrm{E}-03$ & $1.65 \mathrm{E}-03$ & 26 & 30 & OVER \\
\hline GO:0007267 & $\begin{array}{l}\text { Cell-Cell } \\
\text { Signaling } \\
\end{array}$ & $P$ & 4.52E-02 & $1.48 \mathrm{E}-02$ & 12 & 11 & OVER \\
\hline GO:0006725 & $\begin{array}{l}\text { Cellular Aromatic } \\
\text { Compound } \\
\text { Metabolic } \\
\text { Process }\end{array}$ & $P$ & 2.27E-02 & $5.86 \mathrm{E}-03$ & 36 & 54 & OVER \\
\hline GO:0044249 & $\begin{array}{c}\text { Cellular } \\
\text { Biosynthetic } \\
\text { Process }\end{array}$ & $P$ & 4.33E-02 & $1.40 \mathrm{E}-02$ & 27 & 39 & OVER \\
\hline GO:0044248 & $\begin{array}{c}\text { Cellular Catabolic } \\
\text { Process }\end{array}$ & $P$ & 1.69E-03 & $1.73 E-04$ & 23 & 20 & OVER \\
\hline GO:0044085 & $\begin{array}{l}\text { Cellular } \\
\text { Component } \\
\text { Biogenesis }\end{array}$ & $P$ & 4.13E-02 & $1.26 \mathrm{E}-02$ & 32 & 49 & OVER \\
\hline GO:0016043 & $\begin{array}{l}\text { Cellular } \\
\text { Component } \\
\text { Organization }\end{array}$ & $P$ & 1.19E-02 & 2.15E-03 & 51 & 81 & OVER \\
\hline GO:0071840 & $\begin{array}{c}\text { Cellular } \\
\text { Component } \\
\text { Organization Or } \\
\text { Biogenesis }\end{array}$ & $P$ & 2.73E-03 & 3.13E-04 & 56 & 84 & OVER \\
\hline GO:0051641 & $\begin{array}{c}\text { Cellular } \\
\text { Localization }\end{array}$ & $P$ & 3.03E-02 & 8.83E-03 & 14 & 14 & OVER \\
\hline GO:0034645 & $\begin{array}{c}\text { Cellular } \\
\text { Macromolecule } \\
\text { Biosynthetic } \\
\text { Process }\end{array}$ & $P$ & 4.33E-02 & $1.40 \mathrm{E}-02$ & 27 & 39 & OVER \\
\hline GO:0070727 & $\begin{array}{c}\text { Cellular } \\
\text { Macromolecule } \\
\text { Localization }\end{array}$ & $P$ & 1.31E-02 & 2.92E-03 & 10 & 6 & OVER \\
\hline GO:0044237 & $\begin{array}{c}\text { Cellular Metabolic } \\
\text { Process }\end{array}$ & $P$ & $1.43 \mathrm{E}-04$ & 4.86E-06 & 119 & 208 & OVER \\
\hline GO:0044270 & $\begin{array}{l}\text { Cellular Nitrogen } \\
\text { Compound } \\
\text { Catabolic Process }\end{array}$ & $P$ & 1.69E-03 & 1.73E-04 & 23 & 20 & OVER \\
\hline GO:0034641 & $\begin{array}{l}\text { Cellular Nitrogen } \\
\text { Compound } \\
\text { Metabolic } \\
\text { Process }\end{array}$ & $P$ & 1.67E-02 & $3.88 \mathrm{E}-03$ & 64 & 114 & OVER \\
\hline GO:0009987 & Cellular Process & $\mathrm{P}$ & $3.28 \mathrm{E}-05$ & $4.55 \mathrm{E}-07$ & 159 & 297 & OVER \\
\hline GO:0034613 & $\begin{array}{l}\text { Cellular Protein } \\
\text { Localization }\end{array}$ & $\mathrm{P}$ & $1.31 \mathrm{E}-02$ & 2.92E-03 & 10 & 6 & OVER \\
\hline GO-ID & GO Term & Category $^{1}$ & FDR & P-Value & $\#$ & $\#$ & Overl \\
\hline
\end{tabular}




\begin{tabular}{|c|c|c|c|c|c|c|c|}
\hline & (Definition) & & & & SRO $^{2}$ & $\mathrm{PO}^{3}$ & Under $^{4}$ \\
\hline GO:0005737 & Cytoplasm & $\mathrm{C}$ & $2.32 \mathrm{E}-04$ & 8.85E-06 & 124 & 222 & OVER \\
\hline GO:0044444 & Cytoplasmic Part & $C$ & $1.24 \mathrm{E}-03$ & $8.15 \mathrm{E}-05$ & 77 & 123 & OVER \\
\hline GO:0044430 & Cytoskeletal Part & C & 1.19E-02 & $2.20 \mathrm{E}-03$ & 14 & 11 & OVER \\
\hline GO:0005856 & Cytoskeleton & $\mathrm{C}$ & 5.52E-03 & 8.04E-04 & 44 & 63 & OVER \\
\hline GO:0051234 & $\begin{array}{c}\text { Establishment Of } \\
\text { Localization }\end{array}$ & $P$ & 4.62E-03 & $6.26 \mathrm{E}-04$ & 55 & 84 & OVER \\
\hline GO:0051649 & $\begin{array}{c}\text { Establishment Of } \\
\text { Localization In } \\
\text { Cell }\end{array}$ & $P$ & 3.03E-02 & 8.83E-03 & 14 & 14 & OVER \\
\hline GO:0045184 & $\begin{array}{c}\text { Establishment Of } \\
\text { Protein } \\
\text { Localization } \\
\end{array}$ & $P$ & 1.31E-02 & $2.92 \mathrm{E}-03$ & 10 & 6 & OVER \\
\hline GO:0005794 & Golgi Apparatus & C & $5.28 \mathrm{E}-03$ & $7.52 \mathrm{E}-04$ & 13 & 8 & OVER \\
\hline GO:0003924 & GTPase Activity & $\mathrm{F}$ & $5.28 \mathrm{E}-03$ & 7.52E-04 & 13 & 8 & OVER \\
\hline GO:0046700 & $\begin{array}{c}\text { Heterocycle } \\
\text { Catabolic Process }\end{array}$ & $P$ & 1.69E-03 & $1.73 \mathrm{E}-04$ & 23 & 20 & OVER \\
\hline GO:0046483 & $\begin{array}{c}\text { Heterocycle } \\
\text { Metabolic } \\
\text { Process }\end{array}$ & $P$ & 2.27E-02 & 5.86E-03 & 36 & 54 & OVER \\
\hline GO:0016817 & $\begin{array}{c}\text { Hydrolase } \\
\text { Activity, Acting On } \\
\text { Acid Anhydrides }\end{array}$ & $\mathrm{F}$ & 1.69E-03 & $1.82 \mathrm{E}-04$ & 29 & 29 & OVER \\
\hline GO:0016818 & $\begin{array}{c}\text { Hydrolase } \\
\text { Activity, Acting On } \\
\text { Acid Anhydrides, } \\
\text { In Phosphorus- } \\
\text { Containing } \\
\text { Anhydrides } \\
\end{array}$ & $\mathrm{F}$ & $1.69 \mathrm{E}-03$ & $1.82 \mathrm{E}-04$ & 29 & 29 & OVER \\
\hline GO:0005622 & Intracellular & $\mathrm{C}$ & $7.60 \mathrm{E}-05$ & $2.11 \mathrm{E}-06$ & 158 & 303 & OVER \\
\hline GO:0043232 & $\begin{array}{l}\text { Intracellular Non- } \\
\text { Membrane- } \\
\text { Bounded } \\
\text { Organelle }\end{array}$ & C & $9.28 \mathrm{E}-06$ & $6.44 \mathrm{E}-08$ & 78 & 98 & OVER \\
\hline GO:0043229 & $\begin{array}{c}\text { Intracellular } \\
\text { Organelle }\end{array}$ & C & 3.07E-04 & $1.34 \mathrm{E}-05$ & 124 & 225 & OVER \\
\hline GO:0044424 & Intracellular Part & $\mathrm{C}$ & 1.43E-04 & 4.97E-06 & 147 & 278 & OVER \\
\hline GO:0006886 & $\begin{array}{c}\text { Intracellular } \\
\text { Protein Transport }\end{array}$ & $P$ & $1.31 \mathrm{E}-02$ & 2.92E-03 & 10 & 6 & OVER \\
\hline GO:0046907 & $\begin{array}{c}\text { Intracellular } \\
\text { Transport }\end{array}$ & $P$ & 3.03E-02 & 8.83E-03 & 14 & 14 & OVER \\
\hline GO:0051179 & Localization & $\mathrm{P}$ & $3.90 \mathrm{E}-03$ & $4.74 \mathrm{E}-04$ & 59 & 92 & OVER \\
\hline GO:0032991 & $\begin{array}{c}\text { Macromolecular } \\
\text { Complex }\end{array}$ & C & 5.54E-05 & $1.35 \mathrm{E}-06$ & 93 & 141 & OVER \\
\hline GO:0009059 & $\begin{array}{c}\text { Macromolecule } \\
\text { Biosynthetic } \\
\text { Process } \\
\end{array}$ & $P$ & 4.33E-02 & $1.40 \mathrm{E}-02$ & 27 & 39 & OVER \\
\hline GO:0033036 & $\begin{array}{l}\text { Macromolecule } \\
\text { Localization }\end{array}$ & $P$ & $1.31 \mathrm{E}-02$ & 2.92E-03 & 10 & 6 & OVER \\
\hline GO:0016020 & Membrane & $\mathrm{C}$ & 9.92E-03 & $1.65 \mathrm{E}-03$ & 26 & 30 & OVER \\
\hline GO:0061024 & $\begin{array}{l}\text { Membrane } \\
\text { Organization }\end{array}$ & $P$ & $1.06 \mathrm{E}-02$ & $1.80 \mathrm{E}-03$ & 12 & 8 & OVER \\
\hline GO:0008152 & $\begin{array}{l}\text { Metabolic } \\
\text { Process }\end{array}$ & $P$ & 1.15E-05 & $1.20 \mathrm{E}-07$ & 143 & 249 & OVER \\
\hline GO:0015630 & $\begin{array}{l}\text { Microtubule } \\
\text { Cytoskeleton }\end{array}$ & C & 1.19E-02 & $2.20 \mathrm{E}-03$ & 14 & 11 & OVER \\
\hline GO:0005815 & $\begin{array}{c}\text { Microtubule } \\
\text { Organizing Center }\end{array}$ & C & 1.19E-02 & $2.20 \mathrm{E}-03$ & 14 & 11 & OVER \\
\hline GO:0000278 & Mitotic Cell Cycle & $P$ & 2.27E-02 & 6.31E-03 & 6 & 2 & OVER \\
\hline GO:1903047 & $\begin{array}{c}\text { Mitotic Cell Cycle } \\
\text { Process }\end{array}$ & $\mathrm{P}$ & 2.27E-02 & 6.31E-03 & 6 & 2 & OVER \\
\hline GO-ID & GO Term & Category $^{1}$ & FDR & P-Value & $\#$ & $\#$ & Overl \\
\hline
\end{tabular}




\begin{tabular}{|c|c|c|c|c|c|c|c|}
\hline & (Definition) & & & & $\mathrm{SRO}^{2}$ & $\mathrm{PO}^{3}$ & Under $^{4}$ \\
\hline GO:0007067 & $\begin{array}{c}\text { Mitotic Nuclear } \\
\text { Division }\end{array}$ & $P$ & 2.27E-02 & 6.31E-03 & 6 & 2 & OVER \\
\hline GO:0006807 & $\begin{array}{c}\text { Nitrogen } \\
\text { Compound } \\
\text { Metabolic } \\
\text { Process }\end{array}$ & $P$ & 8.74E-03 & 1.37E-03 & 69 & 119 & OVER \\
\hline GO:0043228 & $\begin{array}{l}\text { Non-Membrane- } \\
\text { Bounded } \\
\text { Organelle } \\
\end{array}$ & C & $9.28 \mathrm{E}-06$ & 6.44E-08 & 78 & 98 & OVER \\
\hline GO:0000280 & Nuclear Division & $\mathrm{P}$ & $2.27 \mathrm{E}-02$ & 6.31E-03 & 6 & 2 & OVER \\
\hline GO:0034655 & $\begin{array}{c}\text { Nucleobase- } \\
\text { Containing } \\
\text { Compound } \\
\text { Catabolic Process }\end{array}$ & $P$ & $1.69 \mathrm{E}-03$ & $1.73 \mathrm{E}-04$ & 23 & 20 & OVER \\
\hline GO:0006139 & $\begin{array}{c}\text { Nucleobase- } \\
\text { Containing } \\
\text { Compound } \\
\text { Metabolic } \\
\text { Process }\end{array}$ & $P$ & $2.27 \mathrm{E}-02$ & $5.86 \mathrm{E}-03$ & 36 & 54 & OVER \\
\hline GO:0017111 & $\begin{array}{c}\text { Nucleoside- } \\
\text { Triphosphatase } \\
\text { Activity }\end{array}$ & $\mathrm{F}$ & $1.69 \mathrm{E}-03$ & $1.82 \mathrm{E}-04$ & 29 & 29 & OVER \\
\hline GO:0043226 & Organelle & $\mathrm{C}$ & $4.03 \mathrm{E}-04$ & $2.24 \mathrm{E}-05$ & 128 & 237 & OVER \\
\hline GO:0048285 & Organelle Fission & $\mathrm{P}$ & $2.27 \mathrm{E}-02$ & $6.31 \mathrm{E}-03$ & 6 & 2 & OVER \\
\hline GO:0006996 & $\begin{array}{c}\text { Organelle } \\
\text { Organization }\end{array}$ & $P$ & 1.64E-02 & 3.70E-03 & 31 & 42 & OVER \\
\hline GO:1901361 & $\begin{array}{c}\text { Organic Cyclic } \\
\text { Compound } \\
\text { Catabolic Process } \\
\end{array}$ & $P$ & $1.69 \mathrm{E}-03$ & $1.73 \mathrm{E}-04$ & 23 & 20 & OVER \\
\hline GO:1901360 & $\begin{array}{c}\text { Organic Cyclic } \\
\text { Compound } \\
\text { Metabolic } \\
\text { Process }\end{array}$ & $P$ & 2.27E-02 & $5.86 \mathrm{E}-03$ & 36 & 54 & OVER \\
\hline GO:1901576 & $\begin{array}{c}\text { Organic } \\
\text { Substance } \\
\text { Biosynthetic } \\
\text { Process }\end{array}$ & $P$ & 4.33E-02 & $1.40 \mathrm{E}-02$ & 27 & 39 & OVER \\
\hline GO:1901575 & $\begin{array}{c}\text { Organic } \\
\text { Substance } \\
\text { Catabolic Process }\end{array}$ & $P$ & $1.69 \mathrm{E}-03$ & $1.73 E-04$ & 23 & 20 & OVER \\
\hline GO:0071704 & $\begin{array}{c}\text { Organic } \\
\text { Substance } \\
\text { Metabolic } \\
\text { Process }\end{array}$ & $P$ & 8.36E-04 & $5.22 \mathrm{E}-05$ & 109 & 195 & OVER \\
\hline GO:0071702 & $\begin{array}{l}\text { Organic } \\
\text { Substance } \\
\text { Transport }\end{array}$ & $P$ & $1.31 \mathrm{E}-02$ & 2.92E-03 & 10 & 6 & OVER \\
\hline GO:0005886 & $\begin{array}{c}\text { Plasma } \\
\text { Membrane }\end{array}$ & C & 9.92E-03 & $1.65 \mathrm{E}-03$ & 26 & 30 & OVER \\
\hline GO:0044238 & $\begin{array}{c}\text { Primary Metabolic } \\
\text { Process }\end{array}$ & $P$ & 8.36E-04 & 5.22E-05 & 109 & 195 & OVER \\
\hline GO:0043234 & Protein Complex & $\mathrm{C}$ & $1.71 \mathrm{E}-02$ & $4.03 \mathrm{E}-03$ & 70 & 127 & OVER \\
\hline GO:0008104 & $\begin{array}{c}\text { Protein } \\
\text { Localization } \\
\end{array}$ & $P$ & $1.31 \mathrm{E}-02$ & 2.92E-03 & 10 & 6 & OVER \\
\hline GO:0006605 & Protein Targeting & $\mathrm{P}$ & $1.31 \mathrm{E}-02$ & $2.92 \mathrm{E}-03$ & 10 & 6 & OVER \\
\hline GO:0015031 & Protein Transport & $\mathrm{P}$ & 1.31E-02 & $2.92 \mathrm{E}-03$ & 10 & 6 & OVER \\
\hline GO:0016462 & $\begin{array}{l}\text { Pyrophosphatase } \\
\text { Activity }\end{array}$ & $\mathrm{F}$ & 1.69E-03 & $1.82 \mathrm{E}-04$ & 29 & 29 & OVER \\
\hline GO:0000003 & Reproduction & $\mathrm{P}$ & 1.66E-02 & 3.80E-03 & 15 & 13 & OVER \\
\hline GO:0030529 & $\begin{array}{l}\text { Ribonucleoprotein } \\
\text { Complex }\end{array}$ & C & 3.07E-04 & $1.49 \mathrm{E}-05$ & 23 & 15 & OVER \\
\hline GO-ID & GO Term & Category $^{1}$ & FDR & P-Value & $\#$ & $\#$ & Overl \\
\hline
\end{tabular}




\begin{tabular}{|c|c|c|c|c|c|c|c|}
\hline & (Definition) & & & & $\mathrm{SRO}^{2}$ & $\mathrm{PO}^{3}$ & Under $^{4}$ \\
\hline GO:0022613 & $\begin{array}{c}\text { Ribonucleoprotein } \\
\text { Complex } \\
\text { Biogenesis }\end{array}$ & $P$ & 4.13E-02 & $1.25 \mathrm{E}-02$ & 11 & 10 & OVER \\
\hline GO:0005840 & Ribosome & $C$ & $3.07 \mathrm{E}-04$ & 1.49E-05 & 23 & 15 & OVER \\
\hline GO:0042254 & $\begin{array}{c}\text { Ribosome } \\
\text { Biogenesis }\end{array}$ & $P$ & 3.93E-02 & 1.16E-02 & 7 & 4 & OVER \\
\hline GO:1902578 & $\begin{array}{l}\text { Single-Organism } \\
\text { Localization }\end{array}$ & $P$ & $1.21 \mathrm{E}-02$ & 2.32E-03 & 21 & 22 & OVER \\
\hline GO:0044710 & $\begin{array}{l}\text { Single-Organism } \\
\text { Metabolic } \\
\text { Process }\end{array}$ & $P$ & 7.05E-03 & $1.05 \mathrm{E}-03$ & 55 & 87 & OVER \\
\hline GO:1902589 & $\begin{array}{l}\text { Single-Organism } \\
\text { Organelle } \\
\text { Organization }\end{array}$ & $P$ & 2.27E-02 & 6.31E-03 & 6 & 2 & OVER \\
\hline GO:0044699 & $\begin{array}{l}\text { Single-Organism } \\
\text { Process }\end{array}$ & $P$ & $2.72 \mathrm{E}-03$ & 3.03E-04 & 110 & 207 & OVER \\
\hline GO:0044765 & $\begin{array}{c}\text { Single-Organism } \\
\text { Transport }\end{array}$ & $P$ & $1.21 \mathrm{E}-02$ & 2.32E-03 & 21 & 22 & OVER \\
\hline GO:0044281 & $\begin{array}{l}\text { Small Molecule } \\
\text { Metabolic } \\
\text { Process }\end{array}$ & $P$ & 4.31E-03 & 5.39E-04 & 51 & 75 & OVER \\
\hline GO:0003735 & $\begin{array}{c}\text { Structural } \\
\text { Constituent Of } \\
\text { Ribosome }\end{array}$ & $F$ & 1.69E-03 & $1.42 \mathrm{E}-04$ & 20 & 15 & OVER \\
\hline GO:0005198 & $\begin{array}{c}\text { Structural } \\
\text { Molecule Activity }\end{array}$ & $\mathrm{F}$ & $8.69 \mathrm{E}-03$ & 1.33E-03 & 32 & 40 & OVER \\
\hline GO:0006412 & Translation & $\mathrm{P}$ & 4.33E-02 & $1.40 \mathrm{E}-02$ & 27 & 39 & OVER \\
\hline GO:0055085 & $\begin{array}{c}\text { Transmembrane } \\
\text { Transport }\end{array}$ & $P$ & 4.13E-02 & $1.24 \mathrm{E}-02$ & 13 & 13 & OVER \\
\hline GO:0006810 & Transport & $P$ & $4.62 \mathrm{E}-03$ & $6.26 \mathrm{E}-04$ & 55 & 84 & OVER \\
\hline GO:0016192 & $\begin{array}{c}\text { Vesicle-Mediated } \\
\text { Transport }\end{array}$ & $\mathrm{P}$ & 2.83E-02 & 7.97E-03 & 18 & 20 & OVER \\
\hline
\end{tabular}

Notes:

1: GO categories - P: Biological Process; C: Cellular location; F: Molecular Function

2: Number of sequences in the SRO dataset that are classified within the relevant GO terms

3: Number of sequences in the PO dataset that are classified within the relevant $\mathrm{GO}$ terms

4: Over/Under $=$ the $\mathrm{GO}$ term is overrepresented or underrepresented in the SRO dataset, relative to the PO dataset 
B.

\begin{tabular}{|l|l|c|}
\hline Oyster species & \multicolumn{1}{|c|}{ Go Category } & \# sequences \\
\hline \multirow{5}{*}{ PO } & Cell Adhesion & 6 \\
\cline { 2 - 3 } & Cell Motility & 5 \\
\cline { 2 - 3 } & Cofactor Metabolic Process & 5 \\
\cline { 2 - 3 } & Nucleic Acid Metabolic Process & 6 \\
\cline { 2 - 3 } & Protein Folding & 6 \\
\cline { 2 - 3 } & Single-Multicellular Organism Process & 7 \\
\cline { 2 - 3 } & Single-Organism Developmental Process & 5 \\
\hline \multirow{5}{*}{ SRO } & Cell Morphogenesis & 8 \\
\cline { 2 - 3 } & Cellular Component Assembly & 6 \\
\cline { 2 - 3 } & DNA Metabolic Process & 11 \\
\cline { 2 - 3 } & Generation Of Precursor Metabolites And & 5 \\
\cline { 2 - 3 } & Energy & 11 \\
\cline { 2 - 3 } & Homeostatic Process & 8 \\
\cline { 2 - 3 } & Immune System Process & 5 \\
\cline { 2 - 3 } & Nucleocytoplasmic Transport & \\
\hline
\end{tabular}




\section{Supplementary Methods}

iTRAQ labelling pattern \& Proteolytic digestion:

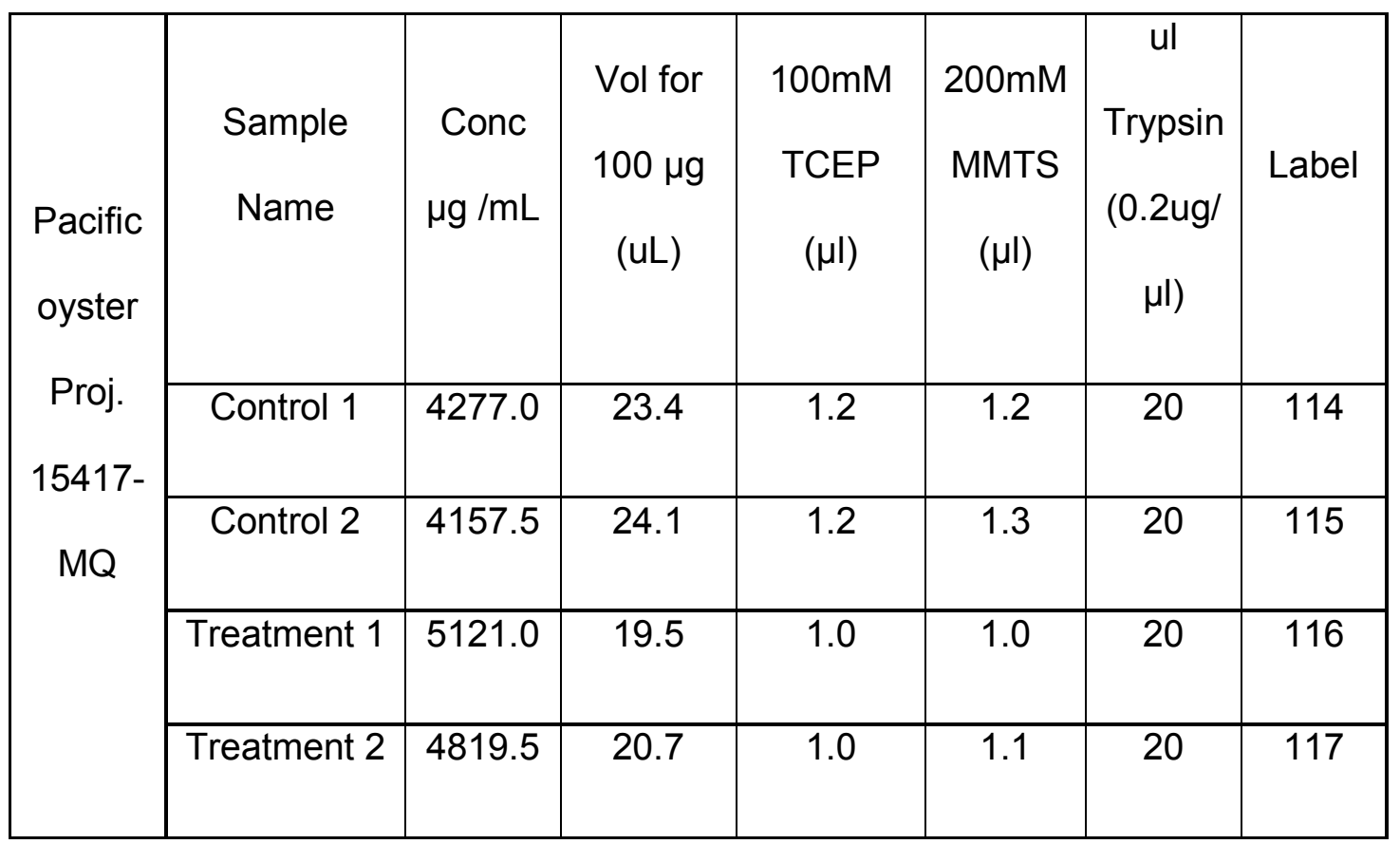

\begin{tabular}{|c|c|c|c|c|c|c|c|}
\hline \multirow{2}{*}{$\begin{array}{c}\text { Sydney } \\
\text { Rock } \\
\text { oyster }\end{array}$} & $\begin{array}{l}\text { Sample } \\
\text { Name. }\end{array}$ & $\begin{array}{l}\text { Conc } \\
\mu \mathrm{g} / \mathrm{mL}\end{array}$ & $\begin{array}{l}\text { Vol for } \\
\text { 100ug } \\
(\mu \mathrm{L})\end{array}$ & $\begin{array}{c}100 \mathrm{mM} \\
\text { TCEP } \\
(\mu \mathrm{L})\end{array}$ & $\begin{array}{c}200 \mathrm{mM} \\
\text { MMTS } \\
(\mu \mathrm{L})\end{array}$ & $\begin{array}{c}\mu \mathrm{l} \\
\text { Trypsin } \\
(0.2 \mu \mathrm{g} / \mu \mathrm{l})\end{array}$ & Label \\
\hline & Treatment 1 & 915 & 109.3 & 5.5 & 5.7 & 20 & 114 \\
\hline $\begin{array}{l}\text { Proj. } \\
14202\end{array}$ & Control 1 & 860 & 116.3 & 5.8 & 6.1 & 20 & 115 \\
\hline \multirow[t]{2}{*}{$-M Q$} & Treatment 2 & 915 & 109.3 & 5.5 & 5.7 & 20 & 116 \\
\hline & Control 2 & 860 & 116.3 & 5.8 & 6.1 & 20 & 117 \\
\hline
\end{tabular}


- Took required volume for $100 u g$ of protein (each sample taken twice)

- Added required amount of 100mM TCEP (9.89mg into $345 \mathrm{uL}$ of p.H2O) into each sample tube

- Vortex to mix, then spin

- Incubated at $60^{\circ} \mathrm{C}$ for one hour with shaking

- Spun briefly

- Added required amount of $200 \mathrm{mM}$ MMTS (1uL into 49uL of IPA) to each sample tube

- Vortex to mix, then spin

- Incubated at RT for 10 minutes

- Added 100uL of Milli-Q water to trypsin vial (20ug total, $0.2 \mathrm{ug} / \mathrm{uL}$ )

- Vortex to mix

- Added $20 \mathrm{uL}$ of trypsin solution to each tube (4ug each; 1:20 ratio)

- Incubated at $37^{\circ} \mathrm{C}$ overnight on Thermomixer with shaking

- After digestion samples dried in speedvac prior to SCX

\section{Conditions used for SCX HPLC:}

SCX HPLC: Agilent 1100 quaternary HPLC system with Polysulfoethyl A 100mmx2.1mm 5um 200A column

The labelled samples were cleaned and fractionated by SCX HPLC. The buffer A was $5 \mathrm{mM}$ Phosphate 25\% Acetonitrile, pH 2.7 and buffer B was 5mM Phosphate 350mM KCL 25\% Acetonitrile, $\mathrm{pH}$ 2.7. The dried iTRAQ labelled sample was resuspended in loading buffer which was the same as the buffer A. After sample loading and washing with buffer A, buffer B concentration increased from $10 \%$ to $45 \%$ in 70 minutes and then increased quickly to $100 \%$ and stayed at $100 \%$ for 10 minutes at a flow rate of $300 \mathrm{ul} / \mathrm{min}$. The eluent of SCX was collected every 2 minutes at 40 minutes and at 4 minutes interval from 62 minutes. A total of 17 fractions were collected and pooled as follows: 1-5, 6, 7, 8, 9, 10, 11, 12, 13, 14, 15, 16-17. 


\section{HPLC separation for MS analysis \& Protein piltot settings:}

Mass spectrometer: Triple TOF 5600 (AB Sciex)

NanoLC system: Eksigent Ultra nanoLC system (Eksigent)

Analytical column: SGE ProteCol C18, 300Å, $3 \mu \mathrm{m}, 150 \mu \mathrm{m} \times 10 \mathrm{~cm}$

The SCX fractions were resuspended in $100 \mu \mathrm{L}$ of loading/desalting solution (2\% acetonitrile $97.9 \%$ water, $0.1 \%$ Formic Acid). Sample $(40 \mu \mathrm{L})$ was injected onto a peptide trap (Michrome peptide Captrap) for pre-concentration and desalted with $0.1 \%$ formic acid, $2 \%$ ACN, at $5 \mu \mathrm{L} / \mathrm{min}$ for 10 minutes. The peptide trap was then switched into line with the analytical column. Peptides were eluted from the column using a linear solvent gradient, with steps, from mobile phase A: mobile phase $B(98: 2)$ to mobile phase A:mobile phase $B(65: 35)$ where mobile phase $A$ is $0.1 \%$ formic acid and mobile phase $B$ is $90 \% A C N / 0.1 \%$ formic acid at $600 \mathrm{~nL} / \mathrm{min}$ over a 100 min period. After peptide elution, the column was cleaned with $95 \%$ buffer B for 15 minutes and then equilibrated with buffer $A$ for 25 minutes before next sample injection.

The reverse phase nanoLC eluent was subject to positive ion nanoflow electrospray analysis in an information dependant acquisition mode (IDA). In IDA mode a TOFMS survey scan was acquired (m/z $400-1500,0.25$ second), with the ten most intense multiply charged ions (counts $>150$ ) in the survey scan sequentially subjected to MS/MS analysis. Product ion spectra were accumulated for $0.2 \mathrm{~s}$ (total cycle time 2.3 seconds) in the mass range $\mathrm{m} / \mathrm{z} 100-1500$ with a modified Enhance All mode Q2 transition setting favouring low mass ions so that the reporting iTRAQ ion $(114,115,116$ and $117 \mathrm{~m} / \mathrm{z})$ intensities were enhanced for quantitation. Dynamic exclusion was used with a $20 \mathrm{sec}$ and 4 Da window. Rolling collision energy setting for product ion scans were $0.0625^{*} \mathrm{~m} / \mathrm{z}+5$ for $z=2,0.0625^{*} \mathrm{~m} / \mathrm{z}+4$ for $z=3$ and $0.0625^{\star} \mathrm{m} / \mathrm{z}+3$ for $z=4$.

The search parameters were set as follows: sample type: iTRAQ 4plex (peptide labelled); cys alkylation: MMTS; digestion: trypsin; special factors: none; ID focus: allow biological 
modifications; Search Effort: Thorough ID; Detected Protein Threshold: 1.3 (95\%); False Discovery Rate Analysis was also selected. Bias correction was also selected.

Bias results for Pacific oyster proj15417 combined search:

\begin{tabular}{|c|c|c|c|c|c|c|c|c|c|}
\hline \multicolumn{2}{|c|}{ Quant Settings } & \multicolumn{8}{|l|}{ Apply } \\
\hline \multicolumn{2}{|c|}{ Denominator: } & IT115 & $\nabla$ & Reagent & $\%$ of -2 & $\%$ of -1 & $\%$ of 0 & $\%$ of +1 & $\%$ of +2 \\
\hline \multicolumn{2}{|c|}{$\sqrt{\checkmark}$ Bias Correction } & Auto & - & iTRAQ114 & 0.00 & 1.00 & 92.90 & 5.90 & 0.20 \\
\hline \multirow{2}{*}{\multicolumn{4}{|c|}{$\Gamma$ Background Correction }} & iTRAQ115 & 0.00 & 2.00 & 92.30 & 5.60 & 0.10 \\
\hline & & & & iTRAQ116 & 0.00 & 3.00 & 92.40 & 4.50 & 0.10 \\
\hline Ratio & Auto Bias & \multicolumn{2}{|c|}{ Manual Bias } & iTRAQ117 & 0.10 & 4.00 & 92.30 & 3.50 & 0.10 \\
\hline IT114:IT115 & 0.8902 & \multicolumn{2}{|l|}{0.8902} & & & & & & \\
\hline IT116:IT115 & 0.8379 & \multicolumn{2}{|l|}{0.8379} & & & & & & \\
\hline IT117:IT115 & 1.0483 & \multicolumn{2}{|l|}{1.0483} & & & & & & \\
\hline
\end{tabular}

Bias results for Sydney Rock oyster proj.14202 combined search:

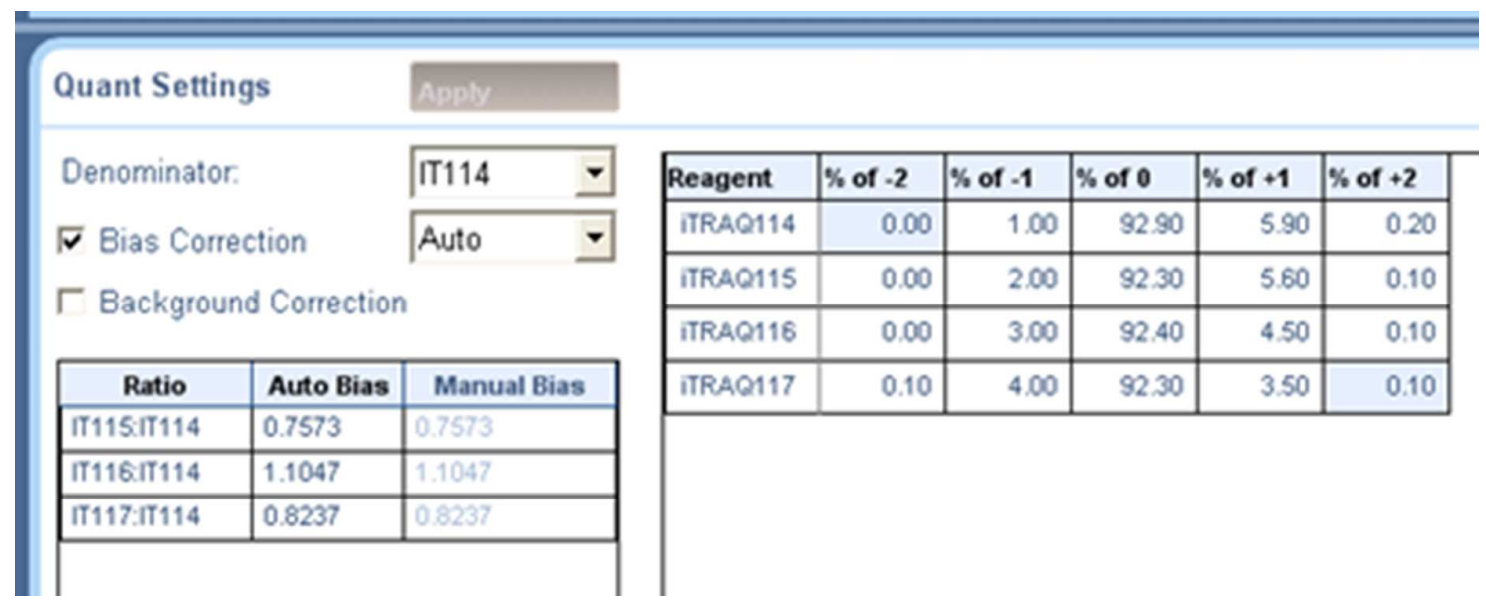

For Bias correction performed by the software - below is an extract from protein pilot.

Bias Correction in the Pro Group ${ }^{\mathrm{TM}}$ Alogrithm Results (Extracted from Protein Pilot) 
\{As part of the processing to create the Pro Group Algorithm Results, all quant ratios (both the average ratio for proteins and the individual peptide ratios) can be corrected for bias. The purpose of this is to correct for unequal mixing during the combination of the different labeled samples, based on the assumption that most proteins do not change in expression. If the samples from each experimental condition are not combined in exactly equal amounts, bias correction fixes this systematic error.

By default, the bias correction algorithm assumes the samples are combined in 1:1 ratios. You can still apply bias correction if your experimental design combines the different labeled samples in other ratios. After the search, edit the bias correction factors as described in Manually Specifying the Bias Correction.

Bias correction is performed when the Bias Correction check box is selected in the Paragon Method dialog box or in the Quant Settings pane of the Summary Statistics tab. During bias correction, the software identifies the median average protein ratio and corrects it to unity, and then applies this factor to all quantitation results. SILAC and Cleavable-ICAT-reagent-labeled samples have one bias correction factor, while iTRAQ-reagent-labeled samples can have up to seven bias correction factors. The bias correction factors are displayed in the Auto Bias column of the table in the lower left corner of Summary Statistics tab.

Bias correction is only performed when there are at least 20 proteins having an average ratio in the Proteins Detected table in the Protein Quant tab. If there are fewer than 20 proteins with ratios, the sample size is too small for the median to be meaningful and no bias correction is applied. (The Auto Bias in the Quant Settings pane of the Summary Statistics tab is 1.)\} 